\title{
Exploring the sales control function : formal sales control practices that drive business excellence
}

Citation for published version (APA):

Suchanek, M. A. M. F. (1998). Exploring the sales control function : formal sales control practices that drive business excellence. [Doctoral Thesis, Maastricht University]. Universiteit Maastricht. https://doi.org/10.26481/dis.19981211ms

Document status and date:

Published: 01/01/1998

DOI:

10.26481/dis.19981211ms

Document Version:

Publisher's PDF, also known as Version of record

\section{Please check the document version of this publication:}

- A submitted manuscript is the version of the article upon submission and before peer-review. There can be important differences between the submitted version and the official published version of record.

People interested in the research are advised to contact the author for the final version of the publication, or visit the DOI to the publisher's website.

- The final author version and the galley proof are versions of the publication after peer review.

- The final published version features the final layout of the paper including the volume, issue and page numbers.

Link to publication

\footnotetext{
General rights rights.

- You may freely distribute the URL identifying the publication in the public portal. please follow below link for the End User Agreement:

www.umlib.nl/taverne-license

Take down policy

If you believe that this document breaches copyright please contact us at:

repository@maastrichtuniversity.nl

providing details and we will investigate your claim.
}

Copyright and moral rights for the publications made accessible in the public portal are retained by the authors and/or other copyright owners and it is a condition of accessing publications that users recognise and abide by the legal requirements associated with these

- Users may download and print one copy of any publication from the public portal for the purpose of private study or research.

- You may not further distribute the material or use it for any profit-making activity or commercial gain

If the publication is distributed under the terms of Article $25 \mathrm{fa}$ of the Dutch Copyright Act, indicated by the "Taverne" license above, 


\section{Exploring the Sales Control Function}

Formal Sales Control Practices that drive Business Excellence 



\section{Exploring the Sales Control Function}

Formal Sales Control Practices that drive Business Excellence

\section{PROEFSCHRIFT}

ter verkrijging van de graad van doctor aan de Universiteit Maastricht,

op gezag van de Rector Magnificus, Prof. Dr. A.C. Nieuwenhuijzen Kruseman, volgens het besluit van het College van Decanen,

in het openbaar te verdedigen

op vrijdag 11 december 1998 om 14.00 uur

door

Mireille A.M.F. Suchanek 


\section{Promotor}

Professor Dr. J.D.P. Kasper

\section{Beoordelingscommissie}

Professor Dr. W.F.J. Buijink, voorzitter

Professor Dr. P. Mathyssens

Dr. A.G.L. Romme

0 1998, Miteille Ann Marie Francine Suchanek, Gouda All rights reserved. No patt of this publication may be reprinted or utilized in any form or by any electronic, mechanical or other means, now known, or hereafter invented, including photocopying and recording, or in any information storage or retrieval systen, without written permission from the copyright owner.

ISBN: $90-9012020-3$

English editor: Miranda Aldham-Breary M.SC. P.G.C.E.

Cover: Mandy Jones 


\section{Table of Contents}

Preface and Acknowledgements

\section{GHAPTER THE PROBLEM STATEMIENT IN IIS CONIEXI}

1.1 THE SALES FUNCTION

1.1.1 The sales function as a boundary spanning role function

1.1.2 The transformation of the sales function: causes

1.1.3 The transformation of the sales function: consequences

1.1.4 Controlling the sales function

1.2 EMPIRICAL STUDIES ON SALES CONTROL PRACTICES 11

1.3 FOCUS OF THIS STUDY 12

$\begin{array}{lll}1.4 & \text { AIM OF THIS STUDY } & 13\end{array}$

1.5 OUTLINE OF THIS THESIS Notes

\section{CHAPTER FORMAL ORGANIZA TIONAL CONTROL}

2.1 THE CONCEPT OF ORGANIZATIONAL CONTROL

2.2 TOWARDS A THEORETICAL FRAMEWORK FOR ORGANIZATIONAL CONTROL

2.3 DESIGNING A CONTROL SYSTEM

2.3.1 Introductory remarks

2.3.2 Dimensions of performance

2.3.3 Performance measures

2.3.4 Evaluation and rewarding 34

2.4 CONSEQUENCES OF SYSTEM DESIGNS

$\begin{array}{ll}2.4 .1 & \text { Introductory remarks }\end{array}$

$\begin{array}{ll}2.4 .2 & \text { Behavioral consequences } \\ 2.3 & 35\end{array}$

$\begin{array}{lll}2.4 .3 & \text { Psychological responses } & 37\end{array}$

$\begin{array}{lll}2.4 .4 & \text { Role related consequences } & 37\end{array}$

2.5 MANAGEMENT CONTROL AND THE SALES FUNCTION 37

$\begin{array}{ll}2.5 .1 & \text { Introductory remarks }\end{array}$

2.5.2 Sales control systems and differentiation strategies 37

2.5.3 Sales control systems and interfaces 43

2.5.4 Sales control systems and information needs 44

2.6 SUMMARY AND CONCLUDING REMARK 46

Notes 


\section{CHATHER CONTROT. ING THIE SALBS FUNCTION}

3.1 CONTROLLING THE SALES FUNCTION

3.1.1 Introductory remarks

3.1.2 A definition of sales control

3.1.3 Our theoretical framework in a sales context 53

3.2 THE SALES FORCE ORGANIZATION AND ITS OUTCOMES

3.3 STRATEGIC PLANNING

3.3.1. Introductory remarks

3.3.2 Organizational strategy levels $\quad 56$

3.3.3 Levels of organizational plans $\quad 56$

3.3.4 Strategic sales program

3.4 SALES MANAGEMENT PLANNING

3.5 PERFORMANCE MEASUREMENT AND EVALUATION

3.5.1 Introductory remarks

3.5.2 Evaluating sales organization's effectiveness

3.5.3 Evaluating salesperson performance

$\begin{array}{lll}3.6 & \text { REWARDING } & 64\end{array}$

3.7 SUMMARY AND CONCLUDING REMARKS 66 Notes

\section{CHAPTER THE RESEARCH METHOD}

4.1 FOCUS OF THE STUDY

4.2 ARGUMENTATION FOR THE CASE METHOD

$\begin{array}{lll}4.3 & \text { THE RESEARCH DESIGN } & 76\end{array}$

4.3.1 Introductory remarks $\quad 76$

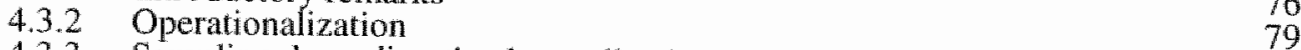

4.3.3 Sampling: bounding the data collection 88

\begin{tabular}{ll} 
4.3.4 Data collection & 88 \\
\hline
\end{tabular}

4.4 ON THE LIMITATIONS OF THE RESEARCH METHOD 83

4.5 SUMMARY AND CONCLUDING REMARKS 86 Notes

\section{CHAYRR COMPARA TIVE CASE ANALYSIS}

5.1 EVALUATION OF THE GENERAL FINDINGS

5.2 THE SALES FORCE ORGANIZATION

$\begin{array}{ll}5.2 .1 & \text { Formalization } \\ 5.2 .2 & \text { Centralization } \\ 5.2 .3 & \text { Integration }\end{array}$ 
5.2.4 Participation

5.2.5 Functionally versus process oriented firms: overview

5.3 STRATEGIC PLANNING

5.4 SALES MANAGEMENT CONTROL

5.4.1 Sales management planning

5.4.2 Performance measurement

5.4.3 Performance evaluation

5.4.4 Feedback

5.4.5 Rewarding

5.5 TASK CONTROL

5.6 SUMMARY AND CONCLUDING REMARKS

Notes

\section{CHAPTER FINAL CONCLUSIONS AND FUTURE RESEARCH}

\subsection{INTRODUCTION}

6.2 SUMMARY OF OUR KEY RESEARCH FINDINGS

6.2.1 Our theoretical framework for studying formal sales control practices

6.2 .2 Some general conclusions

6.2.3 Functionally versus process driven sales force organizations

6.2.4 Explanations for variations in sales control practices

6.3 MANAGERIAL IMPLICATIONS OF THE STUDY

6.3.2 Some challenges

6.4 FUTURE RESEARCH

Notes

\section{APPLNDICES \& RDFERPNCWS}

Case study I

Case study II

Case study III

Case study IV

References

Nederlandse samenvatting

Curriculum Vitae 


\section{List of Figures}

Figure 1.1 Boundary role person

Figure 1.2 Channel options: traditional view

Figure 1.3 The outline of this thesis

Figure 2.1 The control process

Figure 2.2 Theoretical framework

Figure 3.1 Theoretical framework: the control process in a sales context

Figure 3.2 The sales force as part of the corporation's marketing system

Figure 3.3 Sales organization audit framework

Figure 3.4 Assessing sales management functions

Figure 5.1 Theoretical framework: the control process in a sales context

Figure 6.1 Theoretical framework: the control process in a sales context

\section{List of Tables}

Table 2.1 Overview of selected control definitions

Table 3.1 Common output factors, input factors and ratios used to evaluate salespeople

Table 4.1 Constructs and related questions

Table 4.2 Pre-Pilot interviews

Table 4.3 Pilot study I

Table 4.4 Pilot study II

Table 4.5 Summary of interviews conducted

Table 5.1 Characteristics of the sales force organization

Table 5.2 Strategic planning

Table 5.3 Sales management planning

Table 5.4 Performance measurement

Table 5.5 Performance evaluation

Table 5.6 Feedback

Table 5.7 Overview of the differences between functionally and process driven firms

Table 6.1 Overview of the similarities 


\section{Preface and Acknowledgments}

This book was written as a Ph. D thesis at the faculty of economics and business administration of the University of Maastricht; it is concerned with formal sales control practices. Since the early 1970 s the body of theory and research relevant for improving sales management practice has been growing dramatically. The research efforts have focused on understanding why salespersons behave as they do and identifying key sales performance indicators. As a result of these efforts, nearly every issue of the major marketing journals contains at least one article related to sales management. One research field of sales management has received relatively little attention, namely controlling the sales function. In our opinion, it is necessary to gain insights about the three key management practices: planning, implementing and controlling. Assessing sales performance helps management to improve the business performance. The necessity to explore this research field and my curiosity to discover the 'Sales' world were the drivers of this research study.

One can think that preparing and writing a research study is a one-person affair because only one name is mentioned on the cover. Nothing is farther from the truth. Such a study is a multiperson affair in which many persons are involved, each in their own personal manner. Their support and enthusiasm throughout the stages of this study made it possible to explore two interesting research fields, sales management and management control, and to gain new insights in sales control practices.

First, I would to express my sincere gratitude to professor Hans Kasper who offered many valuable comments, criticism and suggestions in the course of the realization of this project. Looking back on the years we worked together, I realize now that he enabled me to conduct scientific research independently: learning by doing. He helped me to take a step back from my research findings and leap forward again. Furthermore, I would like to express my gratitude to my reading committee for their constructive criticism and suggestions to improve further the quality of this thesis. A special thanks goes to Professor Tom Groot and Professor Piet Vanden Abeele who were supporting me during the first stages of my research study. Furthermore, my gratitude should also be expressed to all those managers, both in Belgium and the Netherlands, who willingly participated in this study despite often busy schedules. Their willingness to discuss their business practices gave me an insight in today's control practices. They contributed enormously to the realization of this thesis. They have also 'seduced' to leave the academic world and to work as a consultant in 'control practices'.

The research was performed at the Department of Marketing and Marketing Reseatch of the University Maastricht. This department has always provided the resources, energy and effort necessary to conduct the study. I would therefore like to acknowledge the help given to me by various members of the department. Especially the 'girls' of the department: they made my 6 years at the university both very enjoyable and worthwhile. Thanks to you all Furthermore, I would like to thank Veronique Linssens, Gerben Mak, Bram Broeks, Sander Koenen, Rogier Schalwijk, Mireille Paasen, Patrick Vierveijer, Nicole Fleischeuer and Wilbert Eggink for their assistance in collecting the data for this research study. Their enthusiasm and energy helped me to gather data 60 companies. Working with them gave my project a new and interesting dimension.

Finally, my warmest thanks are to my dearest friends: Lyana Timmermans, Mireille Paasen and Miranda Aldham-Breary. Their friendship helped my to keep me motivated to fulfill my academic ambitions. A special thanks goes to Miranda who has helped me in fine-tunirig my English. I would also like to take the opportunity to express my thanks to my parents for their support. They always encouraged me to go at least one step further than the others; they also supported me in 'hard' times. Without them, this thesis was never written. For your patience and encouragement, it is to you that I dedicate this book as a small token of my gratitude. 



\section{$\overline{\text { Chapter } 1}$ \\ The Problem Statement in its Context}

And The Question Is ...?

\section{Chapter outline}

Historically, the discipline of sales management has been preoccupied with the analysis and planning? phases of sales management. Yet if sales management is truly an integrated managerial process of 'analysis, planning and control', then control issues deserve an equal share of both researchers time and managerial attention. Despite how well a company analyses and plans its sales efforts, the effects can be offset by a poorly conceived control system.

The broad intent behind this dissertation was to begin to fill this knowledge gap between 'analysis and planning' and 'control in sales management. We therefore conducted a study to accomplish this goal. Its foundations and design are explained in this introductory chapter. We start with a brief description of the sales function (section 1.1). Today's marketing environment is undergoing dramatic changes that are producing a severe impact on the nature of the sales function. The causes and consequences of this transformation process will be discussed in detail. A general outline of the existing research on sales control practices will be given in section 1,2. This section will demonstrate the knowledge gap concerning control in marketing and sales management. The focus of the following sections will be on the research project. The problen statement and the goal of our study are discussed and formulated in sections 1.3 and 1.4. Finally, a brief outline of this thesis is given in section 1.5 . 


\subsection{THE SALES FUNCTION}

\subsubsection{The sales function as a boundary spanning role function}

The sales function of any company can be described as a boundary role function (see figure 1.1). Salespersons represent the buying organization in the selling organization as well their own organization to the customer. They interact internally with the marketing department, production department, finance department, etc. and they deal externally with customers or their representatives, e.g. purchasing managers (Cespedes 1991). With respect to business-to-business selling, the nature of the interactions are influenced by the policies, procedures and programs of the involved parties.

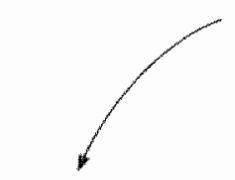

Selling

Organization

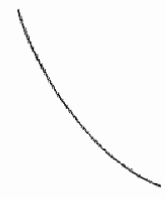

Communication

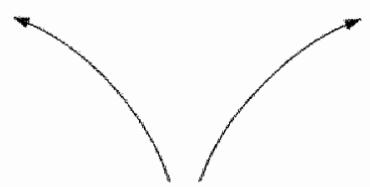

Representative

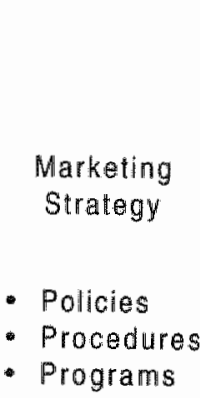

Communication

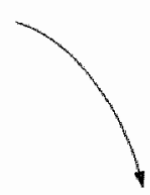

Buying Organization
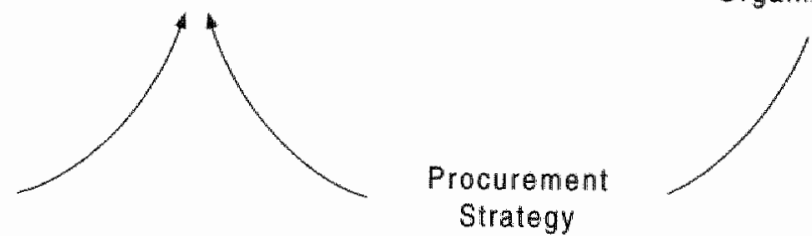
Strategy

- Policies

- Procedures

- Programs

Figure 1.1 Boundary Role Person

Source: Cespedes,F.V. (1991) Organizing and Implementing the Marketing Effort: Text and Cases, Reading: Addison-Wesley Publishing Company, 76

Together with the marketing function, the sales function exists to ensure that information about a firm's product reaches potential and existing customers in a timely and efficient way to generate enough orders to keep the company profitable and growing. Marketing and sales are important business functions. Efficient management of production and other functions is a basic requirement for being successful; without sufficient sales however, these activities would quickly grind to a halt.

Traditionally, marketing" and sales are strongly related. The primary goal of a firm's marketing function is to attract and keep profitable customers. Those managing this business function should, therefore, be responsible for collecting market data, analysing competition, selecting markets, identifying and assessing capabilities, and developing appropriate marketing strategies (Cortadla 1993; Kotler 1994). The sales function and strategy play a crucial role when implementing a company's marketing strategy (Hughes and Singler 1983; Stanton et al. 1990; Churchill et al. 1993; Futrell 1994). The sales function should balance constantly the objectives of the company and the wants of customers. It forms an extension of the marketing function by
(Mckinnon and Bums 1992): 
taking information to potential and existing consumers processing their purchases providing a liaison point with the firm.

Like most other business functions, the sales function has evolved into a quite different business function from that used a few decades ago. It is being transformed by many new ideas and practices, examples of these competitive trends shaping sales and business strategy in general include customer satisfaction and customer focus, emerging technology, total quality management (TQM), empowerment and relationship management. These factors have caused the sales function to be transformed from a primarily transactional one to a more relationship oriented approach. Whereas the major task of the sales department in the past was to sell products, in many organizations the basic task of managers of today's sales function is to identify and to satisfy customers' needs (Cortada 1993). It is necessary to study 'how the sales function is managed' to understand sales controlling practices better. The causes and consequences of the transformation process will be discussed in the next sections.

\subsubsection{The transformation of the sales function: causes}

As in many other areas of the business environment, substantial changes have taken place in the marketing environment. The role of the sales function within an organization appears to be undergoing significant changes. We can explore the causes of these changes from four perspectives: that of the customer, competitors, the company's organization, and technology. These developments affect the way an organization operates in today's market system, requiring adjustments in strategy, policies and selling operations.

\section{Customer}

Driven by more demanding customers, global competition and slow growth economies and industries, many companies search for new ways to achieve a competitive advantage. One strategy is based on customer orientation. Customer oriented thinking implies that organizations should be able to define customer needs and wants from the customer point of view (Kotler 1994). When the management of an organization can define accurately customers' needs and wants in its target markets, it can improve its marketing efforts to meet these needs and wants better than any competitor can. Day (1990) identifies, in accordance with Porter (1980), two generic types of strategies for competing in a market oriented way, namely cost leadership and differentiation/focus ${ }^{23}$.

Cost leadership focuses on relentless cost improvement and on out performing competitors with low costs. A differentiation/focus strategy includes a search for new ways to offer superior customer value ${ }^{4}$ with improved quality or enhanced responsiveness to the specific targeted customers' needs and wants. Value is created by products and services when the benefits that they deliver help customers to achieve their objectives in various situations (Woodruff and Gardial 1996). A customer focus does not only involve a proper understanding and anticipation of the customer's products or service needs; it also includes a good understanding of what benefits and assistance can be provided to increase the total package of value supplied to the customer (Honeycutt Jr. 1996).

As stated, the sales function should act as a fulcrum to provide a balance between the company's objectives and the wants of customers: yet it also involves learning about future customer needs and creating superior value for customers in the future (Wotruba 1996). Surviving in today"s market environment demands a through understanding of its dynamics, including how customers view their suppliers. Customers often view their suppliers and other aspects of their market environment differently than do suppliers (see e.g. King and Cleland 1974; Fint et al. 1997). This implies that the supplier's strategy must be in tune with at least the following customer view factors: 
- the actual needs of the customers, i.e., customers value'

- the customers" satisfaction with the supplier's ability to meet these needs; i.e., to create that value for the customers

- the forces that drive customers'perceptions of value to change over time

Today's sales function should assist the company in predicting what their customers will need now and in the future: it has to thoroughly address the events and processes that will impact customers' perceptions of value and customer retention. The challenge of sales management is to maximize the effectiveness of the firm's customer value creation activities. The firm should, therefore, define (Cortada 1993):

- what services customers should be provided with besides simply a product

- how the sales force and other customer contact personnel should behave

- to what extent offerings are 'pushed' at customers as opposed to executing a 'pull' strategy

It is a fact that maximizing the effectiveness of customer value creation activities is easily to attain, especially when the nature of industrial purchasing is changing and researchers in industrial purchasing indicate that industrial purchasing is undergoing basic changes. Some of these developments are:

- centralization of purchasing

- employing Information Technology (TT) in purchasing

- globalization

- professionalization of buyer

Firms tend increasingly to centralize purchasing (Hutt and Speh 1992; Matthyssens and Faes 1997) and there are various reasons for centralizing purchasing. It can strengthen the buying firm's buying power and its supplier options. Centralization can also lead to changes in buying criteria, e.g. more long term and specialized buying centers, and to substantial strategic benefits, e.g. price reductions.

Furthermore, companies have made substantial investments in Information Technology (TT) (van Weele and Rozemejjer 1996). The extent of IT investments and their degree of use in purchase alter the nature of buyer-seller relationships. IT inwestments can stimulate firms to design networks of sellers with whom the investing buyers regularly trade. Such closer relationships with sellers can be an efficient means for buyers to control the operational transaction costs, such as those arising from processing purchase orders and communicating transaction-related information. Furthermore, buyers can use these networks to manage the threat of opportunistic behavior of sellers in transactions. IT investment also contribute to the reduction of the number of sellers being used. A selected number sellors are becoming part of a buyer's network in which purchasing transactions
take place.

Today"s business environment is globalizing intensively. This trend means that small and large companies are confronted with foreign competitors (see Halliburton and Hünerberg 1993). There are four developments that stimulates global competition (see e.g. Halliburton and Huinerberg
1993; Mathyssens et al. 1998) are: - a shift to more homogeneous living style and consumption patrons of consumers; e.g. customer convergence

internationalization of business operations

liberalization of the world trade

These trends in the business environment make it possible for companies to improve their efficiency by scaling-up their operations. Highly standardized products and marketing efforts can be used to attain scale advantages in production and marketing and also in purchasing.

As a result of the technological developments, including IT, and globalization, buyers are becoming more demanding with regard to the vendors (Marthyssens et al. 1998). The purchasing 
function of companies is becoming more professionalized in comparison to the past. Firms realize that a more professional approach to purchasing offers opportunities for improving the cost efficiency of the organization. This trend has also had an impact on the buyer-seller relationships. Buyers ask for a total solution instead of separate products and services delivered by various vendors. Furthermore, the vendors should be able to deliver the products and services at each subsidiary of the buying firm. This implies that the vendors have to follow their customers in their foreign operations.

\section{Competitors}

In many markets, competition is increasing exponentially. This situation is described as 'hyper competition' (see D'Aveni 1994). Companies must continually create competitive advantage through leadership in four areas: price and quality, timing and knowhow, stronghold creation/invasion, and deep pockets. This might require destruction of old sources of advantage to enable the company to dynamically create a stream of short-term advantages. Innovative and prow active ideas, such as bench marking, downsizing, TQM and reengineering, are implemented in response to the intensifying competition faced by many companies (see e.g.D'Aveni 1994, Wotruba 1996; Matthyssens et al. 1998). Competitors can be considered as a source of valuable information to evaluate and improve a firm's market orientation and customer focus.

Using benchmarking, a company can improve its operations and processes by identifying and emulating the superior practices of competing and non-competing firms (Watson 1994). Such an audit may highlight critical success factors and processes that influence customer satisfaction directly. When these 'best' practices are identified, the firm's current performance, in terms of: products/services and other benefits delivered to customers, can be compared to the performance of other firms. Based on the outcomes of this audit, the company can decide to monitor and respond to competitor activities as well as to customer needs and expectations (Wotruba 1996); yet this is a question of balance. Whereas a strong competitor focus might be characterized as 'reactive" or 'follower', a strong customer focus can be described as 'pro-active' or 'challenger' (Kotler 1994). A strong competitor focus involves a marketing strategy built around comparison with competitors and differentiation from competitors.

A strong customer focus implies that a marketing strategy is built around devising an exchange with the customer. This exchange should satisfy customer needs with the company's resources and competencies (Wotruba 1996). Whereas beating competition is still important, this should be attained by attributes fulfilling the customer's total package of values (Wotruba 1996). In essence, a mix of both competitor and customer focus is necessary to be market oriented or market driven (Day 1990). Beating a competitor on some aspect unimportant to the customer will not produce an effective competitive advantage.

One of the important challenges facing today"s sales function is the trend to relationship selling. The traditional transaction selling approach is increasingly being replaced by more relationship selling models. Instead of emphasizing selling products and services in the short run, salespersons are being required to initiate long term customer relationships by solving customer problems, providing opportunities, and adding value to customer businesses over a longer period of time (Ingram and LaForge 1992). A rellationship oriented sales function can be an effective mechanism to reduce a competitor focus and strengthen the customer focus. A transaction oriented approach with an 'it beats the competition attitude' often implies the creation of opportunities for dubious statements about competitors to boost sales opportunities. This may result in a strong short term orientation of salespersons; but the truth of false promises will often emerge after the purchase thas taken place (Wotruba 1996). A customer oriented approach may result in sales practices by which salespersons can help customers instead of convincing them only to buy empty promises. 


\section{Company's organization}

The importance of a customer focus has extended the salespersons' functions with a broad range of activities to build and maintain long term relationships with customers. From being an effector of sales transactions, contemporary sales people have become relationship builders that have to cope with many tasks. In the traditional approach these tasks and roles are accomplished by other functional areas.

The changing role of salespersons in organizations has led to the introduction of a number of management methods into the sales area that have already been implemented and used in other functional areas. Some well known methods include Management by Objectives (MBO), Management by Planning (MBP), Total Quality Management (TQM) and Business Process Reengineering (BPR). The last two approaches in particular are receiving a growing attention in today's business environment. As stated, a customer focus implies that selling should become a process of meeting customer expectations. Since quality is growing in importance in the sales function, TQM is increasingly being applied to marketing implementation. The fundamental tenets of TQM are:

- all parts of the organization should be committed to satisfying the organization"s customers

- each organizational member must strive to satisfy internal and external customers in the same spirit

To attain these goals, activities at all levels within an organization need to be looked at as a collection of processes which should contain basic elements of quality management. These activities include customer satisfaction and feedback, continuous improvement, quality assurance, leadership and employee involvement, supplier partnership, measurement and strategic quality planning (Cortada 1993). Managing the effectiveness of these activities within the processes will improve the quality of the sales process.

Companies can redesign their processes to improve efficiency and thereby deliver greater value for fewer costs (see Watson 1994; Wotruba 1996). BPR or reengineering can be described as the radical redesign of processes to achieve dramatic improvements in performance, such as cost, quality, service or speed (see Watson 1994). Such a reengineering process can revolutionize selling and related processes and may create many challenges for employees during the transition period. The cumulative effects of a reengineering effort are downsizing, automation and empowerment (Wotruba 1996). Downsizing implies the restructuring and elimination of positions no longer suitable to the reengineered process, for instance, administrative functions in retail banks are increasingly centralized so that branch staff can focus more on selling. Two other factors supporting BPR projects are automation and empowerment ${ }^{6}$. Empowerment is a powerful tool for attaining a customer focus, as empowered personnel can provide quick responses to customer needs and complaints (Bowen and Lawler 1992); and because empowerment is particularly fitting for employees interacting with customers, the result is an aspect of potential value to the customer. This pattern of 'TQM, reengineering, downsizing, automation and empowerment can be found in the sales organization of many companies. For instance, salespersons may be empowered to resolve problems with their customers. These authorities may include issues such as payment terms, delivery and service needs. In various companies, salespersons are provided with a PC for direct communication in placing and monitoring orders and accessing information e.g. for product information or pricing. Consequently, the administrative tasks combined in the sales function and personal contacts requesting information or supervisory approvals are increasingly reduced. Nowadays, sales organizations can be streamlined with fewer managers and office staff (Keenan
jr. 1994).

\section{Technology}

Technological forces have a great impact on today's selling approach. To improve sales productivity, for instance, today's salespersons are forced to use more technology. Technology, in 
the form of computers, fax machines, electronic mail, and the Internet, allows salespersons to communicate more effectively with their clients and their back office (Honeycutt Jr. 1996). Since the early nineties, companies are increasingly involved in sales force automation (SFA)(Columbo 1994). SFA If covers the following activities (Bondra and Davis 1996):

- to computerize of the selling and order filling cycle?

- to invest in sales automation tools, such as laptops and notebooks

- to merge and consolidate information systems into a centralized database

- to link the different selling and nonselling departments in a local networks (LAN)

The recent influx of sales automation tools is having a broad impact on the sales function and its relationship with other business function (Colombo 1994). The integration of IT is also bringing tighter coordination between the selling process and order filling process. For instance, the computerization of the order filling cycle also includes a complete reengineering of this process. It helps the firm to streamline the order filling process. The use of laptops by the salespeople helps to reduce order filling cycle times and to improve communication with different selling and nonselling departments. Performance results provide feedback that influence:

- strategy formulation by focusing managers on Critical Success Factors; e.g. by developing a more balanced measurement system by supplementing sales and financial measures with nonfinancial measures related to quality and customer satisfaction.

- business plan development by providing information on changes and monitoring processes. e gy creating and managing customer databases that improve the effectiveness of sites in dealing with customers and increased sales force productivity

- operational activities by alerting managers to problem areas and improvement; e.g. improving internal coordination between the various deparments by networking the computer systern and facilitating online communications

With the help of these systems new businesses can be prospected whilst maintaining services for a business, present outcomes and the profile of customer segments can be defined for customer acquisition. For instance, retail banks use information technology to encourage customers to take transactions away from the tellers' windows freeing up branch staff to concentrate on selling and relationship management activities. Efficient voice and data transmissions coupled with multiple selling channels have resulted in efficiencies in sales operations. Requests for quotations and promotional material can be transmitted electronically. New forms of technology can reduce the need for central offices and stafis and may allow large and small companies to compete by using Internet (Honeycutt Ir 1996). Furthermore, today's companies often use more than one marketing channel. For many companies, the advantages of direct marketing activities include the acquisition of new customers, a reduction of overheads and the freeing up of other marketing channels, i.e. outside sales force or distributors. Often this is done to sell products and services to other market segments which require face-to-face contact. Additionally, the emergence of marketing databases or customer information files effectively allows organizations to set up a customer information system.

\subsubsection{The transformation of the sales function: consequences}

As stated, the role of sales in the business environment is undergoing significant changes in response to competitive activities and marketplace demands. We can classify these changes into four groups of consequences related to:

- the sales position

- the sales process

- the sales people

- the marketing channels

These types of consequences will be highlighted. 


\section{The sales position}

Not long ago, the main responsibility of a salesperson was to generate revenue (Wotruba 1996). The salesperson's behavior was oriented primarily towards managing actual sales and acquiring new customers. This behavior was mainly transaction oriented because revenue came from the products and services sold. A sale was seen as a single event of a transaction. This transactional approach to selling became popular during a period when there was a great need for analytical rigor in marketing and sales (Webster 1992). At this time marketing was approached as an optimization problem of maximizing profits. Products, price, demand, revenue, costs and profitability were important units for analysis.

The salesperson's role began to change in the 1990s in response to the new marketing environment. Today's business community is characterized by intensive competition, fragmentation of traditional customer bases, customers dictating quality standards and inventory/shipping procedures to be met by vendors, demand for in-depth, specialized knowledge as an input for purchase decisions, and more emphasis on improving sales productivity (Ingram and LaForge 1992). Although revenue generation remains essential for salespersons, their role is evolving into one of developing long term relationships with customers by providing the right skills and excellent products and services. In sum for the sales position, the responsibility for attracting revenue will radiate to all members of the TQM chain (Wotruba 1996).

Today's effective sales force should be well equipped to respond effectively to a variety of customer needs before, during and after the sale (Ingram and LaForge 1992). The sales force becomes increasingly important for:

- communicating what customers need and truly value to others inside the company

- delivering input regarding product development and modification decisions

- finding out what a customer requires to provide a unique composition of the total value package for the individual customer

\section{The sales process}

Today"s selling is becoming less and less a persuasive activity; in the highly competitive, complex environment of the world business community, an emphasis on sales professionalism in mutual long(er) term relationships seems to be the keynote of current sales practices (Ingram and LaForge 1992). The following quotation describes the current approach to sales (Chitwood 1989, in Ingram and LaForge 1992:20): "The sales profession is at a historic crossraad. The path to the past is littered with pseudo salespeople manoeuvring, ambushing, tricking, and cajoling customers into buying a product or service. The path to the future is studded with up-front, empathetic, professional salespeople who serve as advisors, even partners, to their customers. Given these options, the road to choose seems clear."

This quotation highlights the importance of a professional customer oriented approach to personal selling in the current environment. It implies that salespersons should employ truthful, non-manipulative tactics to meet the long term needs of both the customer and the selling firm (Ingram and LaForge 1992). The key element in this approach is the emphasis on the establishment of long term relationships rather than on one time sales shots. Customer information has to be collected to determine present and future customer's needs and demand. This information can be used for product development and modification decisions. Finally, salespersons should be responsible for all exchanges with the customer, i.e. for such things as all the services related to
customer support (Wotruba 1996).

\section{The sales people}

These changes in position and process require a transformation in the type of people who want to succeed in selling (see e.g. Bragg 1988; Weilbaker 1990). Although product knowledge still remains impontant, salespersons should demonstrate an ability to perform in an entrepreneurial way in situations in which this is required (see Churchill et al. 1985). Additionally, salespersons should 
be able to work in project teams.

With customers dictating quality standards and asking for specialized knowledge as an input to purchase decisions, selling teams are becoming more important; meeting customer demands implies not only product knowledge but also skills for sensing and diagnosing what must be offered to customers, coordinating skills and working in groups. Improvements in selection, training and motivation are necessary to find such highly qualified sales personnel (see Honeycutt Jr. 1996; Wotruba 1996 Ford et al. 1987; Ford at al. 1988).

\section{The marketing channels}

Traditionally, marketing channels have been as vertical marketing systems. A manufacturer's product passed the different layers in the distribution system to the customer. Examples of layers are wholesaler, dealer, own sales force or distributor (see Figure 1.2).

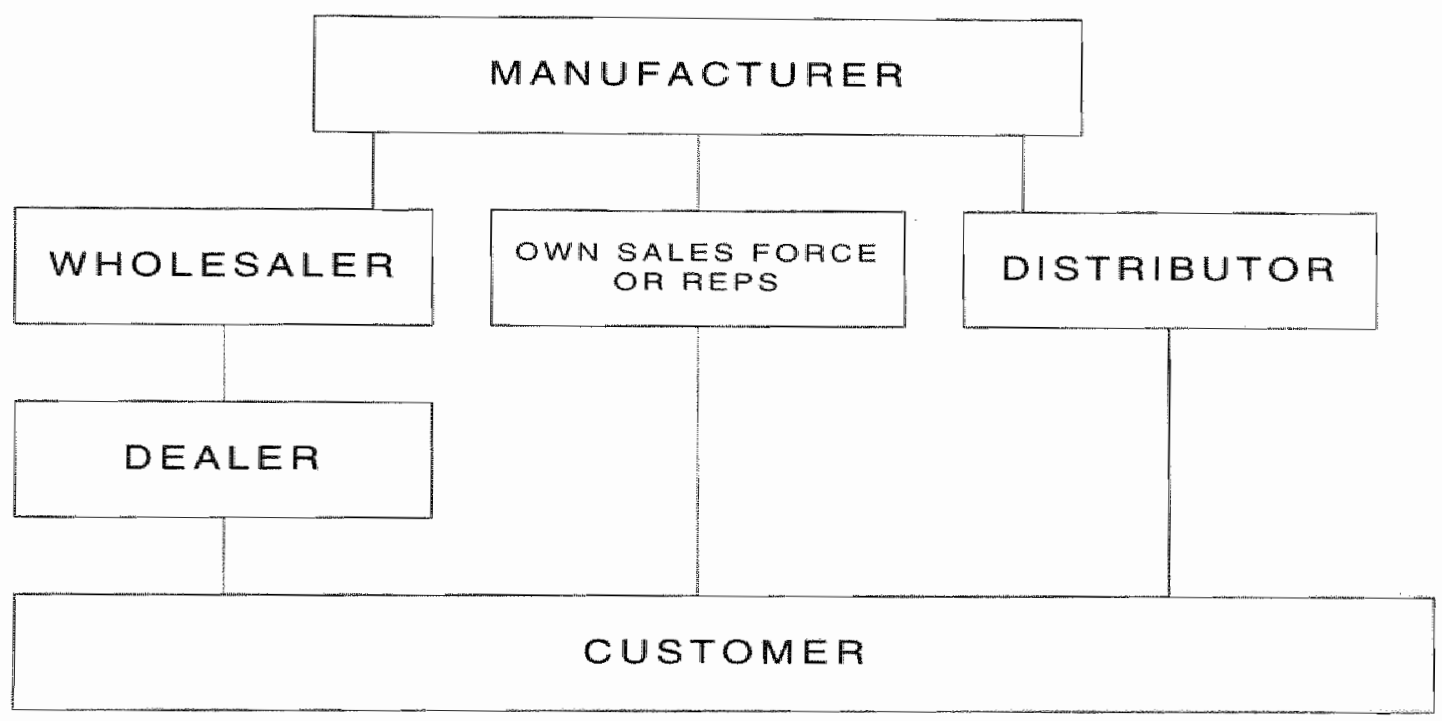

Figure 1.2 Channel options: traditional view

Source: Rangan, V.K. (1994) "Rcorienting Channels of Distribution" in Business Marketing Sirategy.

Cases, Concepts and Applications, edited by Rangan, V.K., B.P. Shapiro and R.T. Moriarty jr. 587

Business dynamics and emerging technologies make a new approach to disuribution channels both essential and feasible. Today's competition is forcing managers to analyse ewery aspect of their operations for identifying major cost savings and productivity improvements in terms of coverage. Three primary trends in channel design can be identified: hybrid channels, multiple channels and shorter channels (Rangan 1994).

One important trend in channel design is hybrid channels. Hybrid channels reflect a channel structure in which some channel members work together, e.g physical distribution, and others specialize in certain channel functions, e.g. after sales service. Forward-looking companies, such as Volvo GM and Okuma America Corporation, make their distribution channels more flexible and responsive by sharing resources and capabilities in novel ways and new situations. Examples include shared information systems and integrated logistics systems. These initiatives can be classified into three categories (Narus and Anderson 1996): 
Satisfying customers" extraordinary needs: e.g. repair parts are shipped within 24 hours of receipt of the order, if these parts are not shipped with this time frame them the customer gets them for free.

What customers want is what they get: e.g.by handling infrequent or emergency requests for unusual products and support services by allying with other distributors.

Superior services through shared capabilities: e.g. by contracting companies that can deliver outstanding services: companies tend to an outstanding job with some services and a mediocre job with others, the proficiencies of the contracted supplier can be used to bolster the inferior services.

Companies nowadays often find out that a single sales channel does not afford the economic efficiencies multiple channels provide. A range of channels offers the possibility to serve business segments with different needs (Rangan 1994). The downside of this trend is that conflicts might occur between suppliers and distributors when multi-channels are used. Amongst others, sales persons have to help solving these conflicts.

There is a trend toward using shorter channels (Rangan 1994). This trend is reinforced by the Intemet and commercial online services, such as Prodigy and American Online. Some companies, such as Amazon, have taken the opportunity to build an interactive relationship with customers, and deliver services and books at very low costs. Businesses online offer today's companies four types of opportunities (Ghost 1996):

- It offers the opportunity to establish a direct link with whe customers and other key players, such as critical suppliers, to complete transactions and trade information more easily.

Internet conmerce helps companies to bypass others in the value chain; e.g. a manufacturer could bypass retailers or distributers and sell directly to its customers.

Online channels can be used to develop new products and services for new customers, i.e. Internet generation Once at company controls the electronic channe] of a specific industry or segments, it controls the access to the customers and can set new business rules.

\subsubsection{Controlling the sales function}

Optimum sales performance in terms of sales volume, net profits and long term growth requires "control", and sales executives play a significant roles in controlling this business function. Control is an essential element of sales management because it allows an organization's managers to review how well sales objectives have been achieved. As a result of the transformation of the sales function, measuring sales performance, has become a complicated issue. Some of the problems related to this issue are given below:

- Performance measures, such as volume and contribution to profits, are used to provide timely feedback on the performance of salespersons, salles districts and salles regions. In many organizations, the responsibitity of satespersons has been extended with activities related to customer relationship management. Besides revenue generation. salespersons are often responsible for initiating, dewelloping and maintaining customer relationships. Measuring sales performance implies that the outcomes of these "non-selling activities" should be measured. "Too often, operational measures of salles performance encourage effectiveness in terms of high sales volumes only in the short term; in firms with such a transaction orientation, salespersons are monitored and rewarded on e.g. how many tansactions per customer are achiewed. In these business environments, salespersons are discouraged for taking enotugh time to develop customer relationships. In firms with a rellationship worientation approach, salespersons are monitored and rewarded for generating sales transactions and developing customer relationships. Inwesting in customer relationships often implies spending much more time with customers to identify the customers' needs.

- Sales tasks performed for a customer focussed approach" are more difficult to prescribe and less programmable than the tasks required for a transaction based approach. Various researchers have focussed on the impact of task programmability on control practices. In this respect, two different types of control practices have been discussed intensively: behavior based and output based control practices. Behawior based control practices. involve intensive managerial supervision of enployees, direction of and intervention in activities, and subjective, complex methods of evaluating perfomance. These methodls are typically focussed on the inputs and thronghput of employees. In contrast, output based control practices include relatively little managerial supervision of employees, reliance on straightforward, objective measures of performance, and rewards based on outcome measures (Anderson and Oliver 1987). Control theorists, such as Ouchi (1977), have found that output based control practices are appropriate in an environment characterized by low task programmability. 
These authors recommend primarily the use of ourcome based sales control practices to support a customer focussed strategy. Examples of output measures inchude sales, contribution of profit and customer satisfoction.

A customer focussed strategy also requires a company wide approach. It implies that sales persons are often involved in productservice development, eic. Their boundary role function offers them the opportunty to collect customer information. This information cain be used to improve product and/ or service performance. Furthermore, today"s products are often becoming so complex that salespersons have to be supported by product specialists during the sales process. In sum, the sales function has many interfaces with other business functions. The transformation of the sales function makes these interfaces even more important than in the past. It implies that controlling the sales function also includes controlling the interfaces with other business functions.

The above mentioned problems indicate that the transformation of the sales function has an impact on sales control practices. An overview of empirical studies on sales control practices will be given in section 1.2. This section will highlight the fact that although sales control practices are an essential element of sales management, until now marketing or sales theorists have paid little attention to these practices, let alone the current change needed in sales control practices.

\subsection{EMPIRICAL STUDIES ON SALES CONTROL PRACTICES}

Untill now, relatively little attention has been directed to the broad question of how organizations control their sales effort (see Shapiro and Kirpalini 1984; Anderson and Olivier 1987; Cravens et al. 1993; Zinkhan and Pereira 1994; Honeycutt jr. 1996). This does not imply that the relevance of this subject has only been recently discovered. The concept of control has grown steadily within the marketing and sales management literature since its introduction by Hersey in a 1937 article about the elements of a marketing control system. Hersey (1937: 201) proposed that "... the immediate purpose of any system of control is to perfect plans, define problems. correct errors, measure results and study trends and changes..." This view of control practices in a marketing and sales context has remained basically intact for nearly thirty years (Haas and Wortroba 1983; Assael 1985, Jaworski 1986).

The emphasis of existing research has been placed mainly on the application of management accounting techniques to marketing and sales operations (see e.g. Heckert and Miner $1953^{10}$ ) and on decision making (see Bass 1963; Winer 1966). The early 'classics' on marketing cost analysis are Heckert and Miner's (1953) work on distribution costs and Longman and Schiff's (1955) work on distribution cost analysis. The early 'classics' on sales analysis are Sevin" marketing productivity analysis and a study produced by the National Industrial Conference Board (1965) of the US.

In the $1970 \mathrm{~s}$, there was increased attention for the importance of the financial orientation in marketing and sales. Due to the external pressures brought by the economic environment e.g. a slower growth rate in many markets, marketing and sales managers were also forced to pay attention to marketing planning, implementation and control (Trebuss 1978, in Shapiro and Kirpalini 1982). Since the 1970s, various researchers (see Mossman et al. 1974; Kotler et al. 1977; Hulbert and Toy 1977) have tried to enhance organizational performance by focussing on the financial performance of marketing and sales on the short term (Trebuss 1978). Financial criteria such as profitability and sales growth are, therefore, often used as primary objectives and measures of performance.

The financial orientation in marketing and sales has resulted in an intensive use of financial techniques such as profitability and variance analysis in marketing decision making (Trebuss 1978). For instance, researchers have studied intensively how salespersons should be rewarded to their performance. Furthermore, the financial orientation of researchers has stimulated the use of financial monitoring and control systems in marketing and sales. Although a financial orientation is still important, researchers have recently begun to look at the importance of the behavioral and psychological consequences of marketing and sales "controls-in-use" (see Fry et al. 1986'). Their research findings highlight the fact that the effectiveness of controls-in-use is not only determined 
by the impact on marketing and sales performance but also by individuall effects such as dysfunctional behavior.

The relevance of studying controls-in-use stems from a lack of interest in sales control issues. In the marketing management literature, relatively little attention has been directed to the areas of strategy implementation and control (Zinkhan and Pereira 1994). The omission may be most acute for matketing and sales control; until now, marketing researchers have been concerned primarily with planning (Jaworkk 1988). The added value of controls-in-use remains, however, unchallenged in the marketing and sales literature; because the control issue seems difficult to study, researchers may have a long way to go before they can give managers empirically based guidelines for the design of effective sales control systems. In essence, there has been thardly any research concerning the relative advantages of various coordination structures for marketing and sales purposes. It has, therefore, become necessary to pay specific attention to control. We are aware that control issues are studied intensively by many researchers in the field of organizational theory and management. accounting/control but until now their insights have not been applied in a sales management context. Their insights can be used to explore the nature of marketing and sales controls-in-use and to develop theoretical frameworks.

\subsection{FOCUS OF THIS STUDY}

Organizational control and control in the accounting field is studied by many theorists and has been approached in many ways. There are several theoretical frameworks that are used to identify techniques, structures or processes that attempt to influence the behaviors of individuals, groups or organizations. Generally, one can make a distinction between formal and informal control. Formal control can be effected by using written or otherwise documented control mechanisms (Jaworski 1988; Wilson et al. 1992).

Formal control systems ${ }^{12}$ are control systems whose structure is visible and whose operation has explicit authorization (Anthony 1988). Using rules, procedures and orders, one authority may influence the behavior of a lower-level authority, e.g. formal controls. Another group of control mechanisms can be distinguished. Informal control refers to a variety of control mechanisms by which the behavior and actions of employees or groups are influenced though management does not initiate these mechanisms (Jaworski 1988). In this thesis, we will focus on the use of formal controls in a sales context. The following problem statement ${ }^{13}$ was, therefore, formulated:

\section{"How do organizations formally control their sales function in today's dynamic marketing environment, and how can these formal control practices be explained?"}

Although it would be shortsighted to overlook the importance of informal controls, this study is mostly concerned with formal control systems. Focussing on formal control systems implies that only a limited part of the controls-in-use are studied. We are aware of this limitation, and this limitation of our research can be justified as follows.

Our literature study has indicated that relatively little attention has been directed towards how organizations control their sales function in general. Within the sales management literature, only a few researchers have studied the sales control function within organizations. Different researchers have approached the topic from their own particular backgrounds and stressed different aspects of the entire sales control process. Only some general insights of organization and management control hiterature are applied to sales practices (see Cravens et al. 1993; Jaworski et al. 1993; Challagalla and Shervani 1996; Ramaswami 1996). To be useful, the research findings about sales control practices need to be organized around a framework. If the topics and subtopics of the framework are well chosen, we can make generalizations about sales controll practices that are generally applicable for one category, such as an industry, but are not applicable for other 
categories. Progress in accumulating knowledge concerning sales control practices depends on the development of frameworks as the basis for making generalizations. These generalizations can be useful to summarize theoretical findings and to draw lessons from case studies. Additionally, they are useful when their relationship to an overall framework is understood.

Besides researchers, control system designers and managers need a framework for developing or adapting sales control systems. A framework permits an orderly arrangement of control topics. As new ideas come to the system designer"s attention, they need to know the limitations of its applicability. This can be determined by organizing, comparing or contrasting these new ideas with previously accepted ones. Managers in a business organization need to understand how to behave effectively. A framework for sales control can help these managers to develop a framework consisting of generalizations about the most effective way to behave, and it permits managers to use these generalizations in a more efficient way.

To develop such a framework, we focussed our attention on formal controls. Anthony (1988) emphasizes that researchers should pay attention first to formal controls because, by definition, managers do not design informal control systems; managers can design a formal system but an informal system develops without a system (Anthony 1988:1-10). Following Anthony's argument, we may consider that the presence of informal sales control is similar to other environmental factors that managers must consider when they design sales control systems. We are aware that the formality characteristic is only one of a control system's descriptors "around which a theory of sales control can be built; however, starting the theory this way may serve the useful purpose of separating the topic which we have the most interest in from a design point of view, formal sales controls, from the rest.

\subsection{AIM OF THIS STUDY}

Now that the background of our research project has been described and the problem statement has been formulated, the aim of this project can be presented more explicitly. With the research presented in this thesis, we want to gain an understanding of formal sales control practices. Our intention is that the research presented in this thesis will allow us to develop a framework that can be used to study sales control practices and to examine an appropriate control system for organizations.

Existing insights concerning the control function within the management control and management accounting literature will be used to develop a framework for controlling the sales function formally by integrating these insights in a theoretical framework. To justify the development of such a theoretical framework, we first need to answer one basic question: why do organizations need to control their sales effort?

Managing the sales function effectively implies developing methods for controlling this business function (see Ingram and LaForge 1992; Churchill et a1. 1993). "These methods are necessary to assess sales effectiveness and efficiency, and 10 initiate corrective actions. Sales management, for its part, is increasingly concemed with controlling the sales effort and giving it direction in the face of market developments (Wasburn 1988). General sales managers, regional managers, and even sales representatives need assurances that they are doing what is required to attain sales goals and targets set by management, as well as to meet the challenges and opportunities of the marketplace (Washburn 1988; Ingram and LaForge 1992). In particular, assessing sales effectiveness and productivity has two basic aims (Washburn 1988). One aim focuses at giving line managers operational control of the day to day revenue producing sales activities and costs associated with it. The other is aimed at helping top management to evaluate the entire sales process so that it can allocate resources and set goals for the sales force organization. Controlling the sales function helps companies to urgently and critically rethink their business mission/goals, and marketing and sales strategies. Sales control can add value to marketing through various ways, some 
of which are identified below.

- Controlling this business function may help managers to evaluate an organization"s strategries and tacti with regard to their effectweness. Managers can detect the causes of significant variances between plann and realized sales outcomes by assessing sales productivity and effectiveness. These variances may caused by the underlyng assumptions made during the planning process, such as forecasts of mark response, segmentation, positioning and product life cycles, or by inappropriate decisions about resour allocation and assignment of responsibility. An evaluation of strategy formation and implementation ca also be used to indicate the quality of planning activities. This information forces management to improv their planning activities in terms of clarity and realism.

Controlling the sales function may improve marketing implementation. The key components of an marketing strategy are target market selection and marketing mix (Ingram and LaForge 1992). Where: target market selection includes a definition of the specific market segments to be served, a marketing mi consists of a marketing offer to appeal to the defined target market(s). Managers also need basic informatio about sales effectiveness and efficiency and about environmental changes to evaluate the marketin implententation within a company. This information helps managers to evaluate the progress of marketin inplementation and the impact of environmental changes on the success of marketing implementation Based on this feedback information, they can decide whether to initiate corrective actions, e.g. reformulate the marketing strategy, reallocate resources or to initiate new activities.

Controlling the sales effort does not only improve marketing implementation and sales effectiveness, it ma also belp to decrease task uncertanty for sales personnel This uncertainty is caused by lack of directiot motivational problems, and personal limitations. Salespeople should be well guided because they occup positions at the boundary of the organization. Many organizations have increased their responsiveness : customer needs by empowering employees, in particular salespersons; and these, salespersons an particularly susceptible to role ambiguity and conflict which often have dysfunctional behavioral effects (se Ford et al. $1975^{15}$ ). The sales personned, especially, may not believe that they have the authority to mak decisions on the customer's behalf and/or they have not received the training, guidelines, and tools to mak such decisions. Controlling the sales function can diminish these uncertainties by delivering informatio about the nature of sales tasks to achicve the organizational goals and capabilities necessary to accomplis specific tasks.

In any company, the relationship between a company and its salespersons can be regarded as a principl agent relationship. An agency relationship is said to exist when, for instance, one party e.g. owners o management delegates authority to another e.g. a salesperson and at the same time an incentive scheme fo the latter is linked to the outcones that they will eventually realize (Van de Poel 1986). Such a contractua relationship has conflicting interests under conditions that allow at least one party to manipulate commonly shared risk: a 'moral hazard' (Van de Poel 1986). This can be the case in a company's sales forc organization. Whereas a company typically wants to increase its profits, salespersons want to increase the personal income. Such a company must try to resolve this principal agent problem and ensure that the effort of its sales force are directed towards the achievement of organizational objectives by using an appropriats governance structure.

\subsection{OUTLINE OF THIS THESIS}

Having described the background of the research project, its structure can be presented. Wh formulated the following questions to tackle our problem statement:

- What are formal control practices?

What are formal sales control practices?

How do organizations controll their sales function formally in today's dynamic market place?

How can these formal sales control practices be explained?

These questions were used to structure the outcomes of our research efforts. This dissertation consists of 6 chapters. These chapters can be roughly divided into three parts.

\section{Part one}

Part one of this thesis deals with the theoretical framework of our research. It consists of two chapters, chapters 2 and 3 , which deal with the existing literature on organizational control and 
sales control. These reviews are used to develop a conceptual model and set the stage for chapters 4 to 7 , which contain a detailed report on the different phases of the empirical research undertaken to validate the proposed model. Several subjects related to organizational control are discussed in chapter 2.

Having determined what organizational control is, the basic elements of a control system are discussed. Special attention is paid to the control process, as this is the starting point for the development of our theoretical framework. We discuss Anthony's model of the formal control process, and extend this model with a number of control mechanisms. Next, we pay attention to designing a control system. We discuss the dimensions of organizational performance, performance measures and measurement systems, and evaluation in the context of control system design. In the last section of this chapter we outline the consequences of control system designs.

Chapter 3 deals with the existing management and accounting literature on sales control. To answer our problem statement, it is necessary to gain some more insights into the research findings about sales management control. We describe concisely the sales function and how this business function has evolved into a quite different function than it was a few decades ago. Finally, we discuss the existing literature on sales control practices. In this section attention is paid to sales control, as the concept formed the starting-point for the transformation of our theoretical framework into a framework for sales control practices. Then the impact of the changing role of sales to its control system will be discussed.

\section{Part two}

Part two deals with the empirical findings. It consists of two chapters. We combine the insights from chapters 2 and 3 and formulate our research design in chapter 4 . An inductive approach to case study research was used to gain insights in sales control practices. The outcomes of our research are described in chapter 5 . The case studies were based upon in depth studies of various firms from the computer industry. The outcomes of four case studies are analysed to draw general conclusions from these studies and potential explanations for similarities and differences between computer firms.

\section{Part Three}

Part three of this thesis consists of chapter 6 in which the main conclusions and managerial implications of the study are discussed. We propose some directions for further research in the area of the sales control function. The outline of this thesis is given graphically in figure 1.3. 


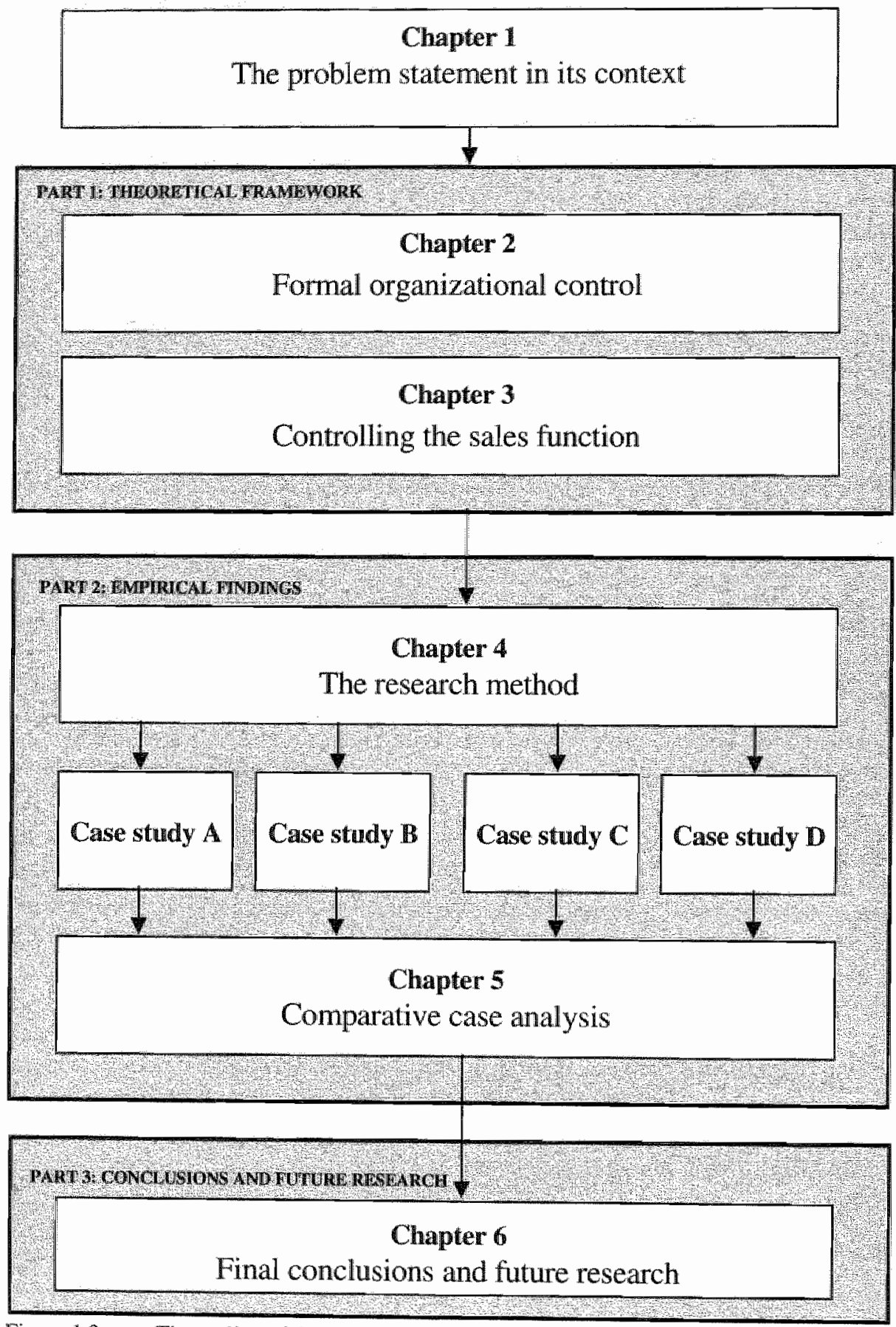

Figure 1.3 The outline of this thesis 


\section{Notes}

1.The American Marketing Association detines marketing (matragenent) as "... the process of plaming and wecuting the conception, pricing, promotion, and distribution of ideas, goods, and services tr create exchanges that satisfy individual and organzational objectives (Kotler 1994: 11). The promotion tools available to any firma are typically classified as personal selling, advertising, sales promonon, and publicity. Sales management is managenent of the company's personal selling finction (Ingram and Latrorge 1992)

\section{A market driven company should combine both (see Day 1990).}

3. The academic and consulting world have applied intensively Porter"s insights raganding compentive strutegies. Porter offered a tool to classify competitive strategies and highighted the cincumstances when a specitic strutegy is more appropriate then the other foms. Since the early nineties Porter s ideas are becoming increasingly critized by warious researchers. Mathyssens el al. (1998) ciassitied the main crivics on Porter's chassification of compective Strategies:

- Successful companies have the ability to create new Critical Success Factors; a g. they combine cost leadership with innovation. It implies that there no "pure" smategles such as Porter have proposed. A successful strategy ranely relies on the repeated implementation of the same move to nuintan atrategic position (Gilbert and Srebel 1991:91).

- Buden-Fuller and Stopford (1994) indicated that companies can combine the varions strategic options, suchin as cost leadership and differentiation. It is the challenge for managenent to solve the contradictions between these strategies instead of making concessions.

- D'Avem (1994) stated that competitive advantages are generally temporary in hyper competitive mankets. Business excellence in the long mu implies that a firm has the ability to create conpetitive adwatages; they dewelop new initiatives in critical stuations instead of protecting their commetitive advantages. This ability makes it possible to generate extra profits by short term adwantages.

- Hamel and Prahalad (1994) emphasized the importance of core competencies. Some companitus have the ability, ie. core competencies, to infuence their environment instead of only reacting on envirommental developnents. It makes that competition takes place in product markets but also in the fivald of cote competencies.

- Samchez (1994:135) stated "... the new patiens of product competinows are of superior flexibility in product creation can be highly destabilizing fo firms that try to adhere wo traditonal product strategies of low cost, differentiation, or focus", It implies that successful companies are those who hawe the following characteristics: (1) to improve quickly the existing products, (2) to commercialize successful products, and (3) intensive market segmentation and "real hime" market research.

- Best (1997) indicated that a SBU has also to fulfill the customer requirements related to the product, brand, and service reputation when it applies a low cost strategy.

4. Customer vallue refers to "... the benefis that custamers in a target manket segment want and how these? customers percewe the relative salue of compening suppliers' offers" (Kohler 1994: 235). It refers to the castomers concern for getting more for money, time and effort invested (Zeithanl and Bitner 1994)

5. Centralization refers to keeping the decision making power in one place; decentralizalion tefers to the dispersion of decision making power down the hicharehy (Mintaberg 1979).

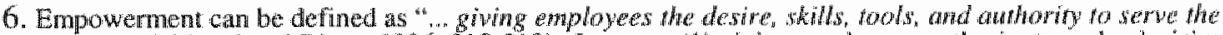
custone " (Zeithand and Bitner $1996: 318-319)$. I means (1) giving employees authority to make decistons on the

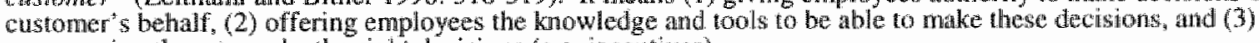
encouraging them to make the right decisions (e.g. incerntiwes).

7 The steps in the selling process and the order filling cycle consists of:

- rorecasting

- prestlie activity

- proposals and quotes

- delivery / feasibility

- approviall cycle

- inwentory management and shippirig

8. Since the early 1990 , companies often use differentiation strategies related to relative perceil wed qually. The ge strategies are used for ganing competitive ad wantage by creatiag customer walue lo satisfy the customers" needs and wants.

9. The sales function has many interfaces with other business functions becatuse of its boundary-rolle function. Mathyssens and Verinulst (1996) discussed four reasons of importancy with regard to the Srles-Marketing interface

The salespersons interact with their customens; these interactions inply a two way communication between 
buty and seller which can be used to improve the company's performane. For instance, the complexiry of today's products and services requires anowledge transfer from buyer coward vendor. Salespersons are often inwolved in the dectorionmaking concerning the choice and inplementation of products and services. This implies that the salespersons should have extended product knowledge about the use and possibilites of the firm's products and services. This need explains the necessity of the interface Sales-Product Maragernemt.

Furthermore, indusubl buying behavior is transforming from an ageressive approach to a more cooperative

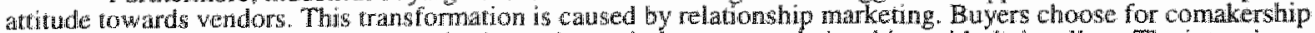
and early stupplier involvement in purchasing to invest in long tem relationships with their sellers. The intertsive information transfer with a supplier make it possibie to deliver a customized solution which contains physical products and core competencies of the vendor. These interactions with the customers implies an intertace Sales RE D; the product manager and salesfacount manager ate part of innowation teams.

Today"s markeis are more fragmented than in the past. This requires an internswe cooperation between gatles and marketing for selling in these micro markets.

Findly, the short product life cycles and "turbo marketing" make a close cooperation between sales and marketing necessary. Sales and marketing departments have to tratsiate the production plan into sales eforts becaluse the tirne-to-market is one of key success faclors for today" sompanies.

\section{See also Longman and Schiff 1955 ; Sevin 1965 ; Simon 1969.}

11. Anderson and Olivier 1987; Ford et al. 1987; Jaworski 1988; Jaworski and Mclonis 1989; Johnston et xil. 1990; Lush and Jaworsk 1991; Agrwal and Ramaswami 1993; Jaworki et al. 1993, Cravens et al. 1993; Olivier and Andarson 1994; Challagala and Shervani 1996; Rawaswami 1996

12. Jaworski (1988) used the timing of management intervention to specify the various forms of formal controls. By applying this criterion, he distinguished three rypes of fomal controls: input process and output controls. Imput oriented controls nefer to behavional control mechanisms by which managers create preconditions in which the desired behavior of employees (or groups) can take place. Process-oriented comnols focus on controlling particular behavior of individuals or groups by inthencing the behavior during the accomplishmert of marketing tasks. The group of behavioral cantrols consists of a wartety of bureatcratic mechanisms of monitoring and directing personnel (Ouch 1980). Output-oriented or resuls controls are formal control mechanisms focussing on outicones of behavior. Based on a formal assessment of performance of individuals or groups, extrinsic rewards are recelwed (Flamhotz at al. 1984; Merchant 1985).

Furthermone, control mechanisms can also be classified into open-loop and closed-loop control. Open-loop controls exist when an altempt is made by an organisation to achieve its desired objectives, but when no adjustments are made, once the actions have been started. Contrary to open-loop controls are, not surprisingly, closed-loop controks, which allow the adjustment of actions during and betore they are started. Two main forms of closed-loop controls are feedforward and feedback controls. These two forms of closed loop controls are distinguishable from each other by the moment at which control is cxercised. Feedforward control starts before any actions have been started, and can be defined as a measurement and prediction system which assesses the system and predicts the output of the system al some future date (Bhaskar and Housden; 1985). It inwolves proactive decision-making. in a sense that it seeks to anticipate, and thereby to awoid, deviations between actual and desired oncomes. Feedback control takes place when the actions have been finished, so that planned and actual performance can be compared. and resulting information can be linked back to the system so that, if necessary, causes for deviations can
be found.

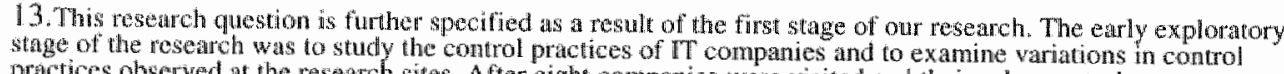
prictices observed at the research sites. After eight companies were visited and their sales control systems were dow imented in exploratory casses, the initial broad research question "How are the dimensions of sales control syistems, specified by our theoteticat model, realized within different types of organizations? How can this be axplaned" became mone focused: "How are the dimersions of sales control spstems, specifed by ow theoretical

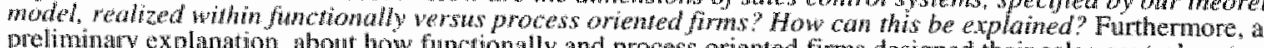

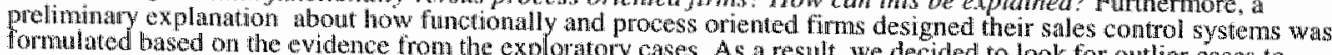
fommated based on the evidence from the exploratory cases. As aresult, we decided to look for outlier cases to

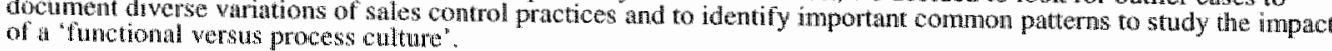

14. Many accounting and managennent theorists have examined the nature of the control function. They therefor developed various dassification schenes to study control practices. Merchan (1985). for instances studies the main contuol ypes by classifying them acconding to the object of control: results, alctions or personel. Results control

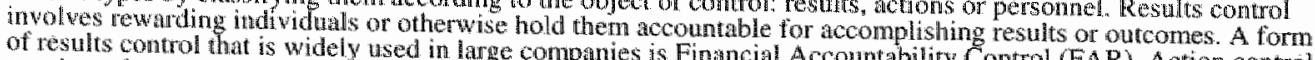
of resuls control that is widely used in large companies is Financial Accountability Control (FAR). Action control to be beneficial of humful to the onganization. Examples are betoviom do not perform certan actions that are know of movernent, and action accountability. A third mipor ategory of control trpes is e. restricting people"s freedom self control and social control.

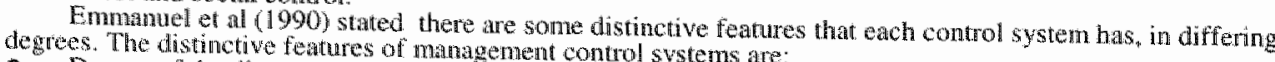

de Dees. The distinctive feathres of management control systems ane: 
- Degree of relevance when a control system has a high degree of relevance the managers the system obtain relevent information direatly related to theit prevailing decisional activity.

- Degree of selectivity; this can be measured by the ratio berween relevant and irrelevant information in the control system.

- Degree of formall responsibility; if the system of financial targets and sub-targets is wery well developed the control system is said to have a high degree of formal responsibility.

- Degree of procedural rigidity; here a difference has to be made between a standard control systen and a contingency control system. Standard control systerns are managed with well defimed provedures and format tools; contingency control systems are "ad hoc" systems tallored wo specific problems at specific moments.

- Style of control; this feature is related to the behavior of managers and can be classified as "tight" or 'loose".

- Quickness; this involves the speed of reaction of the decisional activity of the managers.

- Orientation; this feature indicates the favor towards certain issues, information or objectiwes whin the control system.

15. See also Walker et al. 1975; Ford er al. 1976; Teas 1983; Behrman and Perault jr. 1984; Tyagi 1985; Fry et al. 1986; Fucrell et al. 1986; Cravens et al. 1993; Jaworsk et al. 1993; Challagalla and Shervani 1096; Ramaswami 1996 . 


\section{Chapter 1}

The problem statement in its context

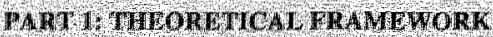

\section{Chapter 2}

Formal organizational control

\section{Chapter 3}

Controlling the sales function

ALT 2: EMPIRICAL FINDINGS

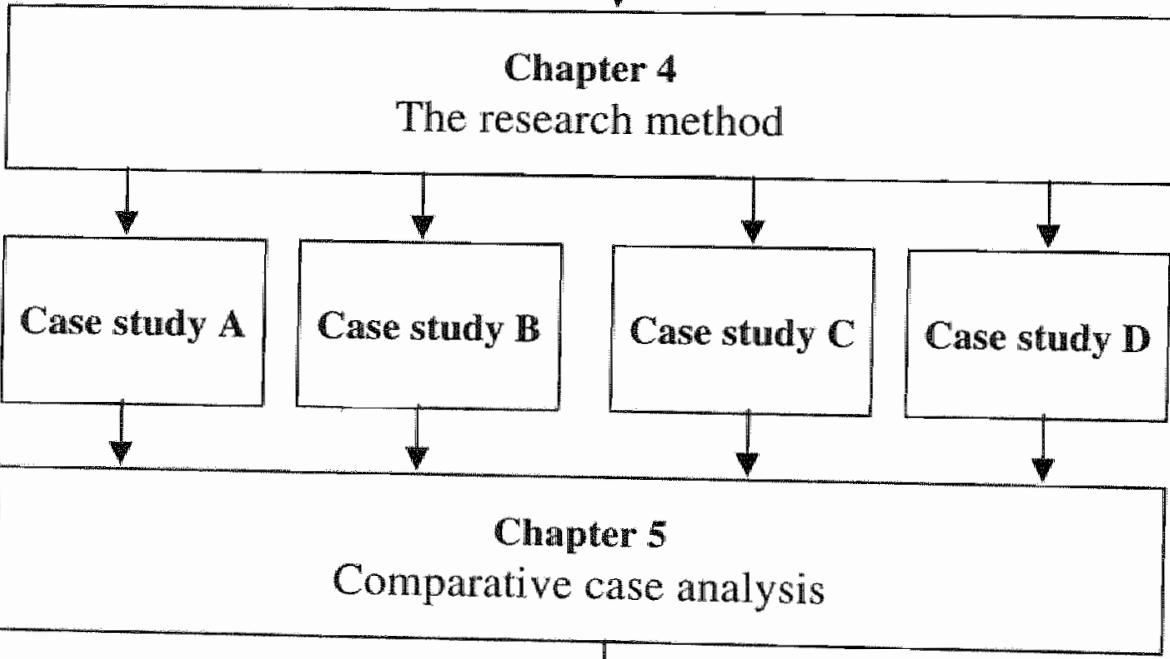

PART 3: CONCLUSIONS AND FUTURE RESLARCH

\section{Chapter 6}

Final conclusions and future research 


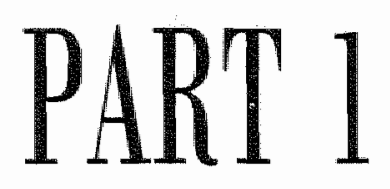

Theoretical Framework 


\section{Chapter 2 \\ Formal Organizational Control}

Introduction to the Basic Concepts

\section{Chapter outline}

In the last twenty years, there bas been a growing interest in the subject of organizational control; researchers have become increasingly aware of the need for planning, and just as importantly, the need to see that the planned actions and results are realized. The need for managers to delegate authority is inereasing, especially now, when organizations and their environments are becoming increasingly complex. The notion of control in business organizations, however, is susceptible to many interpretations. This chapter is, therefore, used to present an elaboration on the basic aspects of formal control that were used to build the theoretical framework for our research project presented in this thesis. Its structure can be described as follow.

We start with a general introduction to the concept of organizational control. Having defined what control is, section 2.3 deals with the basic elements of a formal control system. Various researchers have studied the nature of control systems and the most relevant research findings will be used to develop a basic framework for organizational control systems. The key aspects of designing a control system will be discussed in section 2.4. A system designer generally has to make a selection of control mechanisms to encourage functional behavior, dysfunctional behavior and other effects can, however, also be encouraged. Both the intended and unintended consequences of controls-in-use will be discussed in section 2.5 . Section 2,6 deals with the existing empirical research in the management control literature concerning sales control practices. Finally, a summary will be given together with the concluding remarks. 


\subsection{THE CONCEPT OF ORGANIZATIONAL CONTROL}

\section{Introductory remarks}

Organizational control is studied by many theorists and has been approached in many ways. Insights generated by these different approaches may help us to define the boundaries of control systems, to consider what entity is exercising control, and to identify what entity is being controlled. It is necessary to make a clear distinction between the control process and the control system. These key elements of organizational control are discussed below.

\section{The control process'}

The "control process' is described as a cycle of activities or a managerial process by which management ensures that the organization will attain its goals. For instance, Camillus (1986:11) defines control as "... a behavioral process that imvolves measurement and evaluation of the performance of organizational units, the initiation of appropriate responses to these deviations, and monitoring of remedial actions, all done with the intent of ensuring that managers" decisions and actions are consistent with planned organizational objectives".

Similar definitions are proposed by Anthony (1988:10) and Wilson et al. (1992:548-549). These researchers believe that control is a set of repetitive, goal seeking activities and not as a discrete function. This implies that a standard is set, the standard is monitored, and corrective action is taken when a deviation from the standard is deemed to be significant (Dalton 1971:13). The control process involves at least the following activities (see Merchant 1982; Jaworski 1988):

- formulation of objectives

- statement of performance indicators or standards

- measurement of actual performance

- evaluation of differences between actual and planned performance

- supply of feedback information

- regulation of activities to reduce unwanted deviations

The definitions of organizational control can be classified into two broad categories: control in the sense of 'directing" or "proactive" and control in the sense of "correcting' or 'reactive'. In the first group of definitions, organizational control is depicted as a guiding and directing mechanism. It is not assumed that organizational control does not imply corrective action; but more emphasis is put on the proactive elements of organizational control. The definitions, therefore, show more 'ex ante' aspects of control. An example of a such definition is given by Anthony (in Euske 1984:21). He defines organizational control as "... the process by which managers assure that resources are obtained and used effectively and efficiently in the accomplishment of the organization's objectives."

A second group of definitions defines organizational control from the perspective of correcting. For instance, Eilon (1979:4) has indicated that "Control is associated with an adjustment, namely with a corrective action designed to guide the system to function to a predetemined standard." More emphasis is put on evaluative and corrective aspects of control in this second group of definitions and they, therefore, emphasize a more reactive or "ex post" view of organizational control.

A definition of control in organizations which integrates both views described above, has been given by Berry et all. (1995: 18); they define control as "....a process for motivating and inspiring people to perform organizational activities that will further the organization "s goals. It is also a process for detecting and correcting unintentional performance errors and intextional irregularities, such as theft or misuse of resources." We will adopt Berry ef al."s definition of the control process because it integrates both views towards organizational control. 
E. Anthony (in Euske 1984). ". "Whe process by which managers assure that resources are obtained and used. effectively and efficiently in the accomplishment of the organization" "objectives."

e.g. Elon (1979): "... the process by which managers as whe that resources are obtaned and used effectively and efficiently in the accomplishment of the orgatization "s abjectrives."

c.g. Berry ef all (1995)" "...a process for nnotivating and inspiring people lo perfom organizational activities that will further the organization "s goals. It is" also a process for detecting and correcting unintevional performance crors and intertichal imegularities, such as theft or misuse of rescances"

Tuble 2.1 Overview of selected control definitions

\section{The control system}

The control process is underpinned, and driven by a control system. The term 'control system' refers to mechanisms consisting of processes and techniques (Flamholtz et al. 1985) that can be used to influence behavior. Anthony (1965, in Lowe and Machin 1983:24) defines the area of management control as "Those formal, systematically developed, organization-wide, data-handling systems which is the process by which managers assure that resources are obiained and used effectively and efficiently in the accomplishment of the organization's objectives"2. Anthony's description demonstrates that organizational control systems must be concerned with coordination, information processes, and resource allocation in the management process.

One can look at two distinct but highly interrelated subsystems to study the nature of control systems (e.g. Maciariello 1984; Anthony 1988): the control structure and control processes. Whereas 'structure' of a control system is used to demonstrate what the system 'is', "processes" refer to what the system 'does'.

The control structure can be described in terms of a control hierarchy or structure (e.g. Anthony and Young 1984; Maciariello 1984; Anthony 1988). Each organization can, for instance, be divided into many responsibility centers. A responsibility center is an organizational unit responsible for the attainment of organizational objectives; and it is headed by a manager who is responsible for its activities. Each responsibility center receives inputs, e.g. materials and services, from its environment to accomplish the organizational objectives. Responsibility centers produce output by processing these inputs. Whereas the amount of inputs is usually measured as costs, the amount of output can be measured as e.g. revenue. The sum of responsibility centers forms the structure by which management can control. Large organizations are often characterized by a complex hierarchy of responsibility centers consisting of many organizational units, departments, divisions and so on; this suggests that responsibility centers are mostly interlinked. This means that to reach the overall organizational objectives responsibility centers are linked by their control processes in hierarchical structure of control according to the reporting relationships (Maciariello
1984 ).

The concept of 'control processes' refers to managerial processes which managers use to assure that actual activities conform to planned activities (Anthony 1965). Examples of control processes include goal setting, performance measurement and evaluation, and initiating corrective action to cllose the gaps between goals and performance (see Dalton 1971; Jaworski 1986; and Jaworski 1989). Information flows and management systems are used to support the control process
(Maciariello 1984). 
Structure and processes are so interlinked that it is impossible to situdy them separately. Goal setting and resource allocation are, for instance, accomplished through the structure of the organization (Maciariello 1984).

\subsection{TOWARDS A THEORETICAL FRAMEWORK}

\section{Introductory remarks}

All control processes, ranging from simple to complex, can be considered analogous; because the general purpose of any control process is to alter ex ante or ex post the behavior of persons or things to a desired state of affairs (Anthony 1988). The general model of the control process has, however, to be extended to study the specific nature of the organizational control processes (Anthony 1988). It is necessary to define the system in which a control process can take place to discuss the control system. We define a control system as ".. a set of mechanisms (both processes and techniques), designed to increase the probability that people will behave in ways that lead to the attainment of organizational objectives" (Flamholtz et al. 1985:38). Our framework for an elaboration of the nature of the control process in an organizational setting, will be based on Anthony"s view ${ }^{3}$ of control.

\section{Assumption: organizational structure as a control device}

Before elaborating on Anthony's view, an assumption must be made clear. The structure of an organization is often seen as another control mechanism. We will assume that the organizational structure is a control mechanism in so far as its form directs, influences and shapes managerial behavior.

The idea that structure is a control device per se is not shared by everyone (see Ouchi 1977; Flamholtz 1983; Flamholtz et al. 1985; Jaworski 1985). Flamholtz et al. (1985) state, for instance, that organizational structure has implications for control; but that is not a control device per se. Other researchers (e.g. Blau and Scott 1962; Inkson et al. 1968; Blau and Schoenherr 1971) have suggested that organizational structure is per se a control mechanism. For instance, Inkson et al. (1968) believe that organizational control can be accomplished by bureaucratization or centralization of decision making, i.e. structural dimensions.

In this thesis, it is assumed that organizational control refers to the task of ensuring that planned efforts are producing the desired results to determine whether structure is a control mechanism or not. By definition, organizational structure does so and can therefore be seen as a control mechanism.

\section{Anthony's basic model of the control process}

Control refers to the process of influencing the behavior of members of an organization (Flamholtz et al. 1985; Camillus 1986) and this process is facilitated by a control system. Anthony (1988;1992) indicates that any control system generally contains at least four elements designed to influence behavior:
- an "detector" or "sensor"
- an 'assessor"
- an "efiector"
- a "communication network"

These elements will be elaborated further. The 'detector' or 'sensor' refers to a measuring device ,or a mechanism, that is used to identify what is actually happening in the situation being controlled, an 'assessor' is a device for determining the significance of what is happening. Significance is usually assessed by comparing the information on what is 'actually happening' to some standard or expectation of 'what should be happening'. An 'effector' is a mechanism that can be used to alter 
behavior whenever the assessor indicates a need to do so. The communication network is the set of channels used to transmit information between the detector and the assessor and between the assessor and the effector. Figure 2.1 gives an outline of the control process.

\section{Anthony's extended model of the control process}

Anthony's model is widely applicable, it can be used to illustrate the control processes within such diverse situations as a climate control system or an organization; both these control processes are analogous because the general purpose of any control process is to alter the behavior of persons or things to a desired state of affairs (Anthony 1988).

Organizational controll processes are much more complex compared to simple climate control processes. This complexity is caused by two different aspects; first, organizations involve human beings, and second, the desired state of affairs is the proper implementation of organizational strategies (Anthony 1988).

The standard that will be used for comparing actual performance to, is not preset within an organization. According to Anthony and Dearden (1980:6) "... the siandard is the result of a conscious management process, called planning". Planning, therefore, forms an indispensable process in organizations as it forces managers to take decisions on what the organization should do; it should be a part of the control process which takes place in an organization.

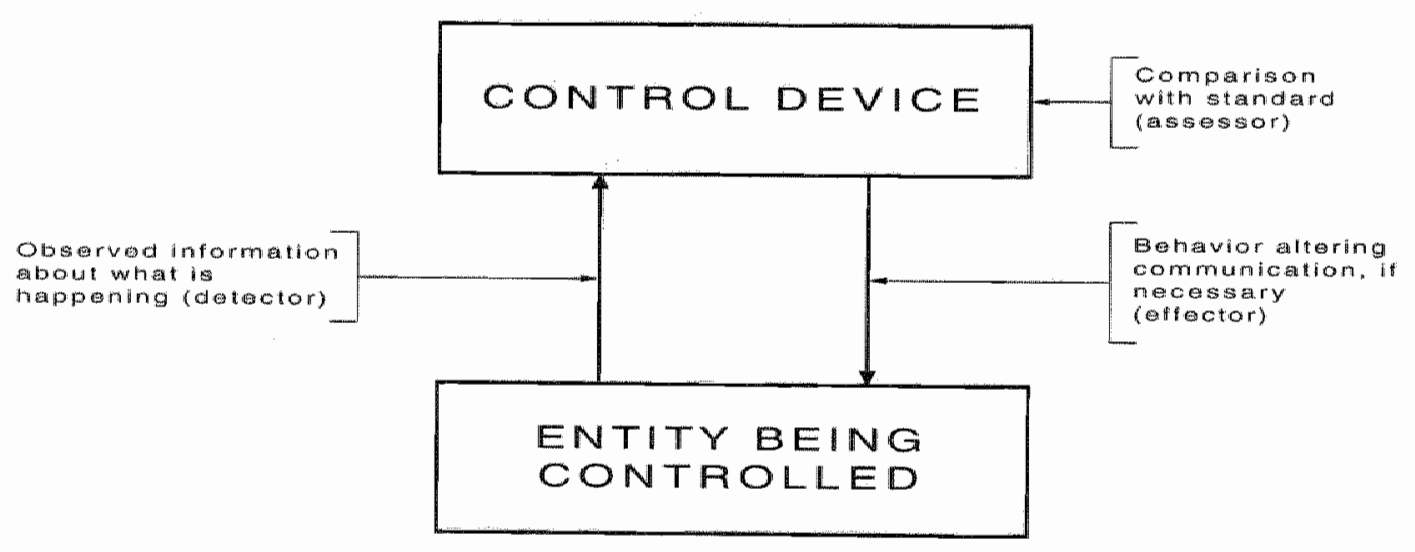

Figure 2.1 The Control Process

Source: Anthony, R.N. (1988), Whe Mannogemeph Function. Boston: The Harward Business School Press, p.8

\section{Planning as (ex ante) control mechanism}

Control in an organizational setting includes planning decisions and corrective actions when actual performance deviates from planned results (stated in plans). It is conventional to see planning and control ats separate managerial processes (Otley 1987). Whereas planning is often defined as the setting of organizational goals and the outlining of a set of actions needed to achieve those goals, control is mostly described as ensuring that these actions are implemented and that the goals are attained. These definitions of planning and control suggest a strong interrelationship between these two processes.

Since planning provides information necessary to direct behavior, we can see it as an 'ex ante' (e.g. Waterhouse and Tiessen 1978; Flamholtz et al. 1985; Jaworski 1986) or 'feedforward' (e.g. Bhaskar and Housden 1985) control mechanism. It is used to anticipate deviations between actual and desired results. Potential errors can be predicted in advance by using planning as a 
feedforward control mechanism. Managers can use this information to make predictions concerning performance at some future date after measuring and evaluating the undesired differences berween planned and actual performance (Bhaskar and Housden 1985). These predictions could lead to actions taken in advance that may enable the organization to achieve its objectives, i.e. proactive decisions.

Strategies and plans are based on assumptions conceming internal and external circumstances at the time when they are formulated (Anthony 1988). If current anticipations differ from the planning assumptions, then it may seem that strategies and plans developed in the past are no longer appropriate. This implies that corrective actions can be designed to prevent these errors from occurring (Berry 1988). When only feedback control devices are used in a control system, errors are allowed to occur. When making these decisions concerning strategy formation and implementation, managers should consider every aspect of the process and determine actions in advance (Wilson et al. 1992).

Organizational control anticipates what conditions are going to be in advance of their actual occurrence (Anthony 1988). Thus, control not only encompasses planning but also forecasting. Anthony (1988), however, has stated that planning and control cannot be seen as two different classes of activities; this is caused mainly by the fact that a lot of processes within an organization include both planning and control activities. Anthony (1988) classifies these activities as follows:

- strategic planning

- management control

- lask control

Strategic planning refers to "... the process of deciding on the goals of the organization and strategies for attaining these goals" (Anthony 1988:11) and management control is defined as "... the process that has to take care that strategies arrived at in the strategic planning process are carried out in a way that the organization's goals are attained" (Anthony 1988:9). Both processes include planning and control activities; but the planning activities are dominant.

Strategic planning consists primarily of planning activities, whereas management control is a mixture of planning and control activities. The outcomes of strategic planning are strategies. These strategies can be seen as the framework for deciding on appropriate actions for accomplishing the goals of the organization. It implies that these guidelines should be taken into account when the managers and their subordinates are going to set goals for the key (functional) areas of each operational subsystem and to formulate a set of actions needed to attain these goals.

Management control involves activities to ensure strategy implementation. Anthony's approach links management control directly to strategy implementation, rather than to goal attainment. The achievement of objectives is an indirect purpose of management control.

The third element in Anthony"s approach is task control, which is defined "... the process of ensuring that specific tasks are carried out effectively and efficiently" (Anthony 1988:12); it involves the control of individual tasks. Consequently, strategic planning is used to set the guidelines for management control, while management control sets the guidelines for task control. Task control consists, in the major part of controlling daily activities.

\section{Other organizational control devices}

We have described Anthony's basic model of the control process; for organizational control processes, this basic model has been extendied with an additional control device, viz. "planning". The other control devices, the detector, the assessor and the effector, can be used in an organizational setting. If Anthony's model is applied in an organizational context, the control devices have to be altered slightly; these changes are:

- Perfomance measurementakes the place of the detector. The dewice "detector" is often called "performance measurement" within an organizational setting. It catin be described as follows. Performance measurement is used to identify what is actually performed by the entity controlled, id. individual, group on organization. The "entity 
controlled' is called the 'operational subsystem". Performance measurement provides managers with the information necessary to initiate corrective action (see Reeves and Woodward 1970; Lawler and Rhode 1976; Flamholtz et al. 1985). This mechanism includes the management information system and the employee performance system of an organization (Flamholtz at al. 1985). Owerall, measurement is an ex post control device; however, it becomes an ex ante control device when managers use it to indicate anticipated performance outcomes, e.g. budget, or a performance context, e.g. sales forecast (Flanholtz et al. 1985).

- Performance evaluaition takes the place of the assessor. Applying Anthony's model in an organizational context, the device 'assessor" can be called "performance evaluation". Performance evaluation is an ex post control mechanism (Flamholtz et al. 1985). It is used to assess the significance of what is performed by comparing the information on what actually is performed to some standard of what should be achieved. This assessment is balsed upon information provided by the performance measurement system. The output of performance evaluation is called 'corrective feedback' (Flamholtz 1983).

- Feedback takes the place of the effector. Anthony (1988) defines 'effector' as a device that is used to alter behavior if the assessor shows the need for doing so. This device is often called 'opinion' by control researchers. Feedback is primarily an ex post control mechanism (Flanholtz et al. 1985). It involves the transfer of information concerning deviations in actual results from planned results. Feedback can have a directional and a motivational function within a control system (see Reeves and Woodward 1970; Lawler 1976; Flamholtz et al. 1985). For instance, feedback includes information necessary for corrective actions. The recipient may use this information to initiate corrective actions (if needed). Thus, feedback is used to direct the behavior of organizational members. Besides the directional or corrective function, feedback can also have a motivational function (e.g. Igen et al. 1979; Flamholtz er al. 1985). This motivational function is related to performance evaluation and reward. A recipient may interpret information concerning goal accomplishment as reward or punishment, or as a promise for future reward or punishment. Control researchers state that the major purpose of any control system is to influence individuals to behave in ways that contribute to the achievement of organizational goals (Otley 1987; Emmanuel et al. 1990). The control process should, therefore, not only focus on measuring and evaluating performance; it should also be oncerned with how and why personnel are motivated to act (Jaworski 1986; Emmamuel et al. 1990). Motivation theories, i.e. content and process theories, consider that the link between incentives, i.e. rewards and/or penalties, and the aspects of desired behavior is central to effective motivation (Emmanuel ef al. 1990). This implies that linking performance with rewards is crucial to motivate individuals. As stated earlier, the control device 'performance evaluation' is used to assess the performance of individuals, groups or organizational units by comparing actual results with the pre-established objectives and standards. Extrinsic and/or intrinsic rewards can be received based on the outcome of this performance evaluation (Flamholtz et al. 1985). While extrinsic rewards are administered after the formal evaluation (e.g. conducted by a superior), intrinsic rewards result from individual, i.e. informal evaluation. Flamholtz (1983:155) has defined the output of a reward system as "evaluative feedback". Rewards are in general ex post control devices. These rewards, however, become ex ante control devices when the anticipation of rewards is used to influence behavior towards desired directions (Flamholtz et all. 1985).

Besides the four control devices mentioned above, two other elements will be further specified to complete our theoretical framework for organizational control: the operational subsystem and its outcomes.

- An operational subsystem takes the place of the entity being controlled. It refers to those operational subsystems including the behavior exhibited by individuals, groups or organizational units. Such a subsystem is relevant for the acquisition, allocation, utilization, development, conservation and disposition of organizational resources (Flamholtz et al. 1985). It is also possible to describe these operational subsystems as "responsibility centers" (Anthony and Young 1984; Anthony 1988; Anthony et al. 1992).

- Outcomes are a result of an operating subsystem's activities including sales volume and productivity, and other performance issues, i.e. behavioral, psychological and role related acts.

\section{Our theoretical framework}

Now that all the control devices and other related elements required for our framework have been discussed, an outline of the formal control process in an organizational setting is given in figure 2.2 


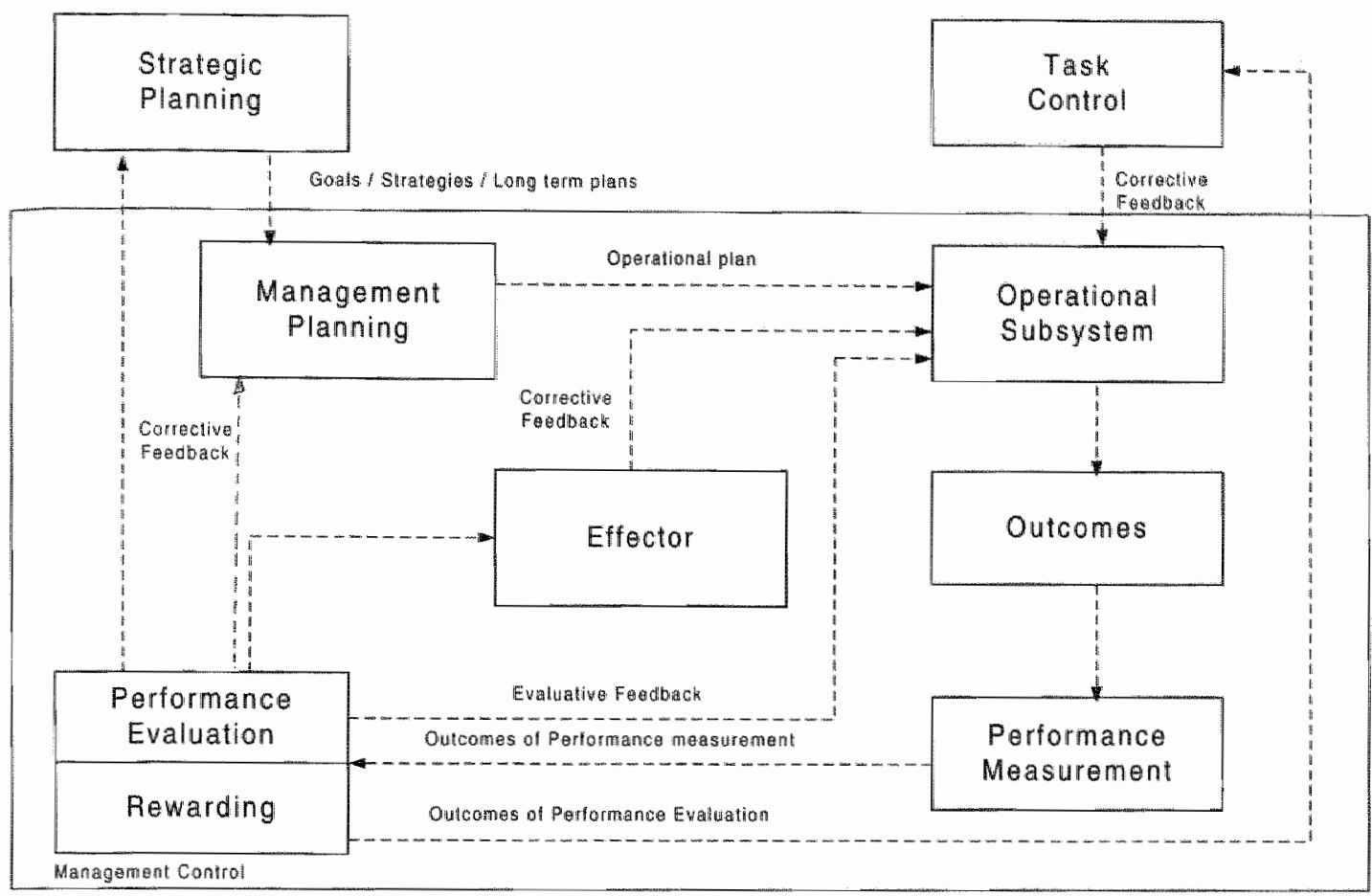

Figure 2.2 Theoretical Framework

The control process described in figure 2.2 takes place as follows. Strategic planming is usually undertaken at a strategic level within the organization. It leads to strategic goals including corporate strategies and long term plans to reach these goals. The strategies are an input to the management planning process, here the strategies are translated into goals for the operational subsystem.

Management planning in a 'going concern organization' starts when the managers of the operational subsystems meet their subordinates to review past performance, to set goals for key (functional) areas of each operational subsystem, and to formulate a set of actions needed to attain these goals. Additionally, performance standards are defined.

Performance standards can be expressed in terms of effectiveness and efficiency. All information is presented in a plan. The activities of the operational subsystem will be directed or guided by the information contained in the plan. The subsystems" outcomes are measured and evaluated, to determine the extent to which the planned results are achieved. Each subordinate reports actual performance for which the outcomes of actions are to be measured at periodic intervals during the period, e.g. weekly, monthly, quarterly or yearly. During this period, the managers meet periodically with their subordinates to evaluate their performance. They will agree on which targets are being met, on where improvement is necessary and on a plan of correction. Three types of corrective action can be initiated:

- adjustments of goals in the light of actual performance, e.g. goals were too ambitious

- adjustments of inputs to stabilize the outcomes at a desired level

- changes of the whole activity being engaged in

Subordinates are rewarded based upon actual performance and improvement in performance. At the next meeting, the managers and their subordinates review current performance together with the results of past corrective actions. The outcomes of the discussion during this meeting are used 
to plan corrective actions. The purpose of these actions is to ensure that predefined targets are attained. It implies that the control process continues in a repetitive manner for each period. Additionally, it continues throughout the organization.

The outcomes of the performance evaluation can be used for task control purposes: evaluating whether the specified tasks are carried out effectively and efficiently. If tasks are not accomplished effectivelly and/or efficiently, then two types of corrective action can be initiated. First, a supervisor can undertake action to conwince an individual to follow the rules and procedures. Second, rules and procedures are improved to respond to changing circumstances by e.g. introducing a new logistic system. The corrective feedback provides information that can be used to decide what corrective action can be undertaken.

\subsection{DESIGNING A CONTROL SYSTEM}

\subsubsection{Introductory remarks}

The development of an organizational control system involves the selection of appropriate control mechanisms to influence behavior. Behavior can be influenced both beforehand and afterwards: ex ante and ex post. The basic control mechanism that serves both an ex ante and an ex post function is performance measurement. It is, therefore, crucial for an organization to have an effective measurement system as it is a basic element of the control system. Such a system generally aims at two basic objectives (Kamensky 1993):

- to improve or sustain organizational performance

- to improve accountability

As Kamensky (1993) has stated, these two goals are not mutually exclusive. A performance measurement system helps to reduce uncertainty about plans and programs. This includes the uncertainty involved in planning future courses of actions and knowing the consequences of past actions in a way useful to a variety of decision-makers (Grizzle 1981). At the same time, accountability obligations may be met by ensuring that resources are used efficiently and effectively (see e.g. Grizzle 1981; Bavon 1995; Merchant1997). Designing an effective measurement system, therefore, implies that the system designer has to answers at least the following questions (Otley 1987):

- What are the dimensions of "good" performance that the organization is trying to encourage?

- How are appropriate performance standards to be set, both for the whole organization and for its subunits?

- What rewards or penalties can be associated with the attainment or non-attainment of the performance targets?

The answers to these questions help to define appropriate performance indicators. Otley (1987) has, stated however, that it is not possible to find definite answers to these questions. Due to internal and external environmental changes, designing performance systems can be seen as a continuous development of new solutions over time to the same questions. We will discuss each of these three questions briefly.

\subsubsection{Dimensions of performance}

Performance refers to results information obtained from organizational entities, processes, products, and services that permits evaluation and comparison relative to objectives, standards, past results, and to others. Defining the dimensions of 'good' performance appears the most fundamental and the most difficult question to answer. The difficulties are caused mainly by problems related to the decomposition of goals into subsidiary goals.

- The decomposition of overall organizational goals into subsidiary goals often results in multiple and partially conflieting goals and may result in conflicting dimensions of performance. (Otley 1987). The "overall organizational goals' can be decomposed into 'subsidiary objectives' and 'instrumental objectives". The subsidiary objectives specify the marketing objectives of the organization per subsidiary in terms of sales 
wolume, market share, and profit. The "instrumental objectives" are associated with the specific use of one or more mix instruments (Leeflang et al. 1987). These objectives are related to such matters as product mange, product quality, price policy and so on.

- Some aspects of 'good' performance are quantifiable in terms of sales volume, market share and profit; however. many other aspects cannot be measured (objectively), for example product image and customer satisfaction. Defining the dimensions of 'good' performance imples that quantifiable and less quantifiable aspects should be integrated. The extent to which objectives are quantifiable may help individuals to understand these objectives. This does not imply automatically that the means, such as plans, budgets, and action prograns, are also well understood (Otley 1987). The effectiveness of any business effort is also influenced by the extent to which individuals understand the means by which specific objectives can be attained.

Furthermore, companies generally express theit performance in financial and marketplace terms. Financial and marketplace performance refers to performance using measures of profitability, operating profit rates, liquidity, cost and revenue, including asset utilization, asset growth, and market share. Financial measures are tracked throughout the organization and are also aggregated to give company-level, composite measures of performance. These measures are important for evaluating the past performance of a company; yet they do not necessarily cover all critical success factors for long term and competitive performance.

Critical success factors refer to organization level requirements derived from short and long term strategic planning. They may include customer driven quality requirements and operational requirements such as productivity, cycle time, deployment of new technology, strategic alliances, supplier development, and research and development. In simplest terms, critical success factors are those things the organization must do well for success in today's and tomorrow's market place. These factors should be taken into account while defining the dimensions of 'good' performance; yet many companies emphasize often the financial dimension of performance.

\subsubsection{Performance measures}

\section{What are appropriate performance measures?}

A central question for the management of any organization is 'how well are we doing?'. Managers can measure continuously and request performance measures, be they for market share or profitability. Performance measures are used to focus the organization on the right direction. In particular, it allows the whole organization to know 'it is doing well" versus "feeling it is doing well'. If performance is not measured, then it is hard to separate success from failure. Today's customers are always looking for better products and services, more knowledgeable support, faster response and lower prices. Overseeing business processes and measuring performance, therefore, is more important now than ever before.

Performance indicators are also used to develop a baseline of performance and to set goals for performance improvements. These measures inform managers and other users about the current state of affairs and the outcomes of performance evaluation prompt their users to initiate corrective action if needed (see Dhavale 1996; Merchant 1997). Supervisors need measures for monitoring actions delegated to subordinates and for achieving continuous improvement and control (Lebas 1995). Customers and suppliers may require some measures of how healthy an organization is, and will be, doing; measures can be created for different users/stakeholders and for different purposes.

Performance standards can provide a means of performance evaluation at different organizational levels: at company, business unit or department level, and at the level of the individual (Dhavale 1996). These measures are the glue that binds business strategy to operational behavior. It is, therefore, critical to link the objectives of the firm effectively to the operational drivers that can be managed internally. 


\section{Seting performance indicators}

Once an organization has determined the dimensions of performance, appropriate performance indicators can be set. Various researchers provide criteria for performance indicators. Maskell (1989), for example, suggests that the following principles can be used to select a preferred set of performance measures.

- The measures should be directiy related to the firm's strategy

- Nonfinancial measures should be adopted

- If should be recoginized that measures vary between locations; one measure is not suitable for all departments or sites

- It should be acknowledged that measures change with circumstances

- The measures should be simple and easy to use

- The measures should provide fast feedback

- The measures should be designed so that they stimulate continuous improvement rather than simply monitor

The definition of performance indicators always causes a conflict between 'what is desirable' and 'what is attainable' for an organization, e.g. improvement of service quality or cost cuts in the area of service delivery (Otley 1987). In general, the feasibility of proposed targets is often difficult to predict (Otley 1987). Many internal and external circumstances have an impact on the feasibility; these circumstances are not always predictable.

The managers who are accountable for meeting a target are often in the best position to evaluate the feasibility. These managers are concerned primarily with the feasibility of performance targets because this indicates the extent to which they can meet these targets. It is obvious that the motivation for managers to meet specific targets becomes less when these targets are less attainable. When targets are less attainable, it often results in unfavorable outcomes in terms of both performance and attitude, e.g. lower commitment to the established targets and role stress. Less ambitious targets can, however, have a negative impact on performance; such targets are often not sufficiently challenging for managers to aim at continuons performance improvement. While lower level managers are more concerned with the feasibility of performance standards, senior managers tend to emphasize overall desirability (Otley 1987); this may result in a conflict between senior and lower level managers. These conflicts may be avoided by (Otley 1987):

- choosing a bottom up planning procedure instead of a top down procedure

- increasing the participation of lower level managers in target setting

- adapting the organizational design, i.e. span of control versus number of hierarchical levels

- adapting the design of management information systems

Desirability and feasibility of organizational performance are both subject to ambiguity. The management of a firm can try to increase profits by cutting costs in an operating system. This can have a positive and a negative effect on profits. A cost cut in service delivery may result in a higher short term profit, but it may have a negative impact on long term profits. For instance, cutting costs may result in cutting prices and lower prices may result in higher sales. The reduction in costs may also result in a lower service quality than consumers expect from the organization causing the consumers to decide to switch to another service provider.

\section{Financial and other traditional performance measures: not a total solution}

The answer to 'how well are we doing?' has traditionally been expressed in terms of economic concepts, e.g. productivity, and financial concepts, e.g. cost and profit. These concepts combined with strategic planning dominated management thinking in the $1960 \mathrm{~s}$ and $1970 \mathrm{~s}$ producing performance indicators like Return On Investment (ROI). The basic idea was to optimize resource usage by maximizing the financial return on investment. Moreover, it was believed that the success of a company is always and simply reflected in its profit.

Gradually, mainstream management thinking recognized that concentrating on resources, especially financial resources, was not always useful. In fact, some parts of financial planning and 
measurement systems with their origins in an uncompetitive era were no longer able to cope with market demands and the speed of change driven by intensive competition. Michael Porter and other prominent theorists of the late 1970 s and early 1980 s began to shift the collective business focus to reach market share.

As "competitiveness" became an increasing concern, Porter-based analyses presented marketshare as the ultimate indicator of success. Market share and profitability have, however, proven to be less than fully successful in predicting even medium-term success. Consider IBM which dominated its markets and. showed strong financial performance just a few short years before heading into record losses. Performance management systems based on traditional performance measures are characterized by a lack of strategic focus and do not provide data on quality, flexibility and customer service (see Skinner 1974; Kaplan 1983). They also fail to provide information on what customers want and what competitors are doing (see Camp 1989; Kaplan and Norton 1992; Watson 1993). The famous PIMS study reveals, for instance, that ROI is influenced mainly by the company's market share and relative quality position (Buzzell and Gale 1987). In sum, the set of traditional measurement can be extended with more nonfinancial measures.

\section{Need for nonfinancial measures}

Various researchers ${ }^{5}$ have advocated the extensive use of nonfinancial measures, e.g. customer satisfaction and quality, in performance measurement The need for more nonfinancial measures has been well articulated by Johnson and Kaplan (1987) and Eccles (1991). Johnson and Kaplan (1987:6) state "... a call for more extensive use of non-financial indicators is a call for a retum to the operations-based measures that were the origin of management accounting systems." Eccles (1991:131-132) states, there has been" "... a shiff frow treating financial figures as whe foundarion for perfomance measurement to treating them as one among a broader set of measures". Such measures can be used to evaluate the long term performance of companies. Financial measures are based on historical data, dependent on current market conditions and selling price, and primarily short term oriented. The selling price of product and margin are the measures of competitiveness for companies using only financial measures; these measures often become total company drivers, dictating confidence and direction.

Furthermore, today's organizations are increasingly involved in service operations such as customer support activities. One may wonder whether performance measures of a quantitative, and especially of a financial, nature can also be applied to service operations (see Edvardsson et al. 1994). Service performance dimensions include aspects such as the creation of service quality, and added value because these dimensions are primarily of a nonfinancial nature. A performance measurement system can, therefore, consist of measures associated directly with these concepts (Heskett et al. 1994: Rust et al. 1995; Kasper et al. 1998); examples of these measures are total value added or value added per employee and per customer. When companies put employees and customer first, a shift occurs in the way they manage and measure business performance (Heskett et al. 1994). Heskett et al. introduced the concept of "Service-Profit Chain". This concept establishes relationships between financial and nonfinancial performance dimensions: profitability, customer loyalty, employee satistaction, loyalty and productivity.

Overall, we think that a performance measurement system should include two types of measures, those that relate to results such as financial performance and competitiveness, and those that focus on the determinants of the results such as quality, added value, resource utilization and innovation. Kaplan and Nortons's 'balanced scorecard' is a framework for performance measurement that integrates concepts of results and determinants. This performance measurement framework is based on the principle that a performance measurement system can provide managers with answers to four basic questions:

- How do we look to our shareholders?, i.e the financial perspective

- What must we excel at ?, i.e. internal business perspective 
- How do our customeresee us? i.e. customer perspective

- How can we continue lo improwe and create value? i.e. Hnowation and leaming perspective

In line with Heskett et al (1994), Kasper et al. (1998) add explicitly as a fifth perspective, the employee's perspective, for service operations. This perspective includes factors such as satisfaction, employee turnover, etc. The importance of this perspective in service performance can be explained by the fact that services are primarily provided by people and thus performance is very dependent on people (see Schneider 1980; Bateson 1989; Grönroos 1990).

\section{Critical remarks concerning nonfinancial measures}

The popularity of nonfinancial measures in performance management literature is on the increase. Rightly $\mathrm{so}_{\text {, }}$ nonfinancial measures take firms in the right measurement direction, namely towards the customer (Hope and Hope 1996); yet these nonfinancial measures cause some problems. Fisher (1992:46) found that it was difficult to tie together nonfinancial measures and profits. He notes that "... the inability to quantify changes in terms of their effects on profits detracts from the impact on nonfinancial systems. Indeed, much of the uncertainty that exists about nonfinancial measures would dissipate if such a linkage was possible". As well as this, Fisher also found that the use of nonfinancial measures may delay performance assessment. Hope and Hope (1996:111) note that "Financial and nonfinancial measures make uncomfortable bedfellows." Nonfinancial performance measures can report conflicting short term results ${ }^{6}$ or encourage dysfunctional behavior?

Another remark can be made concerning the drive for continuous improvement. Eccles and Pyburn (1992:111) note that "Is there a point where improvements in quality no longer lead to increased customer satisfaction? And is there a point where improvements in customer satisfaction no longer lead to increased profilability? Do trade-offs have to be made?". This statement raises the question whether the objectives of total quality and 100 per cent customer satisfaction are always compatible with maximizing long term profitability (Hope and Hope 1.996).

In sum, financial and nonfinancial measures are useful indicators to measure how well a company is doing; yet one should be aware that it is sometimes difficult to quantify nonfinancial performance and the preparation of nonfinancial performance report may be time consuming Furthermore, the question raises whether nonfinancial objectives are always compatible with maximizing short and long term profitability.

\subsubsection{Evaluation and rewarding}

When the dimensions of organizational performance and the related performance targets are determined, mechanisms linking target achievement with financial and nonfinancial rewards can be established. The effectiveness of these control mechanisms has a great impact on motivating personnel. Personnel are more motivated, when rewards are contingent upon performance (Flamholtz et al. 1985).

Linking rewards with marketing performance, however, is not so easy. Due to the interdependency of business functions, the extent to which performance targets are achieved may be influenced by the performance of other subunits. This interdependency makes it often very difficult to attribute the outcome to individuals or departments and evaluate the achieved results properly. The poor performance of one manager may have a negative impact on the performance of another manager, as a result it is often very difficult to link rewards with performance.

\subsection{CONSEQUENCES OF SYSTEM DESIGNS}

\subsubsection{Introductory remarks}

A formal control system can be used to encourage functional behavior by using an appropriate mix of controls. The effects of controls-in-use on individuals are, however, not restricted to managerial 
performance and behavioral responses. Various researchers (see Hofstede 1967; Hopwood 1972; Otey 1978; Brownell 1985) have found that controls-in-use may also have psychological and role related consequences (Jaworski 1988). These consequences may encourage individuals to behave in ways that are to the advantage of the organization; but this is not always the case.

Controls-in-use may also discourage functional behavior. The nature of these consequences influences the effectiveness of a control system. The designers of a control system can not only evaluate the impact of the employed control on the marketing performance of a business unit; they can also evaluate the individual effects of the controls-in-use. The following effects of controls-inuse will be discussed:

- behavioral consequences

- psychological consequences

- role related consequences

\subsubsection{Behavioral consequences}

\section{Introductory remarks}

Control mechanisms can encourage both functional and dysfunctional effects; when used to provide feedback about goal attainment, employees can evaluate their performance and alter their behavior to be more successful in the future. Dysfunctional effects may also occur. Three basic types of dysfunctional effects of control are discussed (see Bimberg et al. 1983; Otley 1987; Jaworski 1988; Merchant 1990\&1997):

- gaming performance indicators

- data manipulation

- encouragement of short term orientation

\section{Gaming performance indicators}

Gaming performance indicators implies that employees will choose actions by which they can achieve the most favorable personal outcome (Jaworski 1986). Thus, self interest determines their actions, and not organizational objectives. For instance, subordinates may choose a more attainable marketing budget under which their performance will be evaluated. By this, these subordinates hope that the budget will be more easily achieved. Such employees will attempt to maximize their performance on this budget, even though they know that this standard is not consistent with what their supervisor and the furm desire. Besides this, they can also build slack into budgets, if the superiors accept these slacks. These budgetary slacks can protect them from environmental uncertainties (Cyert and March 1965; Jaworski 1986).

There is also another situation in which gaming performance indicators may occur, namely where the superior uses a surrogate measure of performance (Birnberg et al. 1983). Reasons for doing this can be measurability, cost, analyzability, etc. In using a surrogate measure, the supervisor assumes a risk while attempting to maximize this measure, the subordinate may reject courses of: action more desirable to their superior. The most common form of gaming occurs when the subordinates select actions that are best for them in their performance reports to their superiors. These performance reports will be credible to the superiors; unless the superiors redesign the measurement system to collect other data to check on the credibility of their subordinates. "This is called the 'moral hazard' issue in the agency literature (Birnberg et al. 1983). Empirical evidence regarding gaming can be found in the work of Granick (1954), Berliner (1957), and ljiri (1975).

\section{Data manipulation}

'Gaming performance indicators' accurs before relevant performance data have been collected. This does, however, not imply that employees exhibit dysfunctional behavior before their performance is measured. Employees may also attempt to manipulate performance measures for their own purposes (Jaworski 1986; Merchant 1990; Jaworski 1988). Smoothing, falsifying and 
focusing/filtering are three basic forms of data manipulation. These forms of data manipulation result from the attempts of subordinates to affect results, especially if these results are used to evaluate their performance. Thus, there is an information asymmetry between superiors and subordinates. The information asymmetry may cause various forms of dysfunctional behavior, some of these are mentioned below.

- Smoothing occurs when an employee attempts to "even out" performance data such as sales figures, costs (Jaworski 1988). Thus, performance data is altered so that a more consistent and more faworable performance pattern appears (Jaworkk 1988; Merchant 1990). This can be accomplished by changing operating decisions e.g. accelerating a shipment or delaying a purchase, by changing measurement rules e.g. changing accounting policies, by setting low goals or by worrying about performance measures instead of real performance (Merchant 1990). Perhaps the most common form of smoothing is the shifting from one period to another of a revenue or expense item (Birnberg et al. 1983). Such smoothing behavior usually results from the need to hold costs down or to increase revenue so as to attain a periodic performance level. In some cases, such shifts can be in the opposite direction to prevent reported results appearing to be too good in the present period ar to ease the work load next period (Bimberg et al. 1983). This 'smoothing' behavior permits managers to utilize the performance measurement system to their benefit and creates a perception of reality that differs from the one they experienced. The underlying rationale for this behavior is the nature of format and informal incentive schemes. The supervisor's ability to change the smoothing behavior of their subordinates is often limited by an absence of observability of the process, lack of analyzability and heterogeneity (Bimberg et al. 1983).

- Subordinates may deliberately report inaccurate or erroneous data (see Hofstede 1967: Lawler 1976; Bimberg et al. 1983; Jaworski 1988; Merchant 1985b and Merchant 1990). This has been called "falsifying" or in some cases 'illegal acfs' when it is an act that violates a private law such as organizational rules or a public law. In some situations, e.g. When specific data are not available or too cosily to obtain, employees may deliberately report invalid data to their superiors (Merchant 1990). Other examples can be found in the work of Roy (1955). Hopwood (1972) and Flamholtz (1979). For instance, Roy (1955) observed that workers falsified performance data when quotas seemed unattainable. The workers hoped that the forenan did not raise the expected level of production for everyone and that he did not alter his expectations concerning their behavior. Additionally, they put pressure upon deviant members who produced too much to return to group levels. Hopwood (1972) and Flamholtz (1979) have reported similar findings. Flamholtz described one example of falsifying the sales figures by manipulating accounting transactions; he found that the management of a toy company hoped to attract investors on the stock market by increasing net income in the external reporting.

- Subordinates may manipulate performance data by enhancing or degrading selected data (Jaworski 1988). This is called "focusing" or "filtering". For instance, a product manager may make sales performance reports more favorable by witholding information that reflects poor performance, or by overstating the competition faced in a specific market segment. Three other strategies that people use to filter information are delaying reports until the report is too late to be of use (see Wilensky 1967), over-collection (see Feldman and March 1981), and aggregation (Bimberg ef a1. 1983).

\section{Short term orientation}

Controls-in-use may also encourage "short term orientation' on the part of managers and discourage new ideas for e.g. projects with long term and/or less certain payoffs (Banks and Wheelwright 1979; Hayes and Abernathy 1980; Hayes and Garvin 1982; Kaplan 1984; Merchant 1990). Kaplan (1984) notes that short run orientation induced by the incentive created for division managers to reduce expenditures on discretionary and intangible investments is perhaps the most damaging dysfunctional behavior. When profit targets become hard to attain, because sales are not increasing as fast as expected or variable and operating costs are rising faster than one could expect, division managers can try to minimize the negative impact on short term earnings by reducing expenditure on e.g. hurnan resources, customer relations or quality improvement. These expenditure reductions help to improve the reported profitability of the division in the short run but they may have a negative impact in the long term competitive position of the company. It may also encourage managers to minimize the variances from standard rather than to seek for continuous improvement. 


\subsubsection{Psychological responses}

A third type of individual consequences refers to psychological responses. Research on control has suggested that controls-in-use not only have behavioral but also psychological consequences (see Hopwood 1972, Otley 1978, Hirst 1981). For instance, the control mechanisms employed maly cause a high level of stress. Job tension or anxiety refers to the extent to which these controls cause stress (Argyris 1953; Jaworski and Y'oung 1992). Controls may also have a positive or negative impact on the work attitudes of employees such as satisfaction, organizational commitment and work alienation (Flamholtz et al. 1985; Jaworski 1988). Empiricall evidence of the links between controlsin-use and work attitudes can, for instance, be found in the work ${ }^{10}$ of Eisenberger et al. (1986) and Oliver and Anderson (1994).

\subsubsection{Role related consequences}

Controls-in-use may also cause role stress. Role stress consists of 'role ambiguity' and 'role conflict" (Michaels et al. 1988). Role conflict refers to the extent to which role expectations are incompatible (Kahn et al. 1964; Michael et al. 1988). It can include many forms of incompatibility such as intersender, intrasender, person-role and role overload.

Role ambiguity indicates the degree to which (clear) information is lacking about expectations related to a certain role, methods and techniques for fulfilling role expectations; and consequences of role performance (Kahn et al. 1964; Michaels et al. 1988). Jaworski (1988) states that the relationships between role perceptions and controls-in-use are mixed. Swieringa and Moncure (1972) notes that the reliance on a budgeting style is characterized by passive and lacking financial controls-in-use and role ambiguity. Otley (1978) has postulated that reliance on strict financial controls and role ambiguity are unrelated. Jaworski et al. (1993) have found some empirical evidence concerning role related consequences of controls-in-use. Their research findings demonstrate a significant relationship between controls-in-use and person role conflict, and between controls-in-use and role ambiguity.

\subsection{MANAGEMENT CONTROL AND THE SALES FUNCTION}

\subsubsection{Introductory remarks}

Sales control is a developing area of research interest in the management control literature. The topic of actual sales control practices has been covered with anecdotall case studies, and in the academic literature several normative and empirical contingency studies have been published (see Banker et al. 1996). A review of these studies will be given in this section. Furthermore, the orientation of recent research addressing sales control practices will be highlighted. We classified the studies into the following groups to elaborate on the outcomes of the empirical studies:

- sales control systems and differentiation strategies

- sales control systems and interdependence

- sales control systems and information needs

\subsubsection{Sales control systems and differentiation strategies}

\subsubsection{Control systems and business strategy}

Since the early 1980 s, there has been a growing interest in the relationship between control systems and strategy (see Salter 1973; Lorange 1982; Hrebiniak and Joyce 1984; Govindarajan and Gupla 1985; Dent 1990; Simons 1990; Samson et al. 1991). Research outcomes suggest that control systems should be tailored explicitly to support the firm's strategy because this leads to competitive advantage and superior performance. Much of the empirical research involves a search for systematic relationships between specific elements of the control system and the strategy of the firm $^{11}$ or strategic change ${ }^{12}$. 
A developing area of research interest is the relationship between control systems and business strategy. Existing research focuses primarily on management control systems and specific manufacturing strategies ${ }^{13}$. This topic has been covered in the control literature with single case studies $^{14}$ and several normative studies ${ }^{15}$. There has, however, been little empirical research that studied controls-in-use and specific differentiation strategies explicitly, except for Banker et al (1993) and Banker et al. (1996).

Since the 1990s, differentiation strategies have often been used as a strategy for gaining competitive advantage. Marketing theorists, such as Kohli and Jaworski (1990), have concluded that intense competition has been identified as a principal reason for organizations choosing business strategies based on discovering customers' needs and wants, and creating customer value to satisfy them. Slater and Narver (1994) have studied the impact of the competitive environment on the market orientation/performance relationship. Their study reveals that competitor concentration as a principal moderator of the impact of customer oriented strategies on organizational performance.

Differentiation strategies are often related to relative perceived quality. Nowadays perceived quality is becoming one of the critical Success Factors (CSF) for many companies. The differentiation strategies to influence the rellative perceived quality are based primarily on customer satisfaction and customer focus, Total Quality Management (TQM) and service quality, and put emphasis on service or service quality as a key differentiator in manufacturing firms. Buzzell and Gale (1987) indicated that relative perceived quality drives market share. They observed that the purchasing behavior of the customer is influenced by the value or the relationship between price and quality. Relative perceived quality refers to the customer's perspective relative to alternative competitive offerings in the market; the perception results in a greater satisfaction of the customer's requirements from the product or service than would be received from those of the competitors. It was found that when relative perceived quality and relative market share are both high, profitability is virtually assured.

In sum, the profitability of a firm can be influenced by perceived quality and relative market share. Perceived quality can be influenced by specific differentiation strategies based on customer focus and satisfaction, etc. It may be assumed that a control system include performance measures related to these performance areas; such performance measures should help the firm to obtain high levels of relative perceived quality in combination with high relative market share. There are some research findings concerning control systems and differentiation strategies.

\subsubsection{Control systems and differentiation strategy: some empirical findings}

Overall, there is limited empirical research about the forms of control systems that suit particular types of differentiation strategies. Yet various control theorists, such as Banker et al. (1996), are developing this relatively new area of research interest. Some of these research findings are useful to discuss in our sales context. We have classified the findings in terms of today's major differentiation strategies to analyze the research findings in a sales context. There are some empirical findings concerning the impact of differentiation strategies on control systems; the key findings are summarized below.

\section{Customer satisfaction and customer focus}

Today"s companies are acknowledging that the historic sources of superiority, such as technology/innovation and economies of scale, will not bring success unless customer needs and wants are taken into account in designing and delivering goods and services (Zeithaml and Bitner 1996). A major reason for this strategic change is the intensifying competition that is motivating many companies to shift their internal focus to an external focus on the customer. This shift has resulted in a more customer focussed business strategy and sales. A customer focussed strategy implies that not only the customers' needs and wants need to be well defined; a firm can also create superior value for customers continuously into the future. A customer focus in sales can be attained 
by making salespersons responsible for maintaining customer relationships by providing the right skills and excellent offerings, and for improving customer fulfilment (Cortada 1993) and 'skipping' the domination of short term and financial output controls; yet individual needs and wants may differ widely across customers. Thus, more customer focussed sales implies that the new sales tasks become more difficult to prescribe and less programmable than the tasks required for a more traditional sales function.

Control system theorists, such as Ouchi (1977) and Eisenhardt (1985), conclude that output controls are more suitable when task programmability decreases and outcomes can still be clearly specified. If there are neither programmable tasks nor measurable outcomes, then socialization or clan control might be appropriate. Organizational control theorists suggest, therefore, that output controls or socialization / clan control when outcomes are not measurable fit a customer focussed strategy.

Some empirical evidence concerning specific relationships between elements of the control system and the customer focussed sales strategy can be found in the control system literature. Banker et al. (1996) studied how contingency factors, such as competitive intensity and customer profile, and behavior-based control influenced the effectiveness of an outcome based incentive compensation supporting a customer focussed service strategy. They found that outcome based incentives related to a high intensity of competition and customer focussed service strategy stimulated the growth of the company's profitability.

\section{From Total Quality Management (TQM) to Customer Value Management (CVM)}

Up to the seventies the sources of wealth generation were primarily technological innovations, inexpensive and reliable transportation and communication. They enabled the design of better quality products, manufacturing them in countries with the lowest production costs, and distributing of the goods around the world. Companies began focussing on quality improvement for increasingly global markets that are not protected effectively by national economic policies (Cortada 1993). Total Quality Management (TQM) has been the term widely used to capture this movement since the early eighties.

Although there is not a universally accepted definition of TQM, it is often seen as a management philosophy based on continuously improving quality in an organization (Cortada 1993; Zeithaml and Bitner 1996). This management philosophy may be defined as any positive effort to realign the organization with the purpose of achieving a goal congruence and customer focus both internally and externally (Zairi 1994). The implementation of TQM can result in loyal customers who come back for more goods and services (Cortada 1993). TQM cuts across all business functions and levels of an organization and it includes a diverse group of techniques and strategies. Examples are employee participation, empowerment, statistical process control, ancl process management.

The underlying principles of TQM are not only applicable in production and logistics but also in sales. Like most other business functions, the sales function has evolved into a quite different business function from what it was a few decades ago. Whereas the major task of the sales function in the past was to sell products, in many organizations the basic task of today's sales function is to identify and to satisfy the customers' needs (Cortada 1993). This change has important consequences for managing this business function. Cortada (1993:43) states that the challenges facing today's sales management are "... to define how customer-contact employeess should behave, what services customers should be provided besides simply a product, and to what extent offerings are 'pushed' on customers as opposed to executing a 'pull strategy."

To be successful, an organization requires a sales force staffed with personnel who can achieve their performance potential. Furthermore, salespersons must maximize revenues in a cost effective manner on a consistent basis, and provide customers with follow up sales and support that is professional and relies on a relationship of integrity and honesty. In other words, the sales force 
becomes increasingly responsible for customer fulfilment and the development of custome relationships. This is exactly the point where the paths of sales management and TQM cross. Th use of TQM in sales has a definite impact on sales performance measurement.

Performance management systems seem to be crucial to improvement efforts as part of TQM because these systems offer the only way for organizations to assess whether improvement i needed, if the desired results are achieved, and if further improvement is needed. The success o TOM depends primarily on measurement. Performance measurement focuses employees t concentrate on continuous improvement (Zairi 1994). Organizations successful in applying TQM therefore, develop a comprehensive performance management program that starts by identifyin customers and stakeholders and their product and service needs.

Some empirical evidence concerning TQM and performance measurement can be found i the TQM literature. TQM theorists, such as Oakland (1993) and Sinclair and Zairi (1995), conclud that inappropriate performance measurement can block the implementation of TQM sinc measurement provides the link between strategies and actions. Sinclair and Zairi (1995) studied th use of performance indicators in companies assumed to be leaders in both performanc measurement and TQM. They found that managers appear to understand the importance $c$ improvements in areas such as customer satisfaction, integration with customers, quality of input: process and output; yet there may be a gap between perceived importance and the reality $c$ performance measurement.

Overall, Sinclair and Zairi (1995) found that 'soft' measures, e.g. service quality, produr quality, on-time delivery, teamwork and process quality, were perceived as important performanc measures. Nevertheless, "hard" measures such as meeting production schedules (manufacturin variable), cost reduction, sales volume, department budget control and production schedule accurac (manufacturing variable) were the key performance measures (see Sinclair and Zairi 1995). In sun managers recognize the importance of quality an other soft performance measures but the tradition: measures are still key indicators. Furthermore, Sinclair and Zairi also found that performanc measurement was perceived as critical for quality improvement; it provides management wit information about opportunities for improving performance. An appropriate performanc measurement system in a TQM context plays the following roles in quality improvement (Oaklan 1993); it is used to:

- ensure that customer requirements have been met

- provide standards for establishing comparisons

- provide visibility and a scoreboard for people to monitor their own performance levels

- highlight quality problems and determines which areas require priority attention

- give an indication of the costs of poor quality

- justify the use of resources

- provide feedback of driving the improvement effort

Salespersons are rewarded according to 'measurable' performance such as sales volumes c contribution margin in traditional sales organizations. Often, these measurement systems crea incentives for individual results. The incentives may also stimulate sales despite what the customs wants - the "push" strategy. According to Cortada (1993), the basic theory behind the tradition: forms of performance measurement is that salespersons perform best when they are rewarded $f$ individual achievements (sales) by quotas.

The traditional methods of measurement create two basic problems. First, it becomes difficu for the company to gain the full cooperation of its salespersons in identifying sales opportunitie Salespersons may fear that once additional sales opportunities are identified, their quotas will $g$ up. Second, transaction based incentive plans do not sufficiently stimulate salespersons to condu relationshipabuilding activities.

The TQM approach in sales requires more service oriented activities of salespersons. Sale productivity goes far beyond quota realization; it is a balance of reducing costs, maximizing ca 
success and maximizing order value and customer satisfaction. This implies that measurement systems are not limited to individual measures, such as sales volumes or quota, but can also include shared measures, such as costs, resource allocation, market shate, and overall customer satisfaction (Cortada 1993). Furthermore, the set of measures has to be extended with measures related to quality improvement such as customer satisfaction and product and service quality. Applying TQM in sales implies that the traditional sales measurement system must include also "soft" measures such as service and product quality, on-time delivery, and teamwork; the traditional measurement system has, therefore, to be extended with measures for improvement and team performance.

Besides TQM, leading-edge companies are becoming extremely sophisticated at measuring what customers value, and correlating these data with their behavior and their projected future intentions. To grow, a company need new customers. How? By offering better value in the marketplace than the competition - better value in the eyes of custoners. Recent empirical research shows that a business's customer value position, relative to competitors, has a dramatic impact on its market-share gain and profitability (e.g. Gale 1994; Roberts 1997). Businesses that achieve a superior customer value position average protit margins on sales three times greater than businesses that are pushed into an inferior customer value position (see Roberts 1997). These research findings show that organizations need to maximize the profitability of each customer segment, to minimize customer turnover, increase customer retention, increase sales and especially sales of existing products and services to existing customers. To do so requires detailed knowledge of each customer to reveal which customers represent the greatest source of profit, so allowing the enterprise to develop a strategic approach to each customer - a long-term view of that customer's profitability. This is what lies at the heart of Customer Value Management ${ }^{16}$.

Cusomer Value Management is strategic in its view of the customer base. An organization which is able to identify customer behaviour can then predict and ultimately shape that behaviour, for instance by pricing distribution channels differently. It can undertake customer profitability profiling; it can produce more accurate forecasting and targeting of sales. Customer Value Management turns each interaction with the customer into an opportunity to learn more and sell more to that customer. Capturing every episode of customer contact enables the enterprise to build a pattern of customer behaviour and usage. Techniques like customer value analysis, economic value analysis, customer satisfaction surveys, business process concept innovation and process design criteria identification are the performance management tools used in customer value management (see Gale 1994).

In sum, we can conclude that the major developments in TQM and CVM have a greal impact: on the use of performance measures. Although financial and sales measures remain important in sales control, nonfinancial measures related to customer satisfaction and value should be part of the control system because these indicators cover the long tem performance of any company.

\section{Emphasis on service as a key differentiator in manufacturing firms}

Besides the services industry, many manufacturing based industries are recognizing the need to provide quality service to compete successfully. A major reason for this strategic change is that product quality alone no longer differentiates one manufacturer from the other, and, customers are becoming more demanding. Today's customers not only expect excellent products, they also expect high service levels along with these products. Offering low prices as a differentiating strategy is disappearing because companies and their competitors are aware that often they accomplish little more in price wars than to eliminate their margins (Rust et al 1995; Zeithaml and Bitner 1996).

Manufacturing firms in industries such as computers and copiers are focussing heavily on services. In times of market saturation and decreasing margins, for instance, many computer firms have found that survival, and success, depends on the ability to transform their business into software and system integration. Selling computers now involves new competencies because technology does not sell itself and it is becoming more difficult to differentiate products. Instead 
of selling just computers, today"s computer firms also offer value added services to customers.

Today's measurement systems still focus on financial performance, productivity and efficiency, and not on customer satisfaction and value (see Zairi 1994; Kaplan and Norton 1996). As companies pursue customer value strategies, such as offering added value services, to differentiate themselves in their marketplaces, their measurement systems have to change accordingly wo reflect these priorities. Non-financial measures related to service quality and customer satisfaction to anticipate organizational performance are pivotal in today's competitive marketplaces. This awareness has also resulted in the creation of many of such variables as part of various quality awards.

One of the most important awards in the US is the Malcolm Baldridge National Quality Award, a quality award initiated by the US government. Participation in such awards has an impact on the performance measurement system of companies. Blackburn and Roosen (1993), for instance: studied the performance measurement and reward systems of Malcolm Baldrigde National Quality Award Winners. Participants in this quality award system have to develop a performance measurement system focussing on many issues, especially the customer. This award provides companies with one of the most pervasive frameworks for incorporating quality and the customer into the management process. It was designed to promote awareness of the importance of quality to competitiveness, understanding of the basic requirements for excellence in quality, and sharing of information on successful quality strategies. Winners are chosen on the basis of a set of core values and concepts. This set includes customer driven quality, leadership, continuous improvement, employee participation and development, fast response, design quality and prevention, a long range outlook, management by fact, partnership development, and corporate responsibility and citizenship. Regarding performance measurement, the guidelines of this quality award indicate that "... indicators should be selected to best represent the atributes that link to customer requirements, customer satisfaction, and competitive performance as well as to operational effectiveness and efficiency. A system of indicators thus represents a clear and objective basis for aligning all activities of the company toward well-defined goals and for tracking progress toward the goal."

Blackburn and Roosen (1993) found that these organizations competing for the award tend to emphasize performance dimensions such as customer satisfaction, service quality, commitment to continuous improvement initiatives and contributions to team performance. Blackbum and Roosen's findings of the impact of quality awards on performance measurement and rewarding systems can be generalized as follows. Nowadays many subsidiaries of U.S. companies participate in the Malcolm Baldrige National Quality Award Winners (see IBM Subsidiary in U.K.). This participation often stimulates companies to develop a sales performance measurement system focussing on the customer. A sales performance measurement system that suits a service oriented approach therefore requires performance measures related to customer requirements, customer satisfaction, and competitive performance as well as to sales effectiveness and efficiency.

\subsubsection{Sales control systems and strategic change: some empirical findings}

Since strategy and control processes and mechanisms are closely related, a strategic change will affect control by definition. Various control system theorists (see Roberts 1990; Archer and Otley 1991; Dent 1991; Knight and Willmott 1993) have searched for systematic relationships between controls-in-use and strategy formation. For instance, Roberts (1990) studied strategic change in a large decentralized organization. His study revealed how accounting controls can encourage conformity and distorted communications that conflict with the requirements for successful strategy formation and implementation. Management meetings, however, play an important integrative function as they can help to resolve conflicts between accounting controls and strategy (see Archer and Otley 1991). The shift to an external focus on the customer will effect the controls-in-use. A customer focus means that marketeers and salespersons serve a critical function in: 
- collecting and interpreting information and resources to and fron the organization and its external customers

- determining the customer"s needs and wathts

- processing purchases

- serving as the customer's liaison with the organization

Consequently, firms that encourage a customer focus on the frontline must design a sales force organization that incorporates the opportunity for flexibility and creates an appropriate environment for a customer focus. Too often, operations measures of performance encourage high efficiency that encourages salespersons to treat all customers in the same manner (see Schneider 1980). For instance, a heavy reliance on cost control mechanisms can have dysfunctional implications. An example of a such an implication includes conflicts with the requirements for successful formulation and implementation of a customer focussed strategy. Salespersons in companies with a "production orientation' were monitored and rewarded on how much time they spend with each customer and not for exploring and meeting the unique needs of customers.

Roberts found that management conferences as an integrative function can give managers means for strategy formation as they encouraged interdependence and reciprocity among the profit center managers. Furthermore, these meetings enable a sharing of market knowledge and helped. to create a set of shared meanings around which activities can be mobilized. This study indicates that dysfunctional implications for strategy formation can be balanced by non-accounting controls. Knight and Wilmott (1993) describe how new accounting control systems were used to effect strategic change in an insurance company. They found a case contrasting with the one of Roberts (1990). Their study emphasized how a control system can play a role in adapting managerial attitudes and behavior to be more consistent with a new strategy and a new competitive environment. Knight and Wilmot (1993) studied a company in which cost controls were the major control mechanisms employed to transform the paternalistic company into an aggressive competitive company. Dent (1991) presented a similar situation. Knight and Wilmot's (1993) findings highlight the power of accounting controls. Yet the dysfunctional effects of cost control were not apparent. Langfield-Smith (1997) suggests that the cost controls that are encouraged are consistent with the thrust of the new strategy.

Regarding to our study, we think that accounting controls can create a climate that can act against successful formation and implementation of a customer focussed sales strategy; however, the dysfunctional effects of such controls will not be apparent when the encouraged control orientation is consistent with the thrust of the new strategy. From the preceding findings we can conclude that if the reliance on accounting controls is not consistent with the thrust of the customer focussed strategy, dysfunctional implications for strategy formation and implementation can be balanced by non-accounting controls, e.g. controls based on customer focus and satisfaction.

\subsubsection{Sales control systems and interfaces}

Various researchers have studied the impact of the functional structure of organizations on control designs. Activities related to the sales function affect and are affected by other business functions. Our literature review highlights that the sales function encompasses various operational interfaces ${ }^{17}$ within the internal business environment.

The existence of these sales interfaces mean that sales managers often contribute to the degree of excellence in coordinating sales and the other functional subsystems of the organization. Some of these functional subsystems are, however, not directly under the control of the sales manager. Coordination can be achieved by improving communications and inter-organizational understanding about the organizational goals. Sales performance indicators may therefore also be related to sales and organizational goals. In this perspective, assessing sales performance is not restricted to the sales department but it is also affected by other organizational units. Furthermore, it is difficult to reduce sales objectives to a single, integrated measure of sales performance reflecting all these 
influences satisfactorily. Sales tasks are often interdependent and intertelated with other non-sales tasks because of the interfaces with other business functions.

For some control theorists (see Hayes (1977), Chenhall and Morris (1986) and Mia and Chenhall (1994)), one performance measure is bound to be inadequate. Hayes (1977) examined the use of financial data in performance management of production, research and development, and marketing subunits. His major conclusion was that budgets, i.e., financial information, are often poor indicators of effectiveness because they are mostly poor surrogates for the entire set of factors that influence departmental performance. This was especially the case for marketing departments. Similarly, Chenhall and Morris (1986) reported that managers of subunits with interdependent activities perceived broad scope information, aggregated information, and integrated information about business operatives as useful. A similar conclusion was reached by Mia and Chenhall (1994), who studied the role of broad scope information made avallable by management accounting systems. They concluded that the use of financial and nonfinancial measures was affected by the type of function performed, marketing versus production. Based on these research outcomes, it appears that the existence of a sales interface calls for a great use of accounting and non-accounting measures and integrating them.

The presence of task interdependencies has an impact on the extent to which formal controls are employed. Macintosh and Daft (1987) suggests that formal controls are less suitable when there is a high degree of interdependence between businesses. They observed that task interdependencies explain the emphasis on three elements in a package of management controls. In environments in which dependence was low, standard operating procedures were an important control mechanism. Furthermore, budget and statistical reports were used more extensively when interdependence was moderate. When interdependence was high, the role of all three control devices diminished. Relying on the findings of Macintosh and Daft (1987), we think that the heavy reliance on traditional controls, such as standard operating procedures, budget and statistical reports, suit a low degree of interdependence between sales and other units. Today's sales units are often characterized by a high interdependence with other business units. "Their task environment is enlarged with many nonselling activities. These units can collect useful customer and product information that can be used to improve marketing and product policies. This information helps a firm to improve its flexibility towards market developments. The contribution of sales units to the firm"s success is therefore enlarge to support other units in their business activities. The sales measurement system should therefore include also nonfinancial controls such as those based on quality programs.

\subsubsection{Sales control systems and information needs}

\section{Perceived Environmental Uncertainty and information needs}

One of the purposes of any performance measurement system is to collect information for management decision making; the value of information is, however, not only determined on the basis of the information content alone (McKinnon and Bruns 1992). Systematic ways of sharing information and knowledge through formal and informal communication are developed by managers and organizations. The nature of the information needs can be explained by Perceived Environmental Uncertainty (PEU) and task characteristics. Various control theorists, such as Gordon and Miller (1976) and McKinnon and Bruns (1992), have studied the impact of information needs on control systems. It is useful to discuss some of these research findings in a sales context. They can be useful to explain the nature of specific sales control designs.

\section{Perceived environmental uncertainty and sales control systems}

Many control theorists ${ }^{18}$ have studied how a performance measurement system interacts with its external environment. Khandwalla (1972) was one of the first researchers to study the effect of the external enviromment on measurement practices. He concluded that the sophistication of a 
performance measurement system, in particular an Accounting Information System (AIS), was affected by the intensity of the competition faced by the company. In situations with an intensive competition in product markets and complex economic conditions, managers tend to seek for information not only in the problem solving area but also information with respect to integrating and coordinating activities and assessing performance; this phenomenon was not observed for markets characterized by a high marketing and price competition.

Govindarajan (1984) and Gordon and Narayanan (1984) noted that if decision makers perceive a high degree of environmental uncertainty then they tend to seek external, nonfinancial, and ex ante information besides internal, financial and ex post information. Similarly, Gul and Chia (1994) reported that in situations with low perceived environmental uncertainty management can easily analyse and interpret the environment because set rules are available and a traditional management accounting system is adequate. The management accounting system can, therefore, be highly sophisticated in terms of broad scope and aggregation in order to reduce uncertainty (Amey 1979; Gul and Chia 1994). If the perceived environmental uncertainty is high, the management accounting system tends to be highly sophisticated in terms of broad scope and aggregation to reduce uncertainty (see Amey 1979; Gordlon and Miller 1976; Ewusi-Mensah 1981; Gul and Chia 1994). Based on the existing literature, we think that if managers perceive their environment to be relatively uncertain then the firm's performance measurement system must be highly sophisticated in terms of broad scope and aggregation to support their work.

\section{Sales control systems and information needs}

McKinnon and Bruns (1992) studied the information requirements of managers. A field study was undertaken to reveal the information managers truly need, and the sources they actually use to obtain this information. The major conclusions are summarized below.

- McKinnon and Bruns found that managers seek information from every source available to support their work. Informal sources of information, such as face to face meetings, observation, telephone calls, and informal reports, generally dominated other information sources for daily management and remained important for longer-term needs. Unit data, i.e. the performance measures in which daily management took place, were often supplemented with financial data. It was also found that financial data are used for the convenience of aggregation across activities, products or services.

- Much of the financial information is prepared by accounting and information professionals using traditional formats, e.g. balance sheets and budget analyses, and conventions. The importance and use of financial information increases as the management horizon lengthens. Financial measures of income and return on capital are considered as generally overall measures of effectiveness and managerial performance. A majon reason for this is the fact that the long term objectives are generally stated in financial terms. It also appeared that distortions in the financial data are smoothed by time. It was found that the reduced pressure for initiating corrective action requires a more analytical and reflective approach than in day to day management. Accounting information and reports were perceived as very valuable for short and long term decision making: yet it appeared that managers need more information than only accounting information.

With respect to the information needs of sales managers, McKinnon and Bruns (1992) found that this group of managers in the companies under study has special interests and needs about the flow of orders to suppont their work. Sales personnel maintain existing customer relationships and initiate new ones to carry out then day to day activities appropriately. Furthermore, sales personnel takes orders and coordinate the filling of these orders with production and ensure the delivery. Sales personnel are also responsible for answering the technical questions of the customer and providing credit or financial advice and other services to the customer. Much of the communication about these sales activities takes place by telephone or in meetings.

With respect to information gathering, it appeared that information is often received in detail, unanalyzed, and obtained through warious media. Information gathered for sales control focuses primarily on physical counts for monitoring orders, but financial information becomes more important as the management horizon lengthens. With respect to information for the longer view, McKinnon and Bruns found that attention shifts to the success of sales programs in terms of revenue, margin and profit. Revenne and margin analysis were used primarily to study the financial impact of bookings or orders. Daily data were accumulated monthly to 
achicve an indication of sales performance which can be expressed in monetary terms.

In sum, the outcomes of this research can be used to demonstrate that unit and financial data remain important for today's mamagement; this data was used for daily management and long term decision making. With respect to the sales function, unit data was dominant but when management lengthens the planning horizon attention shifts from unit to financial data for evaluation purposes. Mckinnon and Bruns also found that managers need more information than just accounting information; yet accounting information temains dominant.

\subsection{SUMMARY AND CONCLUDING REMARKS}

The purpose of chapter 2 was to discuss the nature of formal control processes and to develop a theoretical framework for our research project. The discussion presented in this chapter made it clear that control in an organization is a managerial process consisting of directing and correcting activities. These activities can close the loop between organizational objectives and actual performance. We defined the control process "... as a process for motivating and inspiring people to perform organizational activities that will further the organization's goal. It is also a process for detecting and correcting unintentional performance errors and intentional irregularities, such as theft or misuse of resources". This process takes place within a specific system, called a "control system".

We developed a theoretical framework for our study in section 2.2. This framework consists of a planning element, an operational subsystem, outcomes, a measuring element, task control, an effector, an evaluating/rewarding element and corrective and evaluative feedback. A key element of any control system is performance measurement. A measurement system is used to collect financial and nonfinancial data concerning organizational and individual performance. These data can be used to evaluate organizational and individual performance. Performance evaluation is a useful tool to determine how well an organization is doing. Based on performance evaluation, organizational performance can be linked with rewards to motivate employees. Three basic questions have to be answered to design an effective measurement system: What are the dimensions of 'good' organizational performance?, How are appropriate performance standards to be set?, What rewards are to be associated with goal attainment?

The importance of performance measurement can be explained by the fact that it can be both an ex ante and an ex post control mechanism. Designing an effective performance measurement system implies that at least the following questions can be answered. What are the dimensions of 'good' performance that the organization is trying to encourage? How are appropriate performance standards to be set, both for the whole organization and for its subunits? What rewards or penalties can be associated with the attainment or non-atiainment of performance targets? It implies that financial and nonfinancial measures should be designed to indicate how well a company is doing. We are aware that the use of nonfinancial measures in performance reviews may be difficult and time consuming; yet this type of measures can be useful with respect to assessing long term performance.

Organizational control is related strongly to the behavior of individuals and groups within an organization. It forms a link between the objectives of the organization and the objectives of the indiwiduals within the organization. Organizational control can, however, produce some intended and unintended side effects. These side effects can be classified into three groups: behavioral, psychological and role related consequences. Behavioral consequences include gaming performance indicators, data manipulation and short term orientation; there are also psychological effects, such as job tension, and role related effects, such as role conflict.

It was also found that sales control is a relatively new area of research in management control literature. The key findings concerning these control practices were classified into three types of research interests: 
- differentiation strategies and control systems

- sales interfaces and control designs

- information needs and control systems

The existing findings on actual formal sales control practices found thus far can be used to demonstrate that sales control systems should cover both financial and nonfinancial performance. Research on the impact of differentiation strategies and sales interfaces indicate that measures related to customer requirements, customer satisfaction and competitive performance have to be used. Traditional output controls have to be extended to these nonfinancial performance areas. The study of McKinnon and Burns can be used to demonstrate that unit and financial data remains important for today's management; operational and long term decision making is based on this data.This study does not indicate how this data is used for formal sales control practices.

As a general conclusion to this chapter we can say that control forms an indispensable process in an organization. Without control, there can be no management. This means that management must pay close attention to control issues it as it is not possible to carry out the control function while 'sitting back and relaxing'. Control means action (Euch 1954). This concludes our discussion of the organizational control concept. In the next chapter we shall discuss the nature of the sales control function. 


\section{Notes}

1. This approach to control is based on the idea that organizational control is degigned ro ensure predhable goal achieved. This ype of commol is also callod "diggnostic control" and has three generic features. (1) the ability to metsure the ouput of a prowess. (2) the existence of predetermined standards againat which actual results can be compared. and (3) the ability to correct devations from preset perfornance standards (Simons 1995). The standards are related to cribeal performance variables. Examples of diagnostic control are goals and objectrves systems, and profit pland and budgets.

Simons (1995) studied llow manizations cope with the tension between creatiwe innowation and predictable god antilewement. Besides diagnostic control, he found three other forms of organizational control: betief 5 , boundary and interactive control systems. The beliefs systems are used to inspire and direct the search for new opportunities, whereas the boundary systems are wsed to set limits on oppontunity seeking behavior. The interdetve control systems are employed to encourage organizational learning and the emergence of mew ideas and strategies. These four rypes of control systems create the opposing forces of effective strategy implementation: (1) beliefs systems and interactive control systems creati positive and inspirational forces, and (2) boundary systems and diagnostic control systents create constrains and ensure compliance with orders.

We shall focta on diagnostic control because this lever of control is the backbone of any orgarizational control system. From the perspective of organizational members, diagnostic control allows mamagers to achieve goals without constant monitoring and oversight (Simons 1995). Individuals are held accountable for results but have the freedon to decide how to attain their targets, i.e. management by exception. The backbone of this control lever is feedback based on goal setting. neasurement and rewards. Feedback systems prowde managers with performance infomation to ensure that their subordinates are working in the vight direction and to allow managers to pay only attention to significant deviations. It implies that maragers invest their atention on (1) setting and wegotating goals. (2) receiving updates and exception reports, and (3) following up on significant deviations. Formal goals provide focus and motivation for the attainment of critical perfomance targets. These govals can be used 10 identify problems, to trigger remedial action in a case of negatwe variances between planned and actual results, and to provide guidelines how to andyze the causes of problems. Furthermore, diagnostic control helps mangers to focus on goal achievement for the business and the individual. At the business level. diagnostic controt is enployed to assist managers in the monitoring and accomplishment of critical performance goals by ensuring a explicil top down linkage of strategies to low level targets and the coondination of resources and action plans. At the individual lewel, diagnostic control is used to provide organizational members the focus, resources and individual tatgets. Diagnostic control is the backbone of orgamizational control. We are aware that organizational control is much broade that diagnostic control. As stated in chapter 1 , our intention is to develop a framework that can be used to study sales control practices and to examine an appropriate control system for organization. Until now relatively litule attention has been directed towards sales control. We therefore decided to explore only a specific part of sales cortrol system, manely the diagnostic part. Future research should explore the other levers of control: interactive, belliefs and boundary control systems in al sales control perspective.

2. Formal control can be affected by using written or otherwise documented control mechanisms (Jaworski 1988 : Wiscon et al. 1992). One authority may inthence the behavion of a lower tevel authority by employing rules, procedures and orders. Jaworki (1988) used the timing of management interwention that can be used to specify the varions forms of formal controls. This researcluer distinguishes thee types of formal controls by applying this criterion: input, process and output controls. Input-oriented controls refer to behavioral control mechranisms by which managers create preconditions in which the desired behavior of employees (or groups) ean take place.

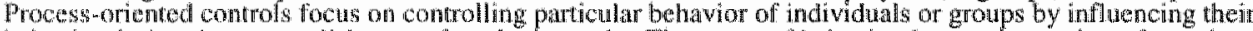
bethavior during the atccomplishment of marketing tasks. The group of behavioral controls consists of a variery of

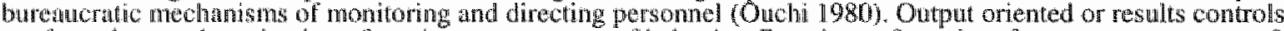
are formal control mechanisns focusing on outomes of behavior. Based on a formal performance assessment of individuals or groups, extrinsic rewards are recived (Flamholtz et al. 1985: Merchant 1985). This performance

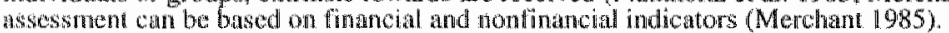

3. Anthony"s view on organizational control is based on two approaches to onganizational control, viz. cybernetics and systen theory. The muin ahateristics of these approaches to control are given below:

- The cybernetic approach is one of the oldest approtehes to organizational control. Cybernetic nodels of control ty 10 capture the processes of planning, comparison, and evaluation in a rigorous foshion (Merchant and Simon 1986). Cybernetic control modtets are dyname models, in the sense that retationships recur in a sequence, with one or more contecting fedthack loops. In particular, a cybermetic control process requires the presence of two dements: negative feedtanck and a comparison process (Maciariello 1984). Negative reedback refers ro the process whereby as system emits a signal that leads to a corrective action to counteract an unfavorable deviation from desined state of affairs (Maciariello 1984). Cybernetic models are intentionally non-specific about the mature of the process being controlled; in this way it is hoped to derne general principles of control that can we: applied in difteren situations. In practice this mest the that the cybernetic spproach assumes that the control process in organizations is essentially the same basic process as is found in physical, biological and social systems" (Koontz al. 1980). "The only change is that humarn regulators, mamely nanagers, are substututed for mechancal tegulators. Cybernetic control models can be helptul in some organizational research, since they have a tight linkage berween controls and objectives and, since they provide sound support for the conclusions produced (Merchut and Simon 1986, Berry ef al, 1995), yet they face various shortcomings. The first problem is cansed by the fact that organizations are open rather than closed systems. It neglects to ancorporate the organizational context becase modeling techniques fall short to deal with the complexity of contemporary

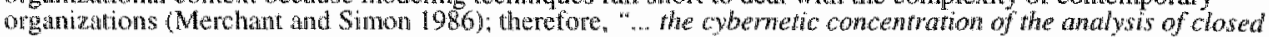


systems does not produce many applicable fundings" (Othey in Lowe and Machin 1983:71). A problem related

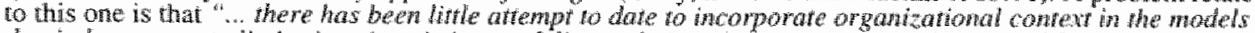

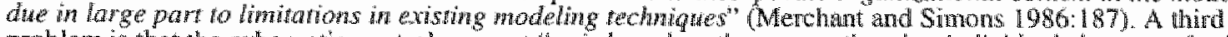

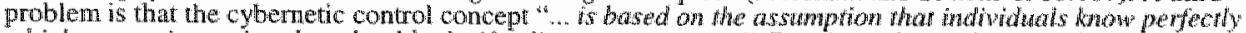
which corrective action they should take of a discrepancy occurs (Borghimet and Vertyeke 19952 ). A lot of work on the cybernetic control concept has been pertomed under the heading of genemil systems theory, which will be described nex

- A second approacl is that of the General Systems Thary. The systems approach stresses the point of view wat sedes to explain behawor by studyme the interelacionship of parts rather than the nature of the parts (Berry ef

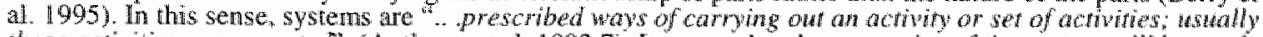
the se activies are repeated (Anthony al. 1992:7). It means that the propenties of the systern will be used to explain a certain behawior. These properties are not possessed by the parts of the system; only by the system as a whole. The problems with systerns theory can, according ro Otey (in Lowe and Machin, 1983: 75). be divided into two callegones. The first criticism is that systems theory is an ideology in the sense that there is "...

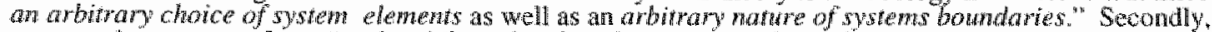

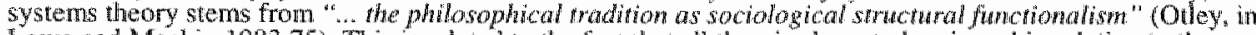
Lowe and Machin 1983.75). This is related to the fact that all theories have to be viewed in relation to the problems that are being handled. The first criticism especially is related fo another approach, which is called contingency theory. This theory takes the influence of the intermal and the extemal anvirominem into account when looking at organizational control.

4. We are aware that our approach fo strategio planning is very narrow. It does not cover the broad spectrum of issues such as premise control or strategic survellaruce. In this thesis, the strategic planding activities are related directly to the operations of the sales force organization. management.

5.See Hopwood 1972; Hirst 1981; Hurst 1983; Daft and Macintosin 1984; Arsari 1989; Kaplan and Atkinson 1989; MoNair et al. 1990; Eccles 1991; Schonberger 1992; Parry et all 1994.

6. One example is the shipping of high margin products at the end of an accounting period at the expense of standand lower-margin products. This transaction results in a gain to the Profit and Loss account but it has at negative effect on on-time delivery schedules and thus on customer satisfaction (Hope and Hope 1996: 1.11).

7. If employees are rewarded for the percentage of on time shipments, they may delay one large shipment to deliwer a number of smaller ones on time given that they had already suffered the imitial penaly (Hope and Hope (996:111)

8. Jaworski (1988) has, however, also stated that sometimes superiors encourage slack building behatior by their subordinates. Thus, he hopes to increase budget commitment and to reduce potentially dysfunctional practices to meet the budger (see e.g. Merchant 1985 b). This type of budgetary slack can not be described as dys functional effect.

9. For instance, Granick (1554) found that workers would focus their teforts in a given perod on the production level to the detriment of other activities such as mantenance and repairs. These workers som an masse of success, but future periods would bear the unreponted costs of weat tund tear. "llhis behavior is also reflected in the phenomenon Berliner (1957) described. Berliner sudied Soviet mangement practices. Ho found hat when production exceded a predetermined level, the next period's quota was increased by the amount ahchicved above the old quota. The spplied bonus systern was tied in to how much above quota a manager coulk produce. At mid-month weryone got anxious to meet or exced the guola. The dysfunctional effects of this behavior were that raw materials were not ondered, repairs were not made in time for the next period and overtime pay was cxcessive leading to overtime costs. "This phenomenon wis labeled as the "ratchel principle". ljiri (1975) also studied gaming and he coined the term "hardness". Hardness, as ljiri (1975: 36) defines it, indicates that an performance indication in

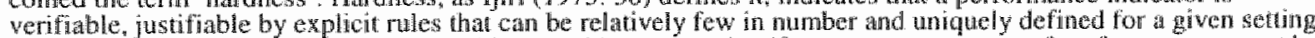
firi moted that even hardness camot avoid the problem of ganing af a surrogate measure of pertonance cannot be fould that moves very closely with the origind measure.

10. Eisenberger ef al. (1986) found that the more a control system was based on behavional controls, the more salespeople are thought to be committed and grateful to the ir employer and that it gave them a mone nurturing climate. Furthermore, behavional controls are as so seen as accepting more of manger" power. This phenomenon is manifested as a greater acceptance of authority, performance reviews, and a mandate wo work in teang. Olivigr atid Anderson (1994) reported similar findings. A behavior-based control system is characterized by thigh levels of superwisor monitoring, directing and intervention in activities, and subjective methods of evaluating parformance typically centered on the salesperson" $\$$ job inpuls, such as personal qualities, activities, and sales strategies (Anderson and Oliver 1987; Oliver and Anderson 1994). These inputs are nor measures of results (oulput but are expected to generate future results. Measuring and evaluating inputs is necessarily more subjective because the manager must decide if and to what degree these inputs generate ontputs. The anpurts are not al ways readily combable or observable, and therefore they are diffucult to measure objectively (Oliver and Anderson 1994 . 
11. See Gowindarajan and Guptu 1985: Simons 1987.

12. See Roberts: 1990; Archer and Otey 1991: Dent 1991; Knight and Willmot 1993.

13. See Nanni et al. 1992; Daniel and Reitsperger 1991; Banker et al. 1993.

14. See Roberts 1990; Archer and Otley 1991; Dent 1991; Knight and Wilmott 1993.

\section{See Nanni at al. 1992: Daniel and Reitsperger 1991}

16. The "father" of customer walue maragement is undisputedly Brad Gale, president of Market Driven Quality, Inc., and author of the book Manding Curtoner Vatue (1994). Cale was manager of the visionary Profit Impact of Market Strategy (PTMS) program in the 1970 s, and later served on the Board of Overseers of the Malcolm Baldrige National Quality A ward.

17. A routine function performed by salespersons is entering orders into atn information system (see Mckinnon and Bruns 1993). In general, all. managers are interested in order data because the pattern of order bookings is frequently the earliest evidence of shifts in market demand that may have long term consequences for a line of business, a department or the organization as a whole. Managers in manufacturing and production departments are especially interested in orders because there is a clear time relationship between orders and production: (1) manufacturing products based on orders from customers; (2) manufacturing products for customers on a continuous basis in a long term contractual relationship; and (3) standardizing the inventory hoping that orders come. For each of these situations there is a set of information needs. Orders represent possible demands on the production system and chatuges in the rate of activity in manufacturing. Marketing managers are also interested in orders. Order data are uscful for situdying trends that might affect future strategic marketing environtments and operations. These data are useful to formulate appropriate marketing actions, e.g. new producrs or decreassing prices. In general, knowledge about the customer base is fundamentally important in the planning processes that organizations employ. Sales and marketing mainagers can provide a foundation for creating expectations throughout the organization by combining knowledge about orders, customer profiles and market communication.

The output of other business functions also has a strong influence on the sales function (see McKinnon and Bruns 1993). One major sales activity is maintaining customer relationships to inithate commercial transacthons. Initiating relationships can be achieved by competitive bidding for projects. Preparing competitive bids often involves cooperation between the sales, marketing, production and accounting departments. Once a customer relationship has been established, customer services issues, such as fulfilling the customer's needs for quality and on time delivery, have to be mataged. It implies that manufacturing and production departments must produce products on a schedule that will satisfy the customer's needs. Ensuring delivery is the responsibility of the company's logistic manager. Financial aspects,e.g. form of payment, have to be handled snoothly and in a manner consistent with contract terms.

18. See Burns and Stalker 1966; Gordon and Miller 1976; Waterhouse and Tiessen 1978: Amey 1979; EwusiMensah 1981 : Onl and Chis 1994. 


\title{
Chapter 3 \\ Controlling the Sales Function
}

\author{
Towards a Theoretical Framework
}

\section{Chapter outline}

Now that we have described the basic concepts of formal control and a theoretical framework for formal control has been developed, we will focus on how organizations might formally control their sales effort. While sales management is generally considered a managetial process of analysis, planning and control, historically control issues have received only cursory attention in the sales literature. As a result, the growth of knowledge in the areas of sales planning and analysis has far exceeded the growth of sales control knowledge. This imbalance in the sales literature can be problematic since any positive effects that might accne because of successful analysis or planning may be offset by a lack of knowledge about sales control processes.

This chapter gives an overview of the existing literature concerning sales management and formally controlling sales force performance to establish a solid foundation of knowledge for our discussion of sales control. Section 3.1 deals with the various definitions of sales control. Based on this discussion, one definition will be selected for this dissertation. Furthermore, our theoretical framework will be described in a sales context. We will review the existing literature on control practices in the sales management literature in section 3.2 to 3.6 ; we will look at the literature on sales control from two disciplines, sales management and organizational control literature. Finally, we will give a summary with concluding remarks. 


\subsection{CONTROLLING THE SALES FUNCTION}

\subsubsection{Introductory remarks}

Chapter 2 of this thesis was used to explore the policies and procedures involved in formally controlling an organizational (sub)system. A theoretical framework was developed based on a comprehensive study of the organization and management control literature. This framework will now be used in a sales context; however, before the different control mechanisms are described in a sales context, we will first discuss the concept 'sales control' (see section 3.1.2).

Based on this discussion, a proper definition of 'sales control' will be selected before our theoretical framework will be adapted to study sales control practices. The various types of salles control mechanisms will be discussed in section 3.1 .3 . These mechanisms are strategic planning, sales management planning, performance measurement, performance evaluation and rewarding, and feedback. In this way, we will, therefore, integrate the relevant sales management literature into the basic framework developed in chapter 2 .

\subsubsection{A definition of sales control}

Various definitions of sales control can be found in the marketing and sales management literature. Hughes and Singler (1983:350-352), for instance, define sales control as ensuring progress toward organizational objectives according to plan. This definition includes the dimensions of rewarding positive behavior, correcting negative behavior, and maintaining positive performance of the sales force. Corrective action may involve coaching, counseling or working with the sales force to develop an agreed upon plan for improving or maintaining current performance level, and correcting. Hughes and Single's definition of sales control corresponds with a cybernetic view of control. It focuses mainly on feedback to correct poor performance.

Anderson and Oliver (1987) propose another definition of sales force control. These researchers define sales force control as "... an organization's set of procedures for monitoring, directing, evaluating and compensating its salespeople" (Anderson and Oliver 1987:76). This description of sales force control conforms to a behavioral rather than cybernetic perspective on control. Jaworski (1988:24) defines control of marketing personnel as "... attempts by management or other stakeholders within the organization to influence the behavior and activities of marketing personnel to achieve desired outcomes." Here the term 'marketing personnel' includes the sales force of an organization. Jaworski's definition also corresponds with a behavioral view of control and is in line with approaches of Tannenbaum (1968) and Flamholtz (1983). Churchill et al. (1993) discuss the evaluation and control of sales force performance. Then, controlling the sales effort involves the following activities: developing methods for monitoring and evaluating sales performance, measuring and evaluating sales performance. Data can be collected on several performance dimensions: sales volume, percent of quota, selling expenses, profitability, and customer service. Three major approaches in controlling the sales effort are distinguished: sales analysis, cost analysis and behavioral analysis.

\section{Our definition}

We will adapt the control definition of Berry et al. (1995:18) in this thesis as stated in chapter 2: Sales control refers to a process for motivating and inspiring sales people to perform sales activities that will further the organization's goals. It is also a process for defecting and correcting unintentional sales perfornance errops and intentional irregularities, such as theft or miswse of resources.

We decided to use this definition for the following reasons. First, this definition emphasizes on both the proactive and evaluative/corrective elements of control (see section 2.1). Second, Berry's definition corresponds with a behavioral view of control, in line with the approaches of Tannenbaum (1968) and Flamholtz (1983). Sales activities are primarily related to the performance 
of people. Controlling sales activities, therefore, means influencing the behavior and activities of sales personnel to achieve desired outcomes. Thirdly, it is in line with our definition of management control and the related arguments given in section 2.1 .

\subsubsection{Our theoretical framework in a sales context}

Out theoretical model ${ }^{2}$ developed in chapter 2 will be applied to study the nature of formal sales control. Figure 3.1 demonstrates the control process in a sales context.

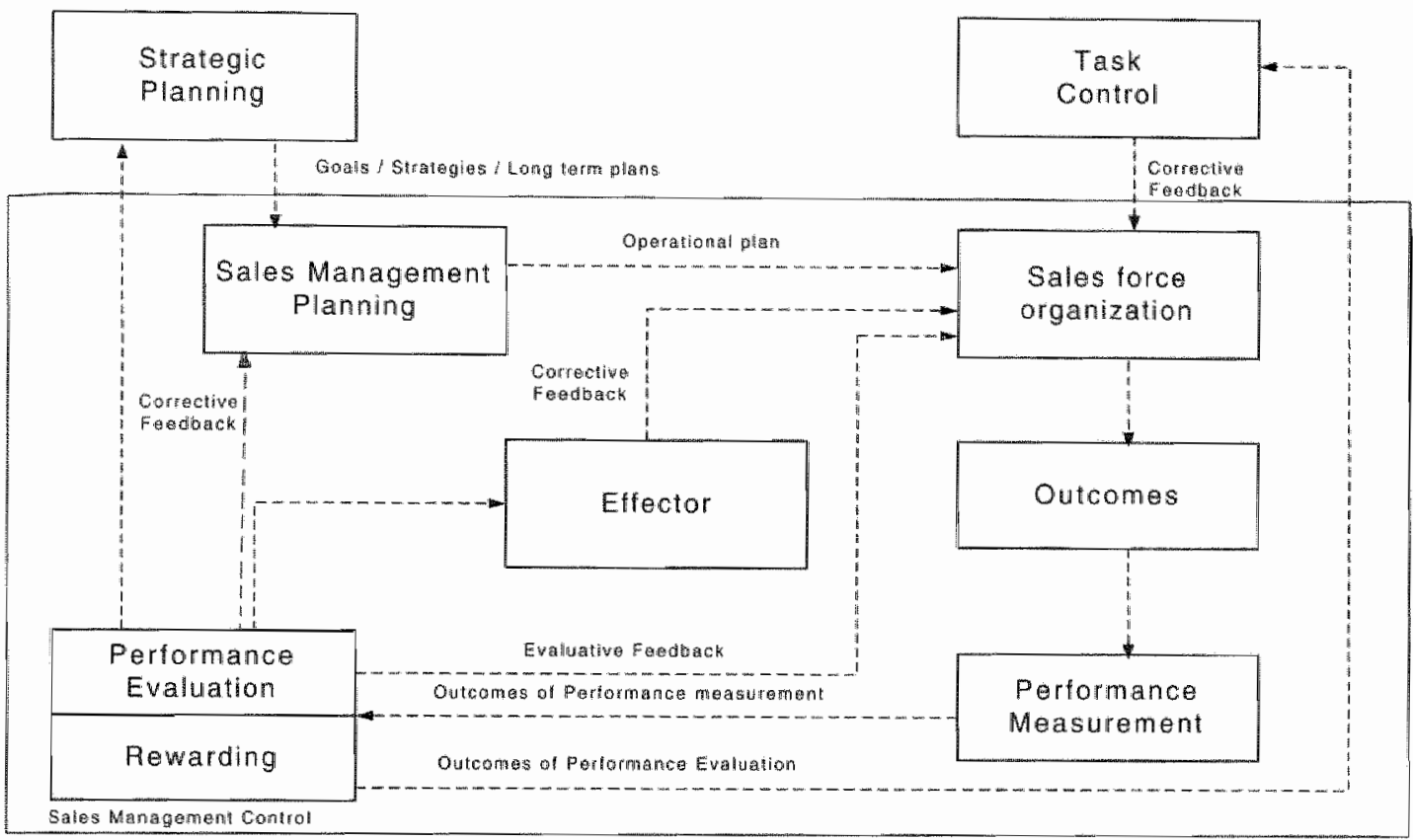

Figure 3.1 Theoretical Framework: The Control Process in a Sales Context

Our model can be described as follows. The formulation of strategies and strategic sales programs is captured under the heading of strategic planning. These strategies and programs are formulated to direct the sales force organization on the long term. The outcomes of strategic planning form an input to sales management planning. This planning process is used to develop a plan for the short term. Sales management planning usually takes place at a lower organizational level than strategic planning. The carrying out of the short term plan takes place in the firm's sales force organization. The performance of the sales force organization is measured and evaluated. The operational plan can be adapted or a supervisor can initiate corrective action based on the outcomes of the performance assessment. The outcomes can also be used to evaluate and reward individual performance.

Having defined what sales control is, we will focus on existing sales management literature to examine the nature of sales control practices. Each sub process in our adapted model will be described in detail to discuss the outcomes of our literature review.

\subsection{THE SALES FORCE ORGANIZATION AND ITS OUTCOMES}

Sales control focuses on the company"s sales force. This organizational unit is a complicated communication system within a company; its functioning is influenced by many factors that are difficult to quantify and that interact in unforeseen ways. For instance, the company's compensation 
plan motivates salespersons to chase the sales volume in new market segments. It may increase the sales cost ratio and a decrease in profit per sales transaction instead of the intended higher profitability. This is only one example of the complexity of the sales function.

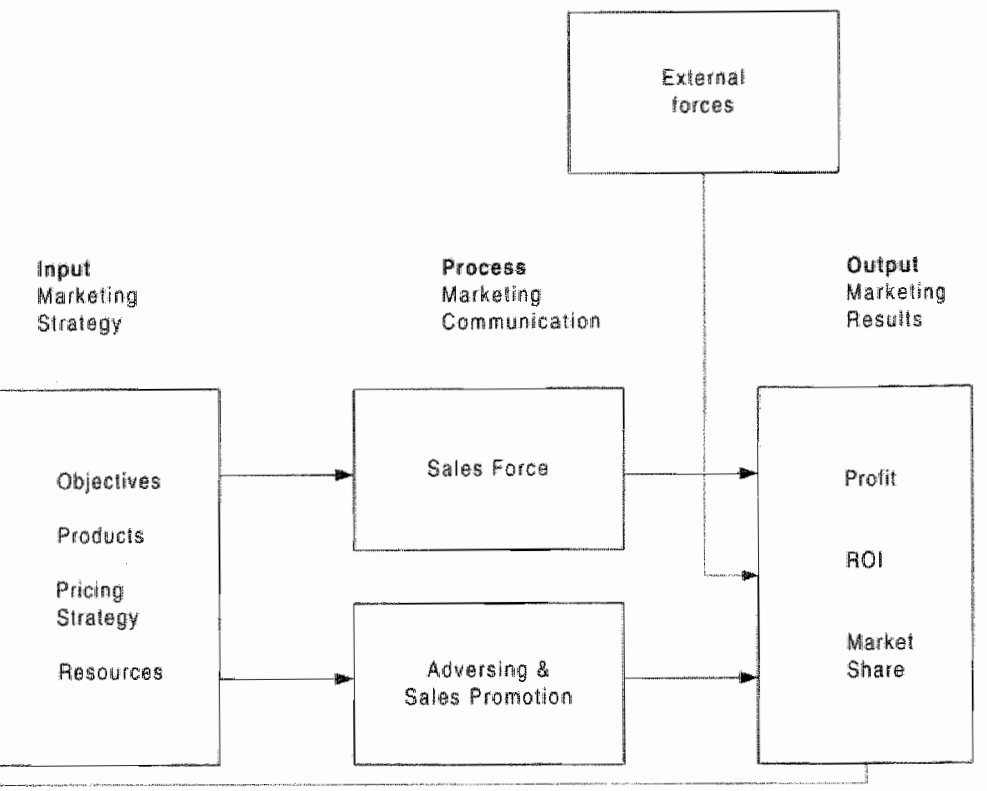

Feedback

Heasurement of

Results

Figure 3.2 The Sales Force as Part of the Corporation's Marketing System

Source: Henry. P. (1975) "Manage Your Sales Force as a System", in Perspectives on Strategic Marketing. Management, eds. R. A. Kerin and R.A. Peterson (1980), Boston: Allyn and Bacon Inc, 378-391

Henry (1975) suggested that the nature of the sales function can be studied by applying the basic principles of the system theory. The unique feature of this system is the interrelationship of the parts within the system (Robbins 1990). This is the result of two forces" differentiation and integration. In a system, units are separated to perform specialized activities; $\mathrm{f} . \mathrm{g}$. the marketing department is respousible for deweloping marketing events. At the same time, the differentiated units form a complete whole; this integration is achieved through devices such as rules, procedures, policies and direct supervision.

Henry's perspective (see Figure 3.2) implies that the sales force can be seen as a subsystem of the corporation's marketing program, which is in term a subsystem of the corporation. The salles system consists of input that go to a transformation process and result in a measurable output. The input of this system includes the marketing objectives, the choice of products / services offered, the pricing strategy and other decisions about the resource allocation necessary to goal attainment. Furthermore, the company has to develop a communication strategy to reach its customers. Market communication can be accomplished through two ways: advertising / sales promotion and the sales force. Essential to the system perspective is that the output of systems can be assessed. With respect to sales systems, output can be assessed in terms of the perfomance dimensions of the corporation: profit, ROI and market share. Examples of measures include: 
- inpur measures: number of cals, quality of calls measures in terms of message contents communcation effectiveness and interpersonal relationships

- throughput measures: delay or waiting time, meetings and report riting, stipervision and oversight, compliance with unnecessary or inappropriate regulations, planaing and budgeting, employee relatious, acquisition and procurement, intemal paperwork and quality related time includes inspection, rework, error prevention, problem determination, problem solving, quality related maintenance, and training.

- output neasures: sales volume, produci mix and sales costs

Feedback helps this system to adjust and allows it to initiate corrective action to produce desired results. This information is received from the marketplace and the results of previous marketing efforts.

\subsection{STRATEGIC PLANNING}

\subsubsection{Introductory remarks}

In this section we will focus on the outcomes of strategic planning. These outcomes can be described in terms of levels ${ }^{3}$ and contents. We will focus on the various organizational strategy levels and the relationship between these levels and the sales function. Furthermore, attention will be paid to strategy implementation. Overall, management has to formulate various plans to implement a strategy. These plans are corporate plans, strategic business unit plans, marketing plans and sales programs. These plans and the relationship between them will be examined shortly. Finally, we will discuss one specific plan in detail: the sales program.

\subsubsection{Organizational strategy levels}

One can draw distinctions between four organizational strategy llevels based on the key decision area and decision maker: corporate, business, marketing and sales strategy. The corporate strategy level consists of basic decisions concerning the corporate mission, strategic business unit definition(s), strategic business units objectives and corporate growth orientation. The key decision maker on this strategy level is corporate management. The strategy formation at the corporate levell is generally a hierarchical and top down process. The outcome of the planning process often forms the framework for decision making at the business, marketing and sales areas.

Once the corporate strategy is developed, management is concemed with implementation, evaluation and control. It has, therefore, to formulate a separate strategy for each strategic business. whit ( $S B U$ ). Overall, the SBU strategy indicates how an SBU can compete successfully against competitive products and services, and it showld be consistent with the company"s corporate strategy. The key decision maker on this strategy level is SBU management. Since SBU's often market multiple products to different customer groups, marketing strategies are developed for the target markets of each SBU.

Marketing strategies consist of the selection of target markets and the development of marketing mixes for each product market. The key decision maker on this strategy level is the SBU and marketing management. Once the marketing strategies for each product market are specified, sales management specifies the relationship strategy and the sales channel strategy. The relationship strategy indicates what type(s) of relationships between sellers and buyers can be developed and what types of activities are required for successful relationships. A sales channel strategy, on the other hand, involves various methods to provide selling coverage to the accounts including an intemal sales force, distributors, independent representatives, team selling, telemarketing, and trade shows (Ingram and LaForge 1992). The strategy levels including corporate, business, marketing and sales can be found in organizations with multiple divisions and those that have divided their operations into Strategic Busimess Units. SBUs are created to improve their planning and resource 
allocation across related groups or markets (Churchill et al. 1993).

\subsubsection{Levels of organizational plans}

Management has to formulate a series of plans to guide activities at different levels of the organization to carry out these strategies. This hierarchy or cascade of strategic plans common!! includes a corporate strategic plan, strategic business unit plan(s), marketing plans, and progranu for specific marketing functions within the marketing domain, such as sales and advertising.

Marketing plans are used to specify specific marketing objectives for each product or produc line. These plans are used to analyze marketing opportunities, identify target markets, and integrat the elements of the marketing mix into at consistent marketing strategy. Programs for individua marketing functions include the strategies, policies and activities to be followed by each functiona area in carrying out a marketing plan; the sales program is one of these programs.

\subsubsection{Strategic sales program}

A strategic sales program is used to indicate how the organization will organize and plan its overal personal selling efforts and integrate these with the other elements of the marketing strategy Overall, the strategic sales program requires five major decisions (Churchill et al. 1993:12):

- What should be the organization's selling strategy?

- What account management policies should be adopted?

- How should the sales force be organized to approach various types of customers as efficiently and effectivel: as possible?

- What level of performance can the sales force be expected to achieve during the next planning period?

- How should the sales force be deployed in terms of the territory design and the routing?

\subsection{SALES MANAGEMENT PLANNING}

Once the strategic sales program is formulated, it is turned into a short term plan and put into th hands of responsible sales managers who will make commitments to execute the operational plan Overall, an operational plan for the sales force organization consists of a financial and a sales plan These two sub plans are closely related.

When management has formulated its strategies and related plans, financial commitment: and projections have to be made by sales managers and their sales reps. These commitments anc projections are stated in an operational plan. With respect to sales force organizations, thest commitments and projections are related to revenue and selling costs.

With respect to profit planning in sales, the reader should be aware that there are severa aspects of profit planning a sales force organization cannot do much about. Overall, sale departments have no direct responsibility for general, administrative and overhead expenses. Many organizations employ direct costing method as accounting system. This method implies that sale departments have no control over costs of materials and labor costs in producing the product; these are accountable elsewhere and (manufacturing) cost accounting will define these costs. Thus revenue and selling costs are the two principal concerns for most sales departments. Financia planning for sales departments is, therefore, based on projections of these revenues and costs.

Sales managers are primarily accountable for revenue produced and selling costs. These two aspects should, therefore, be projected into the future. Not only for a year ahead at budget time, botl can also be projected for several years in advance as part of the strategic sales program. Forecast: can be made for the short term, the medium term and the long range. These forecasts can be madi for customers, customer groups and the different levels of the sales force organization such as the sales territory, the regional division, the national and sometimes the worldwide sales (see Hughe: and Single 1983; Ingram and LaForge 1992; Churchill et al. 1993; Futrell 1994). Besides fo budgeting purposes 4 , sales forecasts are useful management tools for the following reasons (Futrel 1994: 141). 
A sales forecast prowides important information for setting and maintaining a production schedule. It influences manufacturing.

A sales forecast provides information that can be used for determining the quantity and timing of need for labor, equipment, tools, parts, and raw materials. It influences purchasing and personnel.

A sales forecast can also influence the amount of borrowed capital needed to finance the production and the necessary cash flow to operate the business. It influences controlling.

A sales forecast can also be the overall base that determines business and marketing plans which are further broken down into specific goals. It influences marketing planning.

Within the sales management literature, various methods of sales forecasting are discussed. The main methods for sales forecasting are users' expectations ${ }^{5}$, sales force composite, jury of executive opinion, market test, time series analysis and statistical demand analysis (see Hughes and Singler 1983; Ingram and LaForge 1992 Churchill et al. 1993; Futrell 1994). If these forecasts are translated into budgets for sales revenues and costs, they can be used for control purposes. The accuracy of the sales forecast determines the reliability of these budgets and its value for control purposes.

Sales force budgets are extremely important for planning, coordination, and control. Budgets can be used to develop objectives for future periods, to allocate resources and to decide how to attain the objectives. Furthermore, sales force budgets are useful tools for coordinating the activities of the functional units. Finally, sales force budgets include allocation of budgeted funds. This gives senior management control over the way sales managers use these funds. They are responsible for attaining the stated goals in their budgets by using their budgets effectively; because of this important function, final approval of budgets is often made at top corporate level (Futrell 1994).

\subsection{PERFORMANCE MEASUREMENT AND EVALUATION}

\subsubsection{Introductory remarks}

Within the sales management literature, two levels of sales force performance evaluation can be distinguished (Ingram and LaForge 1992):

- evaluating the sales organization's effectiveness

- evaluating salesperson's performance

Whereas evaluating sales organization's effectiveness focuses on the overall sales organization and the different levels within the sales organization such as territories and districts, the evaluations of salespersons' performance are confined to the people themselves. Sales organization's effectiveness is a function of how well the sales organization attained its objectives overall, and salesperson performance depends on how well each salesperson performed in his/her job.

Some empirical evidence for the difference between sales organization's effectiveness and salesperson performance can be found in a study of Cravens et al. (1991). They found that sales organization"s effectiveness is the result of salesperson performance and many other factors such as sales organization structure ${ }^{6}$. Thus, salesperson performance contributes to, but does not completely determine, the sales organization effectiveness (Ingram and La Forge 1992). We will now discuss the two levels of sales force performance evaluation in detail.

\subsubsection{Evaluating sales organization's effectiveness}

The assessment of sales organization's effectiveness can be accomplished by conducting at comprehensive sales force management audit or evaluating sales management functions. These two types will be further elaborated. 


\section{Sales organization audit}

A sales organization audit gives a firm an organizational framework to examine its total sales performance logically, systematically, and comprehensively. When performed periodically by an objective and knowledgeable source, an audit can be used to identify and correct actual and potential shortcomings in the sales force organization. A framework for performing a sales organization audit has been developed by Dubinsky and Hansen (1981).

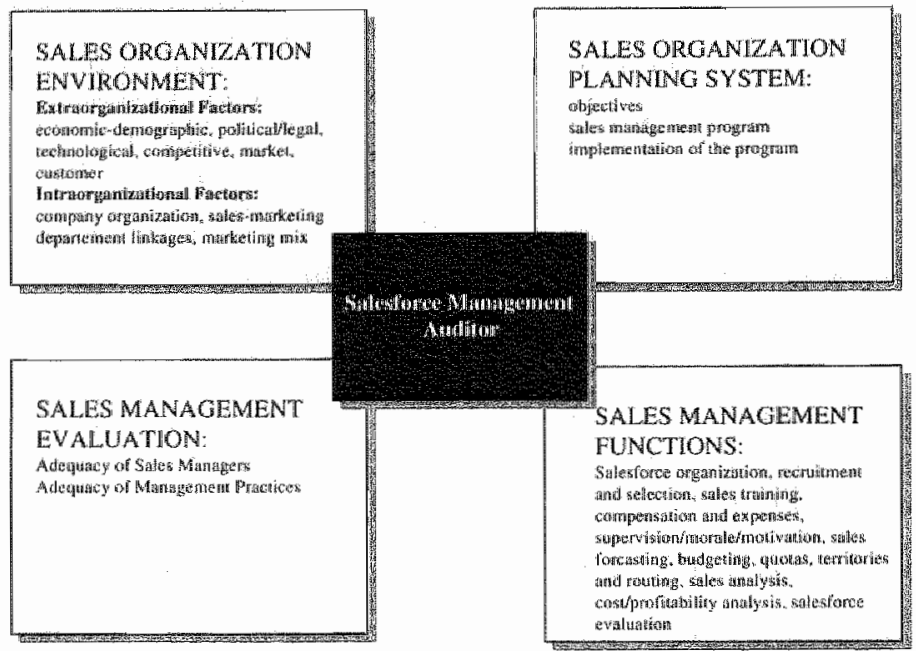

Digure 3.3 Sales Organization Audit Framework

Sounce: Ingram, T.N. and R. W. Lafforge (1992) Sales Management: Decision Making, second edition, Fonth Worth: The Dryden Press.s. 5.519.

As the sales organization audit framework outlined in Figure 3.3 shows, the audit addresses four major areas: sales organization environment, sales management evaluation, sales organization planning system, and salles management functions. Each area should be investigated in a systematic and comprehensive way to identify existing or potential problems, determine their causes, and take the necessary pro-active and corrective action(s). Dubinsky and Hansen (1981:90) developed a list of open ended, checklist questions that can be addressed in a sales organization audit.

Within the marketing literature, many researchers (e.g., Kotler and Rodgers 1977) have attempted to develop normative and conceptual frameworks of audits. Berry et al. (1991) showed that research focusing on marketing audit does not encompass the development of methodologically robust instruments. One can use Kotler's marketing effectiveness rating (Kotler 1991) in a sales setting to cope with these problems. This review is based on the evaluation of five factors of the marketing orientation of a sales organization:

- customer philosophy
- megrated marketing organization
- marketing information
- strategic onientation
operational efficiency

A checklist of closed-ended questions is used to evaluate these five factors with precoded answers. Berry et al. (1991) showed that although marketing effectiveness rating overcomes some drawbacks of open ended questions, it is not sufficiently comprehensive. It focuses mainly on the marketing 
orientation, and this is not enough to evaluate sales organization effectiveness; there is no methodologically robust instrument for conducting a marketing or sales effectiveness rating. Thus, it is necessary to improve the existing measurement instruments by combining the qualitative approach of marketing auditing with an analysis of the achieved results.

\section{Limuted analysis of sales organization effectiveness}

Although a sales audit gives a firm valuable information concerning strengths and shortcomings in its sales force organization, it is time consuming to conduct such an audit periodically. Many firms focus primarily on the sales management function. In particular, they focus on the financial performance of their sales force organization to examine sales performance periodically. Any significant deviations can be identified by frequently measuring the actual financial perfotmance and comparing it with the planned performance levels specified in the sales plan/program (e.g., Ingram and LaForge 1992; Churchill et al. 1994).

Deviations can be caused by changes in economic conditions, customer needs and competitors' actions. 'These changes may cause successful programs/plans and policies suddenly to become inappropriate and ineffective. When deviations between "planned" and "actual" can be identified quickly, a company can initiate changes timely in the strategic sales program or in the implementation policies and procedures (e.g. Bonoma and Clark 1988; Ingram and LaForge 1992; Churchill et al. 1994). This diagnostic approach to sales control is based on the assumption that the causes of these variances are known and can be influenced by the company. A framework for assessing the financial performance of sales force orgamizations has been developed by Ingram and LaForge (1992) (see Figure 3.4).

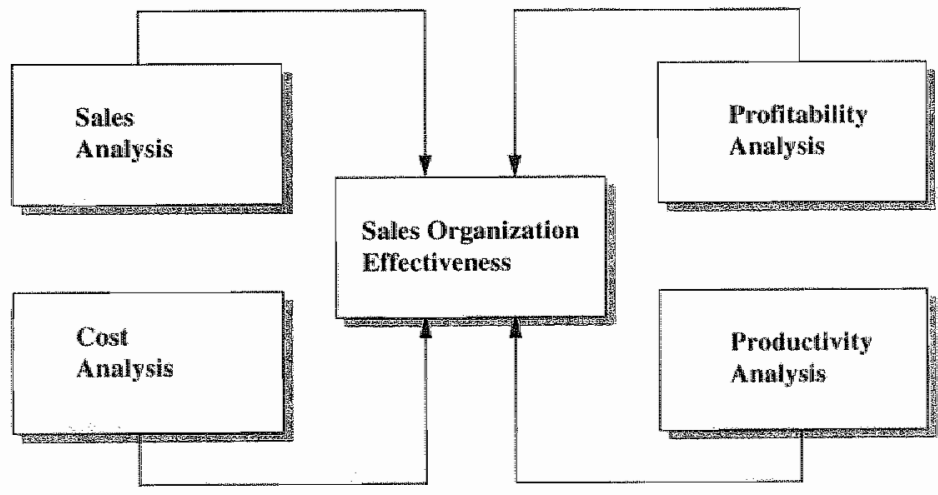

Figure 3.4 Assessing sales management functions

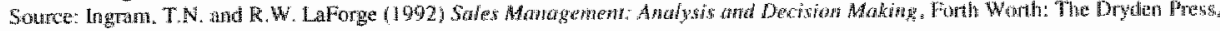
521

Four types of analyses can be distinguished:

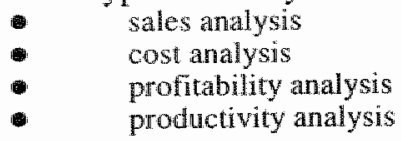

These four types of analyses can be performed at different sales organization levels to assess sales organization effectiveness (Ingram and LaForge 1992). Many companies, however, focus their sales organization assessments on sales analysis?. For instance, Jackson et al. (1982) found that sales volume is the major measure to evaluate industrial marketing and sales activities. Only a relatively 
small percentage of companies reported the use of cost, profit or return on assets analyses. The results of this empirical study confirmed the findings of Dubinsky and Barry (1982). Although sales analysis is an interesting instrument for highlighting the products/customers/orders/territories in which a company's sales are concentrated, it assesses only a small part of the overall sales performance.

Assessing the sales organization effectiveness implies that not one but all the four types of performance analyses should be performed (Ingram and LaForge 1992). Sales researchers suggest that each type of analysis can be performed in different ways, and produces different evaluative and diagnostic information for the management. Each type of analysis is discussed separately here.

i. Sales analysis

A sales analysis includes gathering, classifying, comparing and studying sales data (see Hughes and Singler 1983; Ingram and LaForge 1992; Churchill et al. 1993). Three key decisions have to be made to perform a sales analysis (Churchill et al. 1993):

- What type of evaluation system will be used?

- What type of information will be used?

- What type of sales breakdown will be used?

When managers of a company want to undertake a sales analysis, they first must decide what type of evaluation system they will use. In the sales management literature, two basic types of evaluation systems can be distinguished (Churchill et al. 1993). Will it be a simple or a comparative sales analysis ? A simple sales analysis is a performance analysis in which facts (e.g., sales transactions) are listed and not measured against any performance standards. In a comparative sales analysi.s" sales operations are measured against standards. When a company wishes to undertake at comparative sales analysis, two additional questions arise (Churchill et al. 1993). What is to be the base for the comparison? What type of reporting and control should be used? Within the sales management literature, various bases for comparison can be distinguished. Examples are quotas, last year's sales and forecasted sales ${ }^{10}$.

The second question that arises in a comparative analysis is related to the type of reporting and control system (Churchill et al. 1993). At the extreme, a management board may want to have all comparisons. This type of reporting and control system can inundate managers with information. An overflow of this information can have a negative impact on management performance: managers may be unable to process information effectively. At the other extreme, only significant deviations from the standard can be highlighted. Thus, managers can concentrate on the exceptions.

For many managers, however, this reporting and control system does not provide all the necessary information to operate most effectively. A company has, therefore, to develop a reporting and control system in which all "relevant" comparisons are available for inspection while significant deviations are highlighted. (Hughes and Singler 1983; Churchill et al. 1993). It is appropriate for a company that the following question arises to decide what type of reporting and control system can be used: Will the reporting and control system be one that provides all relevant comparisons. or one that reports only significan exceptions, or some combination? The design of such reporting and control systems depends mainly on the critical success factors and the related key control variables, the specific needs of the users. Such a design may vary from industry to industry.

With the type of evaluation system, management has to select appropriate sources of information for the sales analysis. When a company"s management decides to perform a sales analysis, they can decide what type of intormation is to serve as input and how the basic source documents are to be processed (Churchill et al. 1993). Data for sales analysis can come from many different sources, such as territory records, order forms, call reports and expense records. The availability of computers and multi variate statistical techniques makes it possible to analyze sales data in categories that are almost limitless (e.g., Hughes and Singler 1983; Ingram and LaForge 


\section{2; Futrell 1994).}

Finally, when designing a sales analysis management can take a wariable that will serve as point of aggregation (Churchill et al. 1994). Within the sales management literature, the most common procedure is to assemble and to tabulate sales data by some groupings deemed relevant (e.g., Hughes and Singler 1983; Ingram and LaForge 1992; Churchill et al. 1993; Futrell 1994) like:

- organizational level such as the sales organization, the organizational units, the zones, the regions, the districts, the territories and the accounts

product, product line package size, grade, or color

market including class of customer, end use or channel of distribution

order size

salespeople

time period

financial arrangement such as cash or charge

\section{ii. Cost analysis}

Cost analysis is complementary to sales analysis in the sales management literature (Churchill et al. 1993). Whereas sales analysis focuses on the results achieved by the sales force organization, sales cost analysis focuses on the costs incurred in attaining these results and whether the returns of sales operations justify the costs (Hughes and Singler 1983; Churchill et al. 1993). Cost information for sales management plays an important role in achieving overall company goals and objectives. Organizations require this type of management information to address the following important operational and strategic questions:

- Which parts of a company's sales operations are cost effectively contributing to customer perceived value?

- Which marketing channels are cost effective in distributing products to customers?

- How do indirect costs relate to product costs and customer groups?

- How do the costs relate to the life time value of products?

Various methods of cost management can be used: direct versus indirect costing, and Activity Based Costing ${ }^{\mathrm{II}}$. These methods include gathering, classifying, comparing and studying those costs that affect sales volume such as selling / general / administrative expenses, wages and salaries, distribution costs, promotion costs directly and indirectly.

The major objectives of sales cost analysis are to determine the contribution made to profitability and to evaluate efficiency in all levels of the sales force organization in terms of corporate goals and objectives ${ }^{12}$. Two important applications of cost analysis in sales management are, first, to determine which is the best of many alternatives for sales projects or. business proposals, and second, to isolate problem areas in the sales force organization (e.g., Hughes and Singler 1983; Churchill et al. 1993).

\section{iii. Profitability analysis}

Sales and cost data can be combined in various ways to evaluate sales organization profitability. The present sales management literature draws a distinction between three types of profitability anallysis (Simon 1969; Churchill et al. 1993):

- income statement analysis

- return on assets managed analysis

- residual income analysis

A first type of profitability analysis is based on income statements. The major difficulty in income statement analysis is, however, cost allocation. In particular, some costs can be shared between organizational levels and type of sales ${ }^{13}$. A company can use a full cost (or net profit) or a contribution margin approach to allocate its sales $\operatorname{costs}^{14}$. It is necessary to draw a distinction between direct and indirect sales costs to discuss the nature of both approaches. The full cost approach allocates all the costs of doing business to individual units based on some type of cost 
allocation procedure. It results in a net profit for each unit, i.e., an organizational unit or sales type. The contribution approach allocates only those sales costs that can be specifically identified with an organizational level or sales type.

Only direct sales costs are included in the profit analysis. The profit contribution of a unit is the gross contribution calculated from this approach. This profit contribution can be sufficient to cover indirect cost and overhead, and can provide the net profit for the company (Simon 1969: Ingram and LaForge 1992; Churchill et al. 1993).

Return on assets managed analysis (ROAM) is the second type of sales profitability analysis. Although an income statement analysis is necessary and valuable, it is incomplete because this analysis does not include any evaluation of the investment in assets required to generate the net profit or profit contribution (e.g., Simon 1969; Ingram and LaForge 1992; Churchill et al. 1993). ROAM $^{15}$ can be calculated as follows (Ingram and LaForge 1992:529):

ROAM = (profit contribution ${ }^{\prime \prime}$ as percentage of sales) $x$ asset turnover rate $=\left(\right.$ profit contribution ${ }^{17} /$ sales) $\times$ (sales/assets managed)

The formula indicates that the ROAM is determined by both profit contribution percentage and asset turnover. The ratio between the profit contribution percentage and asset turnover ratio can be calculated to determine the source of variances. The management of the company can initiate corrective action, such as reduced selling costs, to improve future ROAM performance (Ingram and LaForge 1992). This type of profitability analysis is used extensively in retailing. Although ROAM is an interesting approach to profitability assessment because it evaluates profitability in relation to asset investment, it does not include any consideration of sales growth (see Cron and Levy 1987; Ingram and LaForge 1992). This ratio does not take salles growth objectives into account.

Furthermore, Residual Income Analysis (RIA) is desirable for a thorough evaluation of sales organization effectiveness. RIA combines the return on assets managed concept with sales growth objectives. Sales organization effectiveness depends upon both sales growth and profitability. Thus, sales growth is desirable for a company as long as the return on sales exceeds the cost of capital for acquiring the resources to run a business. RIA can be calculated as follows (Ingram and LaForge 1992:530):

\section{Residual income $=$ Profit contribution ${ }^{\mathrm{I}}-$ Accounts receivable cost - Inventory carrying cost}

\section{iv. Productivity analysis}

A fourth major element in the evaluation of sales organization effectiveness is productivity analysis (e.g. Simon 1969; Hughes and Singler 1983; Ingram and LaForge 1992; Churchill et al. 1993). This type of performance analysis focuses on the relationship between outputs, e.g. units sold or revenue, and inputs, e.g. head count. It provides useful evaluative and diagnostic information by highlighting specific areas of both high and low productivity with the sales organization.

Management may initiate corrective action to improve sales productivity based on the outcomes of a productivity analysis. Productivity improvements can be achieved by increasing output with the same level of input or by maintaining the same level of output but using less input. Such improvements can be reflected in increases in profitability of the sales organization.

\subsubsection{Evaluating salesperson performance}

\section{Use of assessing salesperson performance}

Whereas the previous issues on performance assessment focus on sales organization effectiveness, the assessment of individual salespeople performance is confined to the people themselves. Individual sales performance assessment can be used for many purposes (Muczyk and Gable 
1987:47). For instance, this performance evaluation can be used to ensure that financial compensation and other reward disbursements are consistent with actual salesperson performance. Furthermore, these performance analyses can be useful to identify salespeople that might be promoted and salespeople whose employment can be terminated. This performance assessment is also usefull to determine the specific training and counseling needs of the sales force. Additionally, these performance evaluations can provide information for human resource planning and recruitment and selection of salespersons in the future.

Within the sales management literature, several studies can be found concerning the practical side of salesperson evaluation (see Dubinsky and Barry 1982; Jackson jt. et al. 1982; Morris and Atten 1990; Morris at al. 1991). This literature indicates that sales and cost analysis are appropriate techniques for assessing the overall personal selling effort; however, these types of perfomance analyses measure effectiveness rather than performance. This can be explained as follows. The crucial distinction between effectiveness and performance can be described as follows.

Performance can be seen as behavior evaluated in terms of its contribution to the company, e.g. unit sold and revenue. Behavior refers to what the salespersons do or the tasks on which they expend their effort (Churchill et al. 1993). Thus, evaluating salesperson's performance requires other forms of performance analyses than only those based on evaluating sales effectiveness. Many companies, therefore, supplement sales and cost analysis with other measures that more directly reflect each salesmen's performance. "These measures for evaluating salespeople can be classified into the following categories (Churchill et al. 1993): objective and subjective measures.

\section{Objective measures}

Objective measures fall into the following subcategories: output and input measures, and ratios of output and/or inpul. For instance, the most common output measures are orders such as the number of orders and the average size of orders and accounts such as the number of active accounts (see Jackson et al. 1982; Jackson et al. 1983; Morris and Atten 1990; Churchill et al. 1993). In outcome based evaluation systems, salespeople are held accountable for their results ${ }^{19}$ (Anderson and Oliver 1987; Oliver and Anderson 1994). Examples of input measures most used are calls, time and time utilization, expenses and non selling activities such as the letters written to prospects.

Many companies combine the various outputs and/or inputs to form ratios (Churchill et al. 1993). Common ratios used to evaluate salespeople are expense ratios such as sales expense ratio, account development and servicing ratios such as account penetration ratio, and call activity and/or productivity such as the calls per day ratio (see Berry 1987; Churchill et al. 1993). Companies often use the various measures in combination. These measures are an aid to judgment. Besides input and output measures, an organization can also use throughput and especially behavioral measures. These measures can tell managers about the causes of their problems, such as a sales decline, or about their success, such as personal or customer relationships. Until now however, relatively little attention has been paid to throughput measures in the sales management literature.

\section{Subjective measures}

The second group of measures for evaluating salesperson performance are subjective measures. Subjective measures rely on a personal evaluation by someone in the company, such as the immediate supervisor, of how a salesperson is doing (Churchill at al, 1993). These measures are primarily used in behavior-based control systems ${ }^{20}$. Examples of subjective measures are personal characteristics and job knowledge. The supervisor decides if and to what degree the salesperson's input measured by subjective indicators, such as personality or communication skills, generate output such as revenue.

Many companies have formalized this behavior-based performance assessment to enable the supervisor to monitor, direct, and impose subjective judgements (Churchill at al. 1993). For instance, various companies have developed a performance appraisal system that relies on merit 
rating forms. These performance appraisal systems are based on schemes including many attributes and using some kind of rating scale, such as Behaviorally Anchored Rating Scales ${ }^{2 \|}$ (BARS) and Graphic rating/checklist methods ${ }^{22}$. The assessor evaluates how well a salesperson did on each of the attributes included.

Common attributes used to evaluate salespeople are sales results, job knowledge, management of territory, customer and company relationships, and personal characteristics (Churchill et al. 1993:771). The emphasis giwen to each attribute, however, varies per company. Cocanougher and Ivancevich (1978) and Edwards et al. (1984) studied performance appraisal systems that rely on merit rating forms. They found that companies had identified attributes thought to be related to performance; but they often did not evaluate whether these attributes were critical or vital to performance (Cocanougher and Ivancevich 1978). Some companies such as Xerox use a behaviorally anchored rating scale to get to the more critical or vital attributes. A performance appraisal system that relies on a behaviorally anchored rating scale attempts to concentrate on the most critical behaviors and performance criteria that can be controlled by a salesperson (Cocanougher and Ivancevich 1978; Churchill et al. 1993). Performance evaluations are carried out with respect to these criteria only.

\subsection{REWARDING}

The major purpose of a sales control system is to ensure that the sales force behaves in ways that contribute to goal attainment. This implies that such a system should not only focus on performance assessment but it can also address how and why salespersons are motivated to act the way they do. In a business environment characterized by intensive competition and significant resource limitations, firms are relying heavily on the productivity of their salles forces for financial success.

As organizations become lean, salespeople are gaining autonomy and becoming increasingly accountable for key business decisions. These changes imply that the right sales force compensation plan can have a pronounced impact on the sales and profits of an organization. Accordingly, the need to design and implement incentive compensation plans that strategically direct the activities of the sales force and motivate the desired results has become even more important.

Sales force compensation is typically based on some form of performance evaluation, and hence the assessment method used is critical. Some methods are purely output or purely input based, and often employ only one indicator of performance. Still other methods use absolute ratios of outputs to inputs, or compare performance with the "average" performance rather than the "best". Table 3.1 contains an outline of output, input and rations used to evaluate salespeople. 


\begin{tabular}{|c|c|c|}
\hline Mewarding hased on & \multicolumn{2}{|c|}{ Examples of pertormanke neasures } \\
\hline Output factors & $\begin{array}{l}\text { Orders } \\
\text { Accounts }\end{array}$ & $\begin{array}{l}\text { Number of orders } \\
\text { Average size of orders } \\
\text { Number of canceled orders } \\
\text { Number of active accounts } \\
\text { Number of new accounts } \\
\text { Number of lost accounts } \\
\text { Number of owerdue accounts } \\
\text { Number of prospective accounts }\end{array}$ \\
\hline Input factors & $\begin{array}{l}\text { Calls } \\
\text { Time and time utilization } \\
\text { Expenses } \\
\text { Nonselling activities }\end{array}$ & $\begin{array}{l}\text { Number of calls } \\
\text { Number of planned calls } \\
\text { Number of unplanned calls } \\
\text { Days worked } \\
\text { Calls per day } \\
\text { Selling time versus nonselling time } \\
\text { Total expenses } \\
\text { Expenses per type } \\
\text { Expenses as a percentage of sales } \\
\text { Expenses a percentage of quota } \\
\text { Letter written to prospects } \\
\text { Telephone calls to prospects } \\
\text { Number of formal proposals developed } \\
\text { Adverticing displatys set up } \\
\text { Number of meetings held with distributors/dealers } \\
\text { Namber of training sessions held with distributor/dealer } \\
\text { personnel } \\
\text { Number of calls on distributor/dealer customers } \\
\text { Number of service calls made } \\
\text { Number of owerdue accounts collected }\end{array}$ \\
\hline Ratios & $\begin{array}{l}\text { Sales expense ratio } \\
\text { Account penetration ratio } \\
\text { Lost account ratio } \\
\text { Average order size ratio } \\
\text { Calls per day ratio } \\
\text { Pllanned call ratio }\end{array}$ & $\begin{array}{l}\text { Cost per call } \\
\text { New acoount conversion ratio } \\
\text { Sales per account ratio } \\
\text { Order canceled ratio } \\
\text { Call per account tatio } \\
\text { Order per call (hit) ratio }\end{array}$ \\
\hline
\end{tabular}

Table 3.1

Common output factors, input factors and ratios used to evaluate salespeople

Source: adapted from Churchill jr, G.A., Ford. N.M. and O.C. Walker (1993) Sates Fonce Managentent. Chicago: Irwin, $764-765$

A common classification refers to extrinsic and intrinsic rewards. Extrinsic rewards are administered after a formal evaluation conducted by a superior (Flamholtz et al. 1985). Within the sales management literature, the following types of extrinsic rewards can be distinguished: salary, commission, bonuses, combination plans, and sales contests (see Johnson et al. 1986, Still et al. 1988; Churchill et al. 1993). Empirical research shows that sales quotas are frequently used in sales management. In particular, sales quota plans and quota setting procedures are applied:

- to erhance short term sales performance by providing sallespersons with challenging targets set higher than the sales levels that they would achieve otherwise

to induce salespersons to allocate their time and selling effort so as to account for the relative profits generated by the various operations, e.g. the selling of different product/service lines

to profit salespersons with conwenient performance standards that will be used for measuring, evaluating and controlling salespersons'performance

Meeting sales quotas is typically associated with some reward, e.g. a bonus. Sales objectives based on sales quotas are related to short term sales performance. Today's firms have started emphasizing long term relationships with their customers. This long term orientation has an impact on compensation plans: some companies have developed compensation plans based on customer 
satisfaction ratings. Reasons for this development are (Sharma 1997):

- salespeople can have a large influence on customer satisfaction

- customer satisfaction evaluations can be related to customer loyalty

- salespeople can understand the behaviors that lead to enhanced customer satisfaction

- a customer satisfaction-based incentive system will enhance repeat buying and increase sales

Intrinsic rewards are intangible outcomes such as self respect, satisfaction etc. In comparison to extrinsic rewards, these intrinsic rewards are related to higher human needs (Herzberg 1968). This type of reward can only be effective when two conditions are fulfulled: self control can be appreciated and the extent to which intrinsic rewards are received is independent of formal evaluation (Flamholtz at a1. 1985).

\subsection{SUMMARY AND CONCLUDING REMARKS}

In this chapter we explored the policies and procedures involved in controlling the sales function. We first introduced the following definition of sales control:

Sales contral refers to a process for motivating and inspiring sales people to perform sales activities that will further the organization's goals. It is also a process for detecting and correcting unintentional sales performance errors and intentional irregularities, such as theft or misuse of resources.

Our theoretical framework developed in chapter 2 was slightly adapted (see Figure 3.1). The key subprocesses of the sales control process are strategic planning, sales management planning, performance measurement, performance evaluation and rewarding, feedback and task control. This framework was used to structure the existing literature on sales control practices.

The existing sales literature highlights that sales performance assessment is based primarily on financial information; nonfinancial performance, e.g. customer service and quality, is not discussed. There are many users for whom such performance measures remain important. This group includes shareholders and those company executives who deal with them. We may conclude for sales control that controlling the sales function in today"s business seems to be related to managing financial performance and sales productivity. Researchers have tried to enhance organizational performance in the short and long term by optimizing the financial performance and productivity of marketing and sales. Financial criteria such as profitability are, therefore, often used as primary and overall objectives and measures of performance.

The acceptance of financial measures as key for sales performance has resulted in an intensive use of financial techniques, such as profitability analysis and variance analysis in sales decision making. This practice of traditional sales control is rooted in the economists" model of the firm in which the maximization of shareholder value/profit is the overriding objective. Sales costs and output are optimized according to rational behavior. The sales function is seen as a decision making or problem solving process with its emphasis on shareholder/profit maximization. The basic units of actual sales performance assessment mostly are transactions in a competitive market and the related costs; yet there is an increasing recognition that financial performance ${ }^{23}$ can be improved by paying closer attention to measures that relate to customer satisfaction and continuous improvement. It implies that performance measures selected to track sales performance can be judged by how well improvement in these measures correlates with improvement in customer satisfaction and retention. Thus, the set of performance measures can be extended with nonfinancial measures.

This concludes our discussion of the sales control function, we will discuss our research model and method in the next chapter. 


\section{Notes}

1. The concept "sales control' and 'formal sales control' will be used as synonyms.

2. Note that the model is used to structure the existing knowledge concerning formal organizational control. We are aware that there are mary approaches to organizational control; our approach is only one of them.

3. In this context, the concept 'level' refers to organizational strategy levels, organizational plan levels and strategic sales program.

4.Sales forecasts are often used to formulate internal budgets, i.e. master budget (see Horngren et al 1994).

5.The term 'users' refer to end users or clients/customers,

6. The findings of Cravens et all. (1991) imply that besides individual sales performance other factors have to be evaluated for assessing the sales organization effectiveness. The impact of these factors on sales organization effectiveness are measured by sales organization audits, and limited assessments of sales management functions. We therefore decided to spent attention on to these methods besides the methods for assessing individual performance.

7. See Dubinsky and Barry 1982; Jackson et al. 1982; Ingram and LaForge 1992.

8. The two types of performance analysis are used to identify performance deviations between planned and acheved results. These deviations are explained by explanatory varrables. These variables are related to the predefined performance standards, such as price, revenue and sales volume.

9.Examples of comparative sales analysis are: comparisons within the sales organization, comparisons to forecasis, comparisons to sales quotas, comparisons to previous period, and comparisons to industry/competitors (Ingram and Lafiorge 1992).

\section{0.. See Hughes and Singler 1983; Ingran and LaForge 1992; Futrell 1994.}

11. Activity -Based Costing $(A B C)$ is a method of cost management that identifies business activities performed, tracks cost associated with these activities. $A B C$ is a response to the need for an improvennent over traditional production cost accounting methods. These traditional methods tend to allocate most overhead costs on the basis of either direct labor or direct material.

In an $A B C$ system, the types of cost drivers used go beyond those traditionally included in cost systems Multiple cost drivers are used to trace activity costs to products and customers in an ABC systen. The cost driwers reflect the consumption of actiwities by the products or services. Specific cost drivers are selected for each activity to reflect the nature and behavior of the activity.

\section{See Hughes and Singler 1983; Ingram and LaForge 1992; Futrell 1.994.}

13. The various sales levels are: total sales, type of product sales, type of account sales, type of distribution sales, and order size sales.

14. See Hughes and Singler 1983, Irigram and LaForge 1992, Futrell 1994.

15. To measure financial performance in the light of resource utilization, retailers often use very specified ROAM sehemes to judge sales and profit levels in relation to the amount of resources the firm consurned to generate them (see Ghosh 1994).

16. The concept of "profit contribution' refers to 'net profit'.

17. The concept of "profit contribution' refers to 'net profit".

18. The concept of "profit contribution' refers to "net profit". 
19.... and wot for how they achieve these resuits. If salespersons are held accountable for how they achieve results. then the evaluation gygten is a throughput-based system.

20. A behavior-based control system inwolves high levels of supervisor monitoring direction and intervention in alctivities, and subjective methods of performance evaluation (Oliver and Anderson 1994).

21. The Behaviorally Anchored Rating Scales (BARS) are used to link salesperson behavior with specific results: (Ingram and LaForge 1992). The key performance resulks and the critical behawiors required to attain these results are siated in a ewaluation form. When a sales person is evaluated by the superior then this superior assigns numbers to the critical behaviors on a rating scale for each performance result of the subordinate.

22. With respect to graphic rating or checklist method, superiors evaluate their salespersons by using a performance evaluation form criteria used in the evaluation as well as some means to provide feedback on how well a individual salesperson performed on each criterion.

23. Today" sera of cost cutting means that quality expenditures must be funancially accountable (Rust et al. 1995). Quality improvements can have two major benefits. It inproves the firm's ability to attract new customers as well as the firm's ability to advertise the quallity of its offerings. Another effect is that when current customers are more sattiffied with the products and services they buy, they can become repeat customers. Various researchers (e.g. Fontill and Wernerfell 1.987; Reichuheld and Sasser 1990; Dawkins and Reichheld 1990) found that small increases in customer retention rates can have a great financial impact. Existing research (e.g. Fomell 1992 ; Nelson et al. 1992; Boulding et al. 1993) on the impact of improved quality on organizational performance demonstrates that a link between quality and profitability might exist, for a review of the literature in this area, see Zahorik and Rust 1992 and Rust ef al. 1995 . The basic conclusion of these studies is that customer satisfaction and quality have a measurable impact on customer retention, market share and profitability (Rust et al. 1995). 



\section{Chapter 1}

The problem statement in its context

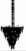

PAT I. THEORETICAL FRANRWORK

\section{Chapter 2}

Formal organizational control

\section{Chapter 3}

Controlling the sales function

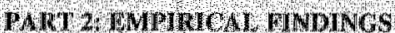

\section{Chapter 4}

The research method

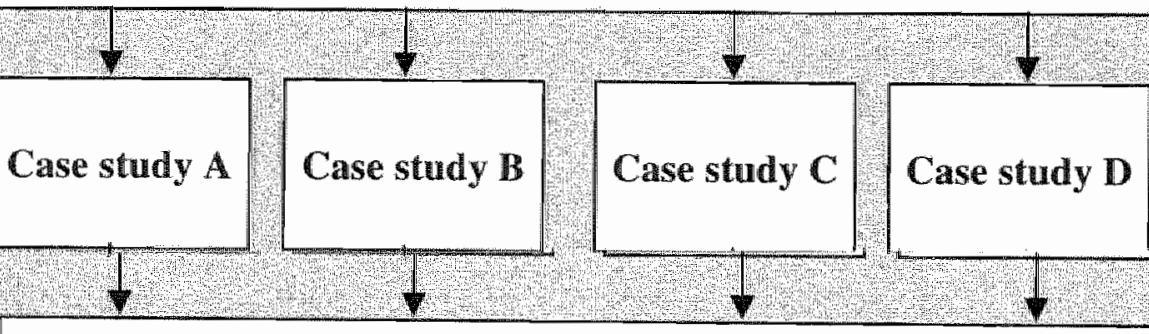

\section{Chapter 5}

Comparative case analysis

PAKT 3: CONCLUSIOWS AND FUTURE RESEARCH

\section{Chapter 6}

Final conclusions and future research 


\section{PART 2}

Empirical Findings 


\section{$\overline{\text { Chapter } 4}$ \\ The Research Method}

How Can You Measure Sales Control Practices?

\section{Chapter outline}

The aim of this chapter is to give the reader a more comprehensive account of the research method used and to explain the research design for the project. A research design is an action plan that is used to guide a researcher while collecting, analyzing and interpreting data in an attempt to answer the research questions. The researcher has, at least, to deal with at least the following questions. What questions should be studied? What data should be collected? How should the results be analyzed? These questions were used to select an appropriate research design for the study and to structure this chapter.

This chapter is structured in four parts. The first part, section 4.1 , contains a brief description of the focus of the research; it is used to discuss the aim of the study and the related problem statement. The problem statement is further specified into two research questions, each research question is discussed briefly. As stated in chapter 1 , the case study method was used as a research method to investigate the nature of formal sales control practices; the arguments for and the limitations of this method will be examined in the second part, section 4.2 . Having discussed the strengths and weaknesses of case study research, the aim of the third part, comprising sections 43 and 4,4 , is to describe the research design and the processes followed to cope with the limitations of case study research as a research methodology. The reader will notice that our research method is of an inductive nature. The final part, section 4.5 , is used to summarize the main points presented in this chapter and to discuss how these points relate to the following chapters of the thesis: 


\subsection{FOCUS OF THE STUDY}

\section{Problem statement}

The focus of the study presented here is the sales control function in an organization. The basic aim of this study was to gain an understanding of design characteristics of formal sales controls that allow organizations to control their sales effort efficiently and effectively. This resulted in the following problem statement:

\section{"How do organizations formally control their sales function in today's dynamic marketing envirommen, and how can these formal control practices be explained?"}

This problem statement was translated into two empirical research questions; these two research questions provided the guidelines to develop the most suitable case research design for the project. The research questions were used to develop and explore further our model from chapter 3.

\section{Research question I}

Chapter 3 was used to discuss a conceptual model for controlling the sales function. One objective of the empirical research was to identify the formal sales control practices as these occur across companies; yet the reader should be aware that the investigation is designed primarily to build explanations'. The theoretical model presented in chapter 3 is regarded as tentative. It is the descriptive value of this model that is investigated.

As indicated earlier, there is relatively little prior research on how organizations formally control their sales effort. The existing research in sales management literature is limited primarily to the traditional control mechanisms based on analyzing financial information. Although these controls remain important in today's business environment, one can question these mechanisms whether they are sufficient enough to cover the concept of business performance. Gaining profit in today's business market is not also a guarantee that profit will be gained in the future. Today's successful companies are often those with a healthy financial structure in combination with a strong customer and quality focus. Examples are companies such as Compaq, Sun Microsystems or Xerox. Gaining profit remains important to ensure the support of the firm's stakeholders but performance areas related to satisfaction and quality may help a firm to remain profitable in the long run. Our literature review was used to demonstrate that this topic could not be found in the existing literature on controlling the sales function. This conclusion was the reason for exploring formal sales control in practice.

The aim of this empirical research is to provide a deeper understanding of sales control by focusing on the reasons behind the realization of sales control designs specified by the theoretical model" therefore, the first research question was formulated "How does the sales control process" take place in practice, and what formal control mechanisws are used?" Answering this question implies that the sales control process in general has to be examined. Based on these insights, the nature of its sub processes can be studied in practice. The results of this study will be confronted with the model of the sales control process, and by doing so, the descriptive value of the modell can be evaluated and assessed.

\section{Research question II}

Each control process takes place within a control system; the concept 'control system' refers to mechanisms or processes and techniques (Flamholtz et al. 1985) or a subset of organizational systems (Machin, in Lowe \& Machin 1983) by which behavior can be influenced. The control system also depends on its organizational context. Considering this, the second research question was formulated "How are the dimensions of sales control systems, specified by the theoretical model, realized within different types of organizations and how can this be explained? 


\subsection{ARGUMENTATION FOR THE CASE METHOD}

Two broad research streams can be identified within the literature on research methodology, namely quantitative and qualitative research methods. Although quantitative research is still the most popular method in the fields of organizational and marketing science, various researchers (see Bonoma 1985a; Biemans 1990) have started to stimulate a wider use of qualitative research techniques (e.g., case studies). To determine the choice of the research method, Bonoma (1985) argues that there are two important selection criteria: the purpose of research and the phenomena of interest. These two criteria were used to determine the appropriate research method for our research project.

\section{Arguments for qualitative research}

The purpose of the research questions follows from the purpose of the research and the related problem statement. Yin (1989) has stated that 'how' and 'why' questions can best be answered by using qualitative methods, while research questions that start with 'what' and 'how many' are more related to quantitative research. Whereas 'how' and "why' questions generally refer more to theory building and development (see Straus 1987; Gersick 1988), "what' and 'how many' questions often refer to theory testing. In this context, case study research is useful when researchers find little prior literature on which to build their theoretical frameworks (Yin 1989; Biemans 1990). Relating this to the research questions, it was decided that qualitative research would be the most appropriate research method for finding answers to our research questions.

A second criterion for selecting a research method relates to the phenomena of interest. This criterion refers to whether the phenomena under investigation can be examined outside their reallife setting and whether they can be operationalized in quantitative terms. Case study research often helps a researcher to discover the variables and their potential relationships by investigating a phenomenon of interest in real life situations and combining multiple sources of information. Mintzberg (1979:583) has argued that "... measuring in real organizational terns means first of all getting out into the field, into real organizations. Questionnaires often won" $t$ do." The nature of sales control cannot be fully understood in isolation and that therefore a more contextual approach is required. Placing sales control practices in such a wider context is necessary to be able to examine them in full detail. This research strategy helps academics to study issues in a real life context, and thus, researchers pursuing such a strategy are more aware of the impact of the rapid development of technology, intensive competition, and so on that can take place. This awareness helps them better to understand the issues that practicing managers are dealing with in their task environment.

\section{Arguments for the case research method}

The cnse research method is employed to study actual sales control methods and practices in this study. There are a number of benefits of case study research and the key benefits for selecting this research method are identified below:

- On research fochses on describing how organizations formally control sales operations, to explain why specific control mechanisms ane employed, and how the managers have developed the reasoning that has led to specitic contuol designs. Such research topics are not easily to be quantified. Furthermore, it appears then researchers have given relatively little attention to sales control practices. Case study research ofters lhe potential for a deeper examination of the control practices and to identify variables that can be used to explain these practices. Case studies can be used to deal with phenomena of interest and context In comparison th conducting surveys, the resencher is not forced to limit the namber of variables to be analyzed and the number of respondents that can be surveyed (Yin 1989). We strongly believe that the nature of sales control conno be fully understood in isolation and that a more contexuall approach is required. This approach offers the oppotunity to confront the case findings with the existing theories. This confrontation is interesting for warious teasons. The confrontation between case and theory may be useful to check and inspect the case for indications against which existing theories warn (Van de Poel 1986). Additionally, case study research mat help to add to the plausibility of a theory by making references (Van de Poel 1986). This awareness helps nesearchers to understand better the isstes practicing managers are dealing with in their task environment. Our 
study aims at answering 'how" and "Why' questions, at description and explanation-building (Anderson 1973). We would like to see and hear what is done and what not, and why and why not to examine sales control practices. Personal interviews were used for the following purposes:

a. to study the managers" perceptions; these findings will be used to study the research questions from various perspectives and to detect links

b. to identify the relevant variables and their importance

c. to find explanations for various sales control practices

This approach leads to an in-depth study of a small number of firms instead of trying to find a global view of sales control practices in many different areas of management.

- The aim of the case study research presented in this thesis was not to identify the best fit between the sales control mechanisms, strategy and other variables but to examine the factors relevant in the interactions between these variables. When studying control variables the interactions are often complex and probably only in depth research will help a researcher to examine the complex nature of these relationships. This is particularly so if we recognize that the control wariables are evolving and multifaceted concepts. Case study research offers the potential for studying a wide range of control mechanisms, including those that are difficult to measure using surveys.

- Our research is primarily directed at theory building in the sense that we are trying to establish the descriptive value of our tentative conceptual model. The interpretation of our case study results will be in terms of "analytic generalization" (Yin 1989) and it implies that we will investigate whether the outcome of empirical research confirms our preliminary theoretical model.

- Case study research can provide opportunities to test certain features that have been put forward by a theory. For instance, case studies may help a researcher to gather highly confidential information, e.g... business unit performance (De Ruyter 1993). The researchers' interactions with respondents may result in a more candid response by consulting them in their own, daily environment (Webb et al. 1966; Carthy 1988; Gummesson 1991). This type of response often helps the researcher to feel relationships and aspects that would otherwist not be understood (Van de Poel 1986). Another reason for conducting case study research in this study was. related to our respondents' attitude toward large scale survey research. Overall, our respondents said that they preferred to participate in case study research because this type of research method give them the oppormnity to discuss management practices more in detail.

- Case study research is highly flexible. Researchers can use semi-structured questionnaires to increase the efficiency of information gathering, and to lead and structure the conversations with respondents. The researcher can decide to change the approach, e.g., single versus multiple case studies, when it should prove necessary (Biemans 1990). For instance, research findings can show that replicated multiple site case studies are more suitable for attenpting to answer the research questions than longitudinal single site case studies and thus, the researchers should change their approach if needed. The outcome of case study research can be the basis for future large scale quantitative studies.

- Multiple sources of information such as documents and observations can be used in case study reseatch (Yin 1989). The reliability of the research results can be improved by combining multiple sources of information (Jick 1979).

\section{Arguments for an inductive approach}

An inductive approach is applied in our case study research because we are interested in theorybuilding and not theory-testing. The outcomes of our literature review demonstrated that there is relative little research concerning our research field. For this reason, we incorporated the context of the phenomena of interest into the investigations. 


\subsection{THE RESEARCH DESIGN}

\subsubsection{Introductory remarks}

The aim of the research presented in this thesis was to investigate how organizations practice formal sales control. The research findings should help us to elaborate on the potential gap between theory and practice; and it implies that the following subjects should be discussed:

- How did we operationalize the theoretical consiructs? (4.3.2)

- What type of sampling did we use? (4.3.3)

- How did we collect, analyze and our data? (4.3.4)

\subsubsection{Operationalization}

A measurement instrument was developed for our project, and the elements of the research model were operationalized separately; each element consists of various items. The conceptual definitions of the variables in our model were translated into operational definitions; this operationalization was based on a literature review. The variables were operationalized as follows.

- Strategic planning. The strategic planning function is concerned with specifying the range of activities to be included in the company's mission, spelling out long term objectives, such as targets for revenue growth and return on investment, and establishing broad strategies for corporate and business unit levels. This function was operationalized as corporate mission, the number and types of long term objectives, object of planning. time horizons, persons involved in planning activities, planning procedure, extent to which objectives are attainable, assignment of responsibilities and link with sales control.

Sales management planning. Sales management planning was defined as selting of operational goals for sales operations and the establishment of standards for each goal. Furthermore it is used to assign responsibilities for strategy implementation. The control mechanism provides information necessary to direct or guide the sales force. The sales management planning function was operationalized as the business mission, the number and types of short term objectives, object of planning, e.g., annual plan and budget, time horizons, persons involved in planning activities, planning procedure, extent to which objectives are attainable, and assignment of responsibilities.

Sales force organization. The concept of "sales force organization" in our research was concerned with how an organization organizes its worldwide sales operations. This was described in terms of the relationships between the firm's head quarters, the regional and the local units. We used therefore described the structure of this organizational unit. Structure defines how tasks are allocated, who is responsible for the accomplishment of these tasks, what are the formal coordinating mechanisms and interaction patterng that should be followed. We operationalized this concept as extent of formalization, extent of centralization, extent of integration and extent of participation. It implies that we assume that organizational structure is seen as a control device per se.

Oufcomes. This concept include business performance, stich as tevenue and unit sold, and behavioral related issues such as employee satisfaction.

Performance measurement. The performance measurement function is concerned with the collection, analysis and transmission of information concerning realized sales results, at specified frequency. This information is distributed to specific, usually predetermined, groups of people. We operationalized this function as measurement of financial and nonfinancial performance, and both attributes were broken down into three subattributes: indicators, frequency and procedure.

Performance eraluation. We defined performance evaluation as assessing the performance of the sales force organization against preestablishedl objectives and standards, based upon the information provided by the performance measurement. To obtain a detailed impression of performance evaluation this element of our research model was broken down into the following attributes: evaluation of financiall and non-financial performance, and both atributes were further broken down into three sub-attributes: indicators, frequency and procedure.

Feedback. Feedback refers to the information process used to provide data on the employees "behawior and its sales outcomes. We can distinguish two types of feedback: corrective and evaluative feedback. Corrective 
feedback is used to direct the companyts sales force by prowiding the necessary information for corrective action and motivates behavior by serving as a promise for future rewards. Evaluative feedback provides information on the work goal accomplishments of the sales fonce. This information can be used to initiate corrective action, to reward or to punish, or promising future rewards or punishment. Both types of fieedback were operationalized as the sign of feedback, positive versus negative, frequency and procedure.

- Rewarding. Rewards are defined as outcomes of behavior that are desirable to salespersons and which can be either extrinsic or intrinsic. Extrinsic rewards are adruinistered after a performance evaluation, and they are tangible outcomes given to salespersons upon completion of their tasks. Intrinsic rewards are rewards that can be received and experienced by salespersons independent of performance evaluation. Extrinsic rewards were broken down into the following attributes: sales contests, incentive payments, commissions, and salary.

- Task control. We defined task control as the process of ensuring that specific tasks are carried out effectively and efficiently. Individuals within a sales force organization have specific tasks ro perform, and task control consists of comparing actual performance with the performance standards and taking appropriate action if there is a significant variance. These control activities are not also carried directly by managers; examples are order-entry systems and cash management systems. Furthermore, the employed performance indicators are not related directly to the company"s strategies, e.g. contribution to team performance and participation in specific projects. We operationalized task control as standardization of work processes, standardization of output, standardization of skills and assessment of individuall performance.

The items were translated into specific questions. We used these questions to obtain an insight into their realization, especially since our study tries to answer both "how" and "why" questions. The constructs and the related questions are illustrated in Table 4.1. 


\begin{tabular}{|c|c|}
\hline & \\
\hline $\begin{array}{l}\text { Salles force. } \\
\text { orgahization }\end{array}$ & $\begin{array}{l}\text { Can you describe the firm's (worldwide) sales force organization? } \\
\text { What is the role of the regional offices in the (worldwide) sales force organization? } \\
\text { What is the role of the local sales offices in the (worldwide) sales force organization? } \\
\text { How are business opperations formalized in the worldwide sales force organization? } \\
\text { How are business opterations formalized in the local sales force organization? } \\
\text { How is decision making authority centralized in the worldwide sales force } \\
\text { organization? } \\
\text { How is decision making authority centralized in the local sales force organization? } \\
\text { What type of integrating mechanisms are used in the worldwide sales organization? } \\
\text { What type of integrating mechanisms are used in the local sales force organization? } \\
\text { How do the differemt management layers in the sales force organization participate in } \\
\text { decision making? } \\
\text { Can you describe the influence of the worldwide product divisions in the decision } \\
\text { making at the firm"s sales force organization? }\end{array}$ \\
\hline Hegle plam & $\begin{array}{l}\text { What long tern objectives are formulated? } \\
\text { Are these objectives feasible? } \\
\text { Who is involved in strategic planning? } \\
\text { Can you describe the strategic planing process? } \\
\text { Is there a formal procedure for strategic planning? If yes, who described the strategic } \\
\text { plamming procedure? } \\
\text { Who supervises the strategic planning activities? }\end{array}$ \\
\hline $\begin{array}{l}\text { Salts manugem } \\
\text { planning }\end{array}$ & $\begin{array}{l}\text { What are the short term objectives? } \\
\text { Are these objectives feasible? } \\
\text { Who is involved in strategic planning? } \\
\text { Can you describe the planning process? } \\
\text { Is there a formal procedure for strategic planning? If yes, who described the salles } \\
\text { management planning procedure? } \\
\text { Who supervise the planning activities? }\end{array}$ \\
\hline Outcomes: & Can you describe the outcomes that your local office generate? \\
\hline $\begin{array}{l}\text { Performance } \\
\text { measurement }\end{array}$ & $\begin{array}{l}\text { What performance metrics are used to measure sales performance of a local office? } \\
\text { What performance metrics are used to measure sales performance of a local unit? } \\
\text { What is the measurement frequency? } \\
\text { How does the meatsurement process take place? }\end{array}$ \\
\hline $\begin{array}{l}\text { Performance } \\
\text { evaluation }\end{array}$ & $\begin{array}{l}\text { What evaluation devices are used to evaluate the sales performance of a local office? } \\
\text { How does the evaluation process take place? } \\
\text { What evaluation devices are used to evaluate the sales performance of a local unit? } \\
\text { How does the evaluation process take place? }\end{array}$ \\
\hline & $\begin{array}{l}\text { What type of feedback is given by the regional management versus local } \\
\text { management? } \\
\text { How does the regional office provide its local management teams with feedback on } \\
\text { performance? Frequency, topic, sign of feedback? } \\
\text { What feedback do the business units receive from their superiors? Frequency, topic. } \\
\text { sign of feedback? }\end{array}$ \\
\hline Tasl comirol & What tools are used to ensure that the employees carry out their tasks effectively? \\
\hline
\end{tabular}

Table 4. Constructs and related questions 
The operational defmitions helped us to decide how to measure the variables more accurataly and to elaborate on the comparability and reliability of our reseanch findings. It permitted us to elabonate on the comparability and reliability of the research findings. Eight pre-pilot interviews in various companies and two pilot studies in two industries were conducted; these were aimed at testing the questionnaire in terms of validity and reliability, and developing field procedures for the final study. These interviews offered us the opportunity to evaluate the questions in terms of "wording" and "sequence'. For instance, it appeared that some words used in the initial questionnaire were not well known, i.e. too academic, or ambiguous. The feedback of the respondents in the first interviews helped us to improve our questionnaire. Furthermore, the first experiences with collecting and analyzing case study results helped us to improve the field procedures in terms of efficiency and reporting. Table 4.2 includes the basic information concerning the pre-pilot interviews and tables 4.3 and 4.4 are used to describe the two pilot studies.

\begin{tabular}{|c|c|c|}
\hline Compinies & Aespononglomis & Number or intervicys (tionirs) \\
\hline Durch subsidiary of thanese Can Producer & Marketing mankger & $1(3)$ \\
\hline Dutch subsidiary of a Jopanese Car Producer & Sales manager & $1(1)$ \\
\hline $\begin{array}{l}\text { Dutch subsidiary of an US manufacturer of } \\
\text { copiers }\end{array}$ & Sales mangager & $2(4)$ \\
\hline $\begin{array}{l}\text { Bulgian subsidiary of US manufacturer of } \mathbb{U T} \\
\text { prodacts }\end{array}$ & Couniry matrager, marketing mandege & $2(4)$ \\
\hline Belgian retail bank & Marketing manager & $1(3)$ \\
\hline Duteh relail bank & Marketing manduger & $1(3)$ \\
\hline
\end{tabular}

Table 4.2. Pre-pilot interviews

\begin{tabular}{|c|c|c|}
\hline 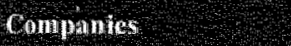 & Rasmonitents & 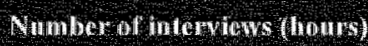 \\
\hline Large Dutch Tour opentor & General manager, office mathager & $4(10)$ \\
\hline Lurge Dutah Tour operator & General mantiger, office mantger & $4(10)$ \\
\hline Snal Dutch Tour operator & Genetal monanger, office mathiger & $316)$ \\
\hline Snatl Duteh Tour openator & General manager, oflice matinger & $3(5)$ \\
\hline
\end{tabular}

Table 4,3 Pilot study

\begin{tabular}{|c|c|c|}
\hline Gonupinnites & Respondents & 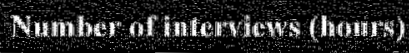 \\
\hline Dutch subsidiary of a US car phoducer & Geraerat mandger & $216 \%$ \\
\hline $\begin{array}{l}\text { Dutch and Bagian subsidialy of a Germath carr } \\
\text { producer }\end{array}$ & General matrages, marketing niansuger & $\$(6)$ \\
\hline Dutel subsidiary of a Cermata cas producer & Matkling manages & $2(7)$ \\
\hline Dutech subsidiary of a French car producere & General mathager, marketing manager & $4(8)$ \\
\hline
\end{tabular}

Table 4.4 Pilot study II

\subsubsection{Sampling: bounding the collection of data}

Sampling in case study research involves two basic actions (Miles and Huberman 1994). The researchers should first define the different aspects of the cases within the limits of their time and means. Thus, these aspects need to be connected drectly to the research question(s) of the project. Second, the researchers should create a framework to help them uncover, or qualify the basic 
processes or constructs that underpin their study. We used our pre-pilot interviews and pilot studies to develop and evaluate our sampling method.

Sampling is crucial for later analysis; it may place limits on the conclusions a researcher can draw, and on how confident others feel about the research that is done (Miles and Huberman 1994). Whereas case study researchers usually work with small samples, nested in their context and studied in-depth, quantitative researchers aim for a larger number of context stripped cases and seek statistical significance.

Sampling should highlight general constructs and their relationships, however, we are aware that there is a difference between quantitative and qualitative sampling. Whereas survey research relies on statistical generalization, case studies and other qualitative research rely on analytical generalization (Yin 1989; Firestone 1993). Thus, case study research is analytic and not 'sample-topopulation".

\section{Our sampling procedures}

The aim of our sampling procedure was to document diverse variations of sales control practices. In particular, the aim of the data collection was to obtain information to characterize and explain both the unique features of the case being studied and the features that the case has in common with other cases; it involved looking for outlier cases to see whether the main patterns of control practices still hold. We therefore developed a sample procedure based on an inductive research approach. The sample procedure consisted of two phases. Diversity was important because the purpose of the research presented in this thesis was to find potential explanations for control methods and practices grounded in the actual experiences of those making the decisions.

\section{Phase One: Initial Case Selection}

\section{Objective}

The aim of the first phase was to determine the extent to which sales control practices varied across the corporations. A sample size of eight companies was chosen because it was small enough to allow us to complete an intensive investigation within two years, yet large enough to ensure that the findings would not depend on the unique experiences of a few companies. The selection of the companies was deliberale in that a diverse set of companies was approached in the first phase of our research; we wanted to observe as full a range of sales control practices and relevant relationships as possible to make the research findings as rich as possible and to increase the possibility that the findings could be applied widely.

\section{Sampling criteria}

Various criteria were used in the first phase. First, potential participants of the research project had to be differentiated multi-site transnational organizations with wholly owned sales and customer support offices in Belgium and the Netherlands. This offered us the opportunity to conduct the case studies in one country, and to replicate them in at second country. This replication was necessary to ensure the quality of the case findings per company. Pre-pilot interviews with managers indicated that the wholly owned subsidiaries of computer firms ${ }^{2}{ }^{3}$ can be classified into three groups: direct sellers, indirect sellers, and mix of direct and indirect selling.

A direct seller is a company that distributes its products using owned subsidiaries. The company's sales force is responsible for selling the company's products in each market in which it is active. An indirect seller has no own sales force, and independent distributors sell the company's products. There are also companies that use both types of distribution channels to sell their products; though the importance of each of these distribution channels may vary from company to company. Furthermore, the companies all had to be players on the global IT market. Based on the outcome of an interview with an expert, a list of ten candidates was made. 


\section{Procedure}

We began the project in the winter of 1995 by requesting, by letter to senior management of the Iocal sales office research, access to the local offices of selected companies. The letter contained an explanation of the aims of the project, described the cooperation we were requesting, and listed our guarantee of anonymity with regard to describing the findings. This letter was followed up two weeks later with a telephone call, and ultimately the Belgian and Dutch subsidiaries of eight computer firms decided to participate in research.

The firms that agreed to participate were diverse. Our Belgian and Dutch samples consisted of two direct sellers (companies $A$ and $R$ ), two indirect sellers (companies $B$ and $O$ ) and four mix sellers (companies C, D, Q, and S). All companies were originally hardware producers; and market developments in the eighties had forced them to sell IT products and services.

- Two direct sellers were included in the sample, namely companies A and R. Both companies have a similar sales force organization. Their sales organization is divided into three or four regions. Each company has regional offices to coordinate the sales operations in these regions. These offices nonitor and supervise the sales operations of local settlements. The settlements are wholly owned subsidiaries responsible for salles operations in one specific country. Sales operations include personal selling, maintenance support and other services, and IT consultancy.

- Our sample included two indirect sellers: companies $B$ and $O$. Companies $B$ and $O$ have divided their sales organization into regions. Each region has a regional office that coordinates the sales operations of local settlements. These local settlements are responsible for the selling operations in one country. This implies that they have to build up and manage a newwork of independent distributors for their products. The local settlements manage the flow of the company's products to the independent distributors.

- Companies C, D, Q, and S have both a company's sales force and independent distributors for local sales operations. They all have a similar sales force organization. The sales force organization is divided into sales regions. Each region has a regional office that coordinates the sales operations of locall settlements. These local settlements are wholly owned subsidianies responsible for sales operations in one specific country. The sales operations include personal selling, maintenance support and other services, and IT consultancy. The subsidiaries also have to build up and manage a network of independent distributors for their products.

\section{Phase Two: $\quad$ Final Case Selection}

\section{Objective}

The choice was made to conduct an intensive study of a number of cases in our sample to gain a thorough understanding of what factors account for variation in control practices. Examination of existing records and semi-structured interviewing were used to collect the data; the research objective was one of seeking explanations rather than testing hypotheses.

\section{Sampling criteria}

A first analysis of the case data demonstrated that the companies under investigations have different organizational forms: functionally ${ }^{4}$ versus process oriented organizations. The initial case findings were analyzed, and it was found that the organizational form, functional versus process oriented, seemed to have a great impact on sales control practices. As a result, we decided to look for outlier cases to document diverse variations of sales control practices and to identify important common patterns to study the impact of a 'functional versus process culture'. We then reformulated the initial problem statement into "How are the dimensions of sales control systems', specified by our theoretical model, realized within functionally versus process oriented firms? How can this be explained?

\section{Sampling procedure}

The final case selection was based on the following criteria. As stated earlier, our sample of computer firms consists of eight companies. Five of the eight companies were characterized by a 
functional structure. Their sales activities were designed around specialization by individuals, and integrated through managerial levels in which decision making is set apart from execution. Two "functionally oriented" and two "process oriented" companies were selected as outliers to study their sales control practices in detail.

- With regard to the functionally oriented companies, it was found that the extent to which decision making is set apart from execution can vary. In our sample, there were two outlier cases: companies A and B. We requested participation from these companies because they are publicly held corporations with a headquarter in the United States. We approached publicly held corporations because they are more likely to face stockmarket pressures that lead to martagement myopia. The study was limited to US based corporations to contral for a broad range of cultural factors that would have limited our ability to synthesize our observations.

- Three of the eight companies in our sample employed a process culture in their sales force organization. Two companies $C$ and $D$ were selected for the following reasons. With regard to company $C$, it was found that the corporation had decided to implement process management in their worldwide sales force organization. This decision implied a fundamental move from a functionally to a process culture. The case reflected changes, and, in particular, abrupt changes in control practices; we thought that studying the adjustment to a process culture could be quite revealing of the control practices. Company $D$ was also selected for its process culture in combination with policy deployment. Policy deployment, also called "Management by planning' or 'Management by policy', develops short term action plans at each organizational level. Consistency for the overall strategy is obtained by linking these action plans to the measures derived from the policies. According to King (1989), policy deployment places great emphasis on individual autonomy and self management at the managerial level. This case offered us the opportunity to characterize and explain both the impact of process management and policy deployment on sales control practices, and to determine the features that the case has in common with the other cases.

\subsubsection{Data collection}

Overall, case study research will include the collection of data base on some or all of the following sources of evidence: documentary evidence, interviews, direct observation, and participation observation (Yin 1989; Brownell 1995). We used only documentary evidence and interview data in our case study research".

The documentary materials used included minutes of meetings, instructions and procedures, internal memos, published reports, and company information on the Internet. We gathered as many relevant internal and external documents as possible to validate the accuracy of the interview data Often much of the information to which we had access in our case study research was confidential. Thus, we agreed that the host companies could screen written material. This was done to make sure that we had properly understood what we were told during the interviews, we had reported all the relevant issues, and that we had not in advertently broken confidence. Interview data was the most importani category of evidence in our research, Table 4.5 shows the number of people interviewed in each company, classified according to role, and the number of hours of interviews conducted. Twenty nine individuals were interviewed, during seventy seven meeting hours. 


\begin{tabular}{|c|c|c|c|}
\hline Conilarar & 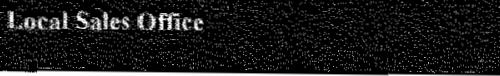 & Inhorvinge Hows & $\begin{array}{l}\text { Monl lantronitay } \\
\text { momss }\end{array}$ \\
\hline $\mathrm{A}$ & 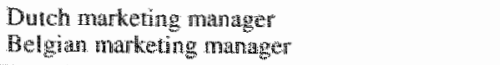 & 4 & 8 \\
\hline मf. & 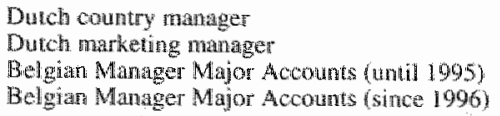 & $\begin{array}{l}2 \\
2 \\
2 \\
4\end{array}$ & 10 \\
\hline $\mathrm{C}$ & 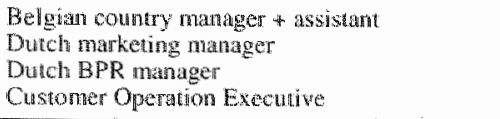 & $\begin{array}{l}2 \\
6 \\
5 \\
2\end{array}$ & 15 \\
\hline ए। & $\begin{array}{l}\text { Belgian sales manager } \\
\text { Belgian ravkethng nathager } \\
\text { Dutch country mangaer }\end{array}$ & $\frac{2}{2}$ & 10 \\
\hline 9 & 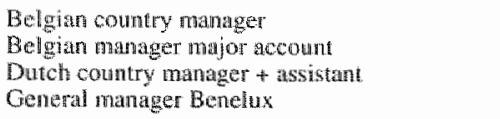 & $\begin{array}{l}2 \\
2 \\
2 \\
1\end{array}$ & 7 \\
\hline ४ै। & $\begin{array}{l}\text { Dutch marketing nandger } \\
\text { Dutch salto manager } \\
\text { General manager Benelux } \\
\text { Belgian general manager }\end{array}$ & $\begin{array}{l}4 \\
2 \\
4 \\
2\end{array}$ & 12 \\
\hline Rे & $\begin{array}{l}\text { Belgian maketing manager } \\
\text { Dutch marketra nathager }\end{array}$ & $\begin{array}{l}4 \\
3\end{array}$ & 7 \\
\hline $\begin{array}{ll}4 \\
+4\end{array}$ & $\begin{array}{l}\text { Dutch gereral manager } \\
\text { Dutch marketing manager } \\
\text { Dutch marketing manager assistant } \\
\text { Belgian major account manager }\end{array}$ & $\begin{array}{l}1 \\
2 \\
1 \\
4\end{array}$ & 8 \\
\hline
\end{tabular}

Table $4.5 \quad$ Summary of interviews conducted

All interviews were conducted on a one to one basis, between the researcher and a manager. Control over this interview process lay with the interviewer who attempted to put the interviewee at ease by using effective interpersonal skills and the willingness to reword questions if necessary. Open questions were used throughout the interviews in this case study research. This type of guestions was used to encourage respondents to expand on their own experiences. Thus, we obtained a wealth of detailed information from the managers in this study. We used a semi-structured interview to ease in depth exploration of the managers" perceptions of the sales control practices, and to assure for asking the same questions at each participating company.

The interviews were costly and time consuming both in terms of organizing and traveling to the interviews and length of the interviews. They lasted between 60 and 320 minutes. We taperecorded and then transcribed all interviews to a typed format for analysis. As interviews involve a form of self reporting, we had to assume that the information given by the managers was accurate (Burns and Grove 1987). Moreover, we checked and cross checked the information during the interview or afterwards. When issues were unclear or (partly) contradictory, we confronted our interviewees with these 'problems' and asked them to clarify the right answer. The data sought in this research relied on managers' perceptions and experiences. Although this does not threaten the vallidity of the findings, it must be taken into consideration during the analytical process.

\subsection{ON THE LIMITATIONS OF THE RESEARCH METHOD}

Apart from the aforementioned advantages, we are aware of the limitations of the case research method. It is necessary to be aware of the limitations of the method when assessing the value of the 
results obtained using cases studies (Lee 1989). Case study research (CSR) is widely used in the organizational and marketing science to investigate phenomena of interest. While providing an important contribution to knowledge, this research method suffers from several weaknesses. Some of these are that:

- CSR is largely descriptive. Although CSR is largely descriptive, it can be used to highlight the experiemces of sales management practitioners Yin (1989:12) said that "... empirical research advances ondy when it is accompanied by logical shinking, and nor when it is treated as a mechanistic endeavor." CSR is preferred when "how" or "why" questions are being posed, when the tesearcher has little control over events and when the focus is on contemporary phenomena (Yin 1989). CSR can be used lo focus on a work site such as an organization or department, events and activities or a person (Bryman 1989). Many classic case studies into control practices have been undertaken in management, including that of Brownell (1981). In our research, we focused on the nature of sales control practices by investigating the descriptive value of our conceptual model. On the basis of the analysis of our cases we examined whether the actual practices structurally diffet from our model. If not, out model can be used as a theoretical framework to transfer the relevant aspects to those companies that wish to design an effective sales control system.

- CSR is very time consuming (Bonoma 1985; Biemans 1990) and labor intensive (Simon et al. 1996). First, catio study research is not only time consuming for the researcher in terms of gaining access to an organization and collecting data but also a considerable amount of time is expected from the respondents at the organization. This limitation may considerably restrict the number of cases that can be investigated (De Ruyter 1993). To deal with this problem, we used the following tactic. We sent questionnaires in advance to interviewees so that they could prepare for the interviews. Additionally, a great deal of information could be obtained beforehand Thus, we could prepare ourselves and pose the relevant questions right away. Second, case study research has a labor intensive nature. For instance, processing interviews is a laborious task. One can do the field work oneself (see De Ruyter 1993) or employ research assistants (see Dawson 1994). We used the second approach. Most of the research assistants were hired and trained to conduct case studies in one industry and in one country under direct superviston of the author. Furthermore, the author also joined them in the first interviews.

- CSR implies exercising caution in ganing the trust and support of host organizations. We were usually given a high degree of access to company documents and personnel. If sales managers at lower levels in the company were interviewed, they can be reluctant to be open with comments if they consider the comments might be likely to reach the ears of management. Dealing with this difficulty associated to case study research requires tact (Simon et al. 1996). One tactic that was used to deal with this limitation was to promise a company that its name and the name of its employees would be disguised. Additionally, during the research process we allowed the companies to read draft papers before public release to check for confidentiality and accuracy.

Several authors have highlighted the fact that case study research (CSR) is often criticized for failing to address clearly issues of validity and reliability in their studies (see Yin 1989; Parkhe 1993; Simon at a1. 1996). Some criticisms against case study research are justified, while others reflect a basic misunderstanding of the roots of the case study method (Parkhe 1993). Research 'purists" tend to see case studies as 'lacking academic rigor' (Simon et al. 1996) or as 'a weak sibling among research methods" (Yin 1989). Assessing the reasons underlying these reservations is important because case studies represent fundamental shift in research orientation for many researchers (Parkhe 1993).

The literature on research methodology and techniques shows that four tests are relevant to judge the quality of any case study design: construct validity, intemal validity, external validity and reliability. The rest of this section will be directed at describing how these tests were used as a ramework to address the reliability and validity in this research study. We formulated carefully our tactics to minimize the effect of the aforementioned limitations. Four tests were used to assess the quality of the research findings: construct validity, internal validity, external validity and reliability. These four tests are summarized in Yin's book, Case Study Research: Design and Methods. A specific strategy was developed for each issue. 


\section{Validity}

As said, a limitation of CSR lies in the validity of the research results (see Campbell and Stanley 1966; Yin 1989). The development of a framework for case study designs begins with the identification of a set of core principles necessary to judge the adequacy of case designs (Brownell 1995). An important consideration in developing case study designs is, therefore, to create research designs with construct, internal and external validity ( $Y$ in 1989:40-45). Overall, these criteriat of validity are defined in the same identical manner in case study research as they are in quantitative research, although case study researchers must make distinctions in terms of tactics for dealing with these tests.

Construct validity. The first test of validity deals with the use of measures that operationalize accurately the constructs of interest in a study (Yin 1989). Researchers who are critical of CSR often point out that constructs are operationalized subjectively (Yin 1989 and 1993), and that subjective judgments are used to collect data (Y in 1989 and 1993). Furthermore, the research results depend largely on the subjective interpretation of the researcher (De Ruyter 1993). Thus, errors and biases may easily occur. We employed five tactics to increase construct validity in our case studly design:

- operationalization of theoretical concepts based on existing literature on control practices (De Ruyter 1993)

- a number of pre-pilot interviews (De Ruyter 1993; Appleton 1995) and a pilot study were conducted (Yin 1989)

- multiple sources of evidence were used (Yin 1989)

- a chain of evidence was established (Yin 1989)

- key informants had to review a draft case study report (Yin 1989).

First, the operationalization of constructs was developed from a theoretical perspective in the previous chapters. We tried to establish correct operational measures for the concepts being studied by establishing close links with theory. Insights of previous research into management control, management accounting and sales management Jiterature were also used.

Furthermore, several pre-pilot interviews and a pilot study were conducted. Methodologically, these interviews and the pilot study provided information about relevant field questions and about the logic of the field inquiry ( $Y$ in 1989). The pre-pilot interviews were conducted to establish a practical and theoretical basis for the operationalization of the constructs of interest in our study. We tried to avoid subjectivity in the collection of data as much as possible by estublishing a case study protocol and formal data collection plan ${ }^{6}$. Besides the documentation and identification of all authorities, approvals and endorsements provided by members of the organization(s) that hosted the study, these procedures were also used to identify the range of data collection techniques planned. Experiments with variations in field procedures were done during the pilot case studies, tradeoffs were acknowledged, and, finally, a satisfactory procedure was developed for the format data collection plan.

Other tactics to deal with construct validity mentioned in the literature on research methods are the use of multiple sources of evidence such as documentation and interviews, and establishing a logical chain of evidence when deriving conclusions from the data material. At the end of data analysis, the researcher returned to the company and discussed the interpretation of the study findings with the manager. We obtained relevant feedback by writing a company report based on the analysis of the interview data. This report was sent to the interview partner for correction and feedback. When the report still showed "leaks", a second or a third interwiew was arranged. In this interview it was also possible to discuss the feedback of the manager with respect to the company report. Again, the tape of the interview was transcribed. Conducting interviews with Belgian and Dutch managers at different management levels ${ }^{7}$, at different points in time provides a form of triangulation by data source. Finally, a definite company case report was written, which was sent to the company for approval. 
The aim of this exercise was to present the study findings to the managers but also to check the credibility of the analysis and to see if the research findings reflected the manager's own experiences and perceptions of the concept of sales control within the company. The remarks of our respondents were used to adjust the case reports.

Internal validity. The second test of walidity concerns the problem of establishing causal relationships, as distinguished from spurious relationships, by which certain conditions are shown to lead to other conditions. Yin (1989) stated that internal validity is a concern only for causal or explanatory studies. This type of study is concerned with making causal statements: the investigator is trying to determine whether event " $x$ " led to event ' $y$ ".

Note that this logic is inapplicable to descriptive or exploratory case studies as these case studies are not concerned with making causal statements. Overall, case study research cannot be used to highlight causal relationships in the same way that experiments can (see Carthy 1988; Yin 1989). We used multiple sources of evidence and the feedback of respondents to investigate alleged causal relationships in the interpretation of our case results. Our respondents were also asked why some issues occurred or not.

External validity. The third test of validity deals with the problem of knowing whether our research findings can be generalized beyond the specific situation of the case to a wider population (Yin 1989). Critics of case study research often state that the results of a study with a limited number of cases cannot be generalized (Yin 1989). They often contrast implicitly the situation to survey research, where a sample, if selected correctly, readily generalizes to a larger universe (Yin 1989). Yin (1989:43), however, states that "This analogy to samples and universes is incorrect when dealing with case studies. "Whereas survey research relies on statistical generalization, case studies rely on analytical generalization (Yin 1989).

A case study researcher tries to generalize a particular set of research results to some broader theory. In this replication logic, it is important that the theory is developed for a variety of cases. Furthermore, it is necessary to investigate whether the conditions specified from the theoretical perspective can be found in diverse practical situations. Testing a theory through replications of the research findings in a second or even a third situation should help researchers to evaluate whether their research results might be accepted for many situations (Yin 1989).

Two tactics were employed to deal with extemal validity. First, we developed a multiple case design. Second, another tactic that can be used to deal with limitations conceming external validity is to collect data from diverse cultural settings (see e.g. Van de Vijver and Poortinga 1982; Albaum and Peterson 1984; Jahoda 1984; Daft 1984; Hui and Triandis 1985; Grunert et al 1989; Jain 1989; McCarthy 1989). Both tactics were employed in our case study research into the IT industry. We approached the Belgian and Dutch subsidiaries of the eight IT-companies. Overall, the European offices of these companies did not participate in our research. The replication logic helped us to improve our research findings for at specific company and an industry. Our case results of one local settlement might be more detailed for the whole sales organization of a specific company by the replication of the research findings. Thus, the quality of our research findings was higher for generalizing a particular set of results to a theory.

\section{Reliability}

A second limitation of CSR lies in the reliability of the results. Reliability can be defined as the degree of consistency with which an instrument measures the attribute it is designed to measure (Polit and Hungler 1991). It refers to consistency, repeatability, replicability or stability of a study in terms of the clarity and accuracy of the research (see Brink 1989; Powers and Knapp 1990; Appleton 1995). Yin (1989:41) describes the criterion of reliability as "... demonstrating that the operations of a study - such as the data collection procedures - can be repeated, with the same 
resuls." "Thus, a later investigator should be able to repeat an earlier case study, with the same results. We employed the following tactics.

The procedures followed in our project were fully documented to allow a later investigator to repeat our case study research; a detailed and consistent research strategy was designed to help a later researcher to follow closely in our footsteps (Eisenhardt 1989). To take as many steps as possible and to conduct CSR as if an external observator was always looking over the reseancher" shoulder helps to improve the reliability of the case study outcomes ( $Y$ in 1989). Case study researchers should create a case study data base. This second tactic for dealing with difficulties concerning reliability deals with the way of organizing and documenting the data collected for case studies (Yin 1989).

As stated earlier, the interview data is the most important category of evidence in our research. Thus, the interviewer was the data gathering instrument. The reliability of the collected data is therefore dependent upon the competence and ability of the researcher's interviewing skills and on any researcher bias (Guba and Lincoln 1981; Field and Morse 1985; Appleton 1995).

We first carried out a number of pre-pilot interviews to develop proper interviewing skills for this research area in an attempt to increase interviewer reliability. Realistically, it is likely that as the study progressed and the researcher's interview technique developed the quality of the gathered data. also improved (Appleton 1995). Additionally, we developed a standardized interview schedule to increase the consistency of the gathered data (Brink 1989; Appleton 1995). Furthermore, we always used a tape recorder to recond all interviews. Finally, the research assistants listened to each tape from their research project, and transcribed each tape themselves within five days.

\subsection{SUMMARY AND CONCLUDING REMARKS}

\section{Reasons for selecting the case study method}

In this chapter we discussed our research method and strategy. We selected case study research as our research method to examine how organizations control their sales effort. The arguments for selecting a qualitative research method ate based on the nature of the research questions. Our research questions are "how' and "why" questions. In particular, we want to know:

- How the sales control process takes place in practice, and what formal mechanisms are used?

- How are the dimensions of sales control systems, specified by our theoretical model, realized within the different types of sales organization. and how can this be explained?

"How" and "why" questions can best be answered by using qualitative methods. The phenomenon of interest is an important criterion in selecting a research method. We believe that sales control practices cannot be fully understood in isolation and that it is therefore necessary to place them in their wider context. We can confront the business practices with existing theories by investigating sales control practices in real life situations and combining multiple sources of information. This may help us to check and inspect the cases for indications against which existing theories wam, and to add to the plausibility of a theory by making teferences. Key arguments for the case research method are identified below:
- Case sudies are useful for description and explanation building
- Case studies can be used to establish the descriptive walue of a conceptual model
- Case studies deall with both the phenomena of interest and context
- Case studies are characterized by a high flexibility

\section{Balancing 'open mindedness' and 'focus' in the field study}

An intensive study of a number of cases in our sample was conducted to gain some idea of what factors account for variation in control practices. The decision to do this emerges from the fact that explanations for variations are not well documented in the literature. Glaser and Strauss (1967) suggested that researchers should not commit themselves to a prior theory at the outset of a field 
research; however, it has also been stated that a 'clean' state is difficult to achieve and that unfocused data collection may overwhelm the researcher with information (Eisenhardt 1989). The following research design was set up in such a way that it allowed us to gradually shift from exploratory to explanatory to maintain a balance between open mindedness and focus.

\section{From exploratory to explanatory research}

The early exploratory stage of the research was to study the control practices of IT companies and to examine variations in control practices observed at the research sites. After eight companies were visited and their sales control systems were documented in exploratory cases, the initial broad research question "How are the dimensions of salles control systems, specified by our theoretical model, realized within different types of organizations? How can this be explained?' became more focused: 'How are the dimensions of sales control systems, specified by our theoretical model. realized within functionally versus process oriented firms? How can this be explained? Furthermore, a preliminary explanation about how functionally and process oriented firms designed their sales control systems was formulated based on the evidence from the exploratory cases. This theory was used as the starting point for the explanatory field research in which the more focused research question regarding the variations in control practices was examined, and it was further enhanced based on evidence from four extended case studies, i.e. companies A, B, C and D. The end result is thus a more mature theory about sales control systems for functionally versus process oriented firms.

\section{On the limitations of the case study method}

We are aware that case studies are the target of much scepticism in the scientific community. These criticisms are primarily related to the following topics.

- Case studies are largelly descriptive.

- Conducting case studies is very time consuming and labor intensive.

- Case studies imply exercising caution in gaining the trust and support of a host organization.

- Case study researchers are often criticized for failing to address clearly issues of validity and reliability of the research.

- Case studies do not allow for generalizations.

Our research strategy was developed carefully to cope with these criticisms. The research design included the instrumentation, the sampling criteria and procedure, and the data collection method. Furthermore, we presented a step by step description of our attempts to cope with the limitations of case study research related to validity and reliability.

This concludes the discussion of our research method. Next, the outcomes of the case study research will be presented. These case studies form the core of this book. The first two case descriptions include research findings concerning two functionally oriented companies, i.e. companies $\mathrm{A}$ and $\mathrm{B}$; the last two case descriptions are related to the two process oriented companies, i.e. companies $\mathrm{C}$ and $\mathrm{D}$. The case descriptions are structured in four parts:

- sales force organization

- strategic planning

- sales management control

- task control 


\section{Notes}

1. This thesis is not written from the perspective in which an explicit comparison between theory and prenctice is made. We will reference the final conclusions to a number of concepts that have recenty emerged in various mantgement disciplines focusing on control pratices in organizations.

\section{The basic arguments for choosing the IT industry as subject of research were:}

- nulti-market competition; many companies are differentiated, offering mix of havdware, sof ware and services and consequently enter competition with each other in different markets, which limits the influence of the product-mix on the research

- the presence in large numbers of globol competitors on the Bielgian and Dutch market; many organizations that contest each ather in the computer market internationally do have sales and customer support offuces in Belgium and the Netherlands as well.

- the abundant availability of company and statistical information; since most computer conpanies are global players corporate information as well as documentation on those organizations and their products in technical magazines is abutidantly awablable.

- industry in which services become more important thus resulting in different control mechanisms, according to chapter 3 .

3. We also selected the banking industry as subject of nesearch. The basto for choosing this industry were quite similar as those of the IT industry:

- presence in large numbers af lox al competitors on the Belgian and Dutch marcet

- the nature of financial services; financial services are highly standardized, so the influence of the services in question on contutol are neglectable.

- the mulu-manket competition; a large number of bank is differentiated, of fering a mix of financial and nonfinancial services (e.g. insurance), and consequently enters into conpetition with each other in different matkets, which limits the influence of the product-mix on the reseach.

- the sales force organization; a large number of local competitors has sales force organization are relatively comparable (homogeneous) in lernus of tasks, responsibilities and size.

- the abundant availability of company and statistical information.

Although the banking industry is an interesting subject of research, the research findings in the first phase were somewhat disappointing in terns of variation in control practices. It was found that the elewen banks in our sample, five Belgian and six. Dutch banks, have almost similar control practices. These similarities can be explained by the fact that the banking industry has some specific business risks. The specific business risks and governmental regulations witli respect to accounting practioes are caused by:

- the need to match borrowed funds with loaned funds

* the long time horizon of certain transactions

- the transfer price of money (Anthony 1988)

The need to match borrowed funds with loaned funds, implies those lending employees need guidelines to their authority to lend at prescribed rates and maturities, and these guidelines require knowledge of the current pattern of deposits (Anthony 1988). The information needed to decide on the guidelines, to communicate them, and to ensure that they are adhered to, needs to be prompt and accurate. As the time horizon of certain transactions is iong, it is difficult to estimate the proficability of the individual transactions.

The performance of the person involved, mostly the lending officer, needs, however, be judged current by, and compensation should be judged on this perfomance, if possible, also, methods of identifyng likely problem loans or canceled policies are essential. Since transactions that generate revenues for a fibuncint institution ane made by different departments from the finamcial institution that obtan funds from deposits, fees, and other soures, trunsfer prices have to be established. Overall, banks often develop quite similar job descriptions, delegation system, and guidelines concerning management planning and reporting to cope with these specific tisks.

4. Ir functionally driven companies, business processes are organized around functions (see Hammer and Champy 1993: Watson 1994). A function refers to a specified type of work applied to a product or service moving within a process. The functions are generally described in a bpical hierarchical organization churt. This chart breaks down the various hierarchical functions from the chief executive office of the company through successive layers of management to the individuat employee who fores the customer, i.e. in a top down form (see Watson 1994). The cmoloyes are grouped according to the major edtegory of work activity. As work crosses the functional boundaries of the organization, intemal suppliers and internal customers are created, and responsibilty for the resources and controls applied to the work changes hands. Employees are motivated to follow functional rules and conserve resources (see Hammer and Charmpy 1993). This hierarebical (vertical) organization simplifies employee supervision and training and maximizes the managerial span of control, will little dependence of the free flow of information.

The concept of process management states that work can be organized and managed as an end to end process, rathar than ws the aggregation of disjowned functions (Gadd and Oakland 1995). The focus is on the key processes for the organization, which provide walue for its customers (Born 1994). "The term "process" is referring to the flow of work through an organization beginning with external suppliers and onding with external customers. Along this flow of work, value is adided at each step through a series of transformations. These transformations Anclude the consumption of resources using an established control (rule based) framework (Gadd and Oakland 1995). The processes are decomposed into subprocesses, activities, tasks and operations.

Process managenent includes the assumption that process improwement can only take place in an 
organzation once it has adopted a process management philosophy. This modem form of management pracher wrally emphasize strategic and company wide intorovements. The primary reason for this is thet process innprovement is both attaned and constraned by existing business processeg, organizanonal sumchures, and the ingtalled technology base (e.g. Born 1994. Watson 1994).

The concept of process inprovernent includes two levels of improvements continuous viz. radical. Contmuous proces improvement is closely associated wih the Total Quality Management (TOM) discipline (Gadd and Oakliand 1995). TQM is based on empowering of self managed teams to make task level improvernent in guality cycle time, and costs. These improvements are usually creative responses to the constant need to get the job done in changing circurnstances.

Radical process improvement is often undertaken in response to dratuatic changes in the axtemal enviroment that apply considerable pressure on the company's ability to fulful its mission, to improve its connethtive positioning, or even to survie. This 'starting over' or "reengineering" in the broadest sense, and can be defined as "... the fundamental rethinking and radical redesign of burness systerts to achieve dramatic

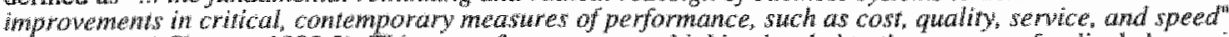
(Hammer and Champy 1993:2). This type of mamagement thinking has led to the concept of radical change an an or 2 anizarion based on total redesign of the processes involved and taking into account the full power of 1 wechology (Bom 1994).

5. The prosess of doita collection and analysis in our research project was iterative and tervative in nature. The formal procedure developed for this research project consisted of the following steps:

\section{Duta collection}

We used only dowmentary evidence and interview data in our case study research. Much of our collected information was confidential. Thus, we agreed that host companies could sereen written material before public release. Although most companies encouraged anore critical assessment of their sales comtrot activities, we used discretion in what intormation was used publicly. Interview data was the most important category of evidence in our research. All interviews were conducted on one to one basis, between the researchen and a respondent. As interviews are a form of self-report, we assumed that the information given by the managers is accurate (see Bums sted Crowe 1987 ). During the interwiews we cross checked opinions.

\section{it. Presenting the texts in a readable and wanageable form}

Before sye stematically wralyzed our data, we first employed data reduction to present the data in a readable and matrageable form. We ellicited meanings and insights from the words of respondents (Marshall \& Rossman 1989; Applation 1995 ) and used the following tactic. Data collection and analysis were conducted by a research team consisting of the researcher and research assistants.

We listened to each tope of his research project, transcribed ach tape ourselves and then read each transcript severat limes to familiarize ourselves wh the data. In the initiall stages of the data reduction. each line of an interview transcript was numbered acoording to the key control issues in the interview schedule, from one to seven. Seven question folders were produced, one for each topic of our model: strategic planming, sales matragement planning, performance measurement, performance evaluation, feedback, task controll and organization structure.

Once coded, the folders were divided up into relevarth question sections and each section was filed up into an appropriate question folder. This meant that all the mangers responses to our questions were assenbled together. The resetrchers read each tratascript several times to familiarize themselves with the collected datan and studisd the question folders.

An original copy of ench manscript was kept neaby so that the research assistant could refer any passages bing to the orignal section in the transcript to ensure that all the comments of the respondent were analyzed in context.

\section{Preliminary ordering of the material}

To maks the data nore mangeable, the data in each of the seven questions folders were reanalyzed and broken down in soveral categortes and subwheadings per questions. These categories and sub-headings were collated and ghtwed together on paper. This process of establishing and labeling of categories is called "latent content analysis" (Fidd and Morse 1985; Applegate 1995).

During this process the research assistant and he projec manager continuonsly questioned and challenged the chwerging patterns of the data (Marshall \& Ross onan 1989). If the data was incomplete, a second or third interviow was organazed.

\section{ii. Awolysis of the matherial}

At this stage of the data andysis, the categories in the interview data were compared with documentary materials and the qualitave data obtuined anlien, i.e. pre-plot interviews and pilot study, so that linkages and potential hypotheses could be followed and checked with our theoretical framework.

The data were analyzed critically and questioned and seven descriptive themes emerged. "The seven themes ware as lollows: strategic planning, sales managend plantuing. perfomance measurement. performance whtulion, rewarding, feedback and task control. We then reviewed these themes within the context of each intervien to increase validity.

At the sal of datanalysis, the reseancher or the assistant returned to the respondent and discussed their interpretation of the study findings with the managen. The ain of this exercise was to present the study findings to the manages to check the credibility of the analysis and to see if the research findlings retlected the manager's own experiences and perceptions about the notion of salles control.

\section{iii. Data display}

In the study, the qualitative data was presented as a natuve text. The data display reflected the emergence of the 
seven descriptive themes and was further enhanced by tables. A final report incomporating additions and changes was written and sent to participants in the research. They could check whether suggested changes wert appropriately reflocted in the case description.

Cross case analyses were written. We must necognize that each individual case study in the program consisted of a "whole" study, or a standalone entity, in we sought which convergent evidence regarding the facts and conclusion for the case. The facts and conclusions were then considered the intormation needing replication by other individual cases ( $Y$ in 1989). Detail descriptive data related to individual cases will be included in tables that correspond to sectuons in the text. We evaluated the results of the cases in the light of theory.

\section{iv. Concliston drawing}

We veritied conclusions as the data analysis proceded and we tested the validity of the data. Various techniques were developed and employed to improved the validity of the case tindings. These techniques are described in section 4.4

6. The data collection procedure developed for our research was vary strict and detaled. We are aware that formalizing data collection improves the reliability and validity of research but at the same time it might decrease the researcher"s tlexibility to examine compary specific topics in detail.

7. With regard to the computer industry, we approathed three groups of managers" the country mamgers, makketing managers and business unit managers. There were reasons for approaching these persons. First, they are intersively inwolved in sales management activities at country level. They communicate with tho reglonal office to set targets for the local settlement and allocate required resources. Additionally, they keep the regional office infomed about those outcomes of local sales operations. With respect to business unit managers, we were particularly interested in noeting business unit managers who were also involved in planning activities at corponte and regional level. We were able to describe the planning and controlling activities at these organizational levels by interviewing these persons. These managers are involved intensively in translating the goals of the local settlement into targets for business units and salespersons. In two cases, we were able to intervew the manager for Benelux. 


\title{
Chapter 5 \\ Comparative Case Analysis
}

\author{
Sales Control Practices in the IT Industry
}

\section{Chapter outline}

The aim of this chapter is to recapitulate the material presented in the four case studies and to provide a synthesis of the sales control practices that were explored. The research findings were approached from both a descriptive and an analytical perspective in the case descriptions. The similarities and differences of the key control devices will be discussed in this chapter. The research findings are presented as what we call a 'mega case' to avoid tedious repetition and to increase the comprehensibility of the research findings. We structured this chapter as follows.

The chapter is split into four parts. The first part, section 5.1, consists of an evaluation of the general case findings. The aim is to provide the reader with guidance regarding how the companies in our sample controlled their sales activities. The similarities and differences between the companies under study are examined in detail in sections 5.2 to 5.5 ; each section also includes a detailed overview of the findings. Section 5.2 includes a discussion of the similarities and differences found between the functionally and the process oriented IT companies with respect to the sales force organization; the issues are related to formalization, centralization, integration and participation. Section 5,3 is used to highlight similarities and differences in strategic planning between the functional and process oriented companies. The similarities and differences in sales management control practices are examined in section 5.4. Task control practices are discussed in section 5.5. Finally, the general conclusions that can be drawn from the comparative case analysis are given in section 5.6 . 


\subsection{EVALUATION OF THE GENERAL FINDINGS}

We can conclude, on the basis of the description of the four cases from the IT industry, that the companies under study have a great deal in common. Strategic planning, for instance, was used to formulate guidelimes for sales management planning and its basic outcomes were stated in a strategic plan covering a period of three to five years. These guidelines were used to formulate operational targets, annual plans, and action plans.

Performance review cycles were used to assess progress to plans, and feedback on performance was used to initiate timely corrective action. The outcome of performance evaluation was also used for rewarding purposes. These control processes take place in the company's control system that is part of the sales force organization. The sales force organizations of all companies under investigation had common characteristics in term of formalization, centralization, integration and participation. In sum, the functionally oriented and the process driven organizations had highly integrated control systems that were used to support management with respect to strategy (re)formulation and implementation.

Besides these similarities, it was found that there were important differences among the firms in our sample. One of the explanatory factors was the nature of the organizational forms: functionally versus process oriented organization. Other factors were size, origin and having settlements in many countries in conjunction with differing business environments.

Our case analysis indicated that the type of organizational form was an important variable to explain variances in control practices. For instance, it appeared that the process driven companies in our sample had a highly integrated and more comprehensive control system with many topics/disciplines. Their control system was built around a specific set of principles, tools and techniques derived from TQM principles. The TQM principles included concepts such as customer focus, employee empowerment, process management and control, continuous and breakthrough improvement, management by objectives and analysis and root cause problem solving. At companies $\mathrm{C}$ and $\mathrm{D}$, the control system was used to drive reengineering in the sales force organization. Improvement cycles are used to stimulate breakthrough improvement.

Detailed information about the similarities and differences between functionally and process driven organization are discussed in the next sections, 5.2 to 5.5. The theoretical framework was used to structure the outcome of the case analysis, see figure 5.1. 


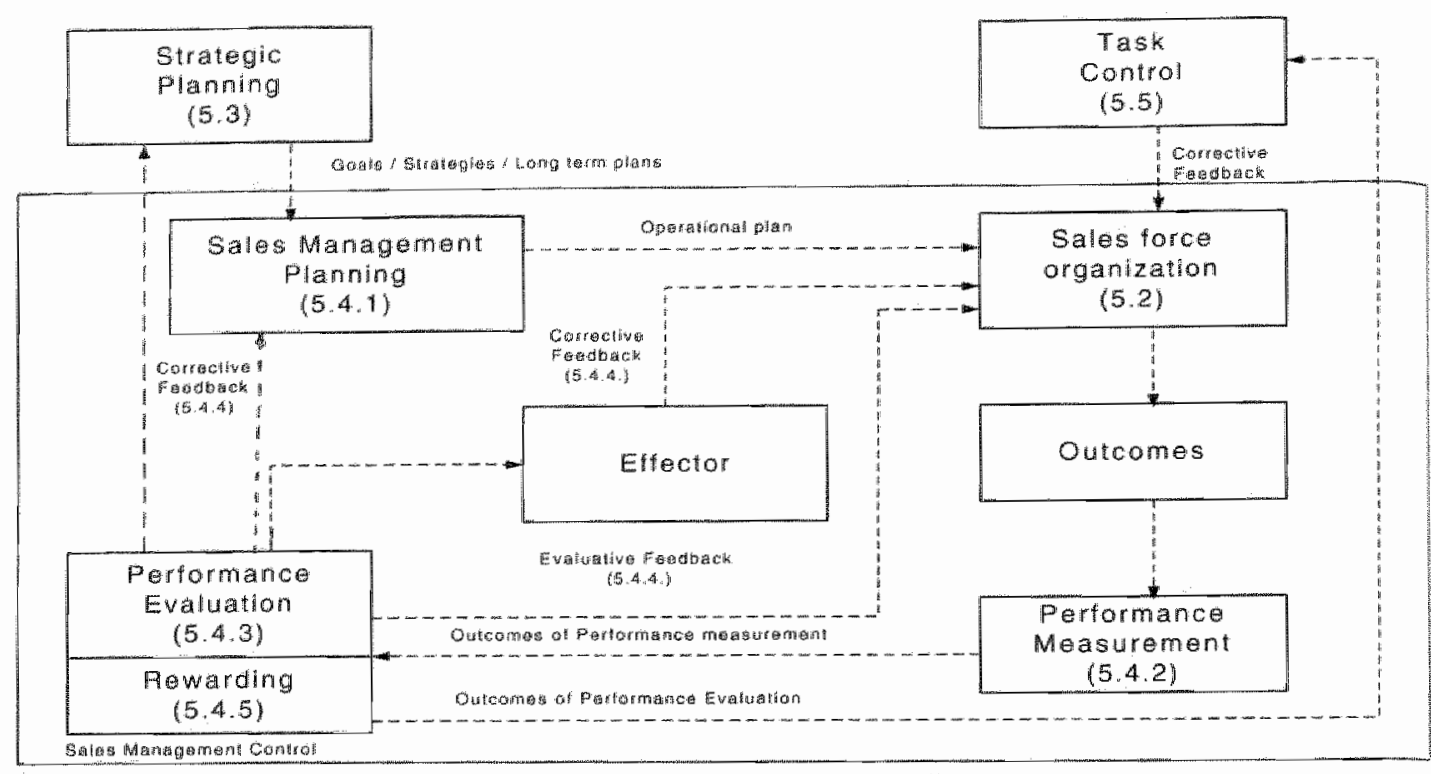

Figure 5.1 Theoretical Framework: The Control Process in a Sales Context

\subsection{THE SALES FORCEORGANIZATION}

\subsubsection{Formalization}

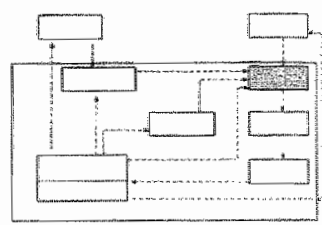

\section{Similarities}

The companies under investigation employ similar forms of formalization. The major forms are "structuring business operations", "function and job descriptions", "ISO 9000 handbooks', and" 'training programs'. Furthernore, our research findings demonstrate that the hierarchy, i.e. line management and superiors, is generally responsible for checking whether rules and other forms of formalization are applied. An external audit is conducted by an ISO consultant at all companies under study. Some of the key findings concerning formalization are listed below.

At three of the four companies, headquarters imposed an organizational chart on the regional and local sales offices, the one exception is company $\mathrm{A}$. The structure of its subsidiaries in Belgium, the Netherlands and Luxembourg was designed by the Benelux organization. It was found that the market situation in the Benelux required an adapted market structure in comparison to other $\mathbb{E} C$ markets. At all the companies, the locall sales units are wholly owned subsidiaries of the parent company: they are profit centers with operating responsibility which implies that they are responsible for the implementation of the strategy of the parent company and, they are responsible for sales in that country either through their own sales force or by using an additional dealer/business partner network.

The lask environment of local sales offices is described in general terms, headquarters imposed a specific product/service mix on the local sales offices. At three of the four companies $(B, C$ and $D)$. there were quite detailed function descriptions for some positions, e.g. country and business unit managers, and technical positions such as product managers; the related task descriptions were formulated by the local management. At company A, there were predefined sales positions and related titles; the tasks per sales position were described by the local management. $A$ task description generally included objectives and priorities, and a profile. Occasionally, there were 
some comporate guidelines for jobs. These corporate guidelines were, however, restricted primarily to technical jobs with respect to knowledge and skills. Headquarters also indicated the type of selling activities: direct selling (company A), indirect selling (company B), direct and indirect selling (companies $\mathrm{C}$ and $\mathrm{D}$ ).

Training programs and other forms of education are organized at various levels of the sales organization. At subsidiary level, these programs included on the job training, and there were opportunities to follow management programs at various institutions. Overall, these training programs and other forms of educations were used to increase product knowledge and improve management skills like leadership skills.

ISO certification appears to be an important form of formalization; the local administrative and support processes are described in an ISO handbook at all the companies. In the cases where no process management was applied, local settlements were often forced by the corporate andor regional management to attain an ISO 9000 certificate.

\section{Differences}

Regarding the extent of formalization, our findings indicated that there are some differences anong the companies in our sample. Companies with a process oniented work culture were the most formalized. The sales force organizations of company $A$ and $B$ seemed to be less formalized; the informal organization played an important role. Potential reasons for the differences between the companies in our sample are fourfold.

- Age and size. The reason for companies $\mathrm{C}$ and $\mathrm{D}$ being highly formalized could be the fact that these organizations are relatively older and larger. Some empirical evidence for our research finding can be found in Mintzberg's works. Mintzberg (1983) suggests that older and larger organizations tend to show a higher: degree of formalization. Size can effect communication channels and the managerial climate (Ticker \& Bowland 1982). A large organization probably camnot process as much control information as a small organization because of the number of management layers. The most efficient method of meeting the coordination element of control in large organizations seems to be the development of standardized rules, routines and procedures and, certainly, business operations will be clearly structured via these rules, routines and procedures.

- Origin of the corporation. One respondent suggested that the differences regarding formalization can be explained by the origin of the company. Differences among all these four American companies can be explained by the location of the corporate head office. According to the respondent, it seems that companies of the West Coast (companies A and D) appear to be less formalized than East Coast (companies C and D) of the United States.

- Having settlements in many countries in conjunction with differing business environments. The degree of formalization may be explained by the fact that companies $C$ and $D$ have settements in many countries in conjunction with differing business environments. In comparison with the other computer firms in our sample; companies $C$ and $D$ have the largest network of subsidiaries. Additionally, they are also innensively diversified. Some empirical evidence of our research finding can be found in Cray's (1984) work. Cray found that control exented over subsidiaries increases significantly with the nutuber of countries in which a mulinational corporation has establishments; yet it is not associated with the percenlage of sales onlside the home country or the number of subsidiaries. The inclusion of nore countries with differing business environments seems to lead to an increased degree of control (Cray 1984).

- Management by processes. The implementation of process management implies that work activities are defined, measurements are accomplished at appropriate steps in the process, and corrective action is taken on process deviations as they occur (Melan 1993). The basic steps of process management are "defining at process". "designing process control", "assessing and evaluating a process", and "perform feedback and conrective action". Managing a process is accomplished by defining the process clearly and unambiguously, this is called "process mapping". This step includes the definition of process ownership, the delineation of process boundaries and interfaces, and the description of a set of work activities in a clearly understandable way. Managing a process also requires an appropriate process control system. Designing process control implies that the customer requirements have to be determined and control points have to be established. The control points are the steps in the process where a review or inspection is done. Proper metrics have to be developed that can be used to 
assess process effectiveness. The process effectiveness can be evaluated by charting the measwrements and setting Largets; the actual performance compared with a standard or norm. The outcome of this evaluation is used to initiate timely corrective action toward unwanted process deviation. In sum, process management leads to increased formalization. This formalization takes place in terms of process descriptions, detailed process control, detailed process evaluations and assessment, and formal performance feedback and corrective action.

All four companies can be distinguished from one of these four points. We, however, believe that the distinction "functional versus process" is the most important one for our study. This distinction reflects clearly differences in behavior of the company and its employces. Other static variables like size or age do not represent this behavioral issue so perfectly, and, differences in behavior cause by differences in control, caused by differences in control systems, is the subject of our study.

Companies $C$ and $D$ had also formalized the key business processes, such as sales and business planning, both companies had invested heavily in a TQM system. Company $\mathrm{C}$ has a TQM system, called Market Driven Quality (MDQ) and company D has its TQM called Quality Maturity System (QMS). MDQ and QMS were both structured systems for satisfying internal and external customers and suppliers by integrating the business environment, continuous improvement, and breakthroughs with development, improvement, and maintenance cycles while changing organizational culture. TQM was embedded in the entire organization, and it influenced consequently the behavior of every single person from the work floor to top management at both companies. Company $\mathrm{C}$ used training sessions and process maps to implement MDQ in sales at each level of the sales force organization. The process maps were used to demonstrate each step from the identification of an opportunity to the final payment for goods and services delivered, and responsibilities and accountabilities were assigned to the people that take these steps.

The headquarters developed specific TQM tools. For instance, Process Vitality Index (PVI) and Process Deployment Index (PDMI) were specific tools for conducting process audits. There were five detailed management handbooks at company $D$ that covered the key dimensions of its quality system: 'strategic direction', 'business planning', "process management', 'process improvernent', 'leadership and participation'. These management handbooks were used to demonstrate business practices and related management tools; they include detailed guidelines and instructions. Other management tools used were the improvement cycles, i.e., DSIM and PDSA, and planning formats, i.e., country balanced scorecard and Hoshin / Business fundamentals.

\subsubsection{Centralization}

\section{Similarities}

We could conclude from the research findings that the computer firms are quite centralized. Centralization took place in terms of strategic formation and strategic marketing mix decision making, but not in terms of operational decision making. Within these centralized structures, strategic plans were formulated and reviewed, if necessary, and all major decisions were made at corporate level.

With respect to strategic planning it appeared that strategic decision making was highly centralized; commonly, the managerial levels of the sales force organization generally had little involvement in the process. The local management team participated in sessions where the strategic direction and strategies were presented. In these sessions, they could give some comments and advice; but strategy formation took place at corporate level.

As for operational planning, it was found that decision making was largely decentralized. Headquarters formulated some basic guidelines for operational planning at all of the companies. The planning guidelines were generally related to product mixes, volume targets, revenues, and costs; the guidelines were formulated for different activity levels: worldwide, regional, product and market segment groups. Regional offices generally translate the planning guidelines into performance targets. Within the regions, the operational planning activities were decentralized 
Iargely; operational planning appeared to be top down and bottom up. Whereas the regional management team designed the framework for target setting, the local management team formulated performance targets for different activity levels, namely subsidiary and business level. They based goal setting primarily on market information, such as market developments and opportunities, and performance in the past, such as financial performance, realized sales targets. The local management level discussed the outcomes of sales management planning with the regional representatives, and the annual plans were adjusted on a basis of these discussions.

With respect to marketing mix decisions, it was found that product development/innovation and promotion decisions were generally made at corporate and regional level. Regarding product decisions, all companies had a centralized approach. With regard to price decisions for commodities, like Pcs, and maintenance services, the local sales units had little or no freedom; the range in which small price variations could take place was determined by the head office. Regarding medium sized and large computer systems, it was found that the head offices of all computer firms had formulated some basic guidelines, local settlements had some freedom in price setting; but their price setting had to cover the product costs, such as production costs, transportation costs, and a contribution margin. Promotion decisions were generally centralized, except for company A where local management were free to design their own promotion campaigns and activities within their assigned budgets. All the other companies were locally free to determine their promotion policy. The corporate logo with its shape and colors had to be respected. The responsibility variable "place" or 'distribution' was, in most companies, decentralized to the sales unit level; however at company $\mathbb{B}$, parts of the distribution decisions were still centralized. The regional office of company $B$ developed a 'distribution channel' model which the local settlements had to implement in their region. This model includes strict guidelines concerning the selection of local business partners and dealers, e.g. size and financial position. Some basic guidelines for the selection of local business partners regarding major accounts were formulated at the headquarter level. Furthermore, the regional office encourages its local offices to use specific companies as business partners; this because the corporation has 'worldwide' contracts.

\section{Differences}

With respect to operational decision making, it was found that there were some differences between the functionally and the process oriented companies. At the process driven organizations, the guiding processes were leadership and process ownership enacted using formal guidance, a vision and/or mission, a solid strategic plan and aggressive strategic annual objectives to develop for their core business processes. Operational decision authority was highly decentralized. Companies $\mathrm{C}$ and $\mathrm{D}$ also decentralized decision making authority with regard to improvement; the term "improvement" refers to both continuous and breakthrough improvement. Improvement included issues, such as:

- developing new business opportunities

- reducing errors, defects, waste, and related costs

- responsiweness and cycle time performance

- productivity and effectiveness in the use of all resources

At company $C$, the different layers of process leaders had specific responsibilities concerning improvement efforts. The worldwide process leader was responsible for leading reengineering activities and providing tools for improvement. The country process leader initiated local improvement projects in line with the policy of the worldwide process leader; business unit process leaders defined and established priorities regarding business unit improvement suggestions and recommendations.

Company D went one step further. The Hoshin management system was used to identify resources for the vital performance issues that supported the company's vision; it was used to 
separate those performance issues that required dramatic improvement from the many incremental improvements that can be achieved at the local level. Improvement was a key issue in the company"s planning activities. It used two different planning tables to document commitments to process improvement: 'Hoshins' and 'Business fundamentals'. The Hoshin table was used to document the manager's commitment to support 'breakthrough'objectives: 'Business fundamentals' was used to document the daily management priorities for key business processes. Both tables were used to list the annual objectives and their owners, and performance measures to be reviewed, they were also used to describe the first level deployment of the current annual plan. Each objective and the related measure were then deployed through the organization to become an objective and measure for the "owner" at the next lewel; this owner then developed objectives that lead to further deployment.

\subsubsection{Integration}

\section{Similarities}

With respect to integration, it was found that the computer firms participating in this research made use of a number of integrating mechanisms. These mechanisms were embodied in the formal and informal organization. They were used to encourage laison contacts between the managerial levels of the sales force organization. The common mechanisms in place were direct contact, management by objectives and integrated roles. These mechanisms were employed as follows.

It appeared that three of the four computer firms, companies $B, C$ and D, employed a matrix structure at the regional leve] of their sales organization. The matrix structure consisted of a product and a market dimension; the product dimension referred to product departments, whereas the market dimension referred to sales regions, such as Europe or Americas, and industry solutions, such as finance and insurance, manufacturing. At the subsidiary level, this matrix structure included the same product departments as at regional level and industry segments. Company A had no matrix structure at its regional level; the local activities are monitored and coordinated by headquarters. With regard to the sales operations in the Netherlands and Belgian, a Benelux organization was designed. The general manager of this cluster, the Belgian country manager, was in charge of managing the local sales operations. There was also a regional representative; yet the responsibilities of these representatives were strictly restricted to monitoring as local management was the highest management layer at the company"s regional sales force organization.

It was also found that companies $C$ and $D$ used a matrix form of organization towards products and geography; company $C$ 's matrix organization was also oriented towards industry. At company $A$ and $B$, some sales units were clustered; the Belgian, the Dutch and Luxembourg settlements were clustered to form the Benelux organization At local level, sales units generally consist of business units or sales teams related to product and/or market combinations, such as IT solutions for banks (see company $C$ ) or computer systems. Companies $C$ and $D$ also incorporated a matrix structure at sales unit leve]; the local sales force of companies $\mathrm{A}$ and $\mathrm{B}$ are organized by markets. Their sales activities were organized according to function within the business units.

Direct contact was also an important integrating mechanism at the companies under study. It was found that there was an intense, direct contact between international product managers and the local business unit managers, and between local business unit managers with respect to operational planning, such as sales management planning and international TT projects. This contact took place both formally and informally.

At companies $A$ and $B$, informal contact played a very important role. It also appeared that all the companies under study encourage direct contact among organizational subunits, e.g. organizing meetings and conferences at the corporation, and to improve the flexibility of the sales force organization and increase marketproduct knowledge. 
Management by objectives (MBO) appeared to be one of the most important integrating mechanism used at the companies. MBO was used to develop goals at the top level of the organization and then to cascade them downward, generally following the organizational structure, throughout the companies. It was found that MBO was used to deploy company goals and encourage employees to attain them. MBO was reflected in written plans that guide and create accountability throughout the organization at all companies under investigation. It is used to reward goal attainment.

With respect to integrated roles, it appeared that regional and local management had an important integrative role; they coordinated and integrated operational planning activities, and business operations. The general managers played an integrated role between the local settlement and the regional offices, and between the departments in the organization; regional management had an integrative role between the headquarters and the local sales offices.

\section{Differences}

It was found that the process oriented organizations had an additional integrating mechanism in comparison with the younger, functionally oriented firms. Horizontal integration was accomplished by quality function deployment in the narrow sense; that of a process focus and deployment of quality activities in the functional organization. The organization of companies $C$ and $D$ was structured around process relationships; it allowed them to stay much closer to their customers than companies $\mathrm{A}$ and $\mathrm{B}$. The management systems were used to create a renewal of the organization through a continuous questioning and alignment processes.

Companies $C$ and $D$ were also characterized by deployment of quality activities in the their sales force organization: they had a focus for cross functional improvement. Improvement was oriented toward involving a team of people representing the various functional departments: Marketing, Sales, Quality Assurance, Finance, Product Support, etc. Cross functional management appeared to be a control improvement activity through which management could set companywide functional targets for setting up policy deployment and daily control in line departments, and for taking action on business operations.

Vertical integration was achieved by structuring of the linkage of business processes for the provision of products and services. The business activities of the organization were viewed as a process that could be divided into a number of subprocesses and support processes. The key processes were identified and formed the basis of responsibility and authority. Companies $\mathrm{C}$ and D employed policy deployment to integrate vertically business operations at the different organizational levels. From the case findings of the process oriented companies, the form of policy deployment used extended the MBO process.

It was found that $\mathrm{MBO}$ at companies $\mathrm{A}$ and $\mathrm{B}$ was a top down approach that was used to emphasize and reward goal achievement. At company $C$ and $D$, a planning mechanism was used to ensure that goals were implemented vertically and horizontally in the organizational structure: managers used policy management to set the strategic direction of their organization, and then to deploy that vision in an active manner, with the focus on the process of implementation. As goals were cascaded downward from the top, actions arose from the bottom or middle to meet them. In other words, a formalized means of achieving and measuring the goals was developed; the companies' management systems ensured goal attainment and continuous company wide improvement. The management tools used were improvement cycles and deployment matrices. The improvement cycles were descriptions of how changes should be made in a quality organization; they included not only the obvious steps of planning and implementing a change, but also those of checking to see that the changes produced the desired or expected improvement, and that of acting to improve based on the checking step.

Both process driven organizations in our sample employed an improvement cycle. Company Cuses the Define Solve Implement Maintain (DSIM) cycle to provide an ongoing, iterative process for continuous improvement; DSIM is incorporated at different levels of the organization, resulting 
in substantial overall improvement. The various DSIM cycles then work together to reinforce an objective or goal. Company D uses the Plan Do Study Act (PDSA) cycle, a management cycle that is quite similar to the one used by $C$. These interative improvement processes ensure three types of improvements. The outcones of the improvement processes are used to modify business plans, and secondly, to improve the reliability of planning and implementation; and the management cycles can be used to align key business processes with the operational targets. Finally, the employees can use these cycles to support the annual plan, using measurement and standardization to ensure goal attainment.

Companies $C$ and $D$ also used specific management tools to ensure the vertical integration of annual plans. For example, company C employed a score card to link its strategic and operational issues at the level of the country organizations. This score card contained a listing of all the important strategic, financial, customer, people, and process goals. The strategic issues included the vision, values and principles, mission, goals and critical success factors; and these issues were linked to the business processes, measurement, performance indicators, largets, and the communication system. The scorecard is deployed throughout the country organizations, creating a strong degree of organizational alignment, providing the basis for comprehensive sets of local measures, and linking measures up, down, and across the organization. The organization's leaders decomposed the organizational goals and 'balanced scorecard' measurements to produce aligned, analogous goals and measurements for each local sales office, each business unit, and the business unit leaders did the same for the sales persons and sales teams of their unit.

At company $D$, two deployment matrices were used to link the local objectives to the strategic issues. The company distinguished two types of improvement: breakthrough versus continuous improvement. Company D planned separately for these two types of activities by employing Hoshins and Business fundamentals. Hoshins were used to record the management's commitment to support the breakthrough objectives. This planning format was used to improve the current business operations. Business fundamentals, i.e. daily management, were used to document the daily management priorities for key business processes and to maintain and control the current business operations. This planning system, which integrated continuous and breakthrough improvement, lad the advantage that key performance areas were marked for improvement effort but the activities related to the current business system are not ignored.

Company D also used its performance appraisal system to support policy deployment. Each employee had a position plan with standards or targets; some of these targets were related to breakhrough improvement, others relate to incremental continuous improvement. Thus, performance appraisal was linked with the key business prionities of the organization. As a result, the perfomance planning process was sharply focused; performance priorities were identified, individual objectives were negotiated to support the performance measures, and supportive competency development plans were established. It was also found that the integration of Hoshin planning with the individual performance review facilitated a clear understanding of how incumbent performance in any of the roles influenced achievement of the accountability measurements. It made the performance appraisal dialogue an opportunity for reinforcing alignment between the individual and the organization.It was also found that company $D$ employed a "management by walking around", "open door policy", and the divisional structure as additional integrating mechanisms. "Management by walking around' and 'the open door policy" were used to stimulate formal and informal contacts between superiors and their subordinates.

\subsubsection{Participation}

\section{Similarities}

With regard to participation, the local management teams did not directly participate in the strategic and sales management planning processes for their regional or corporate headquarters. The 
nanagement board at corporate levell was primarily in charge of strategic formation at all companies in our sample. In this process, they were supported by a group of representatives, such as worldwide product managers and representatives of the regional offices, and other staff members from the corporate lewel; the sales force organization could give some feedback or advisory contribution through discussions or projects, such as new product development. Our research findings indicated that this was the exception rather than the rule.

At the individual level, most companies gave employees the opportunity to participate in the formulation of personal targets. A bottom up approach has the advantage of being more denocratic, and instilling in each employee some responsibility for their own learning and career development; but this approach has the disadvantage of forcing the business unit leaders, faced with some gaps between what subordinate are prepared to do and what the business unit or organization as a whole must achieve, to push additional goals and expectations down to individuals to fill the gaps. At company $\mathrm{C}$ individual targets were imposed, and these targets were only partially negotiable.

\section{Differences}

It was found that local management participated in decision making about sales management; but the degree could vary from company to company. Participation of local management in operational target setting was generally high; but the corporate guidelines had to be implemented. The worldwide product managers and the regional management team participated directy in sales management planning at regional level. The regional and the local management teams participated in operational target setting at local level. From the interviews with respondents it appeared that this high extent of participation in sales management planning could be explained by the fact that there was a clear link between planning outcomes and production schemes at company $\mathrm{A}$ and $\mathrm{B}$. The local market information was used to forecast local demand and these forecasts where used to set targets related to production and inventory. Matching production and sales targets was perceived as critical for profit maximization and improving inventory policy and production schemes. For instance, local management of company $B$ was even rewarded for the quality of its forecasts of local sales.

It was found that two companies, $\mathrm{A}$ and $\mathrm{C}$, employed a top down approach and participative according to the needs. The regional leaders decomposed the organizational goals to produce aligned, operational targets for each country manager. There was some negotiation with each individual country manager to ensure the objectives set for them were realistic, reasonably within their control, and attainable. Company $C$ had the lowest degree of freedom as the objectives of the sales unit were imposed by the process owners at the regional headquarters.

At company $A$, for instance, it was found that operational targets related to contribution margin and revenue were imposed. The related expense budget was negotiable because it contained the required resources and headcount, i.e. number of employees, necessary for ataining the operational targets. The opinions of the country managers were used to ensure that they received enough means to achieve their targets; the regional office had to ensure that the aggregation of the indiwidual expense budgets fitted with its expense

Companies B and D used a top down and bottom up approach in setting salles targets. The individual country managers decided what to do and what their country organization as a whole must achieve. There was then an intensive negotiation with each manager to discuss gaps between e operational goals and expectations of the country manager and those of the regional leaders. Decision making was based on reaching a consensus at both companies; it implied that local targets were adjusted once the local or regional office had arguments for these adjustments.

\subsubsection{Functionally versus process oriented firms: overview}

A.1 the similarities and differences discussed in this section are summarized in the table 5.1 


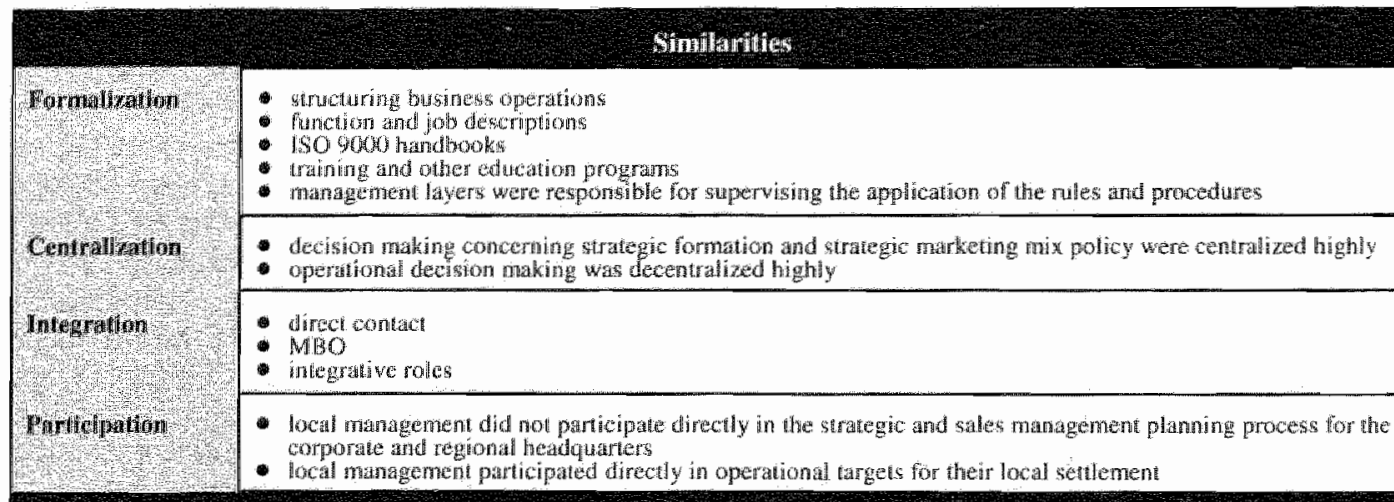

\section{Whinerences:}

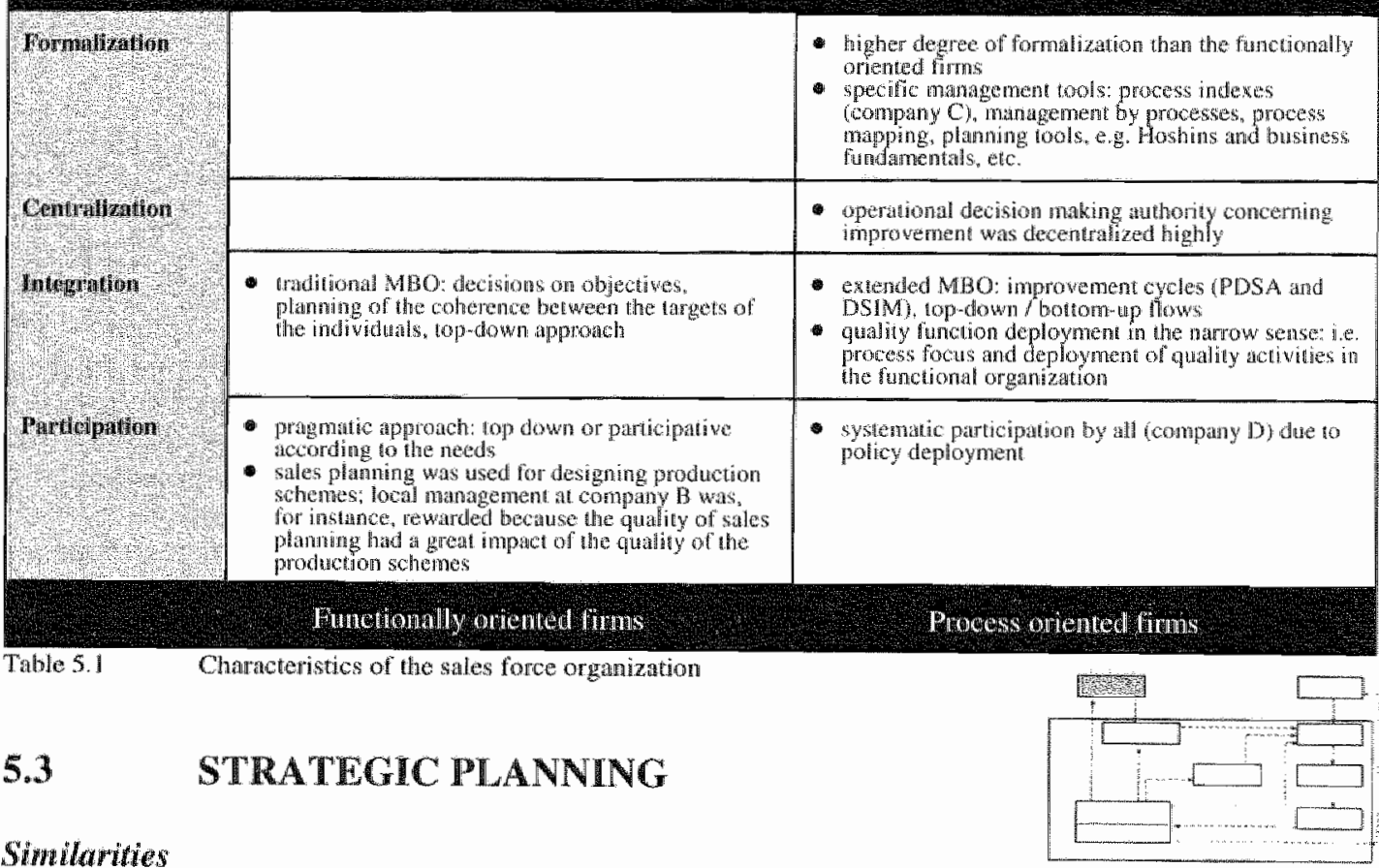

It was found that the companies under study had formalized the process of formulating long term objectives to a large extent. Strategic planning was regarded as an important process to provide direction and meaning to day to day activities of the organization, and was used to provide guidance for day to-day decisions, and to provide a means for assessing progress; the outcome of this process is a strategic plan. It appeared that a planning horizon of more than five years was not seen to be useful nowadays; today"s computer market is too dynamic, and this made predicting market opportunities and threats very difficult. One part of the strategic plan was, therefore, primarily prescriptive; much attention was given to long term and short term programming at all the firms in our sample. Respondents indicated that strategic plans including a prescriptive part were more robust then highly detailed planning information concerming targets and required resources; this prescriptive part contained guidelines for strategy implementation. It appeared that the use of strategic planming depends on the presence of a financial information system. This planning process included the extemal and internal assessments which provided a reality base on which top 
management of all companies built future plans, i.e. strategy formation; the implementation guidelines were not continuously adapted to environmental changes. The involvement of superiors in revision of the plans and actual outcomes was programmed formally; decision making authorities were defined and assigned to specific management layers, such as senior or regional management. It also appeared that there was a top down procedure in which the senior management board including the management of the worldwide product divisions was primarily responsible for strategy formation. The managerial levels of the sales force organization were often only involved to a limited degree. Strategic plans are formulated at the headquarter level of all the companies; strategic and financial planning systems were used interactively. It was also found that there were similarities with respect to the individual planning activities.

At three of the four companies, senior management established the corporate level positions relative to the vision or mission ${ }^{2}$, goals strategy and business philosophy. "They allso established appropriate strategic business units (SBUs). Once this was done, management of the SBUs refined their business scope by identifying product/market segments and competitive priorities; at the next level down. Regional and local management were asked to provide feedback on the corporate plans and to collect the required performance and market information for the corporate planning activities. Functional managers then developed and enacted action programs to support the competitive priorities. When this was accomplished, the line managers within the sales force organization translated the corporate plan into local plans with a planning range of three to five years. Strategy implementation was, in effect, a reality check on the assumptions and future visioning of the planning process and a test of the organization's capacity, unit by unit, to achieve its stated goals. Implementation of a strategy shifted the organization's focus from developing a strategic plan to acting upon it; this was done using operational planning. Evaluation and revision were implied in every step of the strategic planning process; strategic planning was used to examine an organization's values, current status, and environment, and to relate those factors to the organization's desired future state in three to five year time period. Evaluation and revision not only occurred at the end of the planning cycle, it also occurred at any stage within the planning process. In effect, it is both a final step and an intermediate step or continuous process. Just as sudden changes in the environment, such as changes in competition, may imply changes in the organization's vision, a reconceptualization of the organization's mission may require reexamination of its external environment and internal capacity, and, the companies did this.

The strategic plan of the companies included long term objectives, strategies to attain these goals and guidelines concerning product/market combinations, financial and commercial targets; i.e. quite explicitly specified long term objectives. Overall, the long term objectives were of a financial nature. From our case analysis it appeared that these goals are related to cost and expenditure structure, revenue, earnings per share, and return ratios. There were also objectives of quantitative, but nonfinancial nature: sales volume targets, growth objectives and market share. It was also found that in the last few years long term objectives of a qualitative nature had become increasingly important. These objectives were related to customer value, customer relationship management, customer focus, customer confidence/trust and product/service quality (see table 5.2).

\section{Differences}

It was found that the process oriented firms were the only companies in our sample with very detailed written procedures about strategic planning. From our case analysis, it appeared that the process driven organizations had formalized frequent superior/subordinate interactions because this process was perceived as to be one of the key business processes; the planning process was described in a process map. Company $D$ used the principles of Hoshin Kanri in strategic planning to create an organization wide system for generating and achieving breakthroughs that led to improved levels of customer satisfaction. It was found that Hoshin planning is instrumental in helping top management to develop a vision for their organization that could be understood by 
every employee. Strategic planning is used by senior management to provide the lower layers of management a framework and a focus for improvement efforts. Strategic planning provided the context for developing a vision, which was the fundamental driver of all improvement efforts. The more radical the improvement objective, the more important it is to associate process improvement efforts with strategic and business objectives and goals. Strategic planning was also used by regional management to determine the measures and critical success factors that would be used to evaluate the success of improvement projects. This process was used to define the destination, white the process improvement project provided the vehicle. Thus, continuous evaluation and revision at company $C$ were an integral part of the strategic plan development process. This implied that formal evaluation and revision following implementation were unlikely to involve major changes. The advantages of this are obvious; each planning activity involves a degree of investment by the organization in terms of time, energy and commitment, and the later in the planning process a major revision occurs the greater retrenchment necessary (see table 5.2).

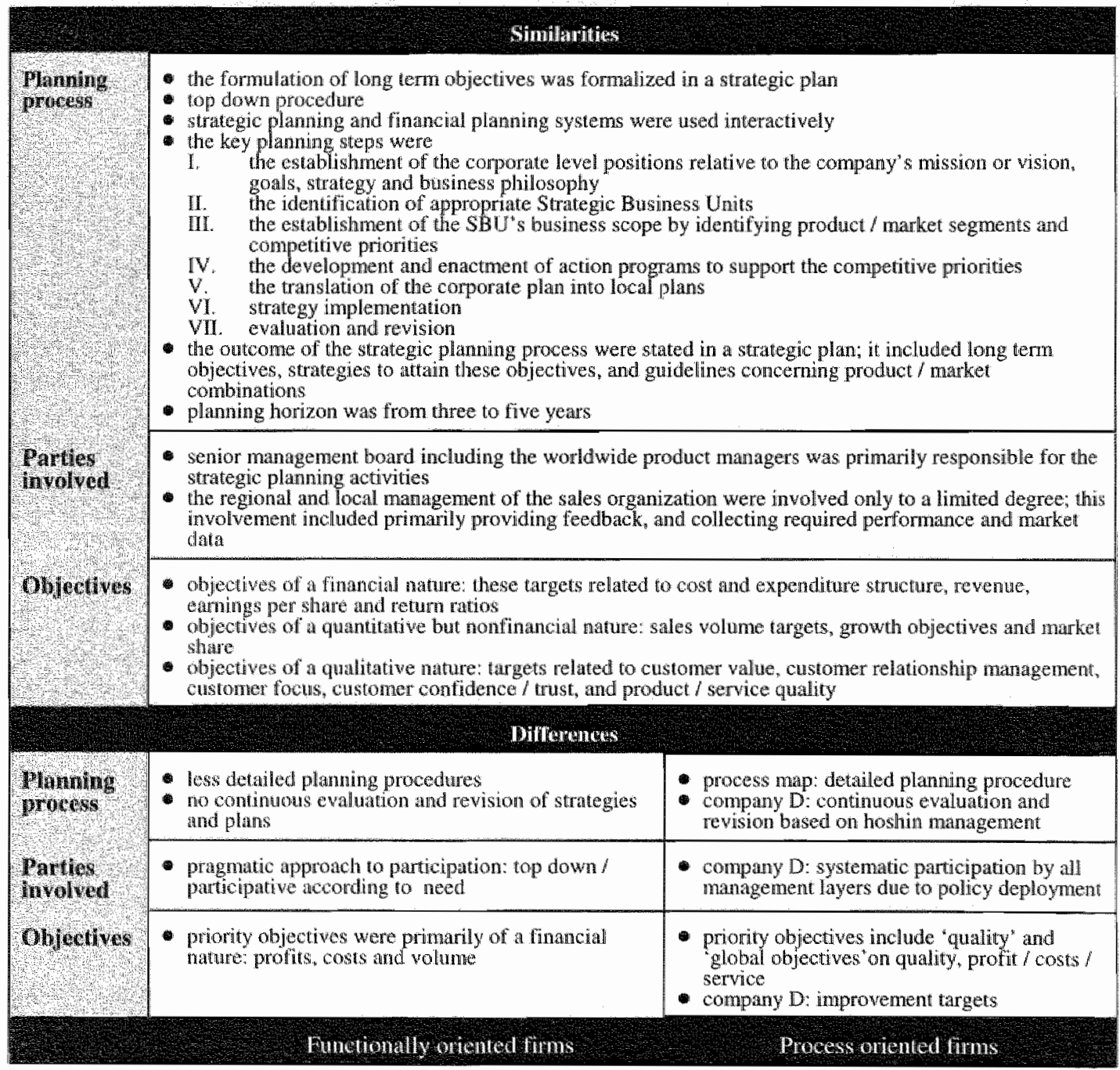




\subsection{SALES MANAGEMENT CONTROL}

\subsubsection{Sales management planning}

\section{Similarities}

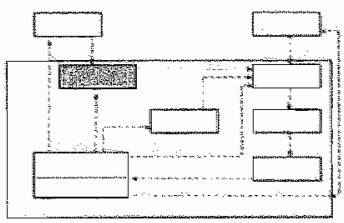

With regard to sales planning procedures, it was found that all the computer firms in our sample had described the planning activities in a written procedure. This procedure was described in a management handbook imposed by the headquarters or in local ISO 9000 handbooks.

Overall, the respondents indicated that superiors at their company were highly involved in negotiations with their subordinates regarding planning and revisions to sales plans and actual outcomes. This involvement was generally to be perceived as an ongoing activity; superiors intervene only if actual outcomes were not in accordance with predetermined standards. Typically, sales management planning was the responsibility of line management, who met with their subordinates to set operational objectives that led to achieving the strategic objectives of the comp the phenomena of interest any. The superiors also supervised the planning activities. The sales planning process included top down and bottom up elements. Sales management planning generally took place as follows.

Regional offices and local business units provided basic planning information about past performance and market developments" the headquarters use this information to set operational sales targets for their regional offices. Once these targets are announced, the regional offices translated corporate guidelines into regional and local guidelines. This implies that the operational targets were decomposed to produce goals for each local sales office, and that the country managers did likewise for the business unit managers at their local salles office. There were some negotiations with individual country managers to ensure that the targets set were realistic and reasonably within their control.

Within the local business units, a bottom up approach was employed. Individual salespersons were asked to formulate what they themselves expected as their sales quota for the next year. The individual targets ${ }^{3}$ were discussed with the business unit manager. Decision making was generally based on consensus to ensure that the sales targets set for exch salesperson were realistic, reasonably within their control, and attainable; if a consensus was not reached then the supervisor set the individwal targets. Thus, potential gaps between what individuals were prepared to do and what the business unit or organization as a whole must achieve could be avoided by pushing additional goals and expectations down to the subordinates to fill the gaps.

It appears that most subordinates were experienced enough to understand clearly what exactly was expected of them, how they were expected to go about achieving these personal objectives, and how their success would be measured. The individual targets were aggregated, and the outcome were the operational sales targets of the business unit.

Once the targets of the business units are know, the operating sales budgets were calculated. An operating budget was created by listing the operational targets, with their accompanying resource requirements; the resource requirements were estimalted amounts of financial, staff time, space, equipment, information and other resources that would be required to achieve the operational sales targets, e.g. direct and indirect costs. The operating budgets of the business units were aggregated, i.e. to form the operating budget of the local sales office. It appeared that the outcome of sales management planning was a annual business plan including short term and action plans.

The short term plans were plans for one year or less in length and define day to day activities of the firm; these plans included a commercial and an operating budget. Action plans were used to operationalize other plans, that is, they were used to accomplish the intermediate plans, i.e. plans that refer to principal objectives derived from short and long term strategic planning. These 
objectives included customer driven quality requirements and operational requirements such as productivity, cycle time, deployment of new technology, strategic alliances, supplier development, and research and development. The development of action plans appeared to be a critical stage in sales planning when general strategies and goals were made specific so that effective companywide understanding and deployment was possible. Deployment of action plans required analysis of overall resource needs and the creation of aligned measures for all country organizations and related business units.

All the companies in our sample had formalized the process of establishing short term objectives; these objectives were stated in the operational business plan. The majority of the short term objectives were of a quantitative and primarily financial nature. The importance of these objectives can be explained by the fact that such objectives were easy to communicate to each managerial level of the sales force organization, easy to monitor with the help of automated systems, and closely related to the strategic objectives of a company.

Comparing the short term objectives of the companies in our sample, it was found that there were four important quantitative objectives: profit, revenue, costs and contribution margin. There were also some short term objectives of quantitative but nonfinancial nature: growth, salles volume and market share. Qualitative objectives were also stated in the annual business plan; these objectives were generally related to customer satisfaction, image, quality and ISO 9000 (see table 5.3).

\section{Differences}

With respect to the sales management planning process, there were some differences between the functional oriented and the process driven organizations. It appeared that the planning activities of the process driven organizations were more formalized than those of the functionally oriented organizations. All planning processes including the sales planning process were identified as key business processes; it implied that these processes were defined in a detailed process map. This process included information about the process owners, the process boundaries and interfaces, and the work activities.

It also appeared that both process driven companies had a broad set of financial and nonfinancial short and long term objectives; these key, or priority, objectives were derived from their strategic plan. The strategic plan included a set of long term targets and means to achieve goals in quality, cost, delivery, and morale or employee satisfaction. The items in quality include defects, cycle time, failures, and customer satisfaction. The items regarding cost included production, price strategies, and general finances like sales revenue and market share. Delivery included new product development cycle and distribution. Morale included satisfaction of stakeholders and employee's skills and training. The key or priority objectives of the functionally oriented objectives were primarily profit, cost or volume. The functionally oriented firms also integrated sales and production platining to avoid a demand or supply surplus. Sales planning information and forecasts were used as a key input to production schernes.

It was also found that the process driven organizations used specific management tools to ensure organizational alignment. Companies $C$ and $D$ employed specific management tools in sales management planning to promote organizational alignment.Management tools, i.e. balanced scorecard and deployment matrices, are used to show how results were achieved and provided a linked system of short term and longer term indicators to help managers manage people and processes and to help subordinates manage their own work. It was also found that these tools were useful:

- to identify and highight critical success factors

- to clatify what needs to be measured

- to drive measurement through the organization

- to link measures throughout the organization

- to help the organization guard against the proliferation of umeeded performance measures 
At company C, for instance, the "Country Balanced Scorecard' contained a listing of all important strategic, financial, customer, product/service, people, and process goals. This scorecard was used as a framework for translating strategic objectives into a limited, coherent set of performance measures. The scorecard linked metrics from four important perspectives: measures of customer satisfaction, financial measures, process metrics and people. Limiting the number of allowable measures in each perspective forces managers to identify and focus on the handful of most critical indicators. This broad set of goals were deployed throughout the worldwide sales force organization, creating a strong degree of organizational alignment and providing the basis for comprehensive sets of local measures, and linking measures up, down, and across the organization.

Company D used Hoshin Kanri to satisfy the promises of its strategy by consistently producing operational results across key performance dimensions. It appeared that Hoshin and Business Fundamentals are multi-dimensional performance scorecards that can be used to correlate specific performance measures with organizational strategy and values. These two management tools are used to bridge the gap between long and short term perspectives. As a result, sales management planning was focused sharply and result oriented: performance priorities were identified, individual performance objectives were negotiated to support the use of the selected measures, and supportive competency development plans were established. Participation at the functionally oriented companies was more pragmatic and top down/participative according to the needs.

Decision making was based primarily on consensus; yet the decision making of regional management was leading in the case when no consensus could be reached. Company $D$ developed a planning approach based on a systematic participation by all management layers. It had. established the basis for organizational alignment within its planning activities as follows. It was found that performance in the focused pursuit of objectives was the essence of organizational alignment and a critical success factor; total organizational alignment is required to drive innovation, nurture continuous improvement and sustain total quality results. This required senior executives, middle managers, line supervisors and employees to interact with a style that reflected the values and mission of the organization. The principles of Hoshin Kanri were implemented in sales management planning to ensure organizational alignment; this planning process takes place as follows at company $\mathrm{D}$ (see table 5.3). 


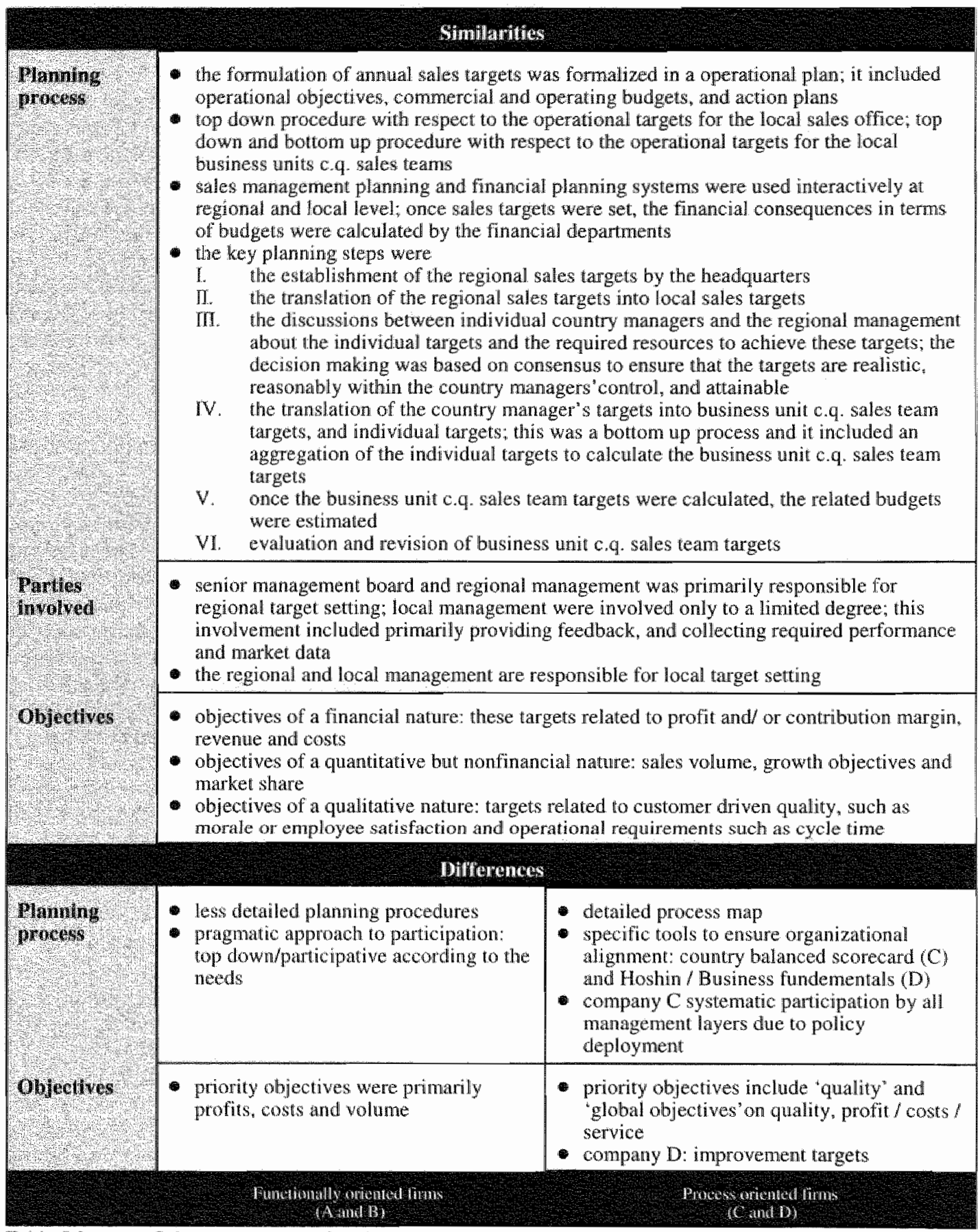

Table 5.3

Sales management planning 


\subsubsection{Performance measurement}

\section{Similarities}

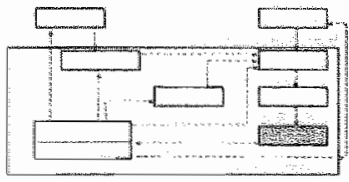

It was found the performance of local subsidiaries was measured intensively. Our research findings showed that performance measures were primarily of a quantitative and especially financial nature; these measures were related to sales volume, revenue, profit, contribution margin and cost issues.Quantitative objectives were decomposed at various activity levels at all the companies. This decomposition resulted in a set of performance measures related to product and product groups, customer segments, and local/regional/worldwide level of the sales force organizations, Overall, executives had defined these financial based measures as their basic group of performance

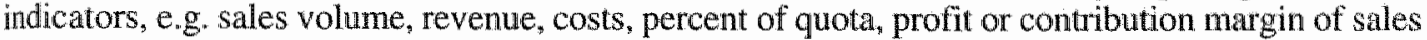
effort. Furthermore, it appeared that at all the sales force organizations the need for financial information dominated performance measurement needs. The reasons mentioned for using these financial measures were:

- relatively easy to monitor with automated systems

- easy to communicate to each level of the branch network

- reported timely, sufficiently and frequently for the recipient's purpose

- relevant to the recipient's decision making requirements

- inclusive of various activity levels

- forward looking as well as being concerned with the past

With respect to frequency of performance measurement based on quantitative measures, our research findings showed that financial performance is measured very intensively whereas nonfinancial performance, e.g. market share, might depend on the activity level ${ }^{4}$. Overall, financial performance was measured at least on a monthly, quarterly, and yearly based. Whereas transactions were automated, data concerning sales activities was available daily. There were also other quantitative measures in place. These nonfinancial indicators were often directly related to the financial targets of the local settlements. Examples included market share and sales volume at different activity levels. With respect to the frequency of measuring, we found that this type of performance was measured regularly ${ }^{5}$ and was primarily automated.

Moreover, there were also nonfinancial measures. Examples included customer complaints, customer satisfaction surveys and ISO 9000 certificates. The frequency for collecting this data is often low and primarily yearly based because the data collection is primarily not automated. It was found that qualitative indicators were less important than quantitative, especially financial, indicators but that these indicators were becoming increasingly important. Local settlements were increasingly involved in management consulting. Measuring nonfinancial and especially qualitative performance was perceived as necessary to assess local sales performance.

With respect to the link between business objectives and performance measures, it appeared that there was a clear link between quantitative short term objectives and performance measures. Operational objectives were related to market share, sales volume, return, costs and profits; these objectives were translated into predefined measures at all the computer firms under study. Such a performance system integrated short term objectives and plans with management accounting. Operational business objectives are generally decomposed (e.g. profit = revenue - costs; revenue $=$ sum of revenues per product/business unit/country). The outcome of the decompositon was used as predefined measures to be controlled (see table 5.4).

\section{Differences}

There were some significant differences between the process driven and the functionally oriented organizations in our sample with respect to performance measurement. It was found that the process 
driven organizations had a broader set of performance measures than the functionally oriented organizations. Performance standards of the process driven firms were derived from strategic and business or tunctional goals and targets where as the standards of the functionally oriented firms were derived primarily from business or functional goals and targets.

Goals and targets were based on the mission, enhanced by knowledge gained, in part, through research, benchmarking, and anallysis, and as well as this, there were measures related to daily management. The concept "daily management" refers to the combination of key business processes, sub or work processes, and their accompanying measurement. Day to day work activities were documented by a process map at companies $C$ and $D$; this map included the description of process interrelationships and performance measures.

It appeared that process management views work in terms of objectives, goals, and strategies within the context of an enterprise; process management relied on feedback to evaluate and improve process performance. Thus, establishing meaningful measures was a primary consideration. These process measures can be classified in four groups:

- Product and service quality measures. These metrics refered to operational performance relative to measures and indicators of product and service requirements, derived from customer preference information. Examples include reliability, on time delivery, defect levels, and service response time.

- Performance measures. These were focused on the degree to which a given interaction between a stakeholder and the process meets requirements or satisfies an objective. These indicators were used to measure factors such as 'how well a product or service meets or even exceeds customer requirements'. The performance areas of these measures were customization, flexibility, and responsiveness.

- Process time measures are concemed with process cycle time, throughput, and responsiveness. Process preess time measures fall into three subcategories. Operations time is defined as the time spent within a process transforming inputs into outputs by adding value to the inputs. It is the direct application of resources or factors of production in making the transformation. Non walue added time is time spent in the process other than operations time or quality related time (described next), It includes delay or waiting time, meetings and report writing, supervision and oversight, compliance with unnecessary or inappropriate regulations, planning and budgeting, employee relations, acquisition and procurement, and internal paperworlk. Quality related time includes inspection, rework, error prevention, problem determination, problem solving, quality related maintenance, and training. Much of these measures were described in the ISO handbooks, and measured during the ISO audit.

- Process cost measures. These measures are concerned with the consumption of resources allocated to the process of producing output products and services. Variable costs include supplies that are used up in producing outputs as well as the factors of production, which include labor, man hours, and facilities integral to process operation. There are also fixed process costs not associated directly with process operation that must be measured, managed, and controlled directly. These include cost of excessive benefits and prequisites, cost of facilities not directly related to work processes, and cost of non income producing assets.

It was found that the critical success factors (CSF) of process performance were used to define the process measures at company C. CSFs were related directly to strategic annual goals and targets; they were used to track how a process must perform to be considered successful. For each critical success factor there was an associated key control indicator that provided the measure, and a standard of performance or allowable variance from planned performance.

Three CSFs were identified with regard to the goal "gross profitability": use of price delegation, selection activity and quality assurance. The used measure for the CSF 'use of price delegation was 'bid prices versus target'. The metrics were designed into the process in such a way as to provide a readily available or continuous reading of performance. For instance, customer satisfaction was measured continuously in the Customer Relationship Management process.

From the case analysis it appeared that company $\mathrm{D}$ also used process measures; however, these measures were stated in the daily management tables, i.e. Hoshin and Business Fundamentals. The Hoshins, for instance, included objectives, targets/goals, strategies, and performance metrics. 
As the objectives and targets/goals were cascaded to the lower layers of the hierachy, strategies were translated into actions that led managers to accomplishmg their objectives. The performance measures were changed accordingly so that the managers could measure their pertormance; every action was assigned a measure or indicator. The metrics used related to customer satisfaction, process targets and/or control values, and financial performance. The selection of measures was standardized by the company's Hoshin management; the high level objective was cascaded to a lower layer of the management hierachy, usually in the same units of performance measure. Thus, actions can change on each layer of hierarchy, but not the type of performance measunes used. The performance measures were customized to the targets/goals, and because of this, the company's performance system went behind performance to control actions at every layer of management.

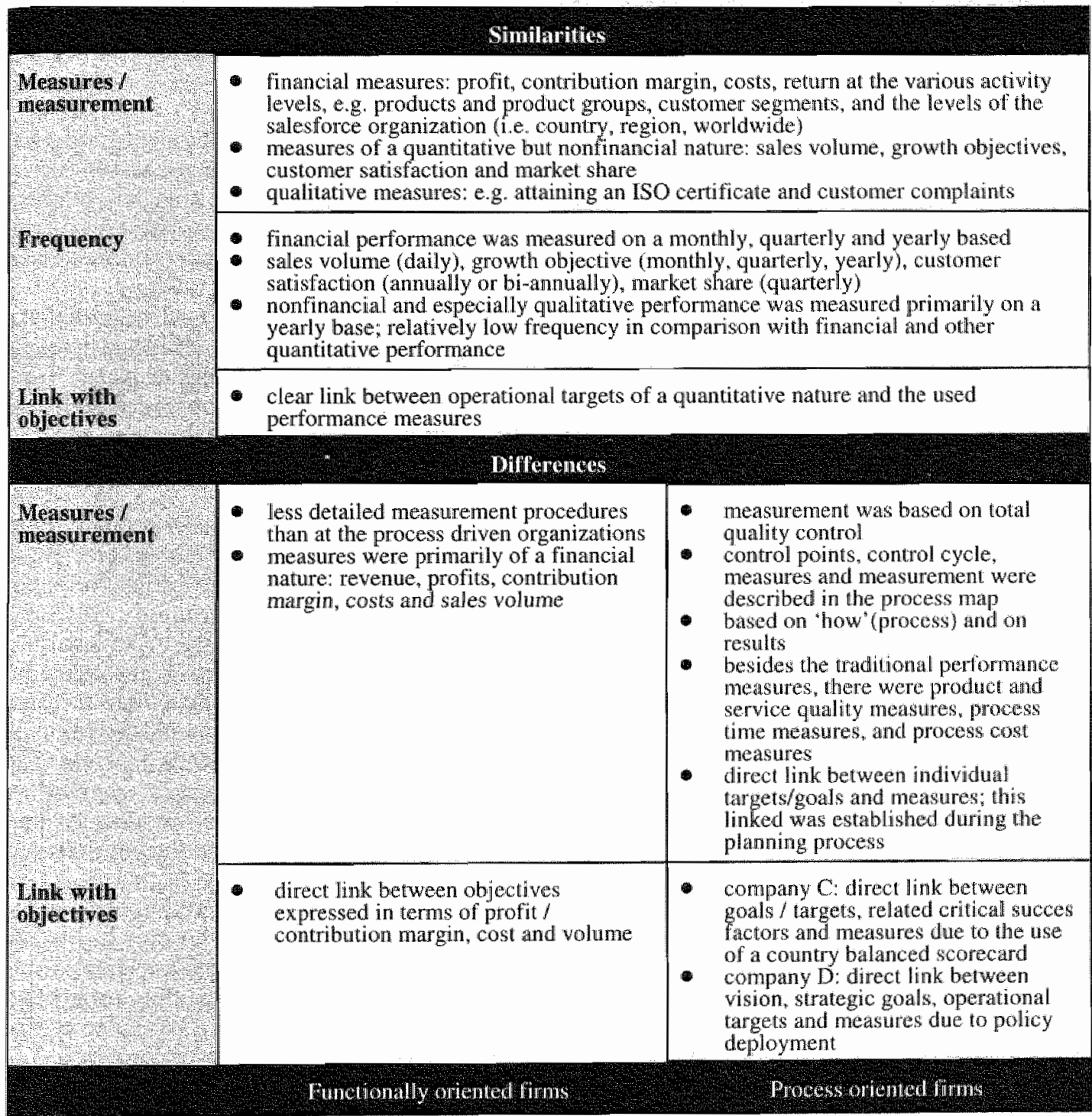

Table 5.4

Performance measurement 


\subsubsection{Performance evaluation}

\section{Similarities}

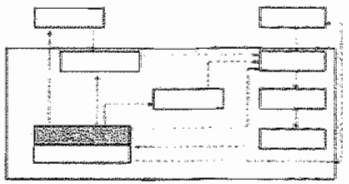

Performance evaluation was a process for assessing operating results against a prior plan to determine the root cause in the gaps between planned and actual performance. The performance gaps at company A were analyzed in term of progress-to-plan to identify the potential causes for the differences between planned and actual performance. All companies in our sample had a formal review process that was used to improve the efficiency and effectiveness of the sales force organization in meeting its objectives. Although each company customized its review process to meet the needs of its culture, sales performance evaluation consisted of

- weekly and monthly rewiews

- consolidated quarterly reports

- an annual audit

The weekly and monthly reviews were used to stimulate adherence to the operational plan and timely corrective action. Local settlements were evaluated at least monthly by their regional office. In doing so, the regional offices closely monitored, controlled and coached their branches. Barriers to progress can be removed at this stage in an effort to improve the quality of the operational plan. Overall, it was found that unexcepted and uncontrollable factors were not taken into account. Furthermore, the regional offices tried to avoid adjustments of objectives.

The quarterly performance reports included information that could be used to assess the collective performance on the company's strategy and group strategic objectives. This performance review was used to modify implementation themes and to explain key obstacles to progress-toplans. Upper management performed this quarterly check to ensure that the operational plan is being implemented as intended. Finally, an annual audit was used to evaluate the effect of actuall performance on the achievement of the long term objectives, and to highlight unresolved or emergent issues that might effect next year's plan.

Analyzing our research findings, it was found that the most important criteria for evaluating the sales performance of local settlements were of a quantitative and primarilly financial nature. These criteria included contribution margin, revenue, costs and profit. Consequently, performance measures that were related directly to financial performance were used primarily to assess performance. Market share as evaluation device was used primarily for the quarterly performance reports and annual audit; this measure appeared to be less important than financial evaluation devices such as profit and costs because it was mentioned that it appeared quite difficult to measure market share in the turbulent computer market with short product cycles. Overall, the regional offices calculated the differences between planned and actual sales performance based on the outcomes of the performance measurement system; they conducted variance analyses to see whether differences were significant or not. These calculations were made at product and product groups, business unit and country level. The outcomes of these analyses were discussed during meetings between a representative of the regional office and the local management team.

Performance evaluation based on nonfinancial measures, e.g. market share and ISO certificates, had a much lower frequency. It was found that these indicators were not important for short term performance evaluation; executives said that when financial performance was excellent 'soft" performance was also excellent. Performance review based on qualitative indicators took place primarily quarterly, e.g. market share, or annually, e.g. customer satisfaction or ISO certificate. This importance was explained by the fact that profit and other financial measures were perceived as key drivers of share holder value (see table 5.5). 


\section{Differences}

There were some basic differences between the process driven and functionally oriented companies in our sample. Functionally oriented firms used traditional evaluation systems based on assessing results, namely assessing the extent to which actions contribute to target achievement. The process driven organizations used, besides this traditional evaluation, also performance evaluation techniques related to throughput; evaluation devices were derived from product and service quality measures, process time measures, and process cost measures. Furthermore, the process driven organizations had a performance review system that drove improvement efforts. Targets and goals also included improvement efforts; management needed therefore a meaningful data collection to orchestrate continuous and breakthrough improvements. Performance devices related to these two performance dimensions were used to evaluate process management success with respect to standards of performance.

The performance evaluation approaches of companies $C$ and $D$ integrated a meaningful measurement tracking system with an efficient approach to determine effective process improvements. Company C's approach, for instance, included DSIM cycle and Statistical Process Control (SPC) to manage and to improve process performance. SPC provided easy, reliable, and proven techniques for evaluating trends and point values and determining variation in the process. Pareto charting, for instance, was used to identify opportunities for the process, and to implement and maintain improvement efforts; a Pareto chart can be used to show a priority for the frequency of occurrence; some other tools used included capability data, graphs and flow charts.

It was also found that at company $C$ critical success factors were used to assess the impact of process improvement actions or projects. This is especially true when the key evaluation device related directly to stakeholder interests. For instance, if customer satisfaction survey results were a key indicator for a process and the standard of performance was set at 90 per cent, any reading below 90 per cent suggested the need for corrective action. At company $\mathrm{D}$, the deployment of the annual company policy was checked and follow up by conducting frequent performance reviews; respondents emphasized that the periodic evaluations were used to provide explicit inter level knowledge exchange process between the various management layers to:

encourage adherence to the company's plan

- report progress-to-plans

- identify obstacles to target achievement

- encourage timely corrective action

- improve the reliability of the plaming system

- improve the quality of initial plans

- share the best practices

All managers of company D tracked their own performance; at each layer of management, employees used fact and root cause analysis to select the appropriate means and measures to close performance gaps. Performance evaluation was a bottom up review process that consisted of four pieces: weekly reviews, monthly reviews, consolidated quarterly reports, and an annual review. It was found that these reviews were data driven; special attention was given to deviations from plan to identify the necessary corrective action.

The weekly, monthly and quarterly reviews at company $\mathrm{D}$ included the periodic check and problem solving of chronic problems and critical issues, and a resultant standardization of solutions. Thus, using the normal PDCA practices of daily management, Hoshin and Business Fundamental related targets were reviewed and if necessary acted upon on a continuing basis. Persistent problems required Hoshin means, targets, and even the policy, to be re-thought and modified. The evaluation devices were performance metrics that are defined in the planning phase; the review table therefore provided a format for examining and reviewing the actual results. Towards the end of the fiscal year information was rolled up from the periodic reviews for feedback to senior management for the next focus phase, which started the annual cycle al] over again. 
Foedback at company $D$ included the results of an annual quality audit, which aimed, at least in part; to assess the progress of the Hoshin and Business Fundamental cycle as a whole. These company wide audits at company D made use of criteria based on a model of how an organizational subunit is managed in terms of a framework. This audit included an evaluation of skills at using the planning system; there was a self evaluation and an audit conducted by headquarters. At company D, this framework was deriwed from the key criteria of the Malcolm Baldrige Award and these criteria were translated into the following dimensions of the company"s quality system:

- strategic direction

- business planning

- process management

- process improvement

- leadership and participation

Regarding the evaluation devices, it appeared that company $D$ differs from the other companies. At

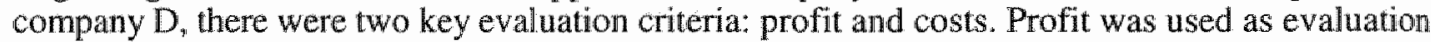
device if the price policy was not determined by the headquarters. In this case, the local management had decision making authority regarding the variables in the profit calculation. Costs were used as evaluation devices when the headquarters defined and imposed strict price guidelines. In this case, local management has some decision making authority regarding the variables in the cost calculation, e.g. marketing and sales costs but not regarding price setting, a key variable in the profit calculation (see table 5.5).

\begin{tabular}{|c|c|c|}
\hline \multirow{2}{*}{$\begin{array}{l}\text { Draluation } \\
\text { dexicest. } \\
\text { praluation } \\
\text { process. } \\
\text { frequency }\end{array}$} & \multicolumn{2}{|c|}{$\begin{array}{l}\text { - key evaluation devices were measures related to profit, contribution margin, costs, return } \\
\text { at the various activity levels, e.g, products and product groups, customer segments, and } \\
\text { the levels of the sallesforce organization (i.e. country, region, worldwide) } \\
\text { performance evaluation was used to ewaluate progress-to-plan and to identify potential } \\
\text { gaps between actual and plan performance }\end{array}$} \\
\hline & \multicolumn{2}{|c|}{$\begin{array}{l}\text { - geekly and monthly review: to initiate timely corrective action } \\
\text { progress-to-plan } \\
\text { - annual audit: to evaluate the effect of actuall performance on the attainment of long term } \\
\text { goals and to highlligh unresolved or emergent issues that might effect the next year's plan }\end{array}$} \\
\hline \multicolumn{3}{|c|}{ Dillenences: } \\
\hline 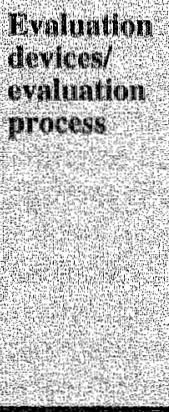 & $\begin{array}{l}\text { - evaluation of pertfonnance was } \\
\text { based primarily on results }\end{array}$ & $\begin{array}{l}\text { besides the traditional evaluation, there were } \\
\text { product and service quality measures, process time } \\
\text { measures, and process cost measures } \\
\text { continuous and breakthrough improvement were } \\
\text { cvaluated at company D } \\
\text { - performance evaluation was based on 'how' } \\
\text { (process) and on results } \\
\text { performance evaluation was integrated into line } \\
\text { management } \\
\text { I. self-evaluation of results/objectives } \\
\text { II. differences }\end{array}$ \\
\hline & Fungtionally oriented firms & Process ontented finms \\
\hline
\end{tabular}

Table 5.5

Performance evaltuation 


\subsubsection{Feedback}

\section{Similarities}

Sales performance feedback was an ongoing process between the layers of management, and between employee and manager where information was exchanged concerning the performance expected and the performance exhibited. Feedback was used to praise good performance or to correct poor performance, and was tied to performance standards which stated of what behaviors or results were expected for sales performance to be considered satisfactory. The performance standards had to be attainable, measurable and stated in terms of quality, quantity, timeliness, or cost. The reasons for these requirements were:

- attainable: unrealistic performance standards have a negative impact on an employee's motivation

- measurable: standards that are measurable make 'performance' visible and tangible

- standards stated in rerms of quality, quantity, timeliness or cost make it possible to conduct regular and frequent reviews up and down the organization; these standards were related to the classic competitive factors such as "time to market". 'costs", "quality'and "delivery'

In general, the performance review cycle was used to provide local management with feedback on their actual performance. There were allso informal contacts between superiors and subordinates. Most of the time, feedback was given during informal visits of the representative of the regional office. Performance feedback could have a positive sign, i.e. praising good performance, or a negative sign, i.e. correcting poor performance. Giving negative feedback included specifying what did not meet expectations. The involvement of superiors in negotiations with subordinates regarding revisions to plans and actual outcomes was generally an ongoing activity and programmed formally. The supervisor and the responsible subordinates obtained agreement on the problem, mutually sought solutions and agreed on an action plan ${ }^{7}$; facts and analysis were used to determine timely corrective actions. In general, it appeared that adjustments to operational objectives were not used as corrective action. Once managers accepted specific sales targets they were held accountable for target achievement.

At all the firms in our sample, superiors intervened only if outcomes were not according to predetermined standards but this intervention did not include an adjustment of operational targets because such an adjustment often implied adjustments of the operational targets at each mangement layer of the sales force organization ${ }^{8}$. Generally, operational targets of country and business unit organizations are adjusted when the headquarters adjust the targets of the regional offices.

The weekly and monthly reviews were used to encourage subordinates to get going and to check their progress. These reviews provided feedback in a timely manner to ensure timely corrective action. The quarterly reviews were used to study the effects of local action plans on the strategic annual objectives, and to understand the key obstacles and adjustments to plan. All the companies under study reviewed overall progress at the end of the fiscal year. This review included an analysis of the performance gap between planned and actual sales results. It was also used to summarize the unresolved issues that may affect the strategy implementation and the next year's operational plan. At all companies, the annual review was the kickoff for the next round of planning. Furthermore, the annual reviews were also used to assess long term performance. This feedback was used to improve the reliability of the planning system, to evaluate the quality of long term objectives and plans, and to initiate revisions to plans and actual outcomes (see table 5.6).

\section{Differences}

There are some differences between the process driven and functionally oriented companies in our sample. These differences are related to the focus of the performance feedback, the parties involved and the use of performance feedback. For instance, performance feedback at functionally oriented firms was focused primarily on 'results' whereas the feedback at process driven firms included 
feedback on 'results" and on 'process issues'. It appeared that performance feedback to the participants in business processes and taking corrective action was perceived to be of fundamental importance in both stabilizing and improving the process.

At the process driven organizations the country process owners instead of line management in the functionally oniented firms were also responsible for initiating timely corrective action. These process owners had decision making responsibility for the variables in the contribution margin, profit or cost calculation. Once a significant difference between planned and actual performance was identified then the regional office informed both the country process owners and their local superiors: the $\mathrm{CCOE}$ at company $\mathrm{C}$, or the country manager at company $\mathrm{D}$.

The regional and the country process owners mutually sought solutions to the problem and agreed on an action plan. The country process owner was responsible for initiating the corrective action. At the functionally oriented organization, the regional office also informed the country manager when a performance gap occured. The responsible business unit manager together with the country manager then developed an appropiate action to ensure corrective action (see table 5.6).

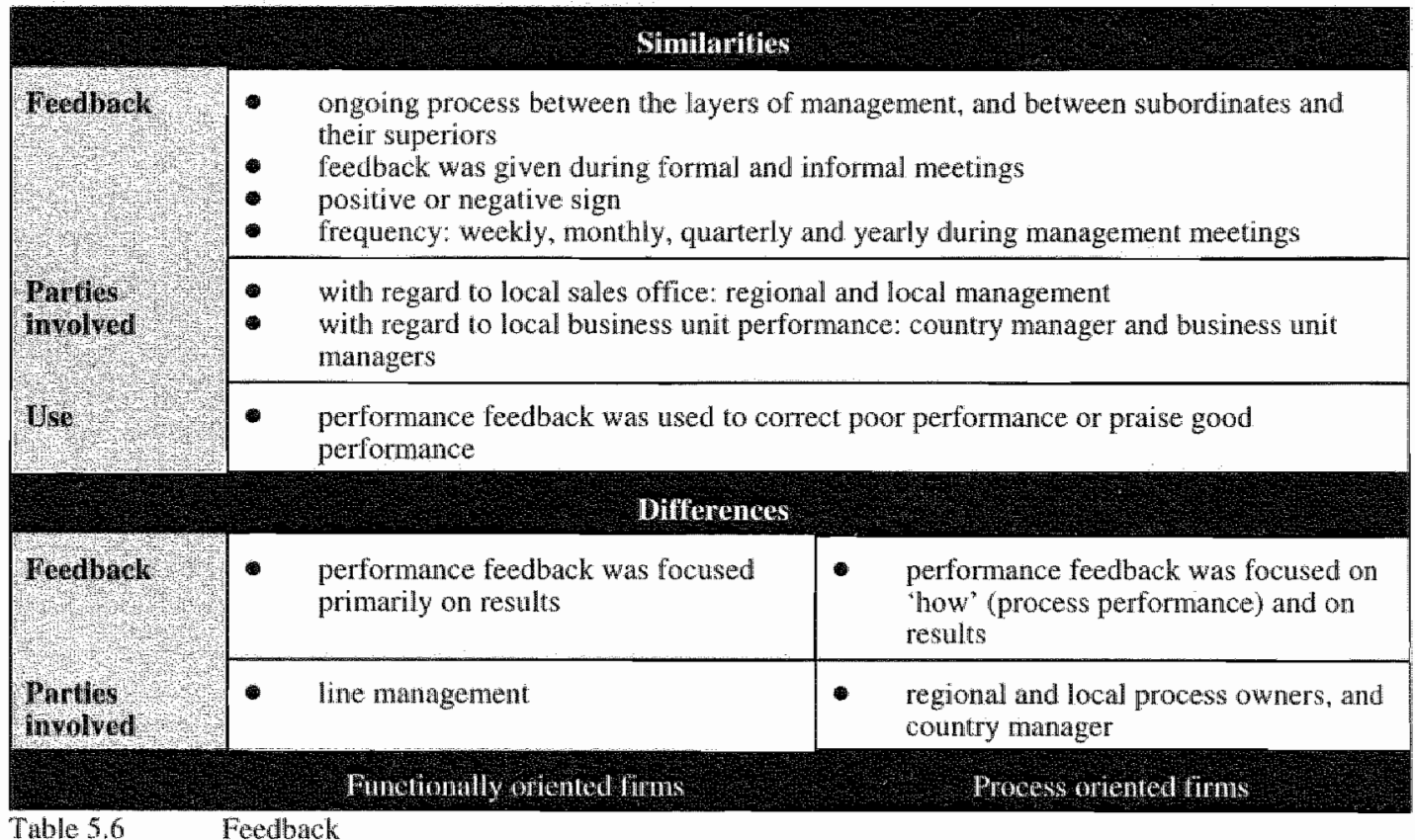

\subsubsection{Rewarding}

\section{Similarities}

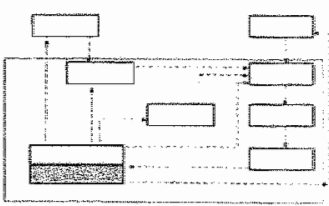

The outcome of the performance reviews was also used to reward personnel. It was found that all companies under investigation employed a performance based reward systen. Pay and recognition were the key categories of rewards available to the local management including country managers and local business unit managers.

Financial incentives were based on sales volume and revenue, and added to these was the more recently used measure of customer satisfaction. Three of the four companies incorporated customer satisfaction ratings as a determinant of country managers' incentive pay. The firms under 
sudy recognized the importance of customer satisfaction for continued profitability. There was an increasing recognition that high customer satisfaction ratings should be an important component of the local management"s evaluation process and compensation programs. For instance, 40 per cent of the incentives of a company's local management teams were based on customer ratings. Our respondents indicated that they did not have a direct influence on customer satisfaction. This was especially the case for companies B, C and D which had indirect selling activities; the deallers and business partners managed the interactions with the customers. With respect to salespersons, it was found that the financial incentives were based primarily on sales volume and revenue. The reasons mentioned were threefold:

- salespersons did not seem to have much influence on customer satisfaction, i.e the problem of controllability

- salespeople were not clear on the type of effort that will increase customer satisfaction. i.e. the problem of controllability

- the performance of dealers, business partners, and the customer service departments were seen as antecedents of customer satisfaction, i.e. the problem of accountability

Compensation for effort and sales performance also included nonfinancial rewards, such as offering opportunities for personal growth, e.g., seminars and workshops, recognition, and opportunities for promotion. Formal recognition programs were very popular in the companies under investigation. Formal recognition generally implied public recognition for accomplishment in the presence of peers and superiors; it also included a symbolic award, such as jewelry or a plaque. Company B had its 'Country of the Year' award, the ultimate recognition for the company D's sales elite was to be named a member of the President's Club. The formal recognition programs were based partly on group competition and individual accomplishments representing improved performance. These programs could be associated with monetary, merchandise, or travel awards.

With respect to pay, financial compensation tended to be dictated by the overall company policy. Financial compensation plans generally include a salary and one or more incentives, e.g., a commission and/or bonus. The two basic types of financial compensation were straight salary and salary plus incentive, with the incentive being a commission and/or a bonus.

Combination pay plans included a garanteed salary, and offered enough flexibility to reward important sales activities. Various forms of financial reward systems were applied, with variations ranging from a 25 per cent to 40 per cent variable. Commission rates varied widely, from constant rate to a regressive rate over a specific pay period, i.e. 3 to 12 months. A regressive rate was used to limit the influence of possible excessive sales that were not the result of individual efforts but of uncontrollable factors, such as market developments or "lucky shots". The variable pay for country managers was linked to leading performance indicators, such as local profits, corporate and I or regional results, and customer satisfaction. Performance indicators, such as regional and corporate results, were used to limit the impact of excessive results due to uncontrollable factors (see table 5.7).

\section{Differences}

There are some interesting differences among the firms in our sample but these differences cannot be explained by the nature of the sales force organization, functionally versus process oriented (see rable 5.7). 


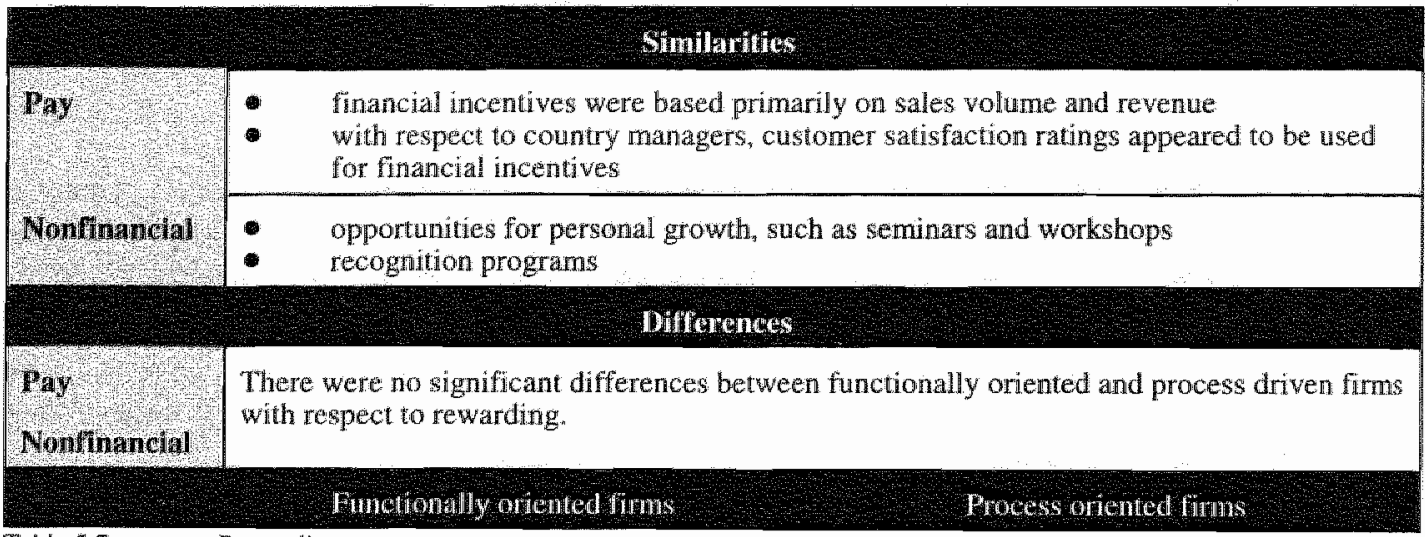

\subsection{TASK CONTROL}

\section{Simillarities}

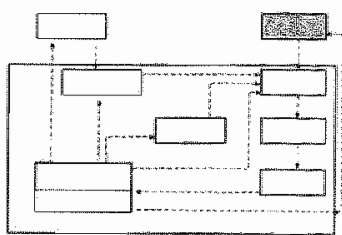

The companies under investigation employed a varierty of task control mechanisms that could be classified into four categories: standardization of processes, standardization of output, standardization of skills and assessment of individual performance.

Standardization of work processes appeared to result from implementing the company's quality system: ISO 9000, QMS or MDQ. ISO 9000 Series standards have become the accepted worldwide requirement for a minimum quality management system. As these standards were customer driven, the quality system becomes a major part of any company's business system and strategy. Internal benefits resulting from adopting ISO standards included: increased quality awareness, a consistent direction for quality, improved communication throughout the organization, involvement of a firm's entire management and staff in the quality system; control of quality costs, improved supplier quality, standardization of processes, and use of customer feedback to improve processes and products.

Standardization of outputs was achieved primarily by using 'Management by Objectives' (MBO). MBO was intented to motivate stronger performance on the part of employees through goal setting, participative management and objective feedback. MBO was tied to two elements of personnel management, namely job evaluation and renumeration. It appeared that the MBO process generally consisted of the following activities:

- development of objectives to be accomplished by a subordinate

- resource commitment to support these objectives

- development of action plans including the milestones for accomplishing these objectives

- periodic performance reviews and the development of corrective actions

- assessment at the end of the MBO cycle of the subordinate"s performance in terms of target achievement

Regarding standardization of skills, training is an important task control mechanism; the companies recognized the need to focus on quality, flexibility and innovation in the workplace. This, in turn, required a knowledgeable and highly skilled workforce. This trend was causing organizations to focus less on job specific training and more on working in teams, and multi killed workers. Ultimately, all members of the workforce were expected to become more responsible for quality, employees were being forced to become more innovative and to become more entrepreneurial and customer focused. The importance of skills such as an ability to analyze, to communicate and to 
work in teams were becoming more critical, as was the need to develop basic literacy and mumeracy skills throughout the workplace. It was also found that the training programs were integrated with other human resource management practices such as providing effective ways of compensating people for their efforts, providing new, flexible forms of work organization, and developing ways of utilizing the skills and expertise of people at all levels. For instance, salespeople at all companies can follow a training to improve their product knowledge and specific skills, such at presentation and linguistic skills. These programs were organized locally, or intemationally. Managers were stimulated to follow e.g. MBA programs to improve their skills.

Finally, each company studied had a formal evaluation system that was used to assess individual performance. The purpose of these employee appraisal systems was to encourage quality work performance, job related development, and effective communication between supervisors and their employees. It was found that the review system was designed to:

- document the performance of an individual employee in a systematic, objective, and equitable manner

- $\quad$ set goals for individual employees

- identify aspects of performance that could be improved

- provide feedback on the extent to which an individual's performance met organizational goals, objectives, and expectations.

- provide information for salary merit increase decisions, promotions, or other employment actions

Employees' performance appraisal was a process of summarizing, assessing and developing the work performance of an employee. It was generally conducted annually; salespeople were, however, evaluated more frequently, usually in line with their sales objectives. In all cases, this evaluation was usually accomplished by conducting a thorough review of the performance level achieved by the employee over the previous period, discussing the evaluation with the employee, and completing an appraisal form which documents both the evaluation and the results of the discussion. With respect to salespersons, the performance was primarily related to revenue and sales volume targets. Supervisors typically met with subordinates to discuss previously set objectives or expectations, to discuss methods for improvement of the employees performance, to discuss disciplinary or corrective measures, and to set new goals for employee performance.

The outcome of performance appraisal was generally stated in a performance evaluation form including future plans/actions and a description of the employee's performance in specific behavioral terms, e.g. a statement of the impact of that performance and assigning a rating. The future plans/actions included goals, education, training and professional development activities that the employee might complete during the following performance review cycle, such as on-the-job training, self study courses, workshops, special projects, participation in professional organizations or on working with cross functional teams, etc. It was also found that both the supervisor and the employee developed objectives for the next 3 , and the next 6 to 12 months, and that these objectives became the basis for evaluating the employee during the next appraisal meeting (see table 5.8).

\section{Differences}

If was found that the process driven organizations were characterized by a higher degree of task control than the functionally oriented companies; especially with regard to the standardization of processes and of output. As a result of process management, the core business processes were first analyzed and described in terms of work activities, customer requirements. Furthermore, process ownership and control points were established. Process ownership was described in terms of tasks and responsibilities; this was done for the following reasons:

\footnotetext{
- to have clear accountability for correcting deviations and making process improvements

- to facilitate problem identification, problem resolution and corrective action taking

- to resolve situation where ambiguity in term of ownership ${ }^{10}$ is

- to provide authority to initiate actions for cost, schedule, quality or productivity reasons

- to get grip on the existing processes and protocols
} 
Regarding individual performance review, company D was the only company that uses its performance appraisal system to support its sales management control system. The Hoshin management system was the heart of the company's management system. It was used to align people, activities and performance metrics with the company's strategic priorities. Employee participation, team performance and early detection of potential pitfalls are behaviors by which company D hopes to achieve its desired results. At company D, each employee had a position plan with standards or targets; some of these targets were related to the employee's business fundamentals, others related to the annual Hoshin commitments. In sum, improvement efforts were also evaluated by the supervisor. Company D's employees performance appraisal was not only a thorough review of the performance level achieved by the employee over the previous evaluation period; it was found that this formal performance assessment also included a review of the the extent to which employees:

- participate in the planning process

- improve their skills as team players

- work to improve their skills in communication, planning and problem solving

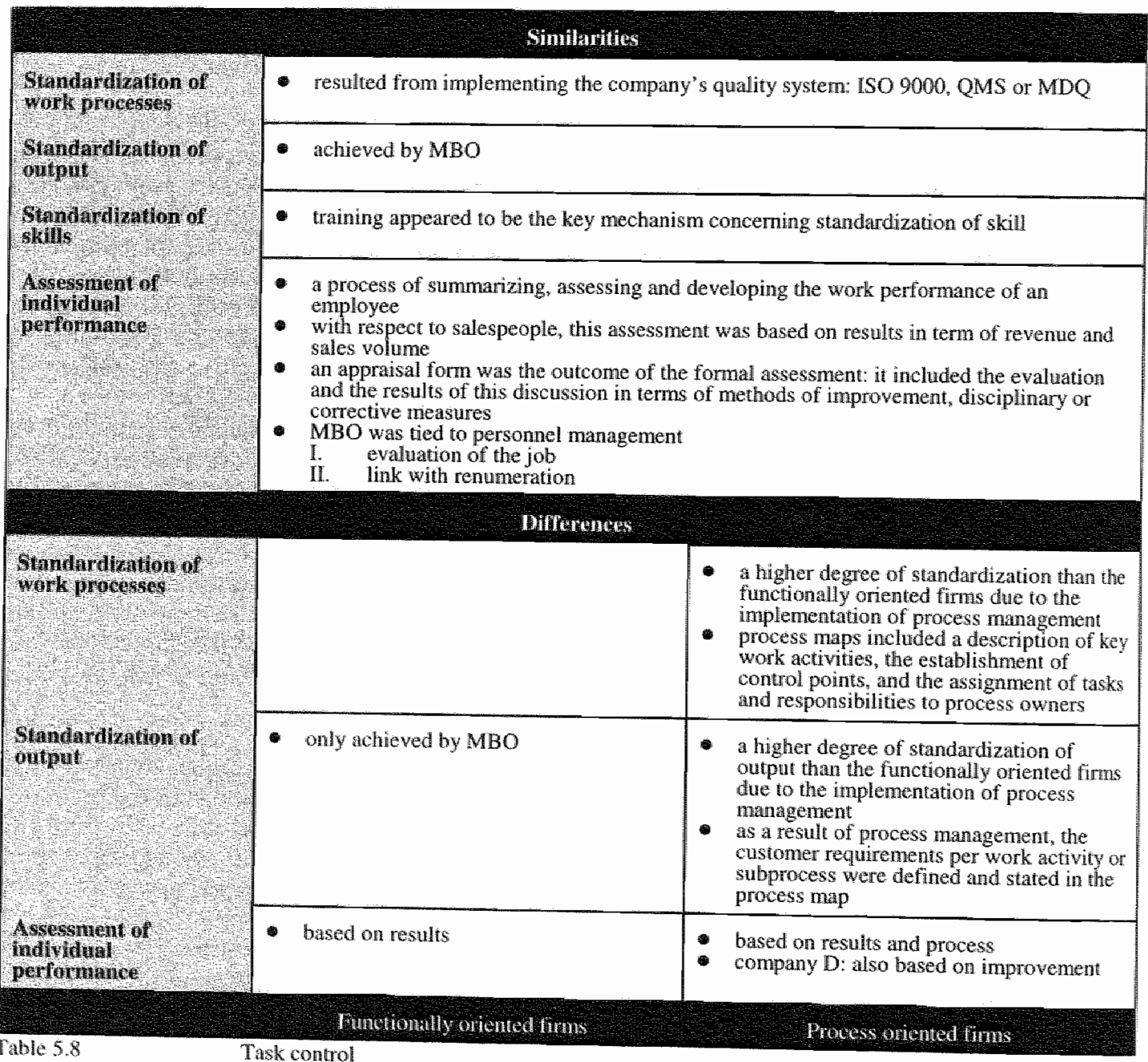




\subsection{SUMMARY AND CONCLUDING REMARKS}

On the basis of the comparative case analysis we can draw the following conclusions concerning the functionally oriented versus process driven organization.

In the first place, we may conclude that there exist differences with respect to the characteristics of the salesforce between the functionally oriented and the process driven. It was found that the process driven firms in our sample were more formalized than the functionally oriented firms. The core business processes were defined and described in details in process maps; these maps included information concerning work activities, control points, process owners, etc. The higher degree of formalization may be a consequence of process management but it may also be caused by other factors such as age/size and origin of the company. It also appeared that the process driven firms imposed various management tools on local management. These tools included improvement cycles, planning instruments and methods, etc.

With respect to operational decision making, it appeared that at the process driven organizations decision making authority concerning improvement was more decentralized than at the functionally oriented organization. The process owners were not only responsible for managing their process but also they have clear accountability for correcting deficiencies and making improvements to a process. The decision making authorities were described in detailed process maps.

In addition, we also found some differences concerning integration. The process driven organizations in our sample employed an extended MBO for integrating business activities. This extended version of MBO included the use of improvement cycles and top down / bottum up information flows. MBO in the functionally oriented firms was characterized by decisions on objectives, i.e. troubleshooting system, and planning of the coherence between the objectives of the individuals. Furthermore, quality function deployment (QFD) in the narrow sense was employed at the process driven organization; it implied a wider and process focus and deployment of quality activities in the functional departments.

In the second place, we found that there were some differences with respect to control practices between the functionally oriented and process driven firms. The process driven firms had highly integrated control systems built around TQM principles. In the context of sales control, they were specifically applied to achieving measurable continuous and breakthrough improvements. The employed control systems were used to:

- specify the methods and measures to achieve organizational objectives

- make visible the cause and effect linkages among local plans

- align the local objectives with the corporate objectives

- improve continuously the planning and other core business processes

We also found some differences with respect to the core control elements of our theoretical framework except for rewarding. With respect to the strategic and sales management planning, these managerial processes were documented in detailed process maps. Planning processes were seen as key business processes, and they were defined and described in detail as a result of process management. The planning processes at the process driven organization were identified as a key factor in performance improvement because these managerial processes determined the measures and critical success factors that were used to evaluate sales performance planning. This managerial process was used to determine the critical success factors and the performance measures needed for performance management. Salespeople were reminded of the importance of the customer focus and of relying on performance measurement.

Company D, for instance, had developed a performance management system characterized by a disciplined approach to planning and based on action. This system emphasized the importance of goals and measures throughout the whole organization. Managing planning processes was accomplished by defining work activities, assigning tasks and responsibilities to various 
management layers and initiating corrective action on process deviations as they occured at each of these levels. The planning processes at the process driven firms included clearly defined process ownership, defined boundaries and interfaces, and a well documented flow of work.

With respect to the outcome of the strategic and the sales planning processes, it appeared that the functionally and the process oriented have quite similar objectives, ranging from financial targets, e.g. revenue and contribution margin, to qualitative ones, e.g. customer focus and trust. With regard to the importance of strategic and operational targets, it was found that the priority objectives of the functionally oriented firms were primarily of a financial nature. These priority objectives included profit, costs and sales volume. The priority objectives of the process driven companies included targets related to "quality" and 'global objectives' on quality, profit, costs, volume and service.

In addition, the performance measurement system was also used to encourage regular reporting; it was used to provide the managers with appropriate information to allow them to evaluate progress-to-plans. The case studies of the process driven organizations, however, demonstrated that performance measurement helped the sales force organization to focus on achieving goal congruence and customer focus both internally and externally. Effective performance measurement enabled managers to evaluate action plans, to set future plans, and to implement these plans. This importance of performance measurement in sales can be illustrated by company's D moto: "... that which is measured gets better; but that which is measured and reported gets better faster".

Studying the outcome of the comparative case analysis highlighted that performance measurement at the process driven firms was formalized highly. This measurement was based on total quality control. The control cycle including the control points, the measures, and the measurement was described in the related process map. The process driven firms in our sample had a broad set of measures that was related directly to the companies' priority objectives: 'quality" and "global objectives" on quality, profit, costs, volume and service:

- product and service quality measures

- performance measures

- process time measures

- process cost measures

The performance measurement process at the functionally oriended firms in our sample was less formalized than at the process driven organizations. The measurement was focused on results as such and not on 'how' these results were attained, i.e. process performance. The set of performance measures was related directly to the companies" priority objectives that included profit, costs and sales volume targets.

With respect to performance evaluation, it appeared that there were some differences between functionally oriented and process driven organizations in our sample. The process driven organization used besides the traditional financial criteria, e.g. profit and costs, also measures related to process performance, e.g. process time and process cost measures, and product and service quality measures; performance evaluation was, therefore, based on 'results" and on "how these results were achieved' (process). The evaluation devices of the functionally oriented firms included only measures related to profit, cost and volume; performance evaluation was therefore based on "results", i.e. outcome based. Furthermore, it was found that the process driven orgamization had a performance evaluation system which was integrated into line management. This evaluation system included an audit ${ }^{11}$ by the director or manager and a self evaluation ${ }^{12}$ of results/objectives.

With regard to feedback, we may conclude that performance feedback was an ongoing process between management layers, and between subordinates and their superiors. The aim of this process was to exchange information concerning the performance expected and performance 
exhibited. We found that the main differences between the functionally and the process oriented firms were related to the feedback information, the review process and to the receivers of the feedback.

It appeared that performance feedback at the functionally oriented firms was focused on results. In particular, the performance feedback included information conceming the extent to which plamed performance was achieved, and whether corrective action was required. Performance feedback at the process driven organizations included information on process perforinance and results. At the process driving firms in our sample, providing performance feedback to process owners and taking corrective action on unwanted process deviation was perceived to be as of fundamental importance in stabilizing and improving business processes. Line management was informed with respect to process deviations but the process owners were responsible for initiating timely corrective action.

With respect to task control, we may conclude that the process driven firms have thigher degree of standardization of output and of work processes than the functionally oriented firms. This was explained by the use of process management. Furthermore, it was found that the assessments of individual performance at functionally oriented firms were focused on results whereas those of the process driven organizations were focused on process and results.

This concludes the cross case analysis of the four case studies described in the previous part of this thesis and interpreted in the format of a mega-case. The key findings concerning the differences among functionally versus process driven firms are presented predominantly in the table 5.9.

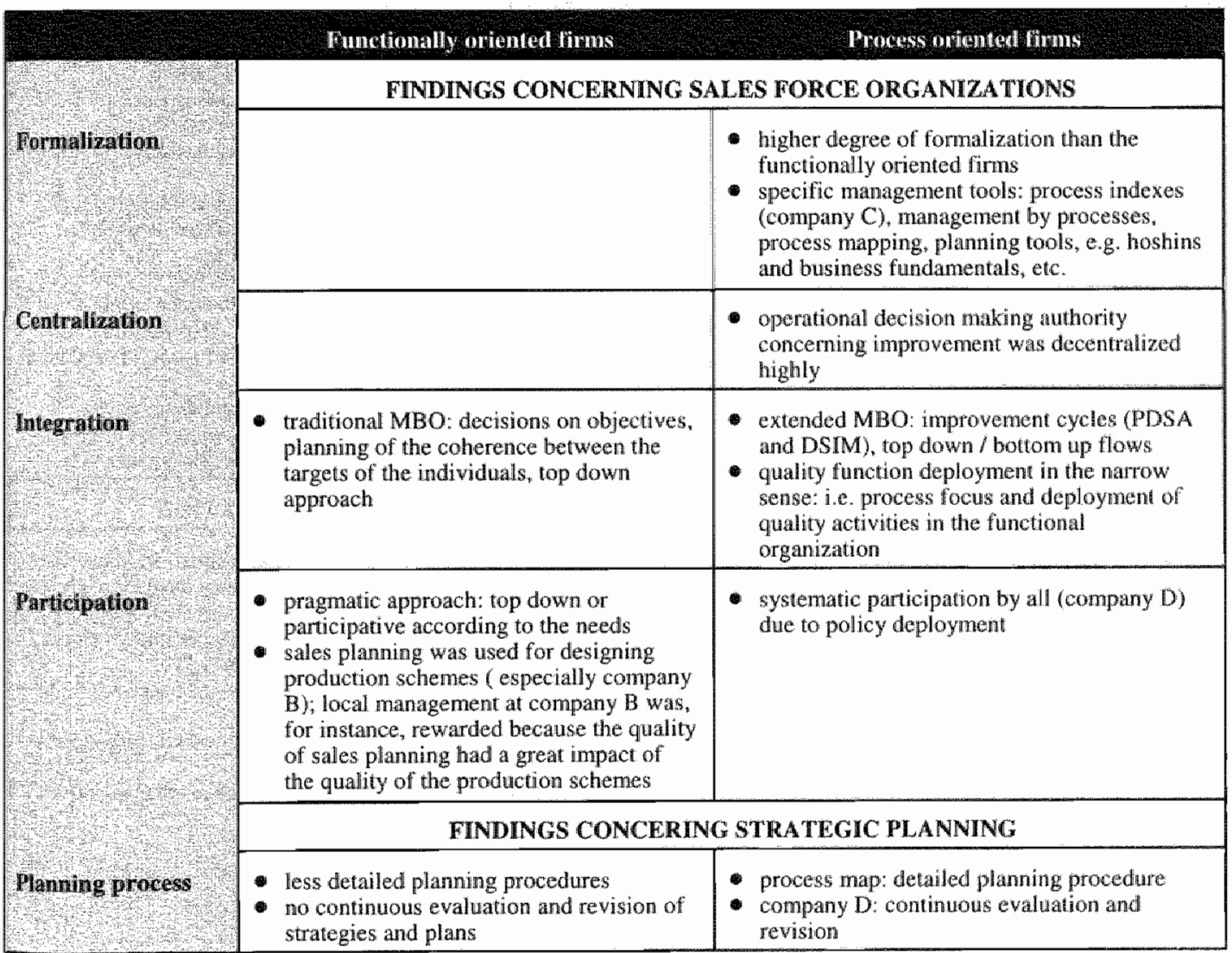




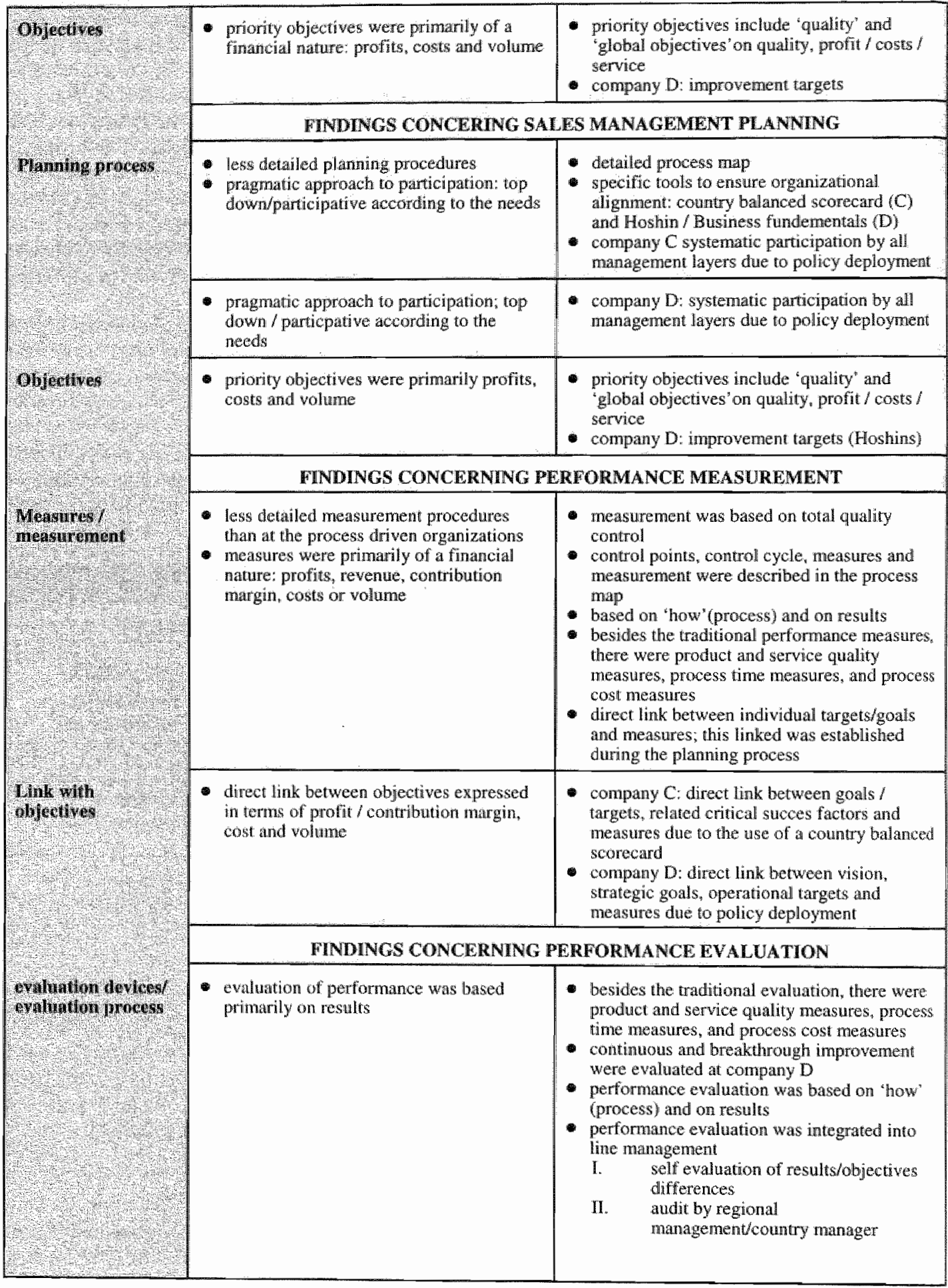




\begin{tabular}{|c|c|c|}
\hline & \multicolumn{2}{|c|}{ FINDINGS CONCER NING FETDAACK } \\
\hline 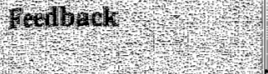 & $\begin{array}{l}\text { - perfomance feedback was focused } \\
\text { primarily on results }\end{array}$ & $\begin{array}{l}\text { - periomance feedback was focmsed on "how" } \\
\text { (process performance) and on results }\end{array}$ \\
\hline portes involver & - line management & $\begin{array}{l}\text { - regional and local process owners. and } \\
\text { country manager }\end{array}$ \\
\hline & \multicolumn{2}{|c|}{ FINDINGS CONCEKNING TASK CONTROL } \\
\hline Shorid proecsses & 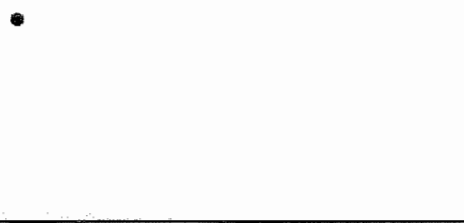 & $\begin{array}{l}\text { a higher degres of stardardization than the } \\
\text { functionally onented firms due to the } \\
\text { implementation of process mangernent } \\
\text { process maps included a description of key } \\
\text { work activites, the establishment of oontrol } \\
\text { points, and the assignment of tasks and } \\
\text { responsibilities to process owners }\end{array}$ \\
\hline 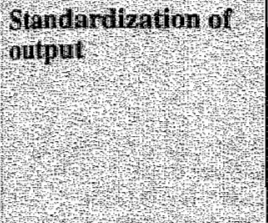 & - only achieved by $\mathrm{MBO}$ & $\begin{array}{l}\text { a higher degree of standadization of output } \\
\text { than the functionally oniented firms due to } \\
\text { the implementation of process management } \\
\text { as a result of process management, the } \\
\text { customer requirements per work activicy or } \\
\text { subprocess were defined and stated in the } \\
\text { process map }\end{array}$ \\
\hline 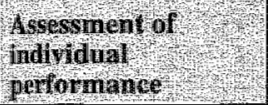 & - based on results & - based on results and process \\
\hline
\end{tabular}

Table 5.9 Overview of the differences between functionally oriented and process driving firms 


\section{Notes}

1.This can be explained by the fact that company $A_{A}$ is the only company in our sample that has no business partners or dealers to sell its products. The Benelux market is, according to the Dutch marketing manager, to small and too fragmented to have separate subsidiaries from the three countries.

2.The vision or mission was used to identify the company's purpose and its desired funure state; interaal assessment and future visioning uncover, within an organization, differing views of its purpose, its cument level of effectiweriess, and its potential for the future.

3. Indiwidual targets were often formulated per quarter of a year. These targets were used to evaluate the periormance of indiwidual salespersons and to calculate the performance based part of their salary.

4.i.e. local business unit, local salles unit, regional, worldwide

5.e.g. sales volume was measured daily; growth objectives was measures monthly, quarterly and yearly: market share was mesastred quarterly.

6.e.g cusstomer satisfaction was measured bi-annually or annually.

7. At company $C$, for instance, one example of an action plan element was to maintain a price leadership position in the printing business. Deployment entailled design of efficient processes, analyzing of resource and asset use, and creating related measures for resource and asset productivity, aligned for the worldwide product division and its sales units. It allso involves use of a cost-accounting system that provided activity level cost information to support daily management. Ongoing comperitive analysis and planning was used to remain sensitive to technological and other changes that might greatly reduce operating costs for the company or its competitors.

8. When the targets of one organizational unit were lowered, then it is often the case that other units have to perform better to compensate the effects of the adjustment.

9. Individual targets were often formulated per quarter of a year. These targets were used to evaluate the performance of individual salespersons and to calculate the performance based part of their salary.

10. For instance, assumed, or ad hoc, process ownership

11. e.g. the process audit at company $C$ and the annual audit at company $D$.

12. e.g. improwement cycless 



\section{Chapter 1}

The problem statement in its context

PAKT 1: THEORETICAL FAA MEWORK

\section{Chapter 2}

Formal organizational control

\section{Chapter 3}

Controlling the sales function

PART 2: EMIPIRICAL FINDINGS

\section{Chapter 4}

The research method

Case study A
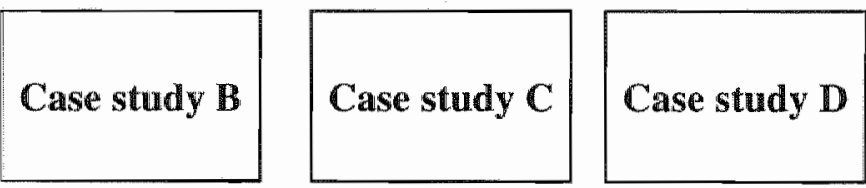

\section{Chapter 5}

Comparative case analysis

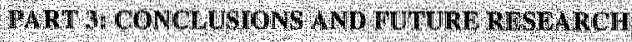

\section{Chapter 6}

Final conclusions and future research 


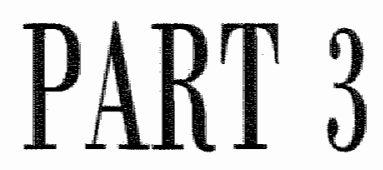

Conclusions and Future Research 


\section{Chapter 6 \\ Final Conclusions and Directions for Future Research}

What We Can Conclude and May Expect ...

\section{Chapter outline}

The purpose of this field study was to gain better insights into the formal control strategies with regard to sales efforts. More specifically, this research set out to examine how formal sales control systems are designed and used in an organization to control the sales function. A field reseatch design was applied combining exploratory and explanatory case studies.

Chapter 6 deals with the overview of the general findings concerning sales control practices and directions for future research. In section 6.1 the main topics of this thesis are discussed. Section 6.2 deals with the findings and the main conclusions regarding each research question. The separate findings on control practices were integrated in a theoretical framework for sales control. The managerial implications of the study are highlighted in section 6.3. Finally, in section 64, suggestions for future research are presented. 


\subsection{INTRODUCTION}

This chapter is used to summarize our major research findings, and to conclude this study with guidelines for formal sales control practices. This study aimed to contribute to the existing research in the following ways:

- The control function in sales management is studied by various researchers (see Cravens et al 1993; Jaworski ef al 1993; Challagalla and Shervani 1996; Ramaswami 1996); they have approached this topic from their own particular backgrownds and stress different aspects of the entire sales control process. This is also the case for this research. We used the insights taken from the cybernetic control and system theory to develop a framework for salles control practices. The research findings about sales control practices are structured around a framework. It is our belief that if the topics and subtopics of the framework are well chosen, then it is possible to make generalizations about sales control practices. These generalizations are useful because they summarize theoretical findings and lessons drawn from case studies (Anthony 1988). Additionally, they are usefull when their relationship to an overall framework is understood. For instance, when strategic planning and sales management planning are recognized as belonging to quite different parts of a framework, it becomes clear that many generalizations that apply to strategic plaming do not apply to sales management plamning. Thus, progress in accumulating knowledge concerning sales control practices depends on the development of frameworks as the basis for arranging generalizations. It implies that the basic control issues should be defined precisely; yet we are aware that there will be many borderline situations for which a precise advice is in doubt.

Managers in a business organization need to know how actions contribute to goal attainment. A framework for sales control can help these managers to develop an intuitive, personal framework consisting of generallizations about effective ways to behave; it permits managers to use these generalizations in a more efficient way. Not only researchers and managers but also system designers need a framiework for developing or adapting sales control systems. A framework permits an orderly arrangement of control topics; as new ideas come to a system designer's attention, these system designers need to know the limits of its applicability. This can be found out by organizing, comparing or contrasting these new ideas with previously accepted ones. A study of sales control systems in companies can lead to changes in the control systems. The task environment of today's sales force organization is enlarged. Although its main purpose is to generate revenue, its time horizon includes both short and long run. It implies that the concept of sales performance covers short and long term performance. It is up to today"s managers and researchers to enlarge the concept of sales control.

These topics were captured in two research questions:

- How does the sales control process take place in practice, and what formal control mechanisms are used? - How are the dimensions of sales control systems, specified by our theoretical model, realized within different types of organizations? How can this be explained?

These research questions were explored first by a literature review. The chapters 2 and 3 dealt with the existing research on organizational control and sales control. The question guiding this analysis was how organizations control formally their sales function in today's dynamic marketing environment. The outcome of this analysis was used to develop an appropriate research design for answering the second research question.

The case study method was selected to examine sales control practices. Our research stralegy consisted of two stages. The first stage included a large number of cases to gain a basic insight of the dimensions of sales control systems and of what factors account for control practices. This stage allowed us to gradually shift from exploratory to explanatory research and still maintain a balance between 'open mindedness' and 'focus'. The second stage was used to study the impact of differences in organizational forms, namely process versus functional, on sales control practices.

Chapter 5 was used to demonstrated the research findings. The findings were organized around the elements of our framework These outcomes are now used to draw final conclusions and highlight potential roads for future research. 


\subsection{SUMMARY OF OUR KEY RESEARCH FINDINGS}

\subsubsection{Our theoretical framework for studying formal sales control practices}

Developing strategies and long term plans for the sales force organization is part of the control process of management. The role of control processes is the subject of some debate: control in the sense of 'directing' or 'proactive' and control in the sense of 'correcting' or 'reactive'. In a widely adopted definition of control, Berry et al. (1995:18) suggested that the control process has proactive and reactive characteristics. It is a

"... a process for motivating and inspiring people to perform organizational activities that will further the organization's goals. It is also a process for detecting and correcting unintentional performance errors and inentional irregularities, such as theft ar misuse of resources."

This managerial process takes place in a control system. Control systems are based on the idea that a system is a set of interconnected elements that functions as a collective whole. Each element is developed to increase the probability that people will behave in ways that lead to the attainment of organizational objectives, i.e., to achieve organizational control. The findings of our literature review were used to develop our framework for organizational control. This framework consisis of:

a planning element

an operational subsystem

outcomes, a measuring element, task control

an effector

an ewaluating and rewarding element

corrective and evaluatiwe feedback

The general framework for organizational control was adapted to a sales context as follows. In this thesis, sales control systems are a collection of control devices; each device is intended to function in such a manner to achieve overall control in the sales force organization. A definition of sales control systems therefore depends on defining sales control. In terms of processes, sales control was defined

¿... as a managerial process for motivating and inspiring sales people to perform sales activities that will further the organization's goals" it is also a process for detecting and correcting unintentional sales performance errors and intentional irregularities, such as theft or misuse of resources."

The nature of the specific control devices were highlighted in chapter 3 . Figure 6.1 is used to outline the theoretical framework for sales control.According to this framework, sales control' takes place as follows.

Strategic planning usually takes place at the strategic level within the company; it is the process by which the guiding members of the organization develop a vision of the future and define a roadmap for attaining that future. Thus, strategic planning aims to exploit the new and different opportunities of tomorrow, in contrast to long range planning, which tries to optimize for tomorrow the trends of today (Drucker 1980); traditional "long term planning" is merely an extrapolation of the current state of the organization. Strategic planning considers a horizon of five or more years and leads to strategic goals including corporate strategies to reach these goals. While strategic planning is usually conducted for the organization as a whole, functional units of the organization and particular lines of business may also conduct strategic planning. The process of deploying and implementing the strategic plan has been termed as strategic management and/or operational/tactical planning and management. Deployment and implementation of the plan come under the topic of strategic management, operational planning and other such terms. Re-evaluation of the plan is recommended. Periodically, management revisits the plan, usually after a year or two. A review and planning process of this nature, when conducted on an annual basis, enables a company to know its market status, its strengths as well as its weaknesses and what tough issues must be tackled if it 
is to control destiny. Again, this is in the spirit of orgamizationalleadership treating the plan as an living document and using it to guide the destiny of the organization. Revising the plan can be used as a means to adjust the course of the organization.

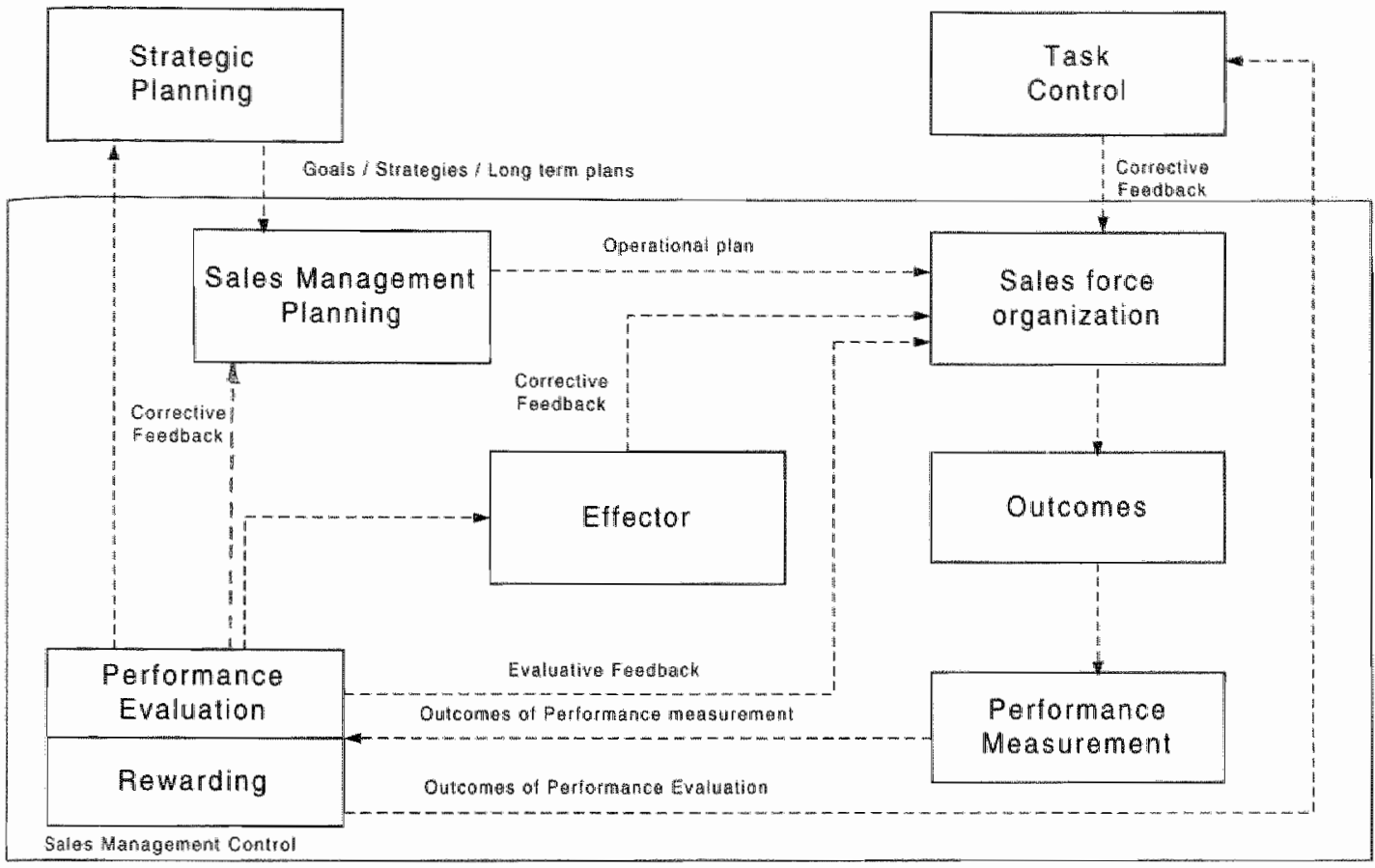

Figure 6.1 Theoretical Franework: The Control Process in a Sales Context

The outcomes of strategic planning are translated into goals for the operational subsystem. This process is called sales management planning in our study. Sales management planning in a "going concem organization' starts when top management meets the operating management teams to review past performance, to set goals for key, functional, areas of the local sales office, and to formulate a set of actions needed to attain these goals. Additionally, performance standards including schedules, benchmarks and Key Performance Indicators (KPIs) are set to monitor progress. This final step of sales management planning is important because only through benchmarking and evaluating performance levels of success can be detemined.

The annual sales planning is an integrated mixture of top down issues prepared at the senior levels and bottom up insight that comes from the operating sales offices. The overall sales planning process enables corporate and operating management to plan for success by shaping strategies for growth and control. It lets them set objectives and then determine what must be done to succeed. The key is to balance and clarify the roles within the process and how those roles are to be intermingled. Top management sometimes sets aggressive stretch targets and then allow operating managers to determine how they will achieve their goals. It is important that the operating unit leaders understand why top management made its decisions, because when implementors get involved in planning, their commitment becomes clear and strong. Sales management planning can enable a company to better recognize a unified mission. It starts a compelling drive for improved effectiveness, profitability and growth. For management, it forces cross functional discussion so all operating managers see how their actions fit into the broader picture and helps ease acceptance of others' ideas. For staff, it is the catalyst for increased customer satisfaction, optimized operations 
and expanded sales. The outcomes of sales planning are presented in a business plan. This business plan focuses on what must be done in the coming year and what resources, infrastructure and head counts are available.

The business operations of the local settlement will be directed or guided by the information of the plan. The sales offices' outcomes are measured and evaluated to determine the extent to which planned results are achieved, i.e. performance assessment. This performance review provides key feedback required to determine not only how well the implementation of the new system is doing relative to goals and budgets, but more importantly, how well the business is doing in accomplishing its objectives over time. Key business measurements are calculated and presented in formats showing actual performance over time against a user defined budget or goal. Performance assessment also helps to determine the areas of the business which required additional attention and why, as well as highlighting those areas meeting and exceeding objectives. Local management, therefore, reports actual performance at periodic intervals during the period for which the outcomes of actions are to be measured. During this period, regional management mees periodically with local management to evaluate their performance. They will agree on which targeis are being met, on where improvement is necessary and on a plan of correction. Overall, three types of corrective action can be initiated:

- adjustments of goals in the light of actual performance, e.g. goals were too ambitious

- adjustments of inputs to stabilize the outcomes at a desired level

- making changes in the entired activity

Local management is rewarded based upon the actual performance and improvement in performance. At the next meeting, regional and local management review current performance together with the results of past corrective actions. Corrective actions are planned and initiated timely to ensure that predefined targets are attained based upon the discussion during this meeting. This implies that the control process continues in a repetitive manner for each period and if continues throughout the organization.

The outcomes of the performance evaluation can be used for task control purposes: evaluating whether the specified tasks are carried out effectively and efficiently. When tasks are not accomplished effectively and/or efficiently, two types of corrective action can be initiated. First, a supervisor can undertake action to convince an individual to follow the rules and procedures. Second, rules and procedures are improved to respond to changing circumstances, e.g. by introducing a new logistic system. Corrective feedback provides information to decide what corrective action they should undertake.

\subsubsection{Some General Conclusions}

\section{There is no 'right' approach to sales control}

We used case studies to look at the manifestations of sales control systems identified in the theory and analyzed how organizations control formally their salles function. The four cases provide us Illustrations how IT companies control their sales function. All four companies are very successful in today's IT market; yet there are some variations in their sales control practices. There are variations in control practices at two levels: within a specific group of firms: between the two functional oriented companies, and between the two process
driven organizations

- between the functional and process driven organization

This finding implies that there is no 'right' approach toward sales control. The effectiveness of sales control systems does not only depend on the selection of "right" control devices; it also depends an the corporate culture and leadership style, the organization's willingness to reward positive behavior change, and linking compensation with achievement of personal targets. It is important to bave 
control system that is fully integrated with the company's culture, strategy, structure and market environment. Furthermore, assessing whether good sales control has been achieved is difficult and subjective because (Merchant 1998):

- the researcher possesses innate human limitations and biases

- adequacy of sales control must be measured against a future that can be very difficult to predict

The companies in our sample, however, are all very successful in their business environment. This can be an indication that they achieved 'good sales control', either because they control sales performance on one or more critical performance dimensions or because they implemented a control system that support management to avoid loss or impairment of assets, deficient revenues, excessive costs, inaccurate records, and report that can lead to poor decisions, business interruptions, etc.

\section{To obtain integrated control processes}

It was found that sales control is an ongoing, proactive effort designed to facilitate getting work. done and develop worker capability. Salespeople must have a clear understanding of expected results, receive coaching and feedback, be included in a structured, recurrent performance review, and be rewarded for meeting expectations. Control processes are, therefore, appropriately integrated with company objectives, plans and measurement systems. These processes:

\section{... provide salespersons with a clear understanding of expected results..}

Making company objectives 'real' for individual workers is among the toughest challenges facing today's managers. The old adage, 'If you don't know where you're going, you may just get there', certainly applies. In its simplest form, sales control helps managers and employees in the field set and reach goals. Objectives are performance standards that can be used as benchmarks against which to evaluate work performance. While job descriptions are used to describe the essential functions and the tasks to be done, the performance standard defines how well each function or task must be performed to meet or exceed expectations. Using effective monitoring and feedback, the individual employee knows exactly what needs to be accomplished to attain expected results.

When objectives are developed in collaboration with the employees for whose positions they are being developed, it is more likely that these objectives are:

- accepted by the subordinate and the performance manager

- understood by the subordinate and performance manager

- more realistic because they reflect the realities of the work context and conditions

- more appropriate to the requirements of the subordinate's job

- creating greater commitment to the organization

...integrate effectively with company objectives...

'What gets measured, gets done' is a well known truth. Management should, therefore, know what it wants before it begins to take measurements. It implies that management should know how to implement a strategy and to drive change. The strategic plan creates a mission for how the organization will behave, what its performance will be, and how others will perceive it. Such a plan helps management to close the gap between this mission and the self assessment snapshot. For the case findings $D$, it was found that this can be achieved when:

- vision and/or mission and strategy are measurable and actionable

- strategies link to departmental, functional, team, and individual objectives, and to long and short term resource allocation

- periodic feedback in a coherent way is critical for assessing performance

The company's sales control system should be structured to support attaining overall company objectives. The system may also be appropriately integrated with other company processes, such as pay, perquisite and recognition programs; integrating company planning and administrative processes with sales control increases the chances of the sales organization for successfully meeting 
the company" mission. Improving performance means e.g. performance metrics that are aligned with, and derived from, the current strategy and vision of the company. The key to appropriate sales control designs is having measures derived from the links between strategies, goals, resources, and feedback. These links helps management to assess strategy implementation and goal attainment. Measures for reviewing performance against strategies are best identified as each strategy is: developed.This way, the company can agree upon the targets for each measure within the context of the planned goals and related strategies. Performance measures are powerful when they balance the critical organizational perspectives, such as customers, employees, and the business. Such a balanced set of measures changes the focus sales planning and performance assessment, its deployment and its feedback.

\section{... simplify hwman resource management...}

Employees are often an organization's most expensive resource. Effectively managing worker performance can ensure that these resources are most effectively applied to the company's ultimate success. Developing a useful sales control system can:

- provide salespeople with a clear understanding of expected results

- effectively organize individual salles performance

... are organized by paper or electronic forms and thorough training.

Talking about effective sales control is one thing; organizing the system to make it work is quite another. Forms, whether on paper or electronic, must be user friendly and effective in captring needed performance information. They can be useful to facilitate monitoring and feedback. In addition, a good foundation of training, for both managers and employees, is vital for successfully implementing any control system. Employees acquire, apply, and build capability around the skills, tools, and techniques needed in this environment.

\subsubsection{Functionally versus process driven sales force organizations}

It appeared from our cross case analysis that the companies under study have much in common regarding sales control practices; salles control is essential for success in today's uncertain and resource constrained environment, so it is an integral part of management. Sales control systens have three core elements: strategic planning, sales management control processes, such as annual planning and performance measurement, and links between results and various organizational rewards. Sales control systems also rely on task controls; these controls are commonly referred to as "internal controls". All the companies had designed formal sales control systems for setting salles and other organizational objectives and deciding how they will be met, and assessing target achievement. Such systems support management with respect to designing, structuring and facilitating action producing strategic thinking and decision making processes. It implies that planning and control activities were highly interrelated at each control level; from strategic planning toward task control. These interrelationships were related to the following control issues:

- developing mission, vision and value statements

- identifying extemal driving forces and strategic issues

- documenting customer needs and market potential

- assessing intemal strengths and weaknesses

- setting organizational goals

- identifying, analyzing and choosing strategies to achieve the goals

- developing action plans to implement the strategies

- communicating goals, strategies and plans to those who will be affected by them

- establishing reporting feedback and monitoring processes.

The identified similarities among the firms in our sample are summarized in table 6.1. These similarities can be used to illustrate the interrelationships between the core elements of sales control systems at the different control levels. 


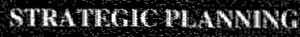

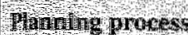

15.t.

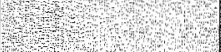

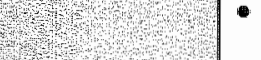

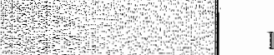

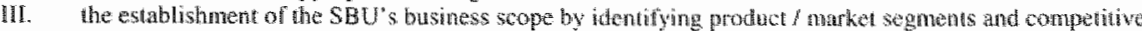
priprities

IV. the development and enactment of acton programs to support the competitive prioritios

V. The translation of the corporate plan into local ptats

VI. stritegy implementation

WII. evaluation and revision

- the outcome of the strategic planning process were stated in at stategic plan; il included long term objectives,

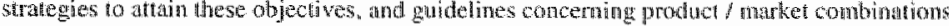

- the planning horizon was from thee to five years

Partices Gnowied

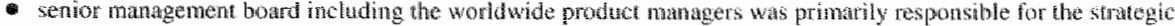
plantring activities

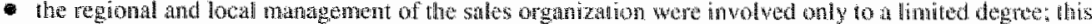

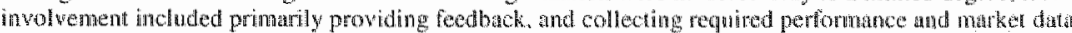

\section{Objectives}

share and return ratios

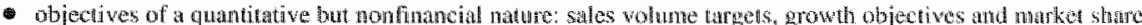

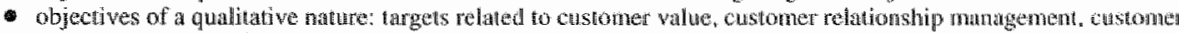
focts, customer confidence / trust, and product/ service qualing

\section{SAIIBS MANAGEMBNT DHANNINK}

Tlanining provess

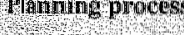

Oijedtive

Cintsuthen objectives
- the formulation of annuall sales targets was formalized in ti operational plan; it included operational obicotives. commercial and operating budgets, and action plans

- lop down procedure with respect to the operational targets for the local sates wiflce top down and bot tom up procedure with respect to the operational targets for the local business urits s.a. siltes teims

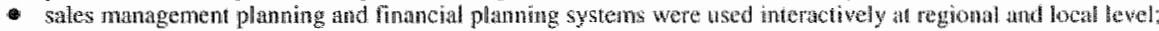
once sales targets were set, the financial conseguences in terms of budigets were calculated by the finducial departinemts

- the key planning steps were

I. Whe establishment of the negional sales targets by the headquarters

II. the transhation of the regional sales targets indo locul salles targets

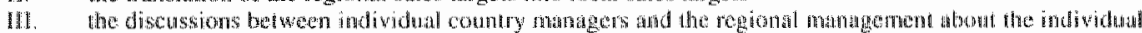

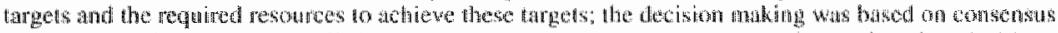

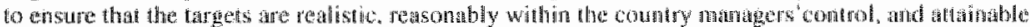

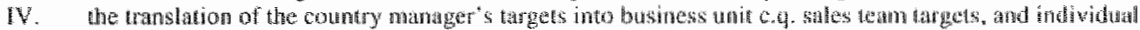

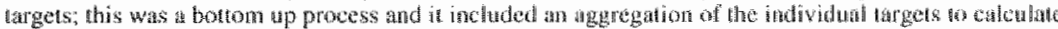
the business wit eq. sal we team targets

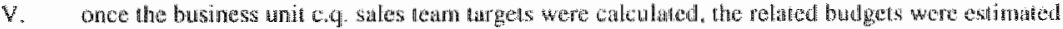

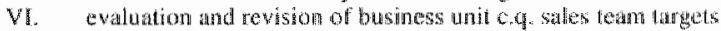

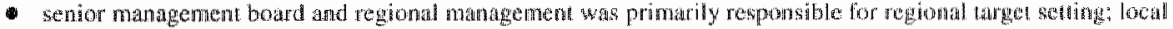

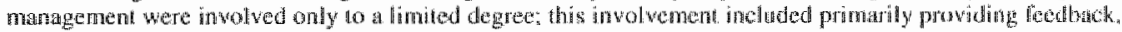
and collecing requined pertormance and markel dat

- the neginat and local managentent are responsible for local tared setting

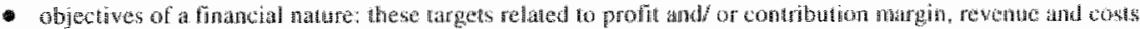

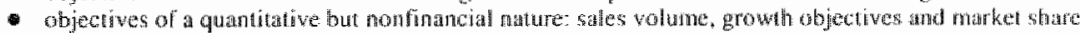

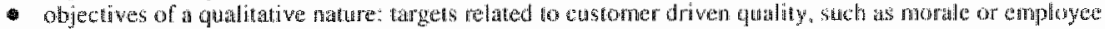

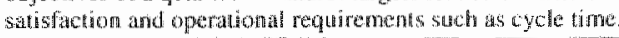

- clear link between operational targets of a catantiative mature and the used performance measures 


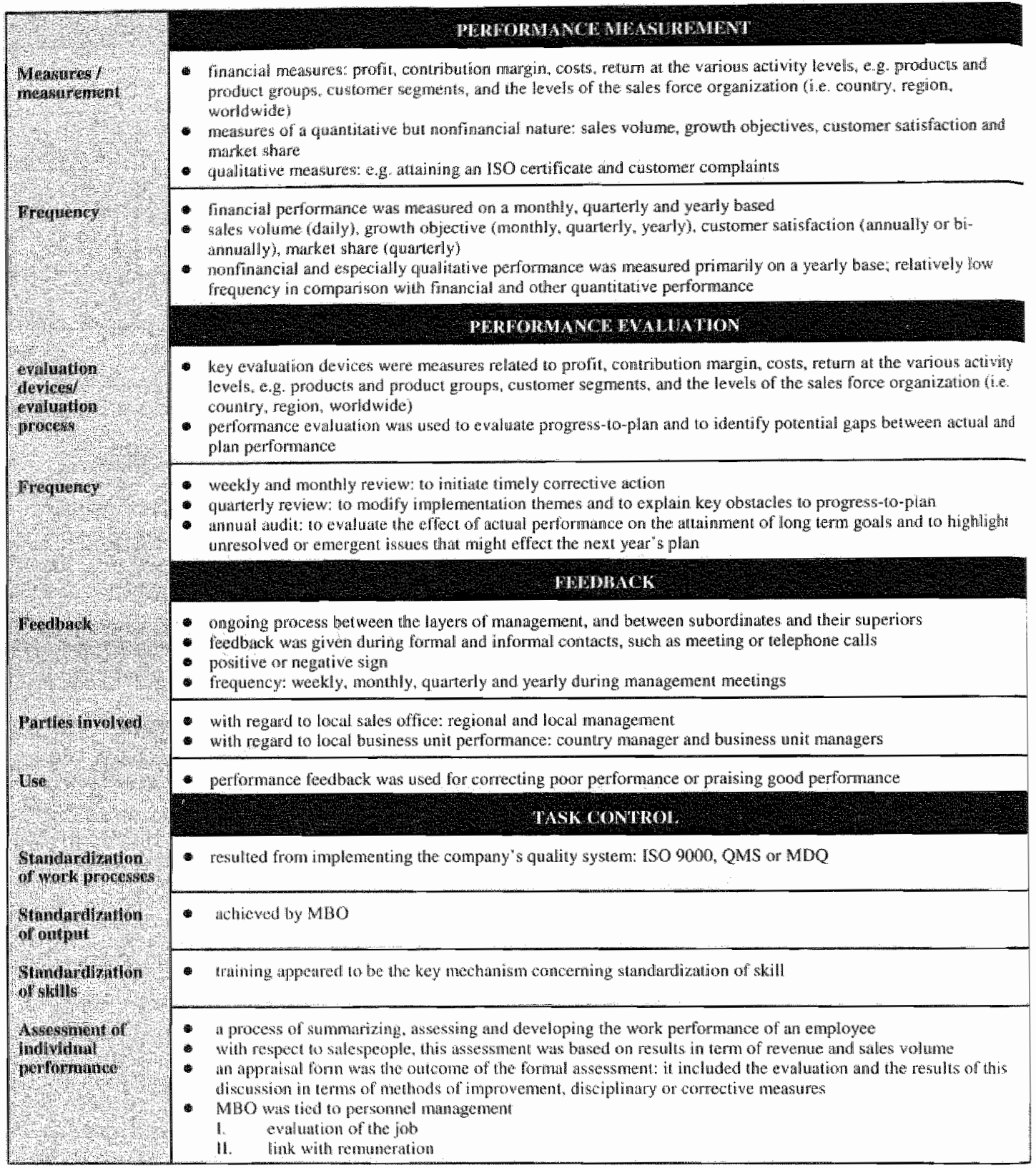

Table 6.1 Overview of the similarities

Examination of the case findings indicated that there was also some variation in sales control practices between the functionally oriented and process driven firms in our sample. It appeared that the implementation of process management had a great impact on how the local sales operations are performed and controlled by headquarters. 


\section{Functionally oriented firms and their sales control practices}

The functionally oriented firms in our sample had organized and grouped interrelated activities by function. This grouping enabled the firms to pool resources among different activities in the sales force organization and to promote specialization and efficient management of similarly skilled sales and marketing personnell. Sales control had been explicit in sales management of the companies under study. Making plans and monitoring and managing performance were perceived as essential activities of all functionally oriented firms. There was a variety of approaches to sales control practices reflecting closely the functional environment of the companies under study.

- The sales force organizations of the functionally oriented firms, for instance, appeared to be less formalized than the process driven firms. Formalization was accomplished by structuring business operations, function and job descriptions, ISO 9000 handbooks, training and other education programs, and management was held responsible for supervising the use of rules and procedures. Furthermore, decision making concerning strategy formation and marketing mix policy was centralized highly. With regard to integration, the traditional form of Management By Objectives (MBO) was used. The purpose of $M B O$ was to give subordinates a voice in the goal setting and planning processes and to clarify for them exactly what they are expected to accomplish in a given time span. Top managers communicated why they adopted $\mathrm{MBO}$, what they would accomplish, and that they were committed to it. Employees were educated about MBO and it must be implemented in a consistent manner. MBO began with collaborative goal setting between a manager and a subordinate; the goals were clarified and written down. The resources needed to achieve the goals were discussed and periodic reviews were held. Feedback served two functions: it helped to keep the subordinate was on track, and it served us an incentive for greater effort. Furthermore, participation in decision making was characterized by a pragmatic approach. Participation was top down or participative according to the needs. Participation was top down regarding to strategy formation; strategic goals and plans were handed down to department heads in a preemptive manner by top management. With respect to operational decision making, participation was encouraged because the opinion was shared that people must accept objectives and goals if they are going to have any motivational effect. Having people participate in setting objectives and goals usually aids a great deal in getting them to accept them. When objectives are dictated without giving people the opportunity to participate in a discussion and negotiation, teams and people in the Western world rarely accept the objectives or goals, or make a commitment to achieving them.

- With respect to strategic and sales management planning, it appeared that the functionally oriented firms in our sample had less detailed planning procedures, and no continuous evaluation and tevision of strategies and plans. Furthermore, participation in decision making was characterized by a pragmatic approach: top down and participative decision making according to the needs. Strategic objectives were the outcomes to be achieved over the foreseeable future, typically 5 years. The priority objectives were primarily of a financial nature: profit, sales, costs and volume. These objectives described results, not efforts, and were stated as desired future conditions; they incorporated performance measures with clear quantiffed target levells of accomplishment. Sales management planning included the development of the annual sales performance plan. This plan generally included the annual goals and the annual action plans, the inputs and outputs needed to achieve the goals. This annual sales performance plan links outcome related performance goals to specific outputs and inputs for a single year. Outcome related goals were expressed in terms of profit, costs and volume targets.

- With regard to performance measurement, it was found that the used measures cover primarily financial performance and related operational targets. Furthermore, the functionally oriented firms rely heavily on departmental function, instead of on cross departmental or cross functional processes; this prevents company view of performance, and encourage operating unit managers to be concerned only with their minor portion of a process that spans multiple organizational units.

- Performance ewaluation is based primarily on budget analysis. This budgetary view of performance evaluation is an inwardly focused exercise; it does not take into account the critical outside perspectives of custoners and stakeholders. Customers define value in terms of quality, effectiveness, and customer satisfaction. These dimensions are not considered explicitly in the financial model.

- Performance feedback focuses primarily on results; e.g. contribution margin, revenue and sales volume. This is performance feedback in a narrow sense. 
- In sum, we may conclude that the functionally oriented firms in our study have strong financial driven control practices monfinancial issues such as customer value in terms of quality, effectiveness and custoner satisfaction are lacking. Nonfinancial performance are assessed primarily by obtaining ISO certificates. The case findings can also be used to demonstrate that the effectiveness of these control practices depends on the belief that these practices are the most appropriate ones for the company, and the degree to which the core elements of ales control systems are integrated.

\section{Process driven firms and their sales control practices}

The fundamentals of process management are threefold: process initiation, process definition and process control. Fundamental to process management of company $\mathrm{C}$ and $\mathrm{D}$ was understanding and improving the firm"s core business processes; it involved applying certain principles in examining and improving the work flow of an operation. Furthermore, process management emphasized systematically the prerequisites for doing well and results, incentive support, strategic capability, and improvement. The cultural aspect of process management entailed that functional power structures were converted into competence centers supporting the creation of added value to customers. As a result of process management, sales management included the notions of work flow, sequential operations, and process control. Making plans and monitoring and managing performance were also perceived as essential activities of the process driven firms in our sample. There was a variety of approaches to sales control practices reflecting closely the (internal) process environment of the companies under study:

- The sales force organizations of the functionally oriented firms, for instance, appeared to be less formalized than the process driven firms. Formalization was accomplished by structuring business operations, function and job descriptions, ISO 9000 handbooks, training and other education programs, and management was held responsible for supervising the use of rules and procedures. Furthermore, decision making concerning strategy formation and marketing mix policy was centralized highly. With regard to integration, the traditional form of Management By Objectives (MBO) was used. The purpose of $\mathrm{MBO}$ was to give subordinates a woice in the goal setting and planning processes and to clarify for them exactly what they are expected to accomplish in a given time span. Top managers communicated why they adopted MBO, what they would accomplish, and that they were committed to it. Employees were educated about MBO and it must be implemented in a consistent manner. MBO began with collaborative goal setting between a manager and a subordinate; the goals were clarified and written down. The resources needed to achieve the goals were discussed and periodic reviews were held. Feedback served two functions: it helped to keep the subordinate was on track, and it served as an incentive for greater effort. Furthermore, participation in decision making was characterized by a pragmatic approach. Participation was top down or participative according to the needs. Participation was top down regarding to strategy formation; strategic goals and plans were handed down to department heads in a preemptive manner by top management. With respect to operational decision making, participation was encouraged because the opinion was shared that people must accept objectives and goals if they are going to have any motivational effect. Having people participate in setting objectives and goals usually aids a great deal in getting them to accept them. When objectives are dictated without giving people the opportunity to participate in a discussion and negotiation, teams and people in the Western world rarely accept the objectives or goals, or make a commitment to achieving them.

- With respect to strategic and sales management planning, it appeared that the functionally oriented firms in our satmple had less detailed planning procedures, and no continuous evaluation and revision of strategies and plans. Furthermore, participation in decision making was characterized by a pragmatic approach: top clown and participative decision making according to the needs. Strategic objectives were the outcomes to be achieved over the foreseeable future, typically 5 years. The priority objectives were primarily of a financial nature: profit. sales, costs and volume. These objectives described results, not efforts, and were stated as desired future conditions: they incorporated performance measures with clear quantified target levels of accomplishment. Sales management planning included the development of the annual sales performance plan. This plin generally included the annual goals and the annual action plans, the inputs and outputs needed to achieve the goals. This annual sales performance plan links outcome related performance goals to specific outputs and inputs for a single year. Outcome-related goals were expressed in terms of profit, costs and volume rargets.

- With regard to performance measurement, it was found that the used measures cover primarily financial performance and related operational targets. Furthermore, the functionally oriented firms rely heavily on departmental function, instead of on cross departmental or cross functional processes; this prevents company 
view of performance, and encourage operating unit managers to be concemed only with their minor portion of a process that spans multiple organizational units.

- Performance evaluation is based primarily on budget analysis. This budgetary wiew of performance evaluation is an inwardly focused exercise; it does not take into account the critical outside perspectives of customers and stakeholders. Customers define value in terms of quality, effectiveness, and customer satisfaction. These dimensions are not considered explicitly in the financial model.

- Performance feedback focuses primarily on results; e.g. contribution margin, revenue and sales volume. This is performance feedback in a narrow sense.

- In sum, we may conclude that the functionally oriented firms in our study have strong financial driwen control practices; nonfinancial issues such as customer value in terms of quality, effectiveness and customer satisfaction are lacking. Nonfinancial performance are assessed primarily by obtaining ISO certificates. The case findings can also be used to demonstrate that the effectiveness of these control practices depends on the belief that these practices are the most appropriate ones for the company, and the degree to which the core elements of sales control systems are integrated.

\section{Process driven firms and their sales control practices}

The fundamentals of process management are threefold: process initiation, process definition and process control. Fundamental to process management of company $C$ and D was understanding and improving the firm's core business processes; it involved applying certain principles in examining and improving the work flow of an operation. Furthermore, process management emphasized systematically the prerequisites for doing well and results, incentive support, strategic capability, and improvement. The cultural aspect of process management entailed that functional power structures were converted into competence centers supporting the creation of added value to customers. As a result of process management, sales management included the notions of work flow, sequential operations, and process control. Making plans and monitoring and managing performance were also perceived as essential activities of the process driven firms in our sample. There was a variety of approaches to sales control practices reflecting closely the (internal) process environment of the companies under study:

- The sales force organization of the process driven firms in our sample was formalized highly ass a result of process management. Establishing process ownership, defining boundlaries and interfaces, and defining the core business processes were the key forms of formalization. A process, e.g. the salles process, was defined as a group of interrelated work actiwities providing output of greater value than the inputs by meaths of transformation. It was found that the sales process was perceiwed as a complex business process consisting of numerous subprocesses and crossing several functional entities of a sales force organization. In this context, work flow was horizontal in nature, and flowing through functional entities organized in a vertical structure. The core business processes were all described by generall attributes in terms of ownership, boundaries. documented work flow, established control points and measurements, and feedback control. Process ownership was generally clear and explicit; a process owner is responsible for yield, cost, quality and schedulle, and manages the process to the targets set on these standards. Specific tools ware developed to support process owners in their decision making: process maps included the process definution and the owners" area of jurisdiction, and specific tools were designed, e.g. planning tools such as Hoshin planning, and inprovement cycles.

With respect to operational decision making, it appeared that operational decision making concerning improvement efforts was decentralized. Process owners were also responsible for process improvement; the owners had the authority to change the process within their area of jurisdiction.

Again, management by Objectives (MBO) appeared to be a core integrating mechanism; yet the process driven firms applied a more extended form of MBO than the functionally oriented firms. The key elements of this extended form of MBO are a planning and implementation process that is improved continuously and at strategic focus. The advantage of the extended form of MBO is cwofold: in uses and reinforces Plan-Do-Check-Act, and decision making is based on top down / bottom up flows. Compariy D extended MBO with policy deployment. This integrating mechanism was used to increase participation and coordination by all levels and departments, to planning and implementation based on facts, and to cascade goals and action plans through the organization. This integrating mechanism improved the company's planning and implementation process. Specifically, it: 
- created a process for repeated breakthrough solutions

- increased interdepartmental cooperation

- created a disciplined planning system that is responsive and flexible

- gave leadership a method to understand problem areas

- created a common focus throughout the organization

- increased participation and coordination by all levels and departments

Integration was also accomplished by quality deployment in the narrow sense. Quality Function Deployment (QFD) provides i methodology for ensuring that both products and services meet customers' needs; it is a structured approach to defining cusiomer needs or requirements and translating them into specific plans to produce products to meet those requirements. Company $C$ and $D$ employed QFD in the narrow sense: focts on the processes, deployment of quality activities in the functional organization.As result of QFD, the organizations can support their departmental functions like marketing, sales, engineering, finance, elc. with cross-functions like qualiry inmprovement, cost reduction, and scheduling, i.e. quantity, productivity, throughput, delivery.

With respect to participation ${ }_{i}$ it was found that Hoshin management was based on a communicative style of management. It encouraged consultation between sales management and people; it draws on the experienca, knowledge and ideas of people in such activities as designing jobs and setting realistic work objectives. Together with a conmitment to effective communication with people and consultative arrangements, Hoshin management contributes to corporate goals and performance management by broadening the input into decision making processes.

- The planning processes of both process driven organizations place wision/mission and goals in the forefron of performance measurement development. Vision/mission drive goals, and goals drive measures. The targets are the roadmaps for actions and behaviors; they provide direction in a variety of critical performance areas. Performance measures pull the entire company toward the vision/mission, toward the kind of organization it is trying to become. The planning processes and related management tools were designed to resolve traditional management systems* inability to link long term strategy to short term actions. In particular:

- to build consensus around the organization's vision/mission and strategy

- to communicate the strategy up and down the organization and to link it lio operating unit and individual performance objectives

- to enable organizations to integrate their financial plans with their business plans

With respect to strategic and sales management planning, it appeared that the process oriented firms in our sample had detailed planning procedures. It was also found that the planning processes were perceived as key business processes. This implied that there were process owners who were responsible for managing and improving the planning processes in general. Specifically, they:

- coordinate gathering, interpretation, and dissemination of planning data by key business process, critical stiocess factors, and objectives

- educate others on planning tecluniques, improwing core actiwities, and conducting quality reviews of the planning process

- conmunicate intended improvenents frequently to management and as part of the normal presentation of the planning outcome; they typically want to hear about changes in format and content, call for suggested improvements and changes in schedules for when to submit performance data or to get reports brick

- perform a formal audit annually

With respect to performance measurement, it appeared that the process driwen firms in our sample had a comprehensive set of measurements. The fact that process management places so much emphasis on process performance grows directly out of a decade of corporate experience in moving from planning to deployment and to achieving results of more effective management experience. From the point of view of measurements, it is the collection and use of proper information to facilitate improved performance. Process management requires a broad sel of measures, related to the thiree parts of a process: something enters the process, something is done to it, and a result or output emerges. Effective process management calls for measuring activities and volumes at all three stages. This measurement can be used to document how nuch the sales force is getting done with the process and how effective it is. The importance of measurement in process management makes that the process driven firms in our sample have a general strategy toward performance measurement. It is important attempting to apply a common approach and vocabulary so that individual working across sales departments and processes. The key steps that were taken are summarized below: 
- to put responsibility for designing the measures and their pertiodic reporting on the process owner" $\mathrm{s}$ shoulder

- to go through a process to idencify critical performance areas, to get buy-in for those, to identify potential measures, to settle on what they should be, and to settle on how they will be conmunicated

to develop a plan for measuring up performance

to appoint and empower a measurement process owner

to assess the quality of the measures on a regullar base

- Management by fact is at the heart of all control systems. Analyzing the data provided by measures becomes a critical activity for all people to ensure that things improve and that one understands the consequences and results of important actions. Performance evaluation is done to determine the state of a business operation. It was found that the process driven organizations used a broad set of evaluation methods. Performance evaluation was, for instance, based on cause and effect analysis. This analysis is a fundamental technicue for identifying how and what to improve. Many formal techniques were used in the process driven organizations. Some techniques were involving statistics, Statistical Process Control (SPC) techniques, and other process bound, e.g. root cause analysis approaches. Furthermore, control or run charts were used to learn from trends. These charts can be very useful for documenting the effects of changes in policies and practices of a company. Trend analysis appeared to be a powerfull technique for understanding how a company operates. Finally, the process driven companies used correlations among performance measures. Management can see a variety of different types of performance data all at once by using tools as balanced score cards and deployment matrices. With respect to the balanced score cards, management is searching for a balance, e.g. sales cost versus productivity. sales cost versus customer satisfaction, and so on. Notes that the requirements are to integrate the performance data in term of the critical performance dimensions and to present all performance data on one sheet of paper and to calculate the percentage of profit or loss by transaction, by type of service and/or product, and for the whole operating unit.

- Providing performance feedback to the participants in a processing and initiating corrective action on unwanted process deviations appeared to be of fundamental importance in managing and improving a business process. Performance feedback focuses on process performance in the broad sense; it focuses on "how a process takes place' and on results.

\subsubsection{Explanations for variations in sales control practices}

The insights gained in the analysis of the four case studies were used to illustrate variations in sales control practices between functionally and process oriented organizations. We reformulated our initial research question "How are the dimensions of sales control systems specified by our theoretical model specified by the theoretical model, realized within different types of organizations? How can this be explained?' into 'How are the dimensions of sales control systems, specified by our theoretical model, realized with functionally versus process oriented firms? How can this be explained?' (See Chapter 4, section 4.4.3). We studied the variations in control practices by organizing the findings around the basic dimensions of our framework. The key findings can be organized around the following issues.

\section{Process management and TQM}

At the salles force organizations of the process driven organizations, TQM appears to be an integrative management concept aimed at continuously improving the quality of goods and services to meet better the needs and wants of their customers. Here, the concept of 'quality' extends considerably beyond traditional meaning; it includes the "quality of management" as much as it means 'improving the management of quality'. Today's managers tend, therefore, to use 'business excellence' instead of "quality". For instance, company D encourages the use of its TQM system because it is convinced that a good implementation of this system helps its subsidiaries and other organizational units to achieve business excellence. The process driven organizations in our sample vary in how they describe their TQM environment and the way in which their sales control system fits. The TQM systems of these organizations, however, share common attributes: customer focus, strategic planning, effective leadership, continuous improvement, fact based management, teamwork, improvement cycles and full company wide participation. Process management appears 
to be a central tool of modern quality management. At the strategic level, it includes the planning of a network of key processes, control, quality assurance, and improvement. Steering the process network constitutes an essential part of a business management system. At the operative level it is a question of managing individual processes in accordance with improvement cycles. Process owners are not only in charge of managing but they are also responsible for improving their processes. As internal customer, they formulate measures for evaluating the required input of their processes. Furthermore, these process owners are also responsible for the quality of the process outcomes. It is up to them to evaluate and improve the process activities. The improvements are necessary to meet the needs and desires of the next process owner; i.e. an internal customer.

\section{Use sales control to drive continuous and radical improvement}

The process driven organizations in our sample are both involved continuously in reengineering activities. They are always searching for the best way to structure the sales force and the whole organization. At each level of the sales force organization, critical processes are identified and assessed. Both companies use specific tools to figure out what are the critical business processes, and how to manage the redesign activities. From our case analysis, it was found that TQM refers to programs and initiatives that emphasize incremental improvement in work processes and outputs over an open-ended period of time, i.e. continuous improvement. In contrast, reengineering or radical improvement means discrete actions that are intended to attain radically redesigned and improved processes in a bounded time frame. Sales control systems can be the mechanism to orchestrate organizational change for achieving sales performance improvement. Achieving performance improvement balances those needs by identifying and delivering early, measurable results while moving systematically to a long term vision. The decision to initiate improvement actions needs to be driven from a thorough analysis of the external and internal environment. This analysis is used to specify where the performance gaps are, and to determine what action is required. It is necessary to deploy vital improvement objectives, and specify the means, measures, and owners.

\section{Use sales control to improve total organizational alignment}

The successful implementation of TQM requires alignment; "alignment" means working together in harmony, going in the same direction, supporting each other within the realities of the surrounding environment, including the company's mission, vision, values, strategy, structure, systems, and individual style and skills. At the process driven organization in our sample, it was found that strategic alignment is a driving force behind the design of control systems for sales force organizations. Total organizational alignment appears to be a powerful tool to enable an organization to act as a whole in serving customers; it stands in sharp contrast to organizations where customers see sales and other 'front office' departments blaming others for glitches instead of stepping up and solving the problem. Getting everyone to buy into the value of total organizational alignment is the first step in getting there.

Getting there, and staying there, are two different things however. Sustaining alignment requires excellent communication throughout the organization and the ability to sustain focus on what's important. A rapidly changing environment makes it especially difficult. It is easy to lose focus and get off course but difficult to get back on. Process reengineering and systems thinking are moving total organizational alignment back to the top of many corporate agendas. It has become crystal clear that many of the greatest opportunities for sales productivity improvement lie at the interfaces of the processes used to sell products and serve customers; and it is useless to excel in one process while lagging in others.

\section{The empluasis on horizontal control structures}

It was found that the process driven companies in our sample had refocused on their performance 
measurement to horizontal control structures, with less emphasis on hierarchical control structures in comparison to the fumctionally oriented companies. Furthermore, the responsibility for control is moved closer to the baseline of the organization, i.e. local management and their employees. Control is based either on the assessment of the final output or on customer feedback to determine the quality of the process outcome. Sales project teams, for instance, were used to obtain horizontal control. It was also found that associated reward systems were used to hold employees accountable for outcomes and encourage creativity and risk taking in defined key performance areas of the organization (see company D).

\subsection{MANAGERIAL IMPLICATIONS OF THE STUDY}

\subsubsection{Some practical considerations}

The aim of this study is to provide insight into the formal sales control practices. Three suggestions arise from the preceding discussion. The key topics can be summarized as follows:

- The effectiveness of ary control design depends largely on the culture of the organization and the management style of its leaders, also, the success of any approach will be dependent upon the organization's willingness to reward positive behavioral change, linking compensation with achievement of personal targets. This does, however, not imply that employees should be penalized for missed targets. Instead of focusing on missed targets, it is important to assess whether employees are participating in the planning process, improving their skills in e.g. communication and problem solving. Participation and empowerment are often behaviors by which today's organizations hope to attain their desired results. The role of the today's manager is shifting from giving direction and rating performance to individual coaching and team facilitation. In sum, we think that the key principle for designing formal sales control systems is the principle of reciprocity, i.e. creating a win-win situation for the company and its employees. Sales control needs the support of the human resources function; this can be accomplished by linking the individual performance review with the key business priorities of the organization.

- A sales control system should be used by management to drive performance improvement. Achieving continuous and breakthrough improvement systematically drives an organizalion towards its strategic vision. Day to day, organizations are consumed with making continuous improvements in ongoing operations; but to reach substantially higher levels of performance it is essential at certain times in an organization's evolution to undertake major initiatives for attaining breakthrough improvements.

- The dynamics in today's business environment encourage flexibility in terms of organization forms. As they struggle to improve their capacity, managers increasingly use terms like the boundaryless corporation, trust, teamwork, and self-organization to describe the organizations they aspire to build. In this context, formal control systems are usefull to promote stability in the existing businesses and in the existing strategic direction of an organization. Market dynamics force managers to create an atmosphere of spontaneous questioning and contentions for formulating and implementing new ideas and practices (Stacey 1996). Burns and Stalker (1961) stated that with an increasing rate of technological and market change more organic structures have to be developed. They argue that organic organizations should include a network structure of control, authority, and communications, with an emphasis on the lateral cooperation and communication that resembles consultation. changing task groups, andi dispersed responsibility with distributed leadership.. A quite similar remedy has been offered more recently by Mintzberg (1979). He concluded that the more dynamic the environment, the more organic the required organizational structure; the nore complex the environment, the more decentralized; the more diverse the environment, the more divisionalized the organization should be.

\subsubsection{Some challenges}

The outcome of the preceding discussion can also be used to demonstrate challenges for managers and system designers, the key points of these challenges can be summarized below.

\section{The challenge to management}

Today's businesses establish visions, missions and goals to let their employees know where the company should be going. The company's sales control system should, therefore, be configured tio 
support attaining overall company objectives. The system should also be appropriately integrated with other company processes, such as pay, perquisite and recognition programs. Integrating company planning and administrative processes with sales control increases the company"s chances for successfully meeting its mission and vision; this approach to sales control helps to improve the long term orientation of a company"s sales force organization. Today's managers should, therefore, be responsible for building organizations where people are continually expanding their capabilities to shape their future.

\section{The challenge to information technologists}

Sales management has often difficulty with accurate forecasts, visibility into sales productivity, and accurately paying them for their accomplishments. Sales force automation, e.g. Opportunity Management System (OMS), can be a powerful IT tool. This IT tool is used to enable business managers to track market activity through pipeline versus forecast reporting and easily coordinate salespeople. An OMS enables, for instance, salespeople to set the milestones for the sales plan and, enabled by workflow, to track its completion. This system also ties easily into performance measurement; e.g., reducing the sales cycle and increasing the close rate since the start and completion of an opportunity can be readily tracked. It should enable the user to display the status of performance against objectives. Integrated with calendaring and "to do" lists can produce action items for daily management. This data can be used to evaluate sales productivity. Furthermore, IT appears to be a useful tool in aligning apparently conflicting departmental objectives. Technology such as client server software for reviewing and analyzing performance against plan; it allows the company to distribute information to many people, both rapidly and cost effectively.

Talking about an IT supported sales control system is one thing; organizing the system to make it work is quite another. A performance measurement system must provide management with a complete view of the organization that links performance to strategic objectives, including a balanced view of the organization, relevant and consistent performance metrics, i.e. called performance drivers. The overall value of the measurement system is dependent upon the quality of the individual measures. A performance measurement solution has to be economical: often the need for measurement data arises against a background of downsizing and reduced IT spend. Business metrics addresses the need for a business measurement solution that's scalable, economical and quick to build, and also easy to modify. Forms must be user friendly and effective in capturing needed information; they must be designed to facilitate coaching and feedback.

Achieving breakthrough performance balances those needs by identifying and delivering early, measurable results while moving systematically to a long term vision. The challenge for IT is to provide the information needed to measure sales performance. Typically, the raw sales performance data is being collected somewhere in the organization, but is often held in a number of unconnected legacy systems, called the 'islands of information' syndrome. Not only are the systems likelly to be running on separate platforms, but they often lack adequate reporting facilities. Users invariably want their performance information immediately, regardless of the fact that the IT department probably already has an application backlog waiting to be tackled. A one off solution is no use because the information requirement is likely to be ongoing. And so the solution they choose has to be able to accommodate future changes to the business.

\subsection{FUTURE RESEARCH}

This study is one step forward in a long process of developing a bodly of empirically verifiable generalizations and explanations of the sales control phenomena. We may conclude that the extant literature, even though it does not offer much more than fragmented insights, provides additional validation for variations in control practices. A new perspective on the problem how organizations can control their sales function is developed by on our literature review and field research. Three directions for future research seem most promising at this early stage of understanding the dynamics 
of control systems for the sales function:

- The first potentially fruitful area for fuhre research lies in replicating the study in other industries to assess the predictive validity of our theory. The scope of the study has been limited to one industry, those concerning sales control practices in the IT industry.

- A second opportunity for future research is to study a number of companies in even greater depth than we could do. This can be done for instance by using a longitudinal design where sales control practices are followed in real time. This approach offers at least two advantages. First, it would further reduce the risk of ex post rationalization which might distort the reported evidence on the sales control practices. Second, such an approach would provide richer insights into how new concepts, such as process management and BPR, are incorporated into the sales control systems. Our firms were constantly searching for the best practices; no one had the idea they already accomplished this desired state.

- A third avenue for future research is to shift to larger samples and test the conclusions about sales control systems quantitatively using statistical methods.

Besides, two additional directions for future research are provided by our respondents with respect to topics to be research in more detail:

- organizational alignment and sales control systems

- organizational leaming and sales control systems

Our respondents suggested these topics as interesting ones for future research. These topics can be described as follows.

\section{Organizational alignment and sales control systems}

This issue refers to the study of the links between sales control systems and organizational alignment. In a world of rapid globalization, deregulation, customer empowerment and fierce competition, the only constant is change. Organizations are feeling the pressure of this change. Today, in addition to the standard response of reducing costs, increasing value to customers and lowering cycle times, companies must rebuild their organization structures to be more flexible. These changes have a great impact on the concept of 'job'; responsibilities change quickly and employees are confronted with 'change' and 'uncertainties'. Project teams are often used to formulate new strategies and related tactics. Employees are often assigned to new tasks well before a prior project is accomplished; they are also expected to support different team leaders, keep different schedules, and perform different tasks. It implies for employees that they accept accountability for their actions and taking action on their accountabilities. They do no longer take direction from a job description or functional superior; rather they respond to changes in the business environment.

Effective control systems help organizations and their employees to perform in new, desirable ways, and they must be sustainable through the ongoing efforts of employees. Performance in the focused pursuit of objectives is the essence of organizational alignment and a critical challenge for today's managers; however, even as the strategic potential of employees is being recognized, they are being required to perform in radically changing organizational climates. The demand for alignment in highly uncertain marketing environments requires a more dynamic connection between organization and employee than the one previously established by traditional reporting relationships and job descriptions.

Alignment can be supported by integrating planning with the individual performance review to support the control process. Each employee should have a position plan with standards or targets, and specific performance measures, such as customer satisfaction survey results or sales to existing customers that an individual employee has responsibility for, or shares with others. These accountabilities can be linked to the annual business plan of the sales organization and are the basis for objective setting. For salespersons, whether individually or in teams, this performance appraisal 
system creates an opportunity for reinforcing alignment between the individual salesperson and the organization. As a result, the salles planning process is sharply focused because performance priorities are identified, individual performance objectives are negotiated to support the measures, and supportive competency action plans can be established. Furthermore, performance assessment using the links between individual accountabilities and annual business plans facilitates a clear understanding of how incumbent performance in any of the roles influences achievement of the accountability measurements. Case D is an example of an organization whose control systems assist in organizational allignment.

Integrating the employee appraisal system with sales planning does not mean that salespersons should be penalized for missed targets; what is most important to evaluate is whether employees are participating in sales planning, and improving their skills in planning and communicating. These behaviors can help any organization to achieve its desired results. Further research could be conducted to investigate the links between organizavional alignment and sales control, indicating how appropriate control system design and use can facilitate the organizational alignment in sales organizations.

\section{Organizational learning and sales control systems}

A final avenue for further research is to study the link between sales control systems and organizational learning. We found that continuous improvement programs and programs for institutionalizing innovation are sprouting up all over as organizations strive to improve themselves and gain competitive advantages. Today's companies must find ways of surviving in times of rapid environmental change. Successful firms are companies that can deal with external and intemal turbulence, such as slowing market growth, accelerating technological change and transforming information processing technologies. Facing these challenges stimulates these firms to develop and implement new concepts: e.g. downsizing, flatter structures, reengineering focused on business processes and lean management.

One realization is at the root of these modern practical concepts: enterprises can only survive in the future if they incorporate the creativity, competence and motivation of their human capital and assign new roles to the workers in the business processes; a key tool appears to be organizational leaming (OL). OL can be defined as a changing of the organization to respond to environmental change (Kloot 1997); this can be adaptive or generative. Adaptive Learning or single loop learning focuses on solving problems in the present without examining the appropriateness of current learning behaviors; adaptive organizations focus on incremental improvements, often based upon the past track record of success. In short, the fundamental assumptions underlying the existing ways of doing work are not questioned. Generative learning focuses on continuous experimentation and leedback in an ongoing examination of the very way organizations go about defining and solving problems. It is about creating; it requires 'systemic thinking", 'shared vision', 'personal mastery", "team leaming", and 'creative tension' between the vision and the current reality (Senge 1990). Unlike adaptive learning, generative leaming requires new ways of looking at the world.

Sales control systems can be designed and used to be proactive rather than reactive with respect to change, and to promote organizational learning, by fitting the control system to the constructs associated with organizational learning. There are four key constructs associated with organizational learning: knowledge acquisition, information distribution, information interpretation and organizational memory (Levitt and March 1988; Huber 1991). There are features of control system design and use which fit each of these constructs, and appropriate system design can assist firms including their sales force organization to learn and survive during a period of environmenta change. Case D is an example of an organization whose control systems assist in formal, adaptive and generative organizational learning. In general, these control systems may have a critical role in facilitating organizational leaming and in a critical role in detecting lack of fit with the environment. Company $\mathrm{D}$ is an organization in which learning opportunities are maximized. This 
firm is characterized by a corporate learning culture, empowerment, environmental scanning, knowledge creation and transfer, learning technology, quality commitment, strategic focus, a supportive atmosphere, teamwork and networking, and vision. Sales control systems can also affect the managers's perception of the environment; they can affect the understanding of:

- what those environmental changes mean for the company

- how and what solutions might be generated

- whether the time has come to move the sales force organization to new structures and paradigm

Furthermore, organizational learning and change may imply that organizational structures may change and control systems thave to be adapted to accommodate these changes. This was demonstrated in case $C$ and $D$, which exhibited the characteristics of a learning organization in its management control system. These findings imply that organizational learning and sales control systems are inextricable interwoven.

Organizational learning in sales force organizations requires a broad types of control mechanisms. For instance, performance data and feedback must be freely and frequently available. Performance information must include not only current accounting information on costs and revenues, but also future estimates and information relating to the external environment. At the level of strategic planning, scenario planning tools can be used for generating the possible futures. Similarly, use of Groupware tools, Intranets, E-mail, and Bulletin Boards can facilitate the processes of performance information distribution and interpretation. Furthermore, freer access to performance information implies closely examining information systems, and dismantling them if necessary to achieve good information flows through the whole organization. Participation decision making and empowerment are powerful tools for encouraging organizational learning.

Control processes should be designed to support participation and empowerment; employees should be encouraged to take responsibility for improvement efforts. Case D is an example of an organization whose control processes encourage participation and empowerment at each level of the company. To summarize, it would be interesting to investigate the links between organizational learning and sales control systems, indicating how appropriate control design and use can facilitate the organizational learning in sales organizations in today's dynamic marketing environment. 


\section{Notes}

1. Reactive and proactive elements are integrated in this framework for organizational control. The control process is sapported by budgeting and accounting systems. Accounting systems can be used to reinforce existing rationales foit action. It halsi also been argued that accounting systems can play a proactive role in shaping change. Accoumting can provide information to assist organizational change, and can make problems wisible.

2.e.g. sales process, after sales services. 
Appendices 


\section{Case study 1}

\section{Company A}

An IT firm with a functionally oriented work culture

\section{BACKGROUND OF THE COMPANY}

\section{Introduction}

Company $A$, with headquarters in the United Stated, is a full service provider that can compete on equal footing with Companies $B, C$ and D. The company has founded in the mid eighties. It first focused on the market for workstations and middle size computers for companies. Within the company, innovation is considered to be a critical success factor. The company's starting points are the "opening" of systems and network computing. The company"s products are sold in more than 140 countries. Selling takes place using a company sales force, via distributors, value added resellers and commercial system integrators. This mission is enhanced by a number of company principles that challenge conventional wisdom.

\section{Products}

Today the company is no longer just a supplier of technical workstations, it is successfully transforming itself into an IT firm focused on global network computing. The product organization consists of four separate product companies. The first product division focuses on the network systems business, it develops, manufactures, markets and sells high performance workstations and servers, and it integrates operating system software, network management products and service from other businesses. The second product division develops, designs and distributes network technologies and products worldwide. The software subsidiary manufactures, markets and sells network operating software and network computing applications. Finally, the service division provides customers with system support, education, system integration and other value-added services.

\section{Worldwide sales force organization}

The company"s international activities are classified by the major geographical areas in which it operates: Americas, Europe and Rest of world (see Figure A.1). Selling and support of the company"s products takes place through the company's own offices, and it has distributots in 100 countries and local sales offices in 29 countries. Selling takes place via an own sales force, wia distributors, walue-added resellers and commercial system integrators. The wholly owned subsidiaries are responsible for implementing the company"s marketing and sales strategy.

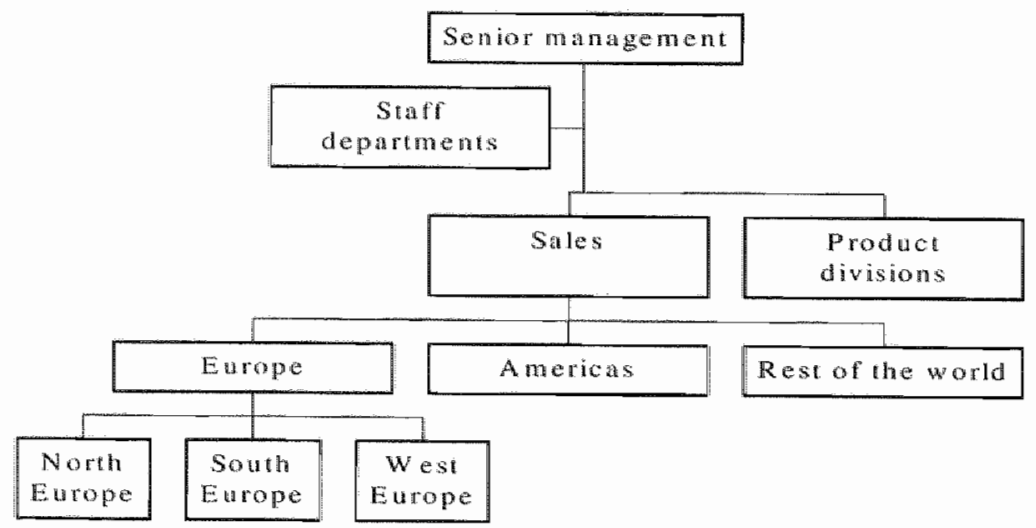

Figure A.1 Organizational chart

Source: adapted from internal documents 1996 
The European salles organization is divided into three regions: North. South and West Europe. The Belgian and Dutch settlements belong to the North European region and form a Benelux entity. The Dutch sales unit forms 60 per cent in this entity, the Belgian sales unit 35 per cent and the Luxemburg sales unit 5 percent; both the Belgian and the Dutch sales unit are a 100 per cent daughter company of the corporation.

Headquarters does not impose a formal organization chart on its sales offices. Overall, local management teams are free to design their own organization structure to match with the local market circumstances and to formulate the related sales positions. Headquarters gives some basic guidelines concerning sales positions but these guidelines are not imposed. With respect to the Benelux arganization, the general manager Benelux has developed a formal organization chart based on local requirements (see Figure A.2). This organization chart is used to structure sales operations in Belgium and the Netherlands.

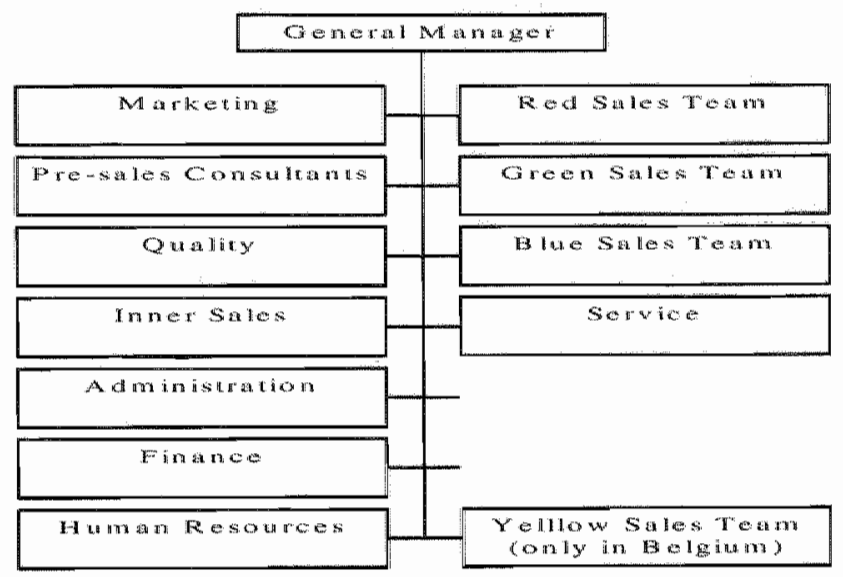

Figure A.2 Organization chant of the country organization Source: adapted from internal document 1996

\section{The Belgian and Dutch sales units}

The Benelux organization is managed by the general manager Benelux. The Dutch and Belgian local settlements are managed by a management team. This management team consists of a General Manager, a Marketing Manager, Sales Teams Managers, a Financial Controller, and a Human Resources Manager. Furthermore, the general manager Benelux is also the general manager for the Belgian sales area.

The country organization consists of a service department that is responsible for e.g. maintenance services and 3 to 4 departments, called "sales teams" that are denoted by the colors Red, Green, Blue, and Yellow (only at the Belgian settlement). These sales teams are differentiated by the kind of market being served. As a consequence it may occur that a sales team does not offer the entire company"s product-mix.

The Red Sales Team sells the company's products to a selected number of strategic accounts. The Green Sales Team sells industry-specific solutions; examples include manufacturing, finance and Internet. The application that provides added value is often supplied by partners. The Blue Sales Team sells workstations in the company's original markets. The Service Team responds to customers' changing needs for service; moving from traditional, proprietary technology to a standards-based computing environment has meant that the role of service and support had to be redefined.The Yellow Sales Team focuses on large governmental organizations, such as the E.C. and NATO The Yellow sales team is unique to the Belgian settlement because these main governmental organizations are located in Brussels.

The sales teams are supported by the following staff organizations: Marketing, Pre-sales Consultants, Quality, Inner Sales, Administration, Finance, and Human Resources Marketing is responsible for the positioning, segmentation, pricing, and advertising of the company's products. The unit Pre-sales Consultants consists of technical consultants that are able to identify and map a custoners" needs and in this way assist the Sales Teams with selling projects. The company is extremely concerned with quality of its products and therefore a decentralized local quality control policy at the worldwide sales force organization exists; it implies that each local sales offices has its own quality department for local operations. This Quality organization reports directly to the General Manager. The sales teams are also supported by the following staff departments: 
- Winer Sales, responsible for Tele sales and related activities

- Administration that takes care of the financial administration as well as the order administration

- Finance that manages and controls the financial information system

- Human Resources, responsilble for recruiting and training personnel

\section{THE SALES FORCE ORGANIZATION}

\subsection{Formalization}

It appeared that varying forms and degrees of formalization are applied at the company's own sales organization. The whole product and service range is imposed on the local offices. Some of these forms are imposed on the sales offices, others are developed by the local management team.

Headquarters does not impose a standard organizational chant on their local offices. The local management teams are responsible for designing and implementing an organizational chart that fits best with the local circumstances. The task environment of the local offices is described in general terms; however, headquarters has some strict guidelines concerning the products and services sold by the sales offices. There are also some corporate guidelines concerning specific sales positions and the related titles but the related task and job descriptions are formulated by the local management team. Finally, the tacit that the company uses for the distribution is "direct selling", which implies that the local offices have to recruit and manage their own sales people. Headquarters supplies also some guidelines conceming business partners. The Belgian marketing manager stated:

"In Comparison with our direct competitors Such as IBM and Hewlet Packard. I can say that at our company the informal organization is sironger than the formal one. Throughout the worldwide sales organization. the re are similar sales positions and titles; but the related tasks and job requirements can vary from country to cowntry. ... O Derall, the task enwiranment is described in general tems. The corporation stimulates the managerial levels of its sales force organization intensively to employ 'Management by objectives'. There is a direct link between target achievement and personiel practices such as promotion and salory decisions. Assessmen" of individual performance is, for instance, not bast on task descriptions but on the achievement of planned results."

Finally the local sales offices are encouraged to attain an ISO $9000^{1}$ certificate for the administrative and support processes. This implies that these processes are described in an ISO 9000 handbook. The local sales offices are audited by an external consultant once a year. ISO 9000 is perceived as to be a powerfull tool for managing specific processes; however, it can have a negative impact on the company's flexibility to meet the customers' needs. If ISO 9000 has a negative impact on business performance, then the local management can decide to adapt its processes. The Dutch marketing manager explained: "Our corponation encourages us to attain an 1509000 certificate for our adninistrative and support processes. These processes include processes such as maintenance services and customer complaint procedures. $11 \mathrm{SO} 9000$ has an negative impact on our business performance, then our sales office will wot wesitate to adapt the process to the customers" requirements. The company has to be flexible in today's markerplace..."

It was also found that the supervision on the use of procedures and rulles is accomplished primarily by the line responsibilities of the various organizational levels. For instance, the superiors supervise their subordinates concerning the use and content of planning and reporting procedures; and in addition the local offices are audited by the ISO auditors.

\subsection{Centralization}

Our respondents indicated the headquarters has intensively decentralized operational decision making authority to its local sales office. The Belgian marketing manager explained:

"One of the hey assumptions of the company's business model states that a high degree of centralization results in a loss of efficiency. Decision making authority is, therefore, delegated to local sales offices. The company, however, operates in a large number of countries. This nakes it impossible to delegate all decision-making authorities to tocal settlements."

With respect to strategy formation, it appears that the corporation is responsible primarily for these planning activities. Decision making authority concerning the marketing mix is highly centralized. The butch marketing manager explained:

"Overall, the comporation is responsible for strategy formation; we are responsible for strotegy implementation. This is also the case for the formulation of the company's marketing strategy; however, the decision waking authorty conceming price, promotion, distribution and personnel are decentralited intensively to the local settements.

It was lound that the product diwisions are responsible for product development and managerment with regard to product decisions. The Belgian marketing manager explained: 
With respect to product decisions, the decision making authority is centralized at the corporate and product division levels. These levels are in charge of product development and product momagement; but there ane Marketing Directors neetings at which local representatives can discuss new product developments. By this, we can provide the corporation with new product ideas and debates of specific requirements of local customers. ${ }^{\text {c }}$

With respect to local product decisions, local management decides which products and services are solld in a courtry. It was found that the European settlements have the complete product lines of the company hecause their customers are primarily international operating companies. This type of customers ask for a broad package of $\mathrm{TT}$ products and services. Decision authority concerning the other marketing mix variables, i.e. price, promotion, distribution and personnel, is delegated to the local sales offices in the Benelux organization; though headquarters gives some broad guidelines, it does not impose specific gudelines. With respect to price decisions, the headquarters gives some guidelines in terms of contribution margin percentages. These percentages are used to calculate the price per product; price setting is based on cost price plus method. The cost price per product consists of product cost, and direct and indirect selling costs. Furthermore, there is a risk coverage for dollar fluctuations. The key restriction regarding price setting is that the planned contribution margins have to be realized.

\title{
23 Integration
}

The firm's worldwide sales force organization is characterized by a matrix structure. The business operations are structured around products and geographical markets. The regional managers and the general manager Benelux have an integrative role. The regional managers coordinate the implementation of the headquarters' marketing strategies in their region. Furthermore, they provide the local management teams with feedback on their local performance. At the Benelux organization, the general manager Benelux coordinates and integrates the business operations of the Belgian, Dutch and Luxembourglan sales offices. This manager formulates a strategic direction for the Benelux organization. This long term plan and the strategic guidelines from headquarters are used to coordinate and integrate the operational planning activities within the three country organizations. The general manager Benellux also supervises the operational planning activities in those offices to ensure that the contribution margin target for the Benelux organization can be achieved. There is a direct communication line between the corporation and its local sales offices.

\subsection{Participation}

From the interviews it appeared that headquarters imposes operational objectives on local sales offices, and that these targets are related to contribution margin and revenue. Regarding the regional level of the sales force organization, it was found that only a few objectives are formulated. The Belgian marketing explained:

"[... The result of the discussions are stated in an annual business plan consisting of two key figures: contribution margin and revenue (and sometimes unit sales). When the targefs related to contribution margin and revenue are formulated, the discussions about the appropriate resounce allocation start. The purpose of these discussions is to determine the required financial and human resources fo ensure the athainment of the "local' contribution margin. Overall, decision making concerning the expense target is based primarity on consensus. If no consensus can be reached, then the corporation will decide."

Regarding the participation of individual employees, it was found that at both sales offices the subordinates formulate their individual objectives during a discussion with their supervisor. The Belgian marketing manager stated:

"Overall, the decision making concerning individual objecriwes is based on consensus. If a consentus" cannot be reached, ther the superior imposes the objectives."

\section{STRATEGIC PLANNING}

\author{
Involwed parties: \\ Our respondents stated that strategic planning takes place primarily at the corporate level of the \\ organization. Senior management and the managers of the product divisions are involved primarily in \\ these planning activities. These management activities are generally detached from line responsibilities \\ as a corporate function and staff departments support these planning activities. Regarding local activities, \\ it appears that the general manager Benelux formulates the strategic direction of his local sales offices. \\ This strategic direction is derived from that of the corporation as a whole. The Belgian marketing \\ manager stated: \\ ... the corporation and the world-wide product divisions are involved in the long term planning. The \\ outcome of this planning process is imposed on the local sales offices. The strategic direction is determimed \\ by the general manager Benelux; yet this strategic direction is based on the corporation's strategic \\ direction. Furthermore, there are no formal and detailed long term plans,"
}




\section{Planning procedure}

There is no formal or written procedure for strategic planning; but the organization has formalized it corporate and local strategic goals. The planning horizon is thee years. The planning activities aro conducted and supervised by senior management and the management of product divisions. The outcomes of the planning activities have to be implemented by the local offices. Progress-to-plans is stated in performance reports. The corporation has formulated specific guidelines concerning the contents of these reports. Each report should include performance information concerning achieved contribution margins, revenue, net profit and number of employees. The Belgian marketing manager explained:

"Strategic planuing is an antual event with a planning horizon of three years. Each year a financial plan is formulated by the corporation and its worldwide product divirions. It includes largets related to contribution margins and revente i.e. at the corporate, the product and local level. We lie. the local sales officel are in charge of strategy implementation. It implies that the corporate guidelines have to be implemented in the local markets. Regarding the performance reports, the corporation has imposed specific guidelines on its local sales offices. Performance reports have to include the following items: revenue, contribution margin, net profit, and the number of employees. The supervision of strategic planning activities is the responsibility of the corporation. At the local level, the generai manager of the local sale: office is responsible for providing reports on goal attainment."

\section{Planining process and outcomes}

The Belgian marketing manager stated that strategic planning consists of hierarchical and top down processes. The planning team first establishes corporate level positions relative to corporate mission, corporate goals and corporate strategy.

The corporate mission of the company is related to quality issues: "To achieve renowned, world. class quality in our products and services, which result in: proud employees, delighted customers, happy investors and improved brand recognition and value'. The core business activities are based on the following statement: "the network is the computer'. The company"s computer systems are based on UNIX, and the company focuses on client/server architecture.

With regard to corporate goals, the company has specific long-term goals. The first group of targets are related to the following financial/accounting items (Internal document 1996):

- continuous growth of return and profit per share

- excellent asset management

- using the solid funancial position to remain leader in the development of new and prominent technology. pay attention to expense and cost structures

\section{There are also some nonfinancial goals (Internal document 1996):}

- to remain a leader within the market of UNIX-BASED systems for technical applications

to convince a broader public of the inherent advantages of UNIX-BASED client service architectures. to focus on Research \& Development to remain a leader in the development of new network technology to attain the predetermined market share

to have a specific image

The company has formulated a specific strategy to attain corporate goals. This corporate strategy can be described as "... anticipating and meering the needs of custoners with consistently superior products and services delivered on mime" (Internal document 1996). The output of the planning activities is a corporate plan with a worldwide financial plan, and the identification of strategic business units is also established at the corporate level. At the next level down, the product divisions refine their business: scope by identifying product-market segments, and specific competitive priorities in terms of product portfolio. The input to these activities includes historical data recording past performance and forecasts.

At the next level, functional managers within a division formulate appropriate marketing strategies and enact action programs including budgets to support the competitive priorities of their product divisions. The local offices translate the guidelines of the corporation and its product divisions into a local strategic direction. The Belgian marketing manager stated:

"Inpus to the plan include historical data recording prior perfornance, i.e, return, contribution margin, whis sold, cosit and expense lewel, and market share, along with forecaists for the current planning harizon. Historical data is related ro revenue, contribution margin units sold, expense level, and marker shore. Fonecasts include projections concerning investments, imtentions of imvestments, and warket grow th in the TT.industry. This data is collected by corporate staff, external consultants, and market analysis. A worldwide financial plan is formulated. The local strategic plans energe from the corporate strategic plan and the worldwide fimancial plan. These plans are imposed on the worldwide sales force organization by the corporation. At the Benelux organization, the general manager Benelux has decision making authority concerning the development and enactment of action programs to support the attainment of the corporate sinategic objectives. There are no specific strategic plans for our regronal office and the local settlement. The regional office is only responsible for coordinating activities among the local offices. The local offices are profit centers and have operating responsibility". This shont term orientation is the main reason that we have no well documented, formal strategic plan." 
The marketing managers also stated that the general manager Benelux describes the strategic direction of the Benelux organization using specific strategic choices for the short term within the framework of the corporate strategy. He explained:

"... these strategic choices are described in the financial plan for three years which is focused on budgeting. Historical data recording prior sales perfonmance, i.e., contribution margin, units sold, cost and expense level, and market share, along with forecasts for the current planning horiton are wied to formulate a financial plan for the next three years. The 'old' financial plas is, therefore, evaluated. adjusted or completed. This plan includes the strategic direcrion and the objectives for thee years, and a detailed plan for the first period; this is an annual business plan and a related budget. The local financial plan has to be in line with the corporate strategic guidelines and the worldwide financial plan. This plan includes the quantifiable objectives. It includes a plan with specific business objectives and the required resounces, in terms of costs and expenses, and number of employees, to acheve them. The targets for the other two years are formulated in general terms. The qualitative objectives related to issues such as brand/product awareness, market operations, product positioning, and focus groups, remain abstract and are not expressed in figures. Although the qualitative objectives are perceived as importamt, the ewphasis remains on the quantitative ones."

Headquarters and the local management team discuss the local financial plan. Except for the long term objectives imposed by the corporation, the decision making is based on reaching a consensus; but the Belgian (and Dutch) marketing manager stated:"... if we can reach no consensus, the corporation imposes targets on the local management team."

Overall, the respondents tended to perceive the objectives as feasible and realistic but also ambitious. It appears that until now all objectives in terms of revenue and contribution margin growth have been attained.

\section{SALES MANAGEMENT CONTROL}

\subsection{Planning, organizing and directing}

\section{Involved parties}

The local management team and headquarters are involved in the sales management planning activities; however, the involvement varies from levell to level.

\section{Planning procedure}

As said, there is no detailed procedure for operational planning activities in sales. Headquarters indicates primarily the key topics of the business plan, and it starts the planning activities by imposing operating business objectives on the local sales offices. The Belgian marketing manager explained:

"... the local management team is responsible for organizing the plaming activities. Since last year (1996), both the Belgian and the Dutch sales office have been intensively involved in describing the planning procedures to attain am 1509000 certificate. The counry manager is responsible for organizing the local planning activities. He organizes and supervises these activities. The Belgian country manager is also the general manager Benehux."

\section{Planwing process and its outcomes}

The major outcomes of the sales management planning process for the local sales offices are objectives related to contribution margin ${ }^{2}$, revenue, expense target ${ }^{3}$, linearity of planning, return per employee, customer satisfaction and ISO. These objectives are formalized in a well documented, formal business plan including a sales and a marketing plan. According to the Belgian marketing manager, the local business plan is:

". not purely a financial plan; it also includes objectives related to e.g. customer satisfaction and ISO9000. The operational abjectives are further specified in sales and marketing plans. The siales plan indicates what product will be sold and how, while the marketing plan includes the strategy for how sales objectives should be attained and how the marketing department can coniribute to this god attainment. in companson with the sales plan, the marketing plan is less financial in nature and covers a longer planning period, i.e., 18 months versus 12 months. Both plans are, however, formulated in the same period of the fiscal year. ${ }^{2 *}$

At the worldwide sales force organization, the operational planning consists primarily of hierarchical and top down processes. Headquarters formulates operational targets for its local offices. The key targets are contribution margin and revenue. These two targets are specified per quarter of a fiscal year.

Headquarters also encourages its sales offices to improve their planning activities. This is called 'linearity of planning'. The company's policy is to encourage sales offices to spread the revenue over the four quarters of the year $(\mathrm{Q} 1: 20 \% ; \mathrm{Q} 2: 25 \% ; \mathrm{Q} 3: 25 \% ; \mathrm{Q} 4: 30 \%)$. The contribution margin and the revenue targets are imposed on the local sales offices. The individual objectives of the general manager Benelux are also the operational targets of the Benelux organization. 
The headquarters and the local representatives discuss the "expense target' and the number of employees necessary to attain the stated contribution margin. Decision making is based on reaching a consensus between the different management layers in the sales force organization. The Belgian marketing manager stated:

"Each year the hedadqunters formulates business abjectives in tems of the contribution margin and revenue. We defune contwbution margin as the difference between the revenue what we obtain for a given product and the costs incurred in generating the revenue. The "costs' include costs related to the products or services and to the infrastructure, with infrastructure I mean the settlement with the rellated costs. There are some objectives related to linearity, i.e., the consistency of larget setting in terms of revenue and returs per employee. The objective 'inearity of planning' is importan because the planning output of the local office is used as inpul for the production scheme at the production divisions. The production wolumes can be bether planned by stimulating lineavity of planning. The objective 'retum of employee' is used prinarily for bench marking purposes. Overall, the stated objectives are the objectives of both the sales office and the general manager Benelux. Once the headquarters has announced the business abjectives per local sales office, the discussions between the headquarters and the general managers start. The issues of the discussions are the expense target and the employees required to attain the contribution margin."

Some planning activities take place at the local level. This planning process includes both top down and bottorm up activities. The imposed contribution margin, however, is the point of departure. The marketing department initiates the local planning activities at both the Dutch and Belgian sales offices. The marketing department starts with collecting market information and data on past performance. These data and the imposed contribution margin are used to make a prediction of future revenues concerning the local sales teams and the local sales office. These forecasts are presented in a management meeting. The Belgian marketing manager explained:

"As stated earlier, the contribution margin is imposed by the headquarters. We use this target as the starting point of our local planning activities. The purpose of these activities is to set sales fargets and to formulate an appropriate business plant including an expewse target. The marketing department starts with the planning activities. Based on historical data, i.e., past revenue, and available market information, my tean and I make a prediction of the expected revenue of the sales teans and of the whole sales office. The outcomes of these planning activities are franshated into a marketing plan. Then $I$ present this plan to the management team for sales team deployment. After my presentation, a discussion among the members of the management team takes place. During this discussion, the following issues are discussed: What should be done? What direction should we choose? When should something be achieved and how whch? These topics are strongly related to the financial plan. The individual members of the management tean may get some specific assigmments such as to report on the market expectations, to conduct an audit of the pre. sales department. The revenue target of the sales office is set, and the discussions concerning the financial plan are limited" they focus quite quickly on the annual business plan."

After the presentation of the marketing manager and the discussions, the sales managers and their teams formulate the revenues for the next fiscal years. This takes place in a bottom up process. The individual sales persons are asked to set a sales quota as an individual target for the next year. Their proposals are discussed with the managers of the sales team

As stated earlier, decision making is based on reaching a consensus; however, if no consensus can be reached then the sales managers set targets in line with their individual targets. The sum of the individual salles targets per salesperson tesults in the target of a sales department. From the interviews it appeared that the sales managers and their sales representatives determine individual objectives during a formal discussion. The Belgian marketing manager stated:

"The managers of the sales teans organize meetings with their sales reps. These sales reps have to set their own sales quora for the next year. These proposals are discussed with the sales manager. Overall, the individual sales quotas are a result of a consensus between sales reps and their bosses. If no consensus cars be reached, then the superior sets the target in line with his target. This can be explained by the fact that he is responsible for attaining the targess of his team. The aggregation of the targets per sales tean tead up to revenue figures for the local siales office. When the targets per salesperson and team are set, a meeting of the management team takes place. During this meeting, the management team studies the contribution margin and return objectives imposed by headquarters, te, the objectives of both the local sales office and the general manager. Discussions take place to adjust the objectives of sales teams in line with the objectives of the sales office. Overal, operational decision making is based an reaching a consensas. If no consensus can be reached, then the country manager decides."

Once the marketing and sales plan are formulated, the anmual plan is presented to headquarters. The headquarter evaluates this plan; specific indicators are used. The Belgian marketing manager explained: "Sonne most important indicators are growth figures, i.e. in terms of revenue and units sold, retum per employee, and expense levels. These indicators are related to the maturity of a local sales offices. Four levels of maturity are distinguished: age of the local office, growith, size of the local office, and marker size. The indicators have specific values for each phase. The se walues represent the bottom line for local sales performance. Once the headquarter has studied the local busmess plan, some adjustments can be proposed. 
These proposals are discussed and finally headquarters gives its approval. The business plan is also presented to the regional office but no approval from the regional representative is nedded."

Our respondents tended to perceive the operational business objectives are realistic and feasible. From the interviews it was found that there is always an internal conflict between setting aggressive targets and achieving a specific level of revenue versus formulating realistic and feasible targets. At the end of the fiscall year, it always appears that the imposed targets are attained, both the Dutch and the Belgian marketing manager stated:

"...to ensure that targets are both feasibleyrealistic and of course ambitious, the headquarter uses a system of performance indicators in which internal, i.e., number and qualifications of local employees, and extemal factors such as market demand and growth factors, are taken into accown. These fargets ane used to direct and evaluate business operations and to initiate corrective actions."

Overall, it appeared that the operational business objectives are used to assign responsibility and to allocate the required financial and human resources. Our respondents stated that local management is responsible for the variables in the contribution margin calculation. These variables include revenue and related costs.

\subsection{Performance measurement}

The annual business objectives can be labeled as predetermined performance measures. These measures can be classified into two groups: financial and nonfinancial. The financial measures are related primarily to the quantifiable targets including rewenue, contribution margin, and direct and indirect costs. The direct costs are related to the local selling effort; the indirect costs are related to overhead costs including infrastructure and administration.

The nonfinancial performance standards are related primarily to the qualitative targets such as customer satisfaction and achieving an ISO-9000 Certificate. Market share is an important nonfinancial, quantitative indicator. This measure is used at the sales team and the product level but not at the local sales office level; because it appears to be difficult to find one standard for calculating market share in the different countries. The performance measures are primarily of a quantitative and especially financial nature. The reasons being that these measures are

"... relatively easy to monitor using automated systems" (stated by Belgian and Dutch marketing managery"

"... timely and sufficient for managerial decision making" (stated by Belgian and Dutch marketing manager),

"... inclusive of operations at all business activity levels" (stated by Belgian marketing manager), and

"... forward looking as well as concermed with the past" (stated by Dutch marketing manager)

With respect to the financial performance, it was found that there is a worldwide management information. Headquarters uses this information system to obtain financial information from each sales office on an ongoing base. From the interviews with our respondents, it appeared that "contribution margin', "revenue" and "costs" are the financial measures used in both sales offices. The objective "return of employee' is used primarily for internal and external bench marking purposes. Data concerning units sold are collected automatically on a daily base, financial performance in terms of revenue, costs and contribution margin is measured automatically on a weekly, monthly, quarterly, semiannually and yearly base. The local management team reports to headquarters by e-mail.

It appeared that there is no fixed format for management reports to headquarters. Our respondents, however, indicated that topics related to contribution margin and revenue have to be included in the report as these measures are seen as important evaluation devices. Both the Belgian and Dutch management teams report directly to headquarters. Overall, the hierarchy is responsible for supervising the management reporting. Local management teams use the company's worldwide management information system to obtain data concerning the financial performance of their settlements and of the other offices in their region. Headquarters aggregates the country data sets for the region.

As stated earlier, nonfinancial indicators are also used as performance measures. Information concerning market shares per product and per sales team is measured on a quarterly base; customer satisfaction and complaints are measured but with a different frequency. The Belgian marketing manager stated:

"Quality is measured using morldwide and local customer satisfaction surveys, and by customer complaints. Customer satisfaction surveys are conducted twice a year. Customer satisfaction is measured worldwide by an external consultancy fim. This fim conducts this 'customer qualisy index" survey on a monthly basis. The customer satisfaction survey does not focus on each stage of she sales process but on product quality and after sale services."

In contrast, the frequency of measuring nonfinancial performance is in comparison with financial performance quite low; the measurement takes place on a quarterly, semi-annually and yearly basis, and the outcomes are generally reported by e-mail. With respect to customer complaint management, 
procedures are described in detail in the 1509000 handbook with emphasis placed on registering customer complaints and follow up.

\subsection{Performance evaluation}

Assessment of business performance at this organization is focused on ensuring that the corporate strategy is implemented as planned; performance evaluation involves primarily examination of the extent to which planned results are achewed and takes place on a weekly, a monthly and a quarterly base. An analysis of planned and actual performance is used to evaluate the progress-to-plans, and it is focused on the potential causes of discrepancies between planned and actual results. This analysis is used to examine the extent to which planned results are achieved, i.e., progress-to-plans, and to identify potential causes for differences between planned and actual performance. This performance analysis is used to determine whether corrective action is needed. The company, therefore, uses the sales forecasts used in the business planning cycle, the forecasting cycle based on the achieved results and the actual performance.

An annual review is conducted by a representative of headquarters; there is one representative for each sales region. "The major evaluation device for local sales offices is "contribution margin". The Belgian marketing manager stated:

"Pevformance evaluation takes place on a monthly and on a quarterly basis. There is a financial review" once a year, this formal review is conducted by a represenfative of headquarters. The evaluation criteria are "contribution margin" and "revenue'; however the key criterion is 'contribution margin'. Each year a representative from headquarters wisits the local sales offices. This visit is called an 'OPS review" and includes an evaluation of the business results. The planned results for the next years are further specifed. i.e. for the next year and for the next period of three years. Regarding strategic direction, we analyzed the planned and actual results once a month. Based on the outcomes of this analysis, the local management team can decide to initiate corrective actions. The perfonnance devices are the operational measures: contribution margin, costs and expenses (general versus sales), and return. We do not measure directly long term performance."

The respondents stated that the sales office is the unit of analysis, and not the sales teams. Headquarters does not evaluate the performanice of sales teams but only the performance of a local office. The Belgian marketing manager explained:

"Thie evaluation is based on the results of the whole sales office, and not of the individual sales teams, it is not the results of the sales teams but the country result that is important. It is "the way rhings are dome within our organization'. It implies that 'the whole group fails or succeeds'. It is not imposed by headquarters."

It was found that the impact of uncontrollable and unexpected factors on actual performance are not taken into account. This is also the case for excessive profits that are not the result of specific local efforts but of unexpected circumstances, such as a change of govermment policies concerning business investments. This approach toward performance evaluation was explained as follows. Target setting is based on mutual agreement; once a target is accepted by the parties involved then it will not be adjusted during the fiscal year. It was found that operational targets are often very aggressive and ambitious but afterwards these targets were also achieved. The feasibility of these targets can be often evaluated retrospectively.

\footnotetext{
"Uncontrollable and unexpected factors influencing sales office performance are not taken into accown It is, however, rarely the case that objectives are adapted upwards or downwards. Overall, our targets are very aggressive and ambitious. We can often evaluate the feasibility of the operational vargets afterwards: but my experience is that although we perceive the targets to be wery ambitious, it appears that afterwards they were atrainable."
}

The perfomance of individual sales teams is also assessed, and this is done by the local management team. This performance assessment helps local management to evaluate the outcomes of their salles efforts, and to initiate corrective actions based on the performance analysis at the level of the sales teams. The evaluation devices used are revenue, the number of units sold, market penetration, costs, the number of new customers in the market segments, the realization of specific projects, and cooperation with. specific business partners.

The "linearity" of sales results is also studied, sales should be divided over the four quarters as follows: $20 \%(\mathrm{Q}), 25 \%(\mathrm{Q} 2), 25 \%(\mathrm{Q} 3)$, and 30\% (Q4). Other nonfinancial indicators used are market share per team and per product, and customer satisfaction. Regarding customer satisfaction and complatints, the Belgian marketing manager stated:

"... no nonfinancial indicators such as customer satisfaction or customer complaints are used for the performance evaluation of sales teans. The outcomes of the customer satisfaction surveys or custoner complaint managemen can be used to initiate specific actions. This, however, is only the case when a clear trend is visible." 
Whereas performance measurement of individual sales teams generally takes place on a weekly and monthly base, the performance data is analyzed on a quarterly basis. The analysis includes an examination of "progress-to-plan" with respect to sales team performance. The variations between planned and actual results are examined and studied to identify the potential cause(s) of discrepancies between planned and actual. The impact of uncontrollable and unexpected factors on sales team perfornance are not taken into account.

\title{
4.4 Feedback and rewarding
}

\section{Feedback}

Our respondents stated that headquarters provides the local managers with evaluative feedback about the outcomes of the performance evaluation on a regular base. This is often done during a personal conversation, at least each quarter. The financial information system is also used to provide each sales offices with information about the performance of the other sales offices. It appeared that this information is used for bench marking purposes. It was stated that there is no contest such as 'best performing sales office". With respect to the business units, it appeared that personal conversations with the sales managers and their general manager are held tegularly, i.e. weekly and monthly, and if needed, additional meetimgs can be planned.

It was found that corrective action is initiated if the performance evaluation indicates that planned results will not be attained; this decision is based on an analysis of planned and actual results. This corrective action includes the development and the enactment of new action programs, and/or the reformulation of business objectives. The responsible manager is in charge of initiating appropriate actions. Corrective action is achieved as follows:

"Overall, the discrepancies between planned and actwal resuls are first observed" by the responsible sates manager. This manager, mostly in consultation with the general manager, looks for the causes and related solutions. In some cases, the problem is discussed in the management meeting. Once the appropriate solution is identified, the sales manager together with the responsible sales representative initiates the carrective action. If the sales manager does not initiate a corrective action, then the coumry manager (or the geveral manager Benelwa) will intervene. In this case, the sales manager will initiate the corrective acrions and the general (or regional) manager will monitor his activities" (Belgian marketing managers). Regarding the local financial plans, the local managentent team is responsible for initiating corrective action. If the anatysis of planned and realized results indicates that the long-term objectives of the local sales office cannot be attained, then the cauntry manager is responsible for intiating corrective actions. Otherwise, the general manager Benelux or headquanters will intervene." (Dutch marketing managers)

Evaluative feedback on long-term performance is delivered on a quarterly and on an amnal base, this feedback results from assessing short term performance. This information may lead to corrective actions; these actions are initiated only if outcomes are not according to predefined performance targets. Often, this adjustment is done annualy. Overall, revisions to strategic plans and actual outcomes are done by headquarters. Our respondents mentioned two reasons for this:

"... a revision to strategic plans and actual performance is generally not an ongoing activity: and prodwct. markets are exposed to a relatively high level of uncertainty. Senior management is primarily in charge of monitoring and intervening in ongoing decision-swaking by using operational plaming and related performance measuremen. (Belgian marketing manager)

\begin{abstract}
"Regarding the local financial plans, the local management team is responsible for initiating corrective" action. If the analysis of planned and realized results indicates that the long-term objectives of the local sales office cannot be atained, then the country wanager is responsible for initiating corrective actions. Otherwise the general manager Benelux or the corporahion will intervene." (Belgian and Dutch marketing managers)
\end{abstract}

\section{Rewarding}

With regard to financial rewards, it was found that at the sales force organization the IT firm employs a compensation system based on fixed and variable rewards. The country and the salles managers receive a management fee with a variable and fixed part. The variable part of their compensation is paid primarily according to contribution margin. The compensation rate is a constant rate, i.e. 40 per cent, over the pay period. The Belgian marketing manager stated:

"The wariable part of the management fee is linked to the performance of the sales office. The key evaluation criterion for country managers is "contribution margin". Their salary is made up of a 40 per cent variable part and 60 per cent fixed part. Each quarter, the planned and realized results of the sales office are examined, 30 per cent of the management fee of the country manager's fee is determined based on the outcomes of this performance assessment, 10 per cent of the management fee is based on the guality performance of the sales office. Evaluation criteria for quality are the customer satisfaction survey and the ISO 9000 certificate. As for sales managers, the wariable part of their salary, i.e., 40 per cent. is linked to the realized results of their team. The key evaluation criterion is "contribution margin of the ir team. 
Each whare, the commissions are calculated as a result of the perfomance evaluation of the sales lean "

Furthermore, there is also a stock option plan to encourage long term performance yet the details conceming this plan were not know by our respondents. With respect to the local management team, it was found that the impact of uncontrollable and expected circumstances are not taken into account. Iit implies that there is no correction for excessive profits or losses. The compensation system of the sales representatives is also performance based. It was stated that 50 per cent of their rewards is variable; this variable part depends on the extent to which individual sales targets are attained. It appeared that the impact of uncontrollable and expected circumstances are not taken into account; there is no correction for excessive profits or losses. The Belgian marketing manager stated:

The largest part of the performance-based incentives of the sales representatives, $i$.e. 40 per cent, is related directly to the extert to which the individual sales quota are attained. The other 10 percent is linked with the contribution to 'quality'. Each guarter, the commissions are calculated as a result of the performance evaluation of the sales teann."

It was also found that compensation for sales effort and performance includes nonfinancial rewards. Recognition of achievement is the most important one. There are various formal recognition programs for members of the local management and their salespersons, i.e. an award for excellent performance. The award criteria are formulated once a year; the key criteria include always the realized revenue, market share growth and customer satisfaction. The local management annually evaluates its top sales people, selects one or two outstanding employees, and offers them a plaque. This is also the case for country managers; once a year the country managers are evaluated and the outstanding managers reoeive a plaque. The evaluation criteria are the realized revenue, market share growth and cuistomer satisfaction.

\section{Task control}

It was found that different forms of task control are applied; these forms are developed primarily by the local management term. For instance, standardization of work processes is achieved by job descriptions and the ISO 9000 handbook. With respect to job descriptions, it was found that the responsibilities and tasks related to a specific job are described in a "job description". The important business processes such as business planning, customer complant management, and service operations are also described in the ISO 9000 handbook. From the interviews it appeared that headquarters stimulates its sales offices to attain an ISO 9000 certificate. The main reason for implementing ISO 9000 is, according to our respondents,

"... the fact that customers are increasingly asking the local sales offices to register their quality system according to ISO norns. Standardization of outputs is attained by setring individual objectives for employees, i. , management by objectives, and by operational planning at the local level of the sales force organization."

Another important form of task control is standardization of skills, examples include training programs and management training. Assessing individual performance is one of the main task control devices. According to our respondents. the subordinates can, in consultation with their superior, set their own individual objectives. These individual objectives are of a quantitative and qualitative nature. The nature of the objectives depends on the task characteristics. It appeared that

"the objectivens should be quantifiable and recognizable. Furthermore, these objectives should focus on specific lask requirements such as presentation or linguistic skills, training programs are offered to attain these targets." (Belgian marketing manager)

Individual targets are stated in a formal report at the beginning of a fiscal year. This report also indicates the available resources and the time schedule. The individual objectives are used to assess the performance of employees. A formal conversation between the supervisor and individual employees takes place twice a year. During this conversation, the employees' realized results and individual objectives are examined, e.g., are the objectives attainable, feasible and attained. This may mesult in the reformulation of the existing objectives or the statement of new targets. The outcomes of these conversations are used as input at the next assessment meeting.

\section{Notes Case Study}

1. The International Organization for Sundardization (ISO) is a worldwide federation of national standards bodies. It thas developed three series of standards relating to Quality Systens known as the ISO 9000 family. ISO 9001, 1509002 , and ISO 9003 . These standards establish a standard framework for Qualiry System. A Quality System is a series of checks and balances which, when introduced and followed, will ensure quality of output, or product. The framework, as embodied by 1509000 , identifies natenty requirements, each of which affeet qualty. The standards themselves deftme the Quality Systems or models applicable to: design. development, production, installation and servicing, inal inspection and test. 
2.Contribution margin percentage is defined as a fixed percentage that is used to calculate the contribution or profit contribution. A profit contribution is generated for each product, product line and each sales office. The profitability calculations for products and product lines include local sales, cost of goods sold, and direct selling costs. With regard to local sales offices, the profitability calculations include sales, cost of goods sold, and local direct and indirect selling costs.

3. The expense target covers the costs concerning selling and marketing efforts, personnel and infrastructure.

4. This is the local business plan.

5.It was found that opportunities for personal growth is also important nonfinancial rewards; yet the employees are responsible for creating their own opportunities. Overall, the company supports its employees by offering training programs and other forms of education. 


\section{Case study II}

\section{Company B}

An IT firm with a functionally oriented work culture

\section{BACKGROUND OF THE COMPANY}

\section{Introduction}

Company $\mathrm{B}$, founded in the mid eighties, is a worldwide supplier of $\mathrm{PC}$ products and servers. Over the years however the focus has changed from a technology focus to a business focus. Nowadays the company focuses on integrating existing technology into a range of products, at a very interesting price and with very interesting features. Its products are sold in more than 100 countries.

The largest part of selling takes place via an extensive network of authorized Marketing Partners, it selects only in the United States directly to end-consumers. Nowadays, this company belongs in the eight largest computer manufacturers of the world. It employs worldwide approximately 15,000 people.

\section{Products}

At the moment the firm's product portfolio no longer contains products only at the high-end of the market, its content is now largely determined by user's preferences. The firm's products are marketed in more than: a hundred countries and they can be classified as:

- Servers: these servers offer the same possibilities as midrange computer systems at a much lower price.

- Desktop PCs: PCs suitable for use at the workplace, as a server or a workstation, and for use at home, as a multimedia PC.

- Portable PCs: despite the fact that these computers are portable they perform as excellent as the company's desktops.

\section{Worldwide sales force organization}

The firm's international activities are classified by the major geographical regions in which it operates: Americas, Europe/Middle-East/Africa and Asia/Pacific (see Figure B.1). Each regional office functions as an intermediary between headquarters and the local sales and support offices.

The local offices are wholly owned subsidiaries with responsibility for the implementation of the firm's marketing and sales strategy. The Dutch and the Belgian sales offices are part of the Europe/Midde East/Africa region, called EMEA.This regional consists of two clusters, the General Business Group. (GBG) and the Business Developing Group (BDG).

GBG consists of relatively small countries: Belgium, the Netherlands, Switzerland, Austria, Italy, Spain/Portugal and the Scandinavian countries. Each CBG has its own vice president, and this manager reports to the European headquarters. Large countries, such as UK, Germany and France, report directly to the European headquarters. BDG consists of five subregions: Africa, Eastern Europe, Russia, South Europe, and Middle East. Each sub region has its own regional director. The main difference between GBG and $B D G$ is that the GBG has its own marketing and finance department whereas the BDG title refers to a manager who only consolidates the results of the related local offices. 


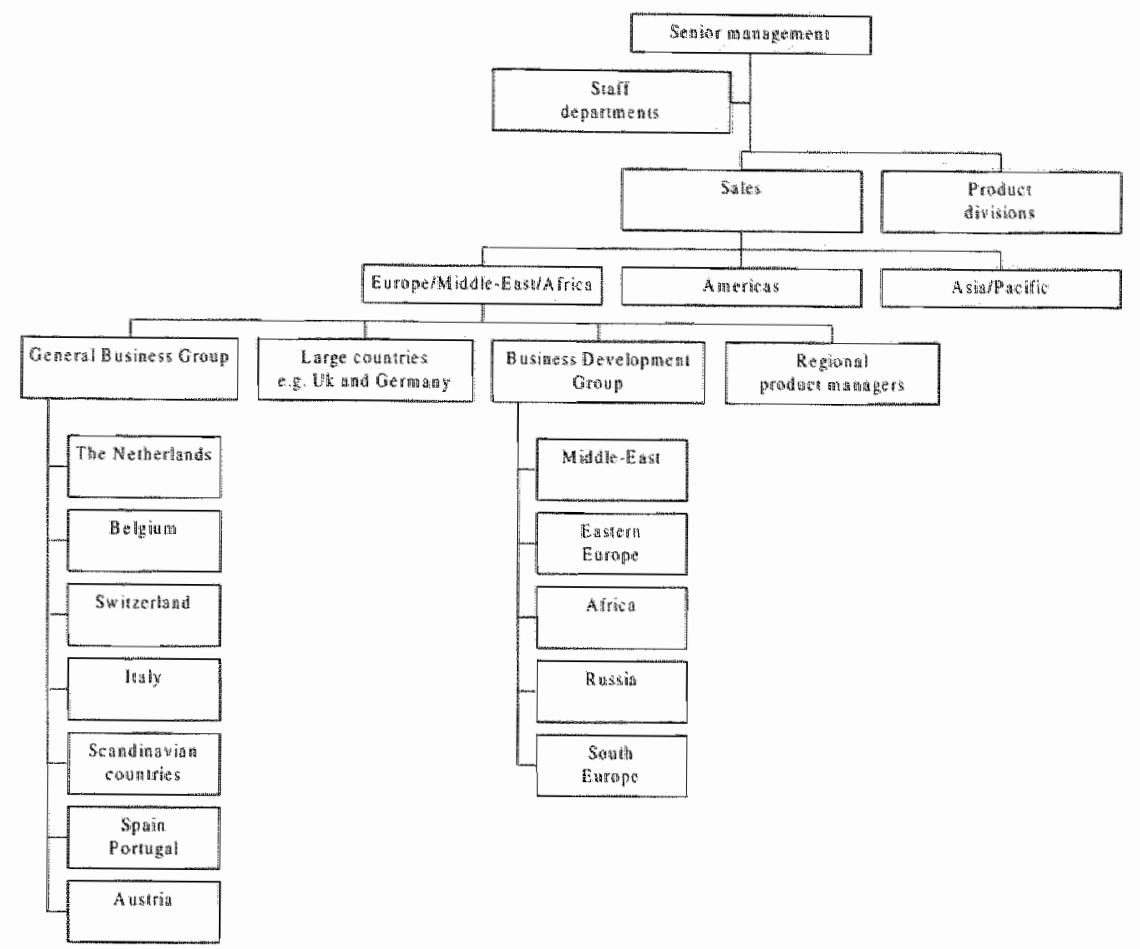

Figure B.11 Organizational chart

Source: adapted from internal documents 1996

\section{The Belgian and Dutch sales units}

The Belgian and Dutch sales outlets have an identical organizational chart (see Figure B.2). Each sales office is managed by a management team consisting of the general manager and the salles unit managers. This management team reports to the GBG regional director.

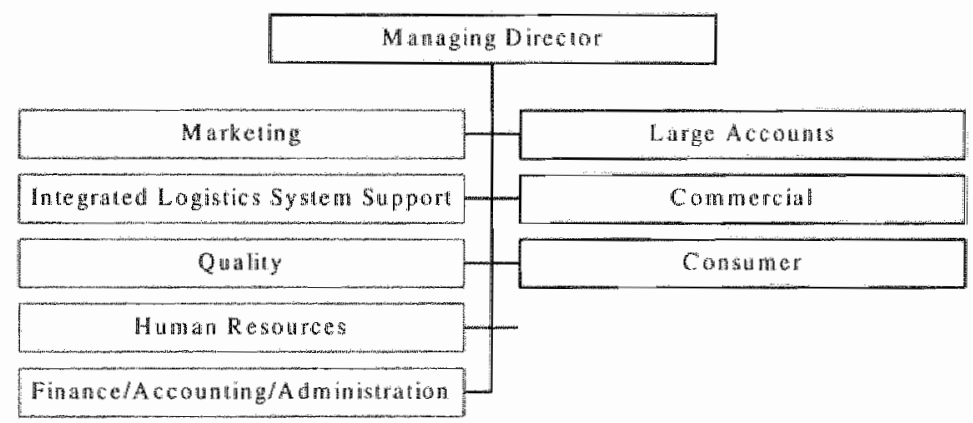

Figure B.2 Organizational chart of the local sales unit Source: derived from internal documents 1996

Three sales departments can be distinguished: Large accounts, Commercial and Consumer. These business units are supported by the following staff departments: Marketing, Integrated Logistics System Support, Quality, Human Resources, and Finance/Accounting/Administration. 
Local sales organizations are solely oriented to provide sales support. Actual sale and delivery of goods is always carried out by the Marketing Partners. The sales units differ one from another by the kind of market being served. As a consequence it may occur that a sales unit does not offer the entire product-mix. The sales unit Large Accounts helps distributors selling the firm's products to a selected number of large companies. The sales unit Commercial targets Small and Medium-sized Enterprises and controls the distribution channel dealers. The sales unit Consumer is entirely focused on the consumer market and consequently controls a special part of the distribution channel dealers, namely retail outlets.

The sales departments are supported by warious staff departments. The Marketing department takes care of positioning, segmentation, pricing, and communication of the company"s products. Integrated Logistic System Support optimizes the company"s service to Marketing Partners as well as to users of the company"s products. This unit is subdivided into separate departments for Transport, Service, Support, and Operations. Finchee/Accounting/Administration organizes and controls the financial administration and the financial information system. Human resources recnits and trains employees, and takes care of the rewarding and compensation system. As headquarters has stressed the importance of quality with regard to its products, it has centralized quality control. The local Quality organization reports directly to the General Manager.

\section{THE SALES FORCE ORGANIZATION}

\subsection{Formalization}

It was found that the Belgian and Dutch sales offices are less formalized in comparison to their main competitors; but the operations will be more formalized in the future. The Belgian major account manager explained:

"Our company is" less formalized. This can be explained by the fact that in the past our local sales officen were quite small, however over the last years the size of the sales offices have been growing strongly. This developntent reinforces the need for formalization."

At the company's sales force organization, various forms of formalization can be found. These forms include an imposed organizational chart, a task environment and ISO 9000 . The supervision of rules and procedures is accomplished primarily by the line responsibilities at the various organizational levels. The local administrative and support processes are audited by the external ISO auditor.

\section{Structuring local sales operations}

It appears that headquarters has developed strict guidelines for organizing local activities. These guidelines include the formation of specific business units and the specification of related business operations. There is a standard organizational chart that is imposed on the local offices. The local management can decide to adapt this chart to the local circumstances; yet these changes are limited.

\section{Function and task descriprions}

The task environment of the local offices is described in general terms by the corporation. These general gutidelines include the products and services to sell, distribution tacits and some function descriptions From the interviews it appeared that the corporation imposes a set of product and service categories on its local offices. The country managers thave decision making authority for individual products but not for product or service categories. The company uses 'through dealers' for distribution with a highly formalized system. It appeared that the EMEA' had developed a distribution model specifying the various marketing channels and business partners. This model is implemented in the European region. With regard to job descriptions, it appeared that there are some general guidelines, i.e., a general description of the task characteristics. The local managenent teams are responsible for formulating the task descriptions. It wal found that the job descriptions are quite vague; which can be explained partly by the fact the company wants to empower their employees to fulfill their tasks.

\section{ISO handbook}

The headquarters launched its ISO 9000 Program in 1987. This program is generally perceived as necessary to ensure growth in the future. The first step in formalization is the attainment of an ISO 9000 certificate at the regional offices and their local settlements. 
The major account manager stated that only the secondary business processes such as business planning. and customer complaint management are described in an ISO 9000 handbook. This handbook does not include the sales process. Both the Belgian and Dutch sales office have attained such a certificate. The regional office imposes the attainment of an ISO 9000 certificate on its sales offices. The aim is to get an ISO 9000 certificate for the entire sales force organization.

\subsection{Centralization}

Strategic decision making is centralized primarily at the corporate level of the organization. A strategy team consisting of senior managers, product division managers and external consultants is in charge of formulating the company's strategic direction.

The outcomes of the strategic planning are imposed on the worldwide salles force organization including local offices. It appeared that operational decision making is highly decentralized. The major account manager explained:

"The company's management philosophy assumes that a highly centralized organization tends to inefficiency. The refore, the operational decision making authority is highty decentralized. The worldwide business operations make it impossible to decentralize completely the decision inaking authority. The corporation formulates a management framework or various guidelines. The regional offices and their sales offices have to implement them within a specific margin."

With respect to the marketing mix, it means that product decisions are primarily madle at the headquarter level. These decisions include worldwide product management and product development. The local management, however, has some influence on decisions concerning the local product mix. If a product is not launched then the local management use their forecasts to evaluate whether a product should be introduced in a local market. The country manager explained:

"A few years ago, I refused to introduce an electronic dairy because the market information indicated that there was not enough market demand. As country manager, I can overrule the regional product managers but I must have a strong argumentation based on local market conditions."."

The evaluation devices for these decisions are based on revenue and profit projections. Once country managers can argue that a product launch in their sales area is not profitable enough, it can be decided not to introduce the product. Once a product is launched and it is not profitable enough ${ }^{2}$, the sales offices have to sell the product. In this case, resources are allocated and the local management has to find an appropriate solution for stimulating sales, such as sales promotion and end of life pricing. Price decisions are largely decentralized. In general, the local sales offices receive specific guidelines for price ranges; the local management teams are free to set their prices within these ranges. Regarding commodity products such as personal computers, the regional office imposes strict price guidelines. The price ranges are minimal; local management can only round up or down the imposed prices. With respect to high end products such as servers and work stations ${ }^{3}$, it appears that the price guidelines are based on gross profit margins. The regional office determines a gross profit margin of 15 to 20 percent on the product costs including the transfer, marketing and selling costs. If the gross profit margin is less than 15 percent then the local management has to contact the regional office to get an approval. This is the General Business Group manager in the case of the Dutch and the Belgian settlement. With regard to promotion decisions, it was found that local market communication is organized by the local sales offices. Each year, the sales offices are given an advertising budget. There are some corporate guidelines that have to be followed. These guidelines include a specific logo, a specific letter size, and a basic message. Distribution decisions are partly decentralized based on a European framework. The Belgian major account manager explained:

"... this model includes the various marketing channels and business partners. It includes strict guidelines concerning the marketing chanwels. These guidelines involve selection criteria such ax size and financial position. Furthermore, the regional office encourages its local offices to use specific compantes as preferred business partners; this because the corporation has 'worldwide' contracts. Overall, this model is implemented at each local sales office. Some small adaptations to local circumstances can be made. [... The Belgian market, for instance, is too fragmented for local companies to have a large dealers nerwork. There are no large companies such as 'AKZO Nobel', Philips or ABN AMRO. Criteria related to size and financial position have to be adapted to the local circumstances." 
Regarding personnel decisions, it appeared that the decision making authority is highly decentralized. Yet there are some guidelines formulated by the regional office. These guidelines are translated into the local human resources management policy.

\subsection{Integration}

The local sales offices are highly independent, the worldwide sales force organization does not employ a matrix structure. There are some contacts between the internationall product managers and the country managers but the country managers are responsible for the operating budgets. There is direct contact between the country managers and their regional office. The GBG regional director has an integrative role; this manager is in charge of coordination and integration at the GBG organization. The local offices in the GBG organization operate independently, each office must contribute to target achievement at the GBG which implies that the GBG director translates the EMEA planning guidelines into local guidelines and coordinates the operational planning activities of the country organizations to ensure that the GBG objectives are achieved. Furthermore, this line manager consolidates the results and reports to the EMEA. headquarter. At the individual sales offices, the business units ${ }^{4}$ are independent. The country managers have an interactive role at this level of the sales force organization; they translate the GBG planning guidelines into business unit guidelines, and coordinate the local planning activities.

\subsection{Participation}

Within the worldwide sales force organization, it appeared that operational objectives are not imposed on local sales offices. Target setting is a partly a top down and partly a bottom up process. With respect to strategic planning, a strategy team including senior management and external consultants are in charge of strategy formation at the corporate level. The different management layers at the sales force organization are not involved directly in these activities; once the corporate goals and strategies are presented then they may give feedback on these planning outcomes. With respect to strategy formation at the regional level of the sales force organization, there are strategy teams consisting of local and regional representatives. Local representatives are asked to participate in this planning process to set long term regional objectives and formulate appropriate strategies to attain these objectives. The country managers generally have a large decision making authority. Decision making is based primarily on reaching a consensus between the regional and the local manageriall levels; if consensus cannot be reached, then the country manager decides. Regarding individual objectives, it appeared that the subordinates formulate their objectives in consultation with their superiors.

\section{STRATEGIC PLANNING}

\section{Involved parties}

It appeared that senior management at headquarters, the product divisions and a group of external consultants are involved primarily in strategic planning. The Belgian major account manager stated:

"At the corporate level, a 'strategy team' consisting of members of the senior management team, the product divisions and some external consultants are involved intensively in strategy formation. I think that ous company has decided to concentrate strategy formation in a small group because this tends to make in easier to develop and coordinate a focused strategic action. At the European office (EMEA), there is also a group formulating strategic plans for the European region. This team consists of product mandigers, sales managers, marketing managers and country managers."

\section{Planwing procedure}

Strategic planning activities are not programmed formally for various reasons, the Dutch country manager explained:

"Defahed planning procedures tend to become obsolete at a rapid rate of change in product the technical life cycle of the company's products is nowadays less than one year. Funthermore, strategic planing does not inchate ongoing activities. We, therefore, have no detailed planning procedures 
It was also found that strategic planning creates strategic direction, i.e, a vision/mission statement, long term objectives and a related corporate strategy. Supervision of planning activities is done by the hierarchy; the corporate management supervises the planning activities at the corporate and product division level, the regional offices supervise the planning activities at local level.

\section{Planming process and its outcomes}

At the headquarter level, a "strategy team" is responsible for strategy formation. Once a year the strategy" teann establishes corporate level positions with regard to the company's vision and the "global leadership" objectives. The company"s vision includes two statements (internal document 1996): "... become the leading platform provider in the information technology industry. evolving from a PC company to a computer company" and "furnish the platform building blocks of personal and corporate computing while selectively participating in sofware (content) and communication (conduit) directly or wa alliarces". The fwe key elements of this vision are summarized below (internal document 1996).

- Provide products and services

- Serve business customers and consumers

- Provide standalone products and systems solutions.

- Emphasize platforms but also participate in content and conduit businesses

- Succeed through internal efforts and partmerships

This vision statement is embodied in the company' $\mathrm{s}$ credo 'Lead but don't blead'. This credo emphasizes the trade off between technology and leadership. The Belgian major account manager stated:

"In the past, the management only accenruated technology and its image of 'high tech company'. Changes" in the management board, i.e., in the early 1990 s, are the reason why doing business is more impartant than the image of being a high tech compasy. To become a "leader", the company spent a lot of attention on its management information system. The company believes that an efficient management information system makes a company more flexible to react to market developments. Furthermore, such an internal system helps to improve the quality of planing and forecasting activities. The managenem board wants to have a management system that is wore efficient than those of their competitors. The tradeoff between technology and leadership, is another key element in the strategy formulation: cost leadership".

Corporate objectives include 'global leadership' and formulating financial objectives. The "global leadership' objectives are strategic issues related to customer/market, costs/distribution, technology/producti, and company/people. These objectives are specified as follows (internal company document 1996):

- Customer/market orientation: maintain an unwavering focus on understanding and satisfying the requirements of our targeted customer base to help the company achieve and maintain leadership in product dependability, price/performance and ease-of-ownership

- Total delivered cost: design, manufacture, distribute and support products and services to achieve the lowest delivered cost on every product in every geographic region through efficient processes, systems, overhead structure, manufacturing, material sourcing and delivery costs

- Technology/product: consistently select and commercialize - both alone and with partners - the "right technology at the right time' to supply leadership products that merge new and evolving technologies into compelling customer solutions that promote market change and set the standard for value and quality effectively

- Company/people: contimue to sharpen employee focus on fulfilling customer expectations by working individually, and in teams, to find the best and most innovative ways to do business around the world, while achieving consistent financial performance

There are also long term goals of a financial nature, these goals include revenue and profit targets for the year 2000 .

The 'strategy team' also identifies appropriate strategic business units (SBU) and refines the business scope of these units by identifying appropriate product-market segments, e.g a specific product line for medium sized companies, and specific competitive priorities, e.g. obtaining a specific market share. The 'strategy team' has to find out what the interesting business opportunities for the future are and what new businesses should be developed. In a next step, the team develops action programs to support the competitive priorities of the SBUs. The output of the planning activities is a formall and welldocumented plan with a planning horizon of three to five years. 
The Belgian major account manager stated that the inputs to this plan:

"... include historical data recording past pefformance along with forecasts for the current planming horizon. The "strategy team" presents the plan to the sentor management to ensure 100 percent commitment to the plan."

The corporate strategic plan includes strict guidelines for the long term and short term planning activities within the worldwide sales force organization and a financial statement. The implementation of this strategic direction in the sales force organization is always discussed by the supervisors and subordinates. Those with the line responsibilities in the sales force organization are invited to give feedback on the outcomes of strategy formation. The major account manager stated that:

"... these discussions are generally seen as two way meetings. The corporation provides each managerial level of the sales force organization with information concerning strategy formation, and regional and local managers are iwvitted to give feedback such as market information and suggestions. Local offices are stimulated to give feedback because this imput can be usied to reformulate the strategic issues at the regional and the corporate lewel. This feedback can lead to the formation of project leams to discuss specific issues. The corporation organizes focus groups and invites local personnel to visit headquarters."

Respondents stated that these planning outcomes provide the managerial levels of the sales force organization with planning guidelines with respect to their strategic and operating planning activities. The major account manager stated:

"... the reglonal and local strategic plans and operating budgets also emerge from the corporate planning process. The regional offices and the product divisions use these planning outcomes for marketing decision making such as marketing strategy formation and manketing mix decisions. The planning horizon at this managerial level is generally restricted to a maximum of two years."

The planning horizon of two years was explained by the fact that the technological life cycle of these products is less than two years and it reflects that product-market combinations are changing continuously. It also appeared that senior management and the product division managers at headquarters are held responsible for the attainment of long term objectives. These objectives are used to allocate the required resources. Although the corporate strategic plan includes strict planning guidelines for the sales force organization, senior management does not use it for allocating resources and assigning responsibility to the line responsibilities because the business environment is changing too quick and there are too many uncontrollable factors that have an impact on business operations. At the regional and the local sales level, functional managers use the strategic plan to develop and enact action programs to support the attainment of corporate goals. All respondents perceived the long term objectives as realistic and feasible but ambitious. The Belgian manager explained:

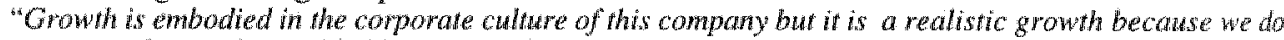
not try to change the word objectives only motrvate people if they are realisticlfeasible and ambitious.

SALES MANAGEMENT CONTROL

\subsection{Planning, organizing and directing}

\section{Involved parties}

Regarding target setting for local sales offices, it appears that the regional office and the local management teams are involved.

\section{Planning procediure}

Our respondents stated that nowadays the operational planning activities are programmed formally in at written procedure. This procedure is a part of the ISO 9000 procedure which is audited by an external procedure annually. Obtaining an ISO 9000 certificate was one of the individual objectives of the country managers. 


\section{Planning process and its outcomes}

We found that the operationall planning process has both top down and bottom up characteristics; however, the top down characteristics dominate. Decision making is based on reaching a consensus between the regional and local representatives. Each year the planning activities start in August as follows. The regional office translates its operational targets into planning guidelines for its sales offices; these guidelines form the basis for the individual targets of the country managers, and these targets are set in consultation with those managers. The operational targets are mainly of a quantitative and especially a financial nature and include targets related to sales quota specified per product group and product, revenue including total revenue and revenue targets specified per product group/products, costs including administrative and sales / marketing costs, expense targets ${ }^{5}$, contribution margin ${ }^{6}$, revenue per employee, and reducing the differences between sales forecasts and actual results to maximal two percent. An important quantitative but nonfinancial target is "percentage of market share" ${ }^{\text {. }}$. Furthermore, the regional office imposes customer satisfaction targets on its local sales office: the sales offices have to achieve a number one position in their local market with respect to customer satisfaction ratings. The company also encourages its organizational units to develop "good" planning and forecasting methods. According to our respondents, such methods help the company to formulate appropriate production schemes to avoid supply or demand surpluses. The country manager explained:

"The regional office translates the corporate strategic guidelines into operational planning guidelines for their sales offices. These guidelines are related to the leadership and financial objectives. The operational targets of our sales office are related to sales quotas per product, costs, revenue, expense targets, market share, contribution margin, custoner satisfaction, revenue per employee, ISO, improving the quality of planning and forecasting methods, and market leadership. Our company also emphasizes the importance of 'good' planning and forecasting methods to reduce costs related to inventory and overcapacity. A 'bad' inventory policy and overcapity in production deteriorates the firm's cost and expense structure, i.e. our key competitive factor. Planning guidelines are used to set targets for the individual country manager. The key targets, are revenue, expense targets, and contribution margin. The country managers discuss the planning guidelines for their local sales office at the regional office. This discussion results in an agreement concerning objectives for the country manager."

It was also found that the regional office is perceived to be an intermediary between the corporation and its local sales offices. The regional office translates the corporate objectives for the region into individual abjectives for the country managers. This does not, however, imply that those objectives are imposed by the regional office but that they are stated in a dialogue between the country manager and the regional office. The major account manager stated:

"The country managers are generally perceived to be 'local experts'. They can evaluate the market potential of the ir local market. Local market experience helps to evaluate the feasibility of operational targets. To improve the quality of planing and forecasts methods, it is necessary to lssten to the "local market circumstances'. Today's success is primarily the result of a 'good' inventory policy and 'good" production schemes. The market experience of country managers helps the company to formulate such 'good' inventory policy and 'good' production schemes" (Belgian country mandger).

The country manager explained further:

"Overall, the targets are set by reaching a consensus. Our regional office does not impose targets on us. If we cannot reach a consensus, then I fake the decision concerning the target. It is wy job, I am paid for this."

It was also found that the operational targets of the sales offices are also the individual targets of the country managers. The regional office holds them accountable for attaining these objectives. Once the sales quota, the revenue targets and contribution margin are accepted by the country managers, the regional office allocates the required resources. These resources are stated in the the operating budget of the local sales office. The major account manager stated:

"Once the targets concerning sales quota, revenwe, and contribution margin are accepted by our country manager, the expense targets are set. There are fixed percentages for specific costs, for instance, a maximal two percent of the total return is reserved for warketing costs. If a country manager wants to have a larger budget for marketing costs, then capproval from the regional office has to be obtained. There are also objectives of a qualitative nature. An example of such an objective is obtaining an ISO 9000 certificate'. In sum, the discussions between the country managers result in generic and business unit targets." 
At the same time as the discussions between country managers and the regional office are taking place, the local business units are setting their business targets. This local planning process has mainly bottom up characteristics; the planning activities are described in a written procedure. Sales projections of salespersons and past performance, sales and expense targets are formulated based on market information. At the Belgian sales office, the sales manager employs a specific system for assigning sales targets to his salespersons. He stated:

"Each year I ask wy sales representatives to make an overview of the potential sales transactions for the next fiscal year. My sales reps also have to indicate the probability that these transactions will be realized. Based on these data, I calculate the expected value of the sales transactions: $i$, the sum of the return multiplied by the probability of realization. The summation of the expected wallue of the sales transactions results in a sales projection of the whole business unit. The financial department calculates the related costs for this sales projection. These costs are then stated in a budget. I discuss these sales and expense proposals with my boss, the country manager. I should remark that the targets of wy department are generally not imposed. Overall, sny boss and I reach a consensus. If we cannot reach a consensus then the country manager imposes the iargets on my department. So. also on we. This is not

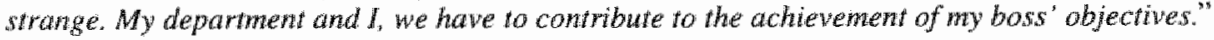

The Belgian major account manager stated that this planning and forecasting method force the sales reps to study the quality of their leads and qualified leads. He explained:

"... my system is not perfect, but it stimulates my sales reps to think about the quality of their leads and qualified leads. They have to act as an entrepreneur by predicting their future cashflow very precisely."

From the interviews, it appeared that the objectives tend to be ambitious but feasible and realistic. The objectives have to be ambitious to stimulate salespeople, but if they are unrealistic then they are not motivating for the employees.

\subsection{Performance measurement}

It appeared that the measures are primarily of a quantitative and especially a financial nature. The performance measures are revenue figures, contribution margin, market share and expense ratios. These measures are related directly to the operational objectives stated in the business plan of local sales offices. The country manager explained:

"the annual plan includes five objectives that are quanifiable: revenue, market share, contribution margin, expense targers, and customer satisfaction. The objectives are also my personal objectives: they are also predefined performance standards, imposed by the corporation and our regional office."

It was found that the financial performance of the sales office is measured by revenue, contribution margin and expense targets, and that performance data is collected automatically on a daily base. The local information systems are part of a company wide system. Nonfinancial performance is measured using various indicators. These indicators include the number of employees at a business unit, market share. local brand awareness, the fill rates for spares, the delivery time of products, the number of "zero-defects" delivered orders, the mean of "days of account receivable", customer satisfaction, and customer complaints. Market shares are measured at two levels: the total market share of a local sales office, and the market share per business unit. The measurement takes place in the distribution channels bimonthly and among end-users on a quarterly base. Brand awareness is measured by a survey once a year. With respect 10 customer satisfaction, it was found that a survey is conducted on a quarterly base. "This survey is conducted by an extermal organization. This research focuses primarily on activities related to after sale; in depth interviews are used to collect the data. Since 1996, the Belgian salles office has also organized a bianually focus group discussion encomprising a fixed number of customers. These focus group discussion are used to evaluate local sales performance in terms of the customers"experiences toward the local customer support, the maintenance services, etc. Furthermore, customer complaints are measured by the local Care Center. It is a call-center that everybody can use to ask questions, to complain, etc. The performance of this center is measured by the wating time for respondents to contact somebody, the number of calls that put down the receiver, etc. The measurement system used is an integrated statical system that measures daily the performance of the call center. A weekly overview of the activities and the results of the care center is made by the technical manager. 


\subsection{Performance evaluation}

The regional office evaluates the performance reports of its sales offices on weekly, monthy. quarterly and yearly base. The aim of this performance evaluation is twofold: to evaluate "progress-to-plans" and to evaluate "progress-to-benchmarks". The performance assessment involves a comparison between planned and actual results, and the comparison between actual and past results. The evaluation devices used are the composition of sales, contribution margin, costs, precision of local planning and forecasting methods and quality, however, the key evaluation devices are 'contribution margin' "revenue', 'market share', and 'market share growth'. The importance of 'contribution margin' as evaluation device is explained by the country manager:

"Contribution margin is defined as the difference between the revenue that we obtan for a given product/service and the incremental cast of sales incurred in genterating that revenue. I... T These costs include the costs related to products and services and the costs related to our settlement. Inean direct costs. The contribution margin is a key evaluation device because a profir as evaluation device is less sensible for, e.g., currency fuctuations and internal flows of goods as a result of transfer pricing. You should know, we are an intemational arganization and factors such as currency fluctuations and the local tan legislation can have a great impact on e.g. the profit calculation. This is the reason why we as aw intemational company use contribution margin as the key evaluation device for our lacal offices. Another important evaluation devices is controlling our expense target. Outside our technological fnowledge, the cost and expense structure is one of the key success factors of our company."

The analysis of planned and actual results is used to demonstrate the extent to which planned results are achieved, i.e., progress-to-plans, and to identify potential causes for differences between planned and achieved performance. The company, therefore, uses the outcomes of the business planning cycle, the forecasting cycle and the actual performance. With regard to the forecasting cycle, the actual performance and the outcomes of the weekly meetings are used to recalculate the sales projects for the current month. the current quarter, and the next quarters. The progress-to-benchmarks is also evaluated; these benchmarks are the financial ratios related to costs, contribution margin and revenue per employee. The benchmarks are set by the regional office and imposed on the local sales office. The Belgian major account manager explained:

"Our organization employs specific financial rarios related to costs" gross margin and revenue per employee. These ratios are set by our regional office, in consultation with the local offices. We perceive these ratios are to be objectives per se; they are also predefined standards for financial perfornance. The regional office evaluates the extent to which these benchmarks are attained in our office."

It was found that the analyzes are used to assess the extent to which the "benchmarks" are attained. The precision of local planning and forecasts are also evaluated. The importance of this evaluation device is explained by the Belgian major account manager.

"The precision of local planning and forecasting methods toward actual performance is vilul for controlling the company"s expense target. This figure is very important for the orgamization because this indicator provides information concerning the quality of the planning and forecasting efforts. Platming and forecasting information is used for material planning at the production plants. A poor atuality of planning and forecast methods makes "good' production plans and a "yood" inventory policy inpossible"; has a negative impact on the company"s expenditure structure."

From the interview with the major account manager and the country manager, it appeared that targets are not adjusted as a result of the impact of unexpected and uncontrollable factors, such a sudden sales drop Various reasons were mentioned. First, adjustment of targets to current market developments is perceived as a time consuming activity, especially when decision making is based on reaching a consensus. Second, these adjustments have an impact on the company's production schemes and inventory policy. An upgrading of targets may imply that more products are needed; it implies that the required production capacity should be available or that the company should have products in stock. With tegard to the individual performance, it was also found that targets are not adjusted due to unexpected and uncontrollable factors. According to the major account manager, it is assumed that these circumstances are a part of the business in which one operates. He explained:

"A good manager knows the professional risks. One expects from thin that he calculates for these risks when setring his targets. The operational objectives are rarely adapted" 
Besides the annual audit, the performance of local sales offices and local business units is described in : ranking system. Once a year, the actuall results of each local sales office are compared with the other sales offices in the region. This ranking is carried out using the following evaluation devices: revenue, market share, achieved percentage of market share growth, and customer satisfaction. This ranking " called 'country of the year" is calculated by the regional office. Each year the number one country in the ranking is honored at an annual conference. There is no reward, but the tangible honor related to this award stimulates local salesperson to achieve this award.

A similar evaluation procedure is used at the business unit level. The evaluation devices used are quite equal to those used for the local sales office: composition of sales, contribution margin, costs, and precision of local planning and forecasting methods. Sales figures are derived from performance reports on marketing channels. These reports indicate sales volumes and sales/revenue per business unit and product. The internal performance assessment is based on the country results, there are also specific evaluation devices for the business units. The specific business unit devices used are the number of employees at a business unit, market shares, local brand awareness, the fill rates for spares, delivery time of products, number of "zero-defects" delivered orders, mean of 'days of account receivable', and customer complaints. It appeared that there are more nonfinancial evalluation devices used at the business level in comparison with the local salles office unit. This was explained by the fact these operational measures are directly related to the task environment of the lower management layers.

\subsection{Feedback and rewarding}

\section{Feedback}

With regard to evaluative feedback, it was found that regional management discusses the outcomes of the performance assessment with local management. This formal feedback with a positive or negative sign is provided at least on a monthly base, there is the possibility to contact the regional office whenever problems may occur. Performance feedback is provided on a weekly, monthly, quarterly and yearly based. This feedback is given primarily during meetings with the regional representatives. Weekly and monthly reviews are used to identify significant performance gaps between planned and actual results and to initiate timely corrective actions. Quarterly reviews are used to integrate company-wide efforts and to modify implementation themes. Annual audits are used to study the annual results, and to identify issues for the next planning cycle. Regarding feedback on business unit performance, it appeared that local business unit managers receive feedback in the form of an overview of the achieved and planned outcome; evaluative feedback is provided on a weekly, monthly, quarterly and yearly based. It appears that for feedback on performance assessment the company focuses on performance per month and per quarter. It was also found that the superiors intervene only if outcomes do not meet predetermined standards. Corrections are only initiated if actual outcomes do not meet predetermined standards, and corrective action is formulated and initiated by the local management team. They can contact the regional office whenever it is needed. It was found that evaluative feedback on long-term performance is provided by assessing short term organizational performance. Corrections are only initiated. if actual outcomes are not according to predetermined standards, these adjustments are initiated annually. Planning meetings at local and regional level are used to follow progression in the attainment of long term objectives, corrective action is discussed and formulated by the parties involved.

\section{Rewarding}

There are various types of reward schemes employed at the local level. People working in sales have traditionally been offered individual incentives based on the attainment of operational targets. The sales compensation plans consist of a combination of fixed salary and commission plans. It was found that a 70 per cent of the salespersons' rewards consists of a straight salary; this straight salary is used to ensure sales representatives a stable income. Furthermore, a 30 per cent of the reward is incentive based. This part of the reward is based on:

- total company performance, i.e. profit

- individual sales performance, i.e. sales volume

- the extent to which qualitative? targets are achieved

With respect to the employed commission rate, it was found that the company employs a combination of a progressive and regressive rate. A progressive rate is used until the targets are achieved; once the targets 
are attained a regressive rate is used. The progressive rate is employed to stimulate salespeople to reach the prespecified targets. The regressive rate is used to encourage salespeople to plan more precisely and to decrease the impact of extreme sales that are not due to personal efforts but to unexpected and uncontrollable factors. Thus, individual targets are not adjusted due to the impact of these factors.

The rewards are calculated on a quarterly base because individual sales objectives are set for a three months period. At the end of each quarter, the individual targets of the next quarters can be adjusted due to uncontrollable and unexpected factors that appeared in the previous quarters; the superior can adjust those objectives that are related directly to the salesperson's rewards. Furthemore, the maximum commission is based on 200 per cent of the initial individual targets stated at the beginning of the FY. From the major account manger it appeared that there is a maximum regarding commissions. He explained:

"We are awape that a unexpected market opporturity may result in an exciting deal. Such a deal may result in an excessiwe conmission for the specific salesperson. Such excessine commissions due to a slice of unexpected luck are unethical. We have decided to avoid such commission by using stated explicin maxima."

The respondents also stated that the company has no worldwide compensation system for their local sales force. Local systems are developed by the management team of the local sales office; yet the reward systems are quite similar in practice. It was also found that compensation for sales effort and performance includes nonfinancial rewards. Recognition of achievement is the most important one ${ }^{10}$. There are two formal recognition programs for salespersons, i.e. the Quota club and the President's club. The Quota club consists of salespersons who exceed 100 percent of their annual sales quota. The local management annually inducts its top sales people into this club, and offers them a symbolic award of psychological value, such as a golden watch and a plaque. The ultimate recognition for the company"s sales elite is to be named a member of the President's club. Key criteria to become member of the club are the realized revenue and the extent to which personal objectives are achieved. The members of the President"s club are all made up of Quota club member, but they must be recommended by their senior management. The importance of these recognition programs was explained by the fact that the face-to-face recognition and constant feedback encourage sales persons to improve their performance. Regarding local management, it appeared that these managers have a straight salary plus a bonus. The bonus is a financial incentive based. on the company"s performance, the individual performance and the outcomes of the customer satisfaction surveys; these issues are equally important. The impact of extreme high performance not due to personal efforts is limited by three factors:

- managers have primarily a straight salary

- the company generally pays a cash bomus of 15 percent of sallary to any member of the local management: this bonus is based on company"s performance, individual performance and customer satisfaction only one third of the bonus is based on individual efforts; assessing individual performance is based on a ranking consisting of more than only sales performance but also qualitative factors such as team performance

Furthemore, there is also a stock option plan. The local management can receive stock options, and they can use these stock options during a period of four years. This is done to motivate and reward long term performance; however, these incentives are based on the performance of the whole worldwide organization. Finally, there are also formal recognition programs for local managers called "Country of the Year". These programs imply public recognition for accomplishment in the presence of peers and superiors in the organization. These programs are organized for country and business unit managers; yet these programs have no impact on the salary of the country managers but they can improve the career perspectives" of the managers. The criteria used are overall revenue, contribution margin, market share, market share growth and customer satisfaction.

\section{TASK CONTROL}

From our interviews it appeared that various task control devices are employed at the local sales office level. These tools are developed primarily by the local management teams.

With regard to the standardization of work processes, it appears that the local business practices have to be described in an ISO 9000 handbook. As yet only the sales process and other primary business processes are deseribed in this handbook. Headquarters also imposes some function descriptions; these descriptions include some general guidelines concerning the responsibilities and tasks of specific sales 
positions. There are also task descriptions; these descriptions are stated by the local management and include a list of tasks and responsibilities concerning local sales positions. Overall, these function and task descriptions are quite vague.

Standardization of outputs is achieved by using 'Management by Objectives'. It appears that thert is a direct link between target achievement and personnel practices, i.e. promotion and salary decisions. It was also found that the skills of employees are standardized by using internal and external training programs. These programs are organized at the corporate, the regional and the local level.

The assessment of individual perfomance is an important task controll device. As stated earlier, the subordinates can formulate their objectives in consultation with their superiors. These objectives should be realistic and feasible, but also ambitious. Overall, the superior uses a standardized format to report the individual objectives to their subordinates, to indicate the related performance measures and to report progress on a yearly base. The performance measures are set by the superior in consultation with the subordinate. It was found that the subordinate can ask for a budget for the required resources and training programs to attain these individual objectives. The subordinates can also formulate qualitative targets related to customer satisfaction, personal development and specific payment terms for customers; but these qualitative targets should reflect the specific job characteristics. The individual objectives are stated in a formal report. Assessment of individual performance takes place on an annual base; the superior evaluates the extent to which individual objectives have been met during a formal conversation with a subordinate, called 'a formal appraisal evaluation". With respect to salespersons, it appeared that the group of employees is evaluated on quarterly base. This evaluation includes the planned and realized sales results; the salespeople also bave a bimonthly, formal discussion with their superiors.

\section{Notes Case Study II}

1. EMEA refers to the European regional office.

2.according to local mantugement

3. With respect to price ranges, it appeared that there is a difference between commodity products and high end products. Conmodity products refer to personal computers, e.g. desktops and laptops. The service component in selling is limited to offering customer support, e.g. call center support. It appears that these markets are homogeneous in terms of products. Furthermore, buyers appear to be price sensitive Headquarters tries to use one worldwide price lists to avoid grey import from one country to another.

4.i.e. sales units or sales departments

5. The expense targets include goals related to managing owerhead costs related to infrastructure and other expenses that can not be assigned directly to business activities, called indirect costs.

6. The contribution matgin is determined by the gross profit margin percentage. The gross profit margin. percentage is a fixed percentage on the standard cost price of good sold. This percentage waries from 15 to 20 percent. The standard cost price inchudes the transfer price. i.e. the product price calculated by the headquarters, and direct costs such as marketing and sales costs. Overhead is not covered by the standard cost prices.

7. This tartget inctudes primarily "attaining a unarket leadership position in specific market segrnents".

8. The company is worldwide knows for its a clear cost and expense structure. Although this company is one of the world's largest IT firms, it hass succedded to handle a simple cost and expense structure for its business operations.

9. Examples of qualitative targets are the number of custoners present on manketing events.

10.It was found that opportunities for personal growth is also important nonfinancial rewards; yet there is no formal career path. The employees are responsible for creating their own opportunities. The company supports its personnel by offering training programs and other forms of education. Employees have to apply for a job; the jobs are not offered automatically to them. 
11. It was found that managers are responsible for creating their own opportunities. The company supports its personnel by offering training programs and other forms of education. Employees have to apply for a job; the jobs are not offered automatically to them. 


\section{Case study III}

\section{Company C \\ An IT firm with a process oriented work culture}

\section{BACKGROUND OF THE COMPANY}

\section{Introduction}

Company $\mathrm{C}$, founded in the mid twenties, is one of the largest IT companies of the world, and one of the four largest industrial companies of the United States. Its products are sold by its sales force and business partners and dealers in more than 140 countries around the world.

\section{Products}

The company has grouped its worldwide business operations under five product divisions. These product divisions are responsible for $\mathrm{R} \& \mathrm{D}$ and product management related to one of the following product groups: large scale systems, midrange systems, personal computers, software and services.

\section{Worldwide sales force organization}

The sales activities are classified by the major geographical areas in which the company operates: Americas, Europe/Middle-East/Arrica ${ }^{\dagger}$ and Asia/Pacific (see Figure C.1). The headquarters of a region operate as an intermediary between the corporate level and the local sales offices. All sales units are wholly owned subsidiaries and they are responsible for implementing the marketing and sales strategy of the company. These subsidiaries are responsible for organizing direct and indirect selling activities. If implies that local management is responsible for recruiting and managing a local sales staff and for developing and managing distribution channels, such as dealers and business partners.

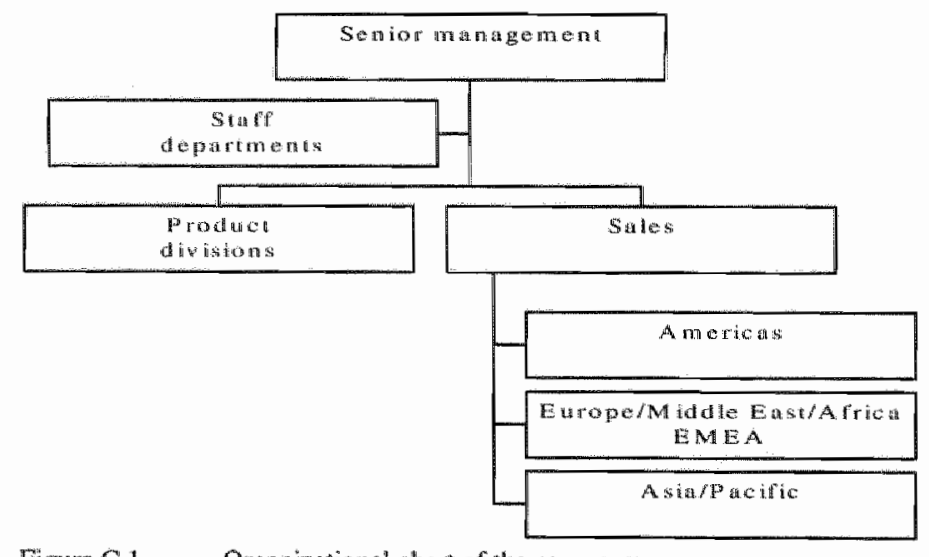

Figure C.1 Organizational chart of the company

Source: adapted from internal docmenents 1996

A matrix organization is employed to structure the business activities at the regional and local offices (see Figure C.2). This matrix organization has two dimensions: product divisions and industries (i.e. based on customer segments). The product divisions include Products, PC Company, Distribution Channel Management, Industry Solutions, Software, Services and International Operations. 
The business units are related to the different industry segments and include Finance/Banking, Insurance, Government, Travel, Distribution, Cross-industries, Scientific/Education, Manufacturing, Telecom/Media, Petroleum, Transport, Health, Process and Utilities. The Belgian and the Dutch sales unit belong to the European/Middle-East/African region (EMMA).

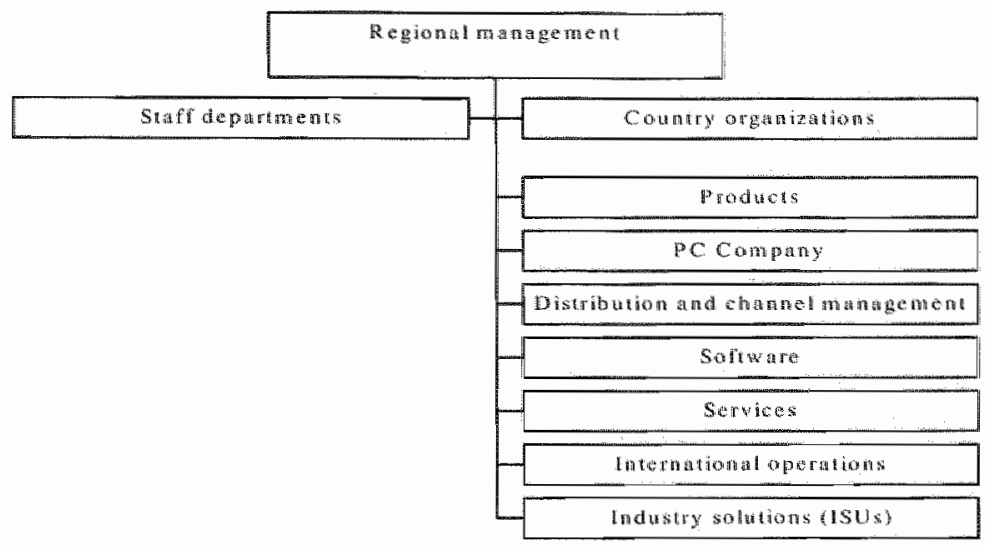

Plgure C.2 Organizational chart of EMMA oftice

Source: adapted from internal documents 1996

\section{The Belgian and Dutch sales units}

It was found that headquarters impose the standard organizational chart on local sales offices, including the Belgian and Dutch sales offices. Overall, local sales offices are managed by a local management tean. This management team consists of the leaders of the business units and staff departments mentioned in the organizational chart (see Figure C.3). The business units include Products, PC company, Distribution and Channel management, Software, Industry solutions and Services, and International operations; the siaff departments include Marketing Staff \& Support Business Fulfilment, Personnel, Finance \& Planning, and Communications \& External Programs Legal.

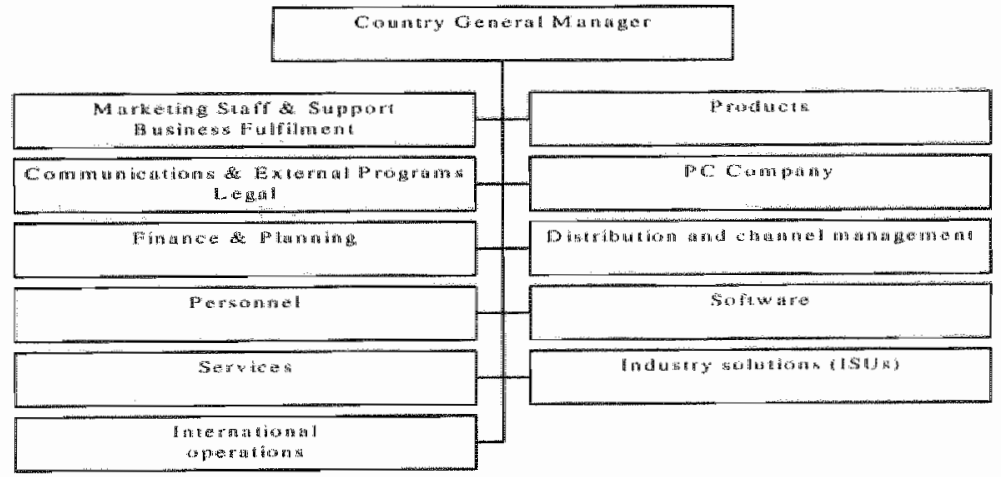

Figure C.3 Organizational chart of a locall sales office

Source adpated from intermal documents: 1996

The local sales office consists of sales and staff departments. Regarding sales departments, it was found that there are two types: product divisions and industries (ISUS). The sales units consist of several sales organizations, namely products, PC Company, Distribution \& Channel Management, Industry Solutions, Software, Services and International Operations. These organizations are supported by several staff organizations: Marketing Staff \& Support, Finance \& Plarning, Personnel, and Communications and Legal. A brief description of sales and staff organizations is given below. 
Within the products business unit the activities are organized by product. There are separate units for the different kinds of products sold: AS/400, AIX/UNLX. Storage. Printers, Large Scalle, Networks, Client/Sever and Original Equipment Manufacturing and the manufachuring of products for third parties: 'The 'PC Company' markets personal computers and provides sales support to those selling them. The business unit 'Distribution \& Channel Management' is divided into subunits: GBM, DRM, and Channels. All sales activities toward small and medium-sized enterprises are concentrated in the "GBM" unit. "DRM" is the direct marketing organization aimed at designing and organizing direct marketing efforts, and 'Channels' focuses on all activities that involve third parties like value-added resellers (VAR's), dealers and agents. The business unit 'Software' sells the company's own software systems and the business unt Service offers services. The business unit 'International Operations' is divided into three subunits: The International Logistics Center (ILC), the European Repair Center (ERC) and the Central Ordering Point (COP). All three units are EMMA units. ILC serves as an EMMA landing point for several products, from where the products are shipped to customers in other EMMA countries. ERC takes care of the reparation of products, and the COP manages inventories and distribution of spare parts. The business unit Industry Solutions (ISUs) groups customers by their business activities. The company distinguishes fourteen industries, for each of which a separate business unit has been set up: Finance/Banking, Insurance, Government, Travel, Distribution, Cross-industries, Scientific/Education, Manufacturing, Telecom/Media, Petroleum, Transport. Health, Process and Utilities.

The sales departments are supported by various staff departments. Marketing Staff \& Support is, among other things, responsible for planning and budgeting at the micro level. It is also responsible for the Customer Relationship Management (CRM) system. CRM includes all the sales and customer support processes taking place at the different layers of the sales force organizations. The department Business Fulfillment is part of this unit and is responsible for the sales order administration, actual delivery of goods, inwoicing, and control on accounts receivable. Finance \& Planning is responsible for the financial administration and for plans and budgets for the subsidiary as a whole. Customer financial Services (CFS), the company's internal lease company for customers, is part of this unit. Personnel takes care of all activities concerning personnel, and Communications \& Legal takes care of corporate communication and provides legal support.

\section{THE MOVE TO A PROCESS CULTURE}

\section{Cause of the move to a process culture}

The company had problems with its profitability in the late eighties; it appeared these problems werc caused primarily by the global competition and the rapid teclunological changes in the computer market. These market developments lead to an apparent contradiction within the organization. Constant innovation was required to retain competitiveness; yet costs had be reduced to the minimum. Company $C$ was not able to combine innowativeness with cost effectiveness due to its bureaucratic structure. Headquarters, therefore, decided to implement Total Quality Management (TQM) and Business Process Management (BPM) at each level of the onganization, from headquarters to local sales offices. This means a move from a functionally oriented culture to a process culture

\section{Market Driven Quality}

The discussion to apply TQM was based on three principles: respect for the individual, customer service. and excellence in all that is done (internal document 1995). The TQM process that emerged, called "Market Driven Quality" (MDQ), focuses on the following issues:

(stated by the Belgian Country manager) "... defining the market needs, producing and delivering products and senves with few or mo faults, reducing cycle time, increasing employee participation, and measuring
progress"

MDQ has led to a catalog of conditions for excellence across the entire organization: executive vision, supporting strategies, management commitment, education, communication, customer involvement, supplier quality assurance, process management, visible measurements, periodic reviews, employee participation, and rewards and recognition. The firm has announced four market-driven principles to ensure clarity of common purpose in terms all employees should understand (internal document 1995 ): 
- make the customer the finial arbiter

- anderstand the markets

- commit to leadership in the markets the company chooses to serve

- axecute with excellence across the organization

These principles govern many actions taken across the organization. Fundamental measures of success are customer satisfaction, revenue growth and market share, profit and financial retums. The company"s culture has been developed toward the process model because of its use. It implies that work is not designed around clearly defined specialization per individual and integrated deep management hierarchies in which decision making is clearly set apart from actual execution.

\section{Process management as management tool}

The company's new management tool, called 'Business process management (BPM), is based on the TQM principles of process management and continuous improvement. BPM is "... a continuous and disciplined method for specifying, analyzing, and improving the performance of key business processes based on the needs and wants of the customers" (internal document 1995). It consists of three phases: process assessment, process analysis, and process improvement.

Process assessment involves the identification of the customers' needs " mapping' the processes, collecting information regarding to process performance and ordering the processes. The company has formullated a checklist consisting of four steps to formalize these activities (internal document 1995): get organized, talk to customers, walk to the process, and set priorities. Each step of this checklist is described in detail, i.e., the activities and the related outcomes. The company has identified key business processes requiring excellent performance, hence continuous improvement. The framework for selecting these processes grew directly out of the Malcolm Baldrige model. The current list includes the following processes: market information capture, market selection, customer requirements, hardware development, software development, plan integration, production, solution integration, marketing, customer fulfillment, customer relationships and customer feedback (internal document 1995).

Once the process is assessed, the phase 'Process analysis' uses all the information collected for designing and evaluating proposals of process improvements. A specific checklist is therefore used. This checklist includes the following steps: benchmark your process ${ }_{n}$ develop solutions , get buyin, and finallize your improvement plan. 'Get buyin' implies that support, commitment and cooperation have to be created by which the proposed change can be implemented in the whole organization. The last phase, i.e., process improvement, involves activities related to:

- the implementation of process improvement plans.

- the acquisition of customer feedback with respect to results

- the reformulation of the improvement plans

- an execution called 'rolling out' of solutions for the whole company

A process audit is conducted twice a year. Figure C. 4 illustrates the company"s business process management practices.

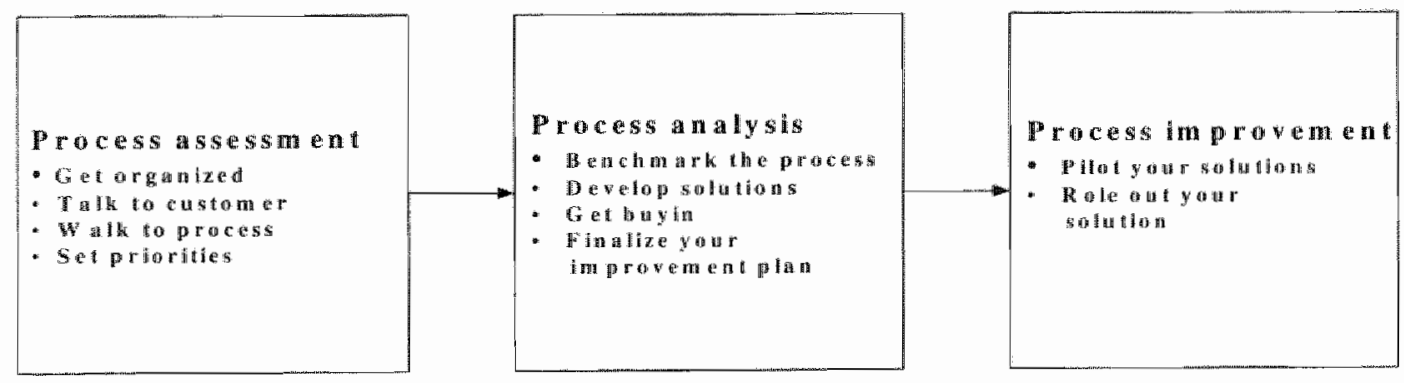

Figure C.4

Business process management

Source: internal document (1993) 
The goals of Business process management

The implementation of BPM within the worldwide organization has various goals. These goals are (internal document 1993):

- the outcomes of the processes should be at least in line with the wants of the customer

- the processes should genterate these outcomes effectively and efficiently

- the processes should be 'superior'competitive; they have to be improved continuously, adapted to the changing requirements of the customer, and result in "World class" results

- the processes should be consistent, and monitored and managed on a similar way

- the deficiencies of the current business processes have to be solved

- the company has to improve its flexibility in terms of meeting the customers' needs and reacting on market opportunitiess

- improving the expenses and cost structures to become more competitive

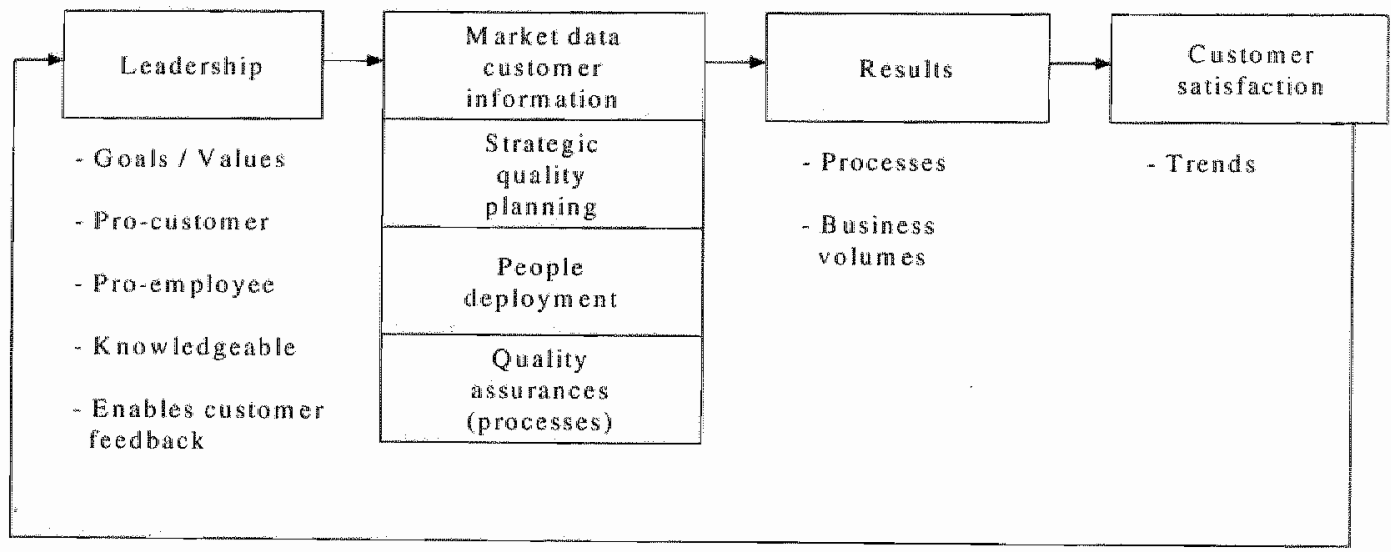

Figure C:5 Process view of a marketwiven sales force organization

Soure: Cortada, I. W. (1993) TOM for Sales and Marketing Mandagement, New York: MacGraw-Hill p.70

Figure C.6 outlines the hierarchy of the various objectives and shows the current versus the desired situation $^{2}$. 
Process

ration

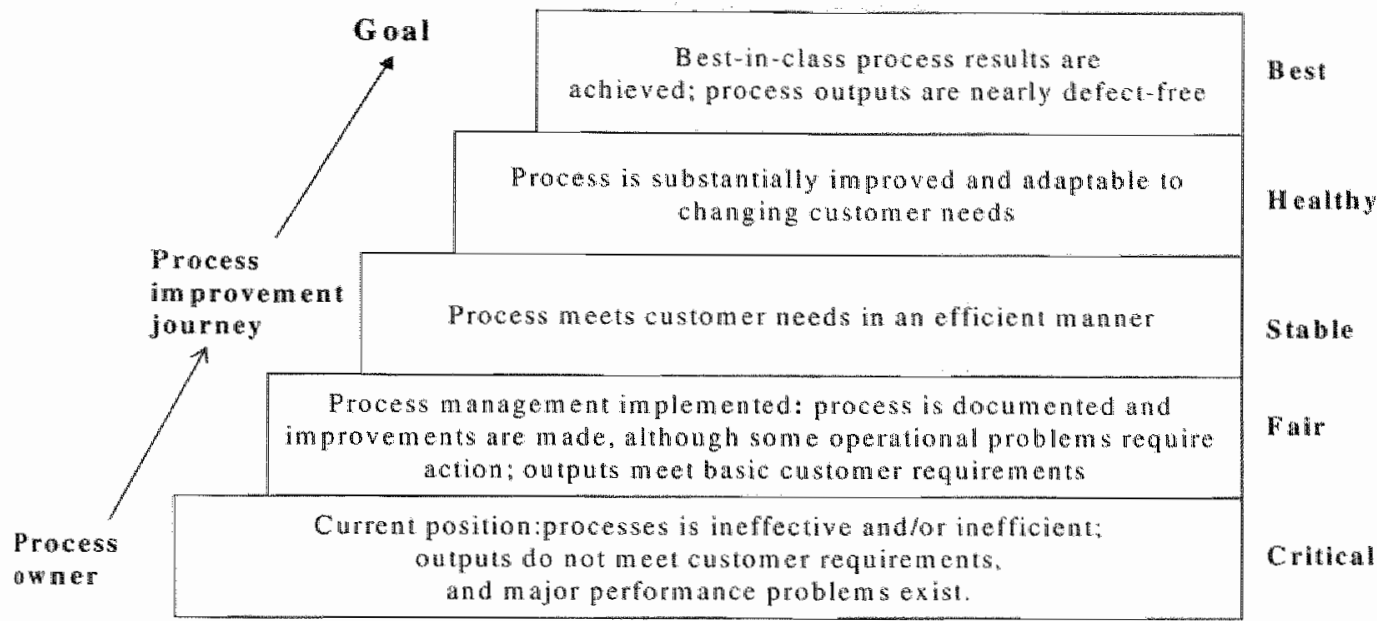

Todaly

TIM E

Figure C.6

Goals of Business process management source: Internal document (1993)

\section{APPLYING BPM AT THE SALES ORGANIZATION}

\section{Implementation}

BPM was implemented in the worldwide sales force organization in the beginning of 1995. Figure C.6 illustrates the company's process wiew of the market driven sales force organization. This process view can be explained as follows. First, the company has to formulate its leadership objectives; these objectives are related to 'goals/values', "pro-customer" targets such as customer satisfaction levels, "pro-employee" targets such a specific level of employee satisfaction, knowledgeable such as 'being an innovator in a specific product market', and "enables customer feedback'. The company has deweloped specific maragement tools to attain these goals, namely: market data customer information, strategic quality planning, people deployment and quality assurances. The outcome of the efforts can be measured in terms of process outcomes, business volumes and customer satisfaction; these outcomes are used to reformulate the company"s leadership objectives and to redesign the management tools.

\section{Process hierarchy}

The MDQ philosophy implies that the sales force organization is responsible for improving the quality of delivening goods and services and developing long term relationships with customers by providing the right skills and excellent offerings. Both marketers and salespersons coordinate customer feedback to provide a closed process back up through "production' and right to the "market information capture" process. The various key processes were examined in detail in the early nineties. This audit resulted in a detail map of key business processes, called 'Quality process management in the company's sales force arganization". Figure C.7 illustrates the overall structure of the map. 


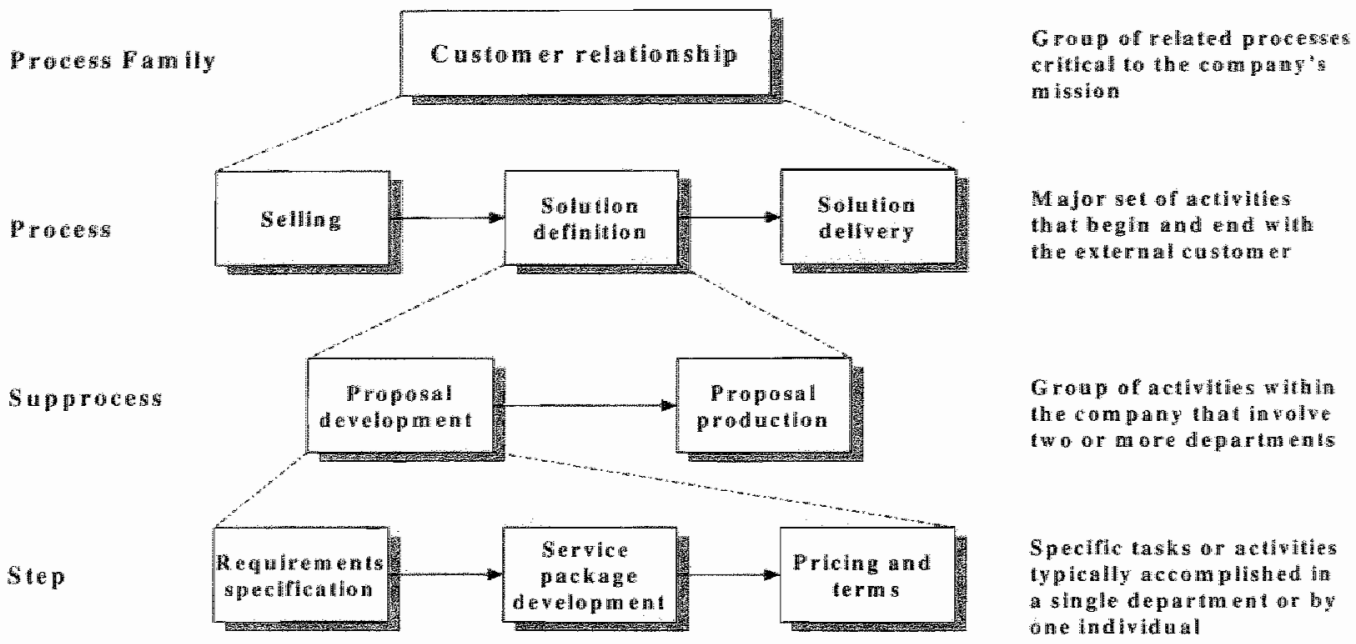

Figure C.7 Qwality process management in the sales force organization source: internal document (1993)

\section{Process family wersus processes}

All the key business processes in the sales force organization are integrated in the 'process family', called "customer relationship". The identified key processes include various sub processes critical to the company"s mission: selling, solution definition and solution delivery. These processes involve activities that begin and end with the external customer. They are critical to the company's mission "... to be the world's most successful and inportant information technology company; successful in helping our customers, applying this technology to new customers. Important, because we will continue to be the basic resousce of much of what is invented in the industry" (internal document 1995). The key processes are split into various sub processes; a sub process is defined as a group of activities within the company that involves more than one department. Figure C.8 outlines the major sub processes in the curnent sales force organization.

\begin{tabular}{|c|c|c|}
\hline Opportunity ldentification & Quotas and measurement & Distribution/deliwery \\
\hline Cuktoner leedbak & Fesource Deployment & Recogntion \\
\hline Combunatcation & Orgratization & Pricing \\
\hline Skills Develinpment & Quality asessment & Business partners \\
\hline Accounts reces yable & Complatints & Facilltues Management \\
\hline Serwice and Repair & Prodtact liability & Salles platuming \\
\hline Revonto and Pront accounting & Competitive anallysis & Suggestions \\
\hline Telephanes & Compensation & Inventory nanagement \\
\hline Supplier & Enployee feedback & Sirategtc platunting \\
\hline Advertising & Order process & Personnel prachices \\
\hline
\end{tabular}

Figure $\mathrm{C}$. 8 sub procestes in the company"s sales force organization

Source: Contada, I. (1993) "Important processes in a sales organization", in TQM for Sales and Markeng. Management, New York: MacGraw-Hill Inc. p. 72

\section{Processes wersus sub processes and steps}

The identified sub processes are further described in terms of specific tasks or activities typically accomplished in a single department, i.e., sub processes, and by an individual, i.e., a step.

\section{Process leaders versus process managers}

There are no process owners but process leaders and process managers ${ }^{3}$ at each level of the sales force organization. According to the BPR manager, the concept of 'process owner' lead to misunderstandings. He explained:

"Nobody can own a process; processes can only be monitored, managed and improved. To avoid misimierpretation, headquarters has chosen to use the terms 'process leaders" and "process manager" instead of 'pracess winer'. The process leaders are responsible for managing their process, allocating 
resources and defining measurement points. Farthermore, they are also in charge of solving "conflict of interess'. There are also process managers responsible for accomplishing process activities. They are also in charge of performance measwement and education and they are also expected to simulate the ir persownel to use the predefined processes.

\section{THE SALES FORCE ORGANIZATION}

\subsection{Formalization}

Our respondents perceived their organization as to be highly formalized; one reason given was that the size of the organization makes it difficult to rely on informal organization. The company encourages informal contacts but the formal organization remains the most dominant one It was found that company Cemploys various forms of formalization. Some of these forms are imposed by the headquarters; these forms include the structuring of the sales operations, the business code and the general function descriptions. Supervision of the use of rules and procedures is accomplished primarily by the line responsibilities. For instance, subordinates are supervised by their superiors concerning planming and reporting procedures. The local management also supervises their subordinates conceming the use of these local procedures and rules, examples include task description and the ISO 9000 handbook. The major forms of formalization are discussed below.

\section{Structuring local operations}

Headquarters imposes an organization structure on each level of the sales force organization. The local offices are wholly owned subsidiaries responsible for the implementation of the company's marketing and sales strategy. Overall, these offices are responsible for direct and indirect selling activities. The task environment of the sales offices is specified by the headquarters. For instance, the tacits the company uses for distribution are 'direct selling' and 'through dealers and business partners'. With respect to the commodity products such as desktop and laptop PC's, the company put its business through its party outlets such as dealers and distributors. The more complex product, such as products based on system integration, are sold by its own sales force or by party outlets such as partners and dealers. Headquarters have formulated some strict guidelines with respect to the selection of party outlets; these guidelines are related to the financial position ${ }^{4}$ and quality requirements, such as education level of personnel.

\section{Business Process Management}

Headquarters have also imposed BPM on the sales offices. The management system consists of detailed guidelines concerning the sales process called 'Customer Relationship Management' (CRM), business planning and process improvement. Detaled process maps have been developed for CRM and business planning. The maps include details concerning tasks and responsibilities, activities, outcomes, and the information flows are highlighted. The maps also show when and how the required information should be gathered, i.e., manual versus automated. For instance, the CRM process map includes a description of the processes and related sub processes involving more than two departments/business units of a sales office, the specific tasks typically accomplished in a single department or by one individual, and the related 'roles". Employees are trained to fulfill their roles within the CRM. The CRM process takes place as follows at the worldwide sales force organization.

- The process starts with the identification of an opportunity. Overall, the (market) opportunities can be identified by every employee. This is the 'opportunity noticer'. Once an opportunity is identified and registered in an automated information system, the opportunity is evaluated whether it fits with the company's strategy; this is generally accomplished by the 'opportunity noticer's in consultation with an 'opportunity advisor'.

- If the opportunity fits with the company"s strategy, then the "resource coordinator' Jooks for an "opportunity owner' with the appropriate skills. This coordinator can use a worldwide skill database in which all employees with their specific skills are stored; employees have to fill in a questionnaire with more than 200 questions about their skills, and the answers are registered in the database. Once an appropriate "opportunity owner' has been found, the 'research coordinator' contacts this employee and indicates that he is now the owner of the identified opportunity.

- The 'opportunity owner' confirms that he or she will be responsible for managing the opportunity. The "opportunity owner' evaluates customer satisfaction after each step in the sales process. The confirmation 
results in "owner commitment". The required resources are identified and allocated based on "owner commitment". Ant important consequence of "confirmation of acceptance' is that resources are no longer fully avalable for the line managers and their departments. The "opportunity owner" is fully responsible for managing the opportunity. This implies that a proposal has to be written and evaluated. The "opportunity owwer", therefore, selects a "proposal team leader"; but the "opportunity owner' remains responsible for the follow-up of the opportunity.

- The "proposal team leader" firstit confirms his / her assignment; then this team leader starts with the activitues related to "proposal development" and "proposal production'. These activities include the creation of a solution strategy such as a service package development and a search and selection of existing solutions. He or she also formulates a request for the dlesign resources; these activities result in a specific proposal for the customer. The members of the "proposal team' define an implementation plan and a rellated schediule. Finaliy, the pricing and other terms are determined.

- The proposal, including the requirement specification, the solution strategy, the implementation plan and related schedule and the pricing and other terms, has to be approved by the external customer. Once the customer has accepted the proposal, the "delivery tean' concurs with the customer related project plan. They order the required components and resources and build (and test) the sollution.

- Once the solution is tested and reviewed, it is delivered to the customer. The project leader of the delivery tieam closes the project and asks for customer feedback. Solution support activities are activated. Furthermore there are also other business processes. An example of such a process is "After salles". These processes are improved continually in terms of local requirements and priorities. Therefore, the experience of local employees is used. These "support processes" are described in the ISO 9000 handbook of the local sales offices. The business unit process leader" is responsible primarily for obtaining the ISO 9000 certificate.

The implementation of CRM at the local sales offices has had a great impact on how local sales operations are organized and conducted. These sales operations include both the activities of the company's sales force and business partners; it appears that business partners have to implement the CRM process in their own orgatization. The headquarters had developed various tools for improving processes; these tools include country scorecards, checklists for process leaders, and indexes as "Process Vitality Index" and "Process Deployment Management Index".

\section{ISO handbooks}

It appears that the Belgian and Dutch sales offices have an ISO 9000 certification. Local business practices are described in an ISO 9000 handbook. This was primarily an initiative of the local management team. All business and administrative processes are described in those handbooks.

\section{Function descriptions}

The business processes and related functions/tasks were inventoried and formalized at the beginnimg of the 1990s. The outcomes of these activities were sixty-eight function descriptions; these function descriptions are imposed on the local sales offices by headquarters. The responsibilities and related tasks are further specified by the local business unit managers.

\section{Business code}

There is also a strict business code. New employees have to sign this code which includes values and norms employed in the worldwide organization. The top managenent of headquarters formulated this code, and the local departments 'Business Fulfilment' and 'Legal' supervise the worldwidle application of this code.

\subsection{Centralization}

It appears that strategic decision making is centralized at the corporate llevel of the organization. The senior management at the headquarters are responsible primarily for formulating the company $s$ strategy direction. The lower levels are in charge of strategy implementation. For instance, the strategic decisions concerning marketing and R\&D for ali sales offices are made by headquarters. It was found that the full decentralization of operational dectsion making authority in such a large international organization is almost impossible. Although the organization chart has not changed, the decision making authorities have been reformulated. With respect to CRM, there are four types of process leaders: worldwide, regional, 
country and business unit process leaders. CRM was first developed by the worldwide process leader; then regional process leaders, were assigned. These process leaders assigned country process leaders. It appears that the lower level of process leaders had no influence on the filling-in of their sub process. The worldwide process leader described the sub processes of the regional process leaders, and in turn, the regional process leaders specified the sub processes of the country and business unit process leaders. Figure C. 9 is used to summarize the responsibilities per managerial level.

\begin{tabular}{|c|c|}
\hline Types of process leaders & Responsibilities \\
\hline $\begin{array}{l}\text { Worldwide process } \\
\text { leader }\end{array}$ & $\begin{array}{l}\text { Leading the reengineering activities of processes: these activities will cause } \\
\text { fundamental changes in the structure of processes. } \\
\text { Ensuring that at each country their processes are implemented similar } \\
\text { Providing tools for conmunication and improvement } \\
\text { Defining a consistent system for process measurement } \\
\text { Monitoring and controlling the performance of the process (worldwide) } \\
\text { Providing worldwide 'process tools' }\end{array}$ \\
\hline Regional process leader & $\begin{array}{l}\text { - Coordinating process managenent activities at the regional level of the sales force } \\
\text { organization } \\
\text { Interface between worlduride and country level }\end{array}$ \\
\hline Country process leader & $\begin{array}{l}\text { Monitoring and controlling the performance of their process } \\
\text { Validating the requirements of the customer } \\
\text { Defining and establishing priorities regarding improvement requirements } \\
\text { Initiating local improving in line with the policy of the world-wide process leader, } \\
\text { these improvements should suit with the worldwide implementation } \\
\text { Being the interface between world-wide process leader and local management }\end{array}$ \\
\hline $\begin{array}{l}\text { Business unit process } \\
\text { leader }\end{array}$ & $\begin{array}{l}\text { Defining and establishing priorities regarding business unit improvencuat. } \\
\text { suggestions and recommendations } \\
\text { Sharing ideas with the local (sales) community } \\
\text { Measuring developments, performance and improyements of processes } \\
\text { Ensuring that the process is based on the business controls, the audit, and the ISO } \\
9000 \text { requirements }\end{array}$ \\
\hline
\end{tabular}

Figure C.9

The responsibilities of the various process leaders

Source: internal documents 1993

There are also worldwide, regional and country process managers. The link between the worldwide and country process managers is established by the regional process managers. Overall, the task characteristics of the three process managers are almost similar. Process managers initiate small process improvements. They also validate the customers'needs, and define and establish priorities with respect to process improvement requirements and opportunities. The process managers communicate and select process improvements; however the country and the regional process managers have first to contact the worldwide process manager. They manage and improve processes by using a basic checklist of process assessment, analysis and improvement. Finally, the process managers measure the developments, performance and improvements of the processes (Internal document 1993; interview with Dutch BPR manager). Figure C.9 outlines the various roles and the related relationships between process leaders and managers.

With respect to process management, figure C.10 indicates that all process leaders are directly involved but the process managers are only involved indirectly. Process leader's use "process management" to ensure that processes work out well; if not, then process improvements have to be executed. Regarding 'manage by process' it appears that country process leaders, country business unit and line managers are directly involved whereas process leaders and the regional process managers are only indirectly involved. The concept "manage by process' refers to "managing by using processes". These processes are designed and improved by process management; the use of these processes throughoul the worldwide sales force organization has to be stimulated. Country process managers, country business unit managers, and line managers supervise their subordinates regarding the use of these business processes. This situation can be described as follows: 
(stated by the Dutch BPR manager) "... "business process management" has laid the highways and "manage by process' stimulates the traffic to use there rocads ".

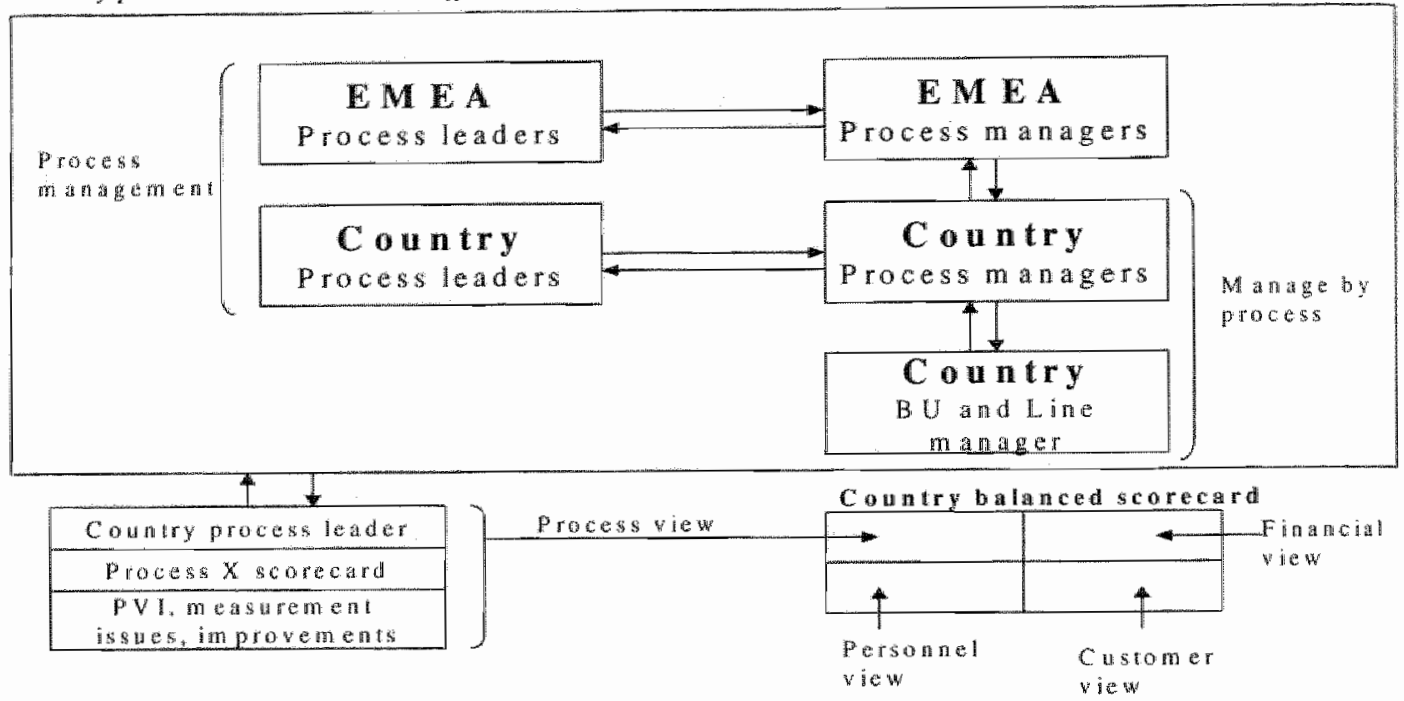

Figure C.10: Roles and relationships in the cunrent sales force organization Source: Internal document 1993

The operational decision making authority within the sales force organization is changed due to the implementation of BPM. This is especially the case for the business unit manager and the country manager. It appears now that the decision making authority of business unit managers is enlarged in comparison with the country managers.

Overall, the business unit managers are responsible for managing the business operations in their unit, they are responsible for ensuring that their business unit autains their targets related to revenue and contribution margin. In this functional context, their superiors are generally the country managers. Performance reponts are directed to the specific country manager. As process leader, the business unit managers are responsible for monitoring and controlling the performance of their processes. The superiors of the business unit manager are the regional process leaders in this process context. Performance reports. are directed to the specific regional process leader.

The implementation of BPM had a great impact on the position of the country manager. The country managers were responsible primarily for the business operations of their sales offices under the old management system. They were also responsible for attaining the general revenue targets of the salles. office. Now the country manager's are no longer responsible for the business units; they have no "revenue" or "contribution margin" responsibility for the local operations. This responsibility is assigned to the business unit managers because their efforts are directly related to revenue generation and means c.q. efforts to generate the desired revenue targets. The key business processes are monitored and managed by the worldwide, regional and country process leaders. These process leaders have to justify the course of processes and related process improvements.

Reganding country managers, it appears that the line responsibilities are constrained to the following areas: business responsibilities, local narket opportunities, customer relations \& company representation, people responsibilities, local processes and overall competitiveness, and the company and legal obligations. These responsibilities are described as follows (internal document 1997).

- The country managers ensure that effective local business execution is in line with plans and strategies, and make sure that all aspects of corporate responsibilities are met in superior way within the legal, regulatory and cultural context of the country. Their main business responsibility is to ensure effective local execution of the company"s strategies expressed through the business, process and infrastructure lines of execution. They are members of the regional management board and participate with their colleagues in the development of plans and strategies. Business budgets are fenced and managed regionall-wide by the regional executiwes and, in each country, jointly with the country manager. 
- As for local market opportunities, the country managers contribute to the identification of emerging or new market opportunities in the territory. As a top deal-maker in the country, they get actively involved in generating company-wide opportunities through high-level contacts. In emerging markets, they play a very active role in pursuing business expansion and in achieving committed returns on investments from the plan developed and agreed to with the concemed Regional business and infrastructure executives.

- As country manager, they represent the company externally and internally and are the custodians of the company"s mind share in the country. They maintain high level government and business relationships in the country and follow corporate initiatives to promote the company's image and business influence. They develop and maintain high level customer and supplier relationships, ensuring coordinated actions and facilitating the company-wide responsibility for customer satisfaction with the company as a whole. They are the guardians of customer satisfaction with the company as a whole.

- The country managers have the primary responsibility to lead change and transformation, promoting the company"s values, ensuring effective internal communication and overall country's employee moral. They ensure that local top quality talent, leadership and expertise are developed in the country and the company has the ability to attract top external hires. Furthermore, the country managers manage with regional executives local employees'career, salary and development. They ensure quality and leadership of the country top team, proposing the best person for a given job. Besides, they are responsible for country resource balancing and for managing redeployment and restructuring actions agreed to with the concerned Regional executives. In this context, the country managers have the primary responsibility for industrial relations in their country.

- With respect to local processes and overall competitiveness, the country managers make recommendations to the regional businesses on the optimum deployment of the company's resources in the country including portfolio changes between businesses and strategy redirection. They play a key role in the local execution of the worldwide and regional processes, ensuring seamless operations in front of the customer. They coach local teams in their new roles and in driving company-wide local efficiency. Furthermore, they ensure that personnel issues, like labor costs and social constraints, are addressed.

- The country managers also ensure that all corporate obligations in the country are met, and compliance with internal/external audit and business controls is secured. They work with the regionall Business and Infrastnucture Executives to correct out-of-line situations. As signatory of the financial statements, they carry responsibility for related activities performed through the business and infrastructure organizations.

With respect to the marketing mix decisions, we found that all product and promotion decisions are made by the headquarters. The marketing manager explained:

"Product development and product management iake place at the headquarters and the product divisions. All activities related to prowotion are conducted by an international advertising firm. As for local advertising campaigns, the language of $e$.g. the commercials can be adapted to the local circumstances. With respect in the price-setting. I can say that the extem to which decision making authority is decentralized varies from product group to product group. We, i.e. the local sales office. have no impact on price serting for commodities e.g. desktop PC $C^{\prime}$, laptops, printers etc. These price decisions are centralized an the corporate and product division level. With respect to more customized product and services e.g. MT-consultancy. information systems, the headquarters formulates specific price ranges. We have, however, to respect the price wargins imposed by our headquarters."

With respect to personnel decisions, it appeared that the decision making authority is decentralized to a large extent. The salles offices can recruit their personnel, and develop local career paths. Besides, the local management can develop their own human resource management policies. This does not imply that the headquarters have no influence on local human resource practices. There is direct contact between the local and regional human resource managers. Besides, the headquarters can impose some restrictions to the number of personnel on its subsidiaries. The local offices were, for instance, forced to diminish the number of personnel in the early nineties. 


\subsection{Integration}

At the worldwide sales force organization, integration is accomplished primarily by a worldwide matrix organization supported by BPM. The worldwide, regional, and local business operations are organized in terms of products/industries and processes.

As for the European business operations, integration is accomplished primarily by the worldwide and the regional process leaders. These executives are responsible for integrating and coordinating local planning activities to ensure that the regional objectives can be attained.Regarding the local sales offices, it appeared that the country managers generally have an important integrative role. These managers are responsible for the effective local execution of the company's strategies expressed through the business, process and infrastructure lines of execution. For instance, they coordinate and integrate the local planning activities. They also organize meetings between the country process leaders and managers, and they are responsible for the local buman resource management. Direct contacts take place between the various process leaders and process managers. With regard to the country managers, it appears that they have still an integrative role in the regional and local sales force organization, and two new field positions reporting to them are created. According to internal documents, these new field positions cover the following responsibilities:

- The Country Customer Operations Executives (CCOE) have an important integrative role at the local and the regional level. These executives are responsible to ensure the effectiveness of all CRM processes with particular focus on the Opportunity Management process. They act as the coordinator of the Country Execution team meetings led by the country manager. The Country Customer Operations Executives are responsible for its effective operation ensuring that decisions made are in compliance with the Regional management system and are implemented through the authorized line of execution. Furthermore, these executives are responsible for developing and evaluating any proposals for changes in the portfolio, e.g. changes in resource allocation or market focus, that would improve performance in the country. The executing team is responsible for considering and, where in agreement, forwarding these recommendations to the appropriate business head(s). Portfolio changes are only implemented through the appropriate line of execution. Finally, the CCOE's report to the country managers and receive business direction from the Regional vice president of Customer Operations.

- The Regional Infrastructure Executives (RIE) are responsible for efficiency of all internal infrastructures and field support activities at regional level and the reorganization of the administration and field support activities in all countries belonging to the geographic region along the Regional infrastructure strategies. These executives drive for cross-border consolidation and domonce operations to achieve step by step improvements. Furthermore, the RIE's receive business direction from the regional vice president of Infrastructures and works in close relationship with the country managers and the regional manager and Regional Infrastructure Unit leader, to accelerate the execution of their specific strategies and projects. Finally, they manage locally the Infrastructure Units closely linked to the field operations (e.g. fulfilment, business information) and the many market support activities that have not been formalized as Regional Infirastructure Units. Furthermore, they have room for optimization regarding the sales plan support, the marketing centers, internal and external events management.

Integration is also achieved by regular direct contact between the different layers of management. Country managers, for instance, have a monthly meeting with their superiors at the regional office. There are also the worldwide, regional and country process managers, the link between worldwide and country process managers is established by the regional process managers. Overall, the task characteristics of the three process managers are almost similar.

Furthermore, integration is accomplished by quality function deployment, and process management. It was found that horizontal integration is accomplished by quality function in the narrow sense: a process focus and deployment of quality activities. With regard to quality deployment, improvement effort is criented toward involving a team of employees representing the various functional departments. Vertical integration is accomplished by structuring the linkages of processes in the provision of the company"s products and services. Since 1995 BPM has been implemented at the worldwide sales force organization. The sales process and its subprocesses are described in detailed process maps; these maps are used by all local sales offices. The company has also developed specific tools to ensure vertical integration regarding planning and improvement effort: the Define Solve Implement Maintain (DSIM) cycle, and the 'Country Balanced Scorecard'. 
The DSMM is used to allign key processes with the operational targets, to modify operational plans, and to improve the reliability of planning and implementation. Furthermone, Management by Objective (MBO) is used to achieve cross-organizational integration. At company $\mathrm{C}, \mathrm{MBO}$ is employed as a planning and performance management system to steer the sales force organization in the direction of the company"s mission and strategic imperatives. MBO is conducted as follows, top management establishes objectives and these objectives are communicated down the organization in a vertical way to create functional and individual targets. Superiors set targets for their subordinates, and employees are evaluated as to whether or not they met these targets.

Finally, the company uses a management tool called 'Country Balanced Scorecard" to link operational elements with the strategic direction of the company. The strategic direction includes ellements such as strategic issues including the company's vision, values and principles, mission, goals and ctitical success factors. These elements are linked with the business processes, measurement, indicators, targets, assessment and improvement, the roles and the related responsibilities, the organizational structure, and the communication system. The 'Country Balanced Scorecard' is used to help to document the key elements and how these strategic issues should be attained. The use of this scorecard will be explained in the section about sales management control.

\subsection{Participation}

Overall, strategic decisions are imposed on the local sales offices by the corporate or the regional management. The local management teams are not involved in this decision making. The worldwide process leaders, i.e., senior management at the headquarters, are involved in strategic planning. With respect to operational decision making at the regional level of the sales force organization, it was found that the regional offices impose policies and tactics on the local offices, yet in consultation with the local management team.

Regarding the formulation of country objectives, it appears that the local management teams participate intensively in the target setting. Overall, three operational plans are formulated by local management: a business plan for the product units, a business plan for the Industry Solution Units (ISU's) and an overall plan for the sales office. It also appears that the operational goals for the local offices and their business units are set in consultation with regional executives.

\section{STRATEGIC PLANNING}

\section{Involved parties}

Strategic planning is a managerial process conducted by the worldwide process leaders, i.e., the senior management, and is staff supported. It appears that the worldwide process leaders are responsible primarily for the whole strategic planning process. This responsibility covers the following activities (internal document 1985):

- to design the strategic planning process

- to formulate the strategic objectives of strategic planning

- to identify the strategic opportunities of strategic planning

- to design the process measurement system for the long term

- to initiate process improvements

- to manage and superwise continuous and radical process improvements

- to manage and supervise the implementation of strategic plans

The local offices are not inwolved directly in these planning activities, they collect primarily the required data on past performance and future market development, and give feedback on the corporate strategic plan. The country manager explained:

"We" are not involved in strategic planning; however, this does not imply that we do not contribute to these" activities. Our role is limited to gathering data on past performance and fufure market developments. Our senior managenent team in [...]. the line manageps of the product divisions and of the four sales regions conduct the planning activities. Of course" these activities are staff supported." 
Regarding strategy control, it appears that the regional and country process leaders are in charge of managing and monitoring the strategy implementation. The worldwide process leaders delegate responsibilities for strategy implementation to the country process leaders, i.e. country managers; if needed in consultation with these process leaders. The BPR manager explained:

"The implementation of BPM has a great inpact on strategic planning. Before BPM, the corporate senior management including the product unit managers were primarily involved. A consequence of $B P M$ is that nowadays the worldwide process leaders are in charge of strategic planning. The process leader is mainly responsible for strategic planning. He designs this process. He formulates the strategic objectives of this process. He identifies the strategic opporiunities. He designs the process measurement for the long term. He is also the moving spint behind improvements. He manages and supertises continuous and radical improvements. As a process leader, he mamages and supervises the implementation of strategic plans. Strategic control, however, takes place at the regional and local level. Regional level, for instance, EMMA process leaders. Lacal level, for instance, the country process leader. It implies that the worldwide process leader delegates responsibilities for strategy implementation, if necessary in consultation with the cowntry processs leaders."

\section{Planning procedure}

Overall, the strategic planning activities are programmed formally. As a core business process, strategic planning is described in detail. A process map includes a description of key planning processes and sub processes, the planning activities, the tasks and responsibilities, and operations. The worldwide process leader is responsible for designing and improving this process; the hierarchy supervises their subordinates regarding to the use of the planning procedure. The BPR manager stated:

"The worldwide process leader is in charge of the strategic planning process. In particular, he is responsible for designing and improving this planning process. The process and its sub processes, the related activities, and the outcomes are described in a process map. The tasks and responsibilities are also described Each planning activity is defined in terws of the required input, the responsible manager or managers caq. department (s), and outcomes. This formalized planning procedure is the result of the transformation of the company's business operations into business processes. The hierarchy supervises the use of this procedure on each level of the organization, i.e. from the headquarters to each managerial level of the sales force organization."

\section{Planning process and its outcomes}

At company $\mathrm{C}$, the strategic planning process can be best described as formal and structured processes following phased procedures. All the planning processes are hierarchical and top down. The outcomes of this managerial process are stated in a formal and well-documented plan. It also appears that most strategic planning requirements call for a planning horizon of three to five years; the strategic plans are revisited and updated every year to capture changes in mission, customer requirements, and the extemal enviroument.

The principal deliverable in the strategic planning step is the strategic plan ifself. The strategic plan is developed by considering the interrelationships of mission, strategic imperatives, customer base requirements stated in the "battle fields" and related "customer segments, and environment with respect to potential organizational performance. This step is considered complete once the strategic plan has been reviewed and approved by the senior leadership. Once the plan is approved, the worldwide process leader assigns responsibilities at the lower levels. The worldwide and the regional process leaders translate the strategic pllan into specific goals, action plans, and measures in consultation with the country process leaders. "The worldwide and the regional process leaders are not only responsible for attaining the strategic goals but they are also responsible for process management.

It also appears that the planning group has first established the corporate level positions relative 10 the corporate mission. The strategic imperatives have to be implemented. These imperatives or strategic objectives are (internal documents 1995):

- Exploiting the existing technology far better, getting teclmology out of the labs and into the marketplace, and doing this quickly, is critical to success in a fast-changing industry.

- Increasing the share of the client/server computing market; at that moment the company was focusing primarily on ease of use, system management and tools that improve the way products from the company and other vendors work together.

- Establishing leadership in the emerging network-centric computing world; currently the company is moving on many fronts to define this new market and this new model of computing. 
- Realigning the way value is delivered to customers; responding to what customers said they wanted from the company, global solutions, a single, worldwide sales and service organization is created. It is organized by industry and technology specialization.

- Rapidly expanding the position in key emerging geographic markets; the organization is on track to develop. within the next five years, large operations in China, Eastern Europe, South Africa and India.

- Leveraging size and scale to achieve cost and narket advantages, rationalizing activities that can give competitive advantages, for example, via economies of scales that competitors may not have.

The planning group identifies appropriate strategic business units (SBU) at the corporate level; the strategic business units identify appropriate product-market segments and specific competitive priorities, Regarding the competitive priorities, the headquarters have formulated six principles. These principles are (internal document 1995)

- The marketplace is the driving force

- We are a technology company with commitment to quality

- Primary measures of success are customer satisfaction and shareholder value

- We operate as an entrepreneurial with a minimum of bureaucracy and a focus of productivity

- We never lose sight of our strategic vision

- We think and act with a sense of urgency

- Outstanding, dedicated people make it all happen, particulary when they work as a team

- We are sensitive to the needs of all employees and to the communities in which we operate

Six "battlefields" and "customer segments" are identified. The battlefields include technology, ease of use, object technology, services, network services, and customer targets. Specific customer segments are identified for each battlefield. The worldwide organization has to focus on these "battlefields' and on the predefined "customer segments". Furthermore, appropriate marketing strategies have to be formulated. The functional managers at the corporate and regional level are in charge of formulating these strategies. The country manager explained:

"Once the appropriate product-market combinations and the specific competitue priorities are established, the SBUs, i.e., worldwide product divisions, develop and enact action plans to support their competitive priorities. Product and indwstry managers at the corporate and the regional level formulate strategies related to product managenent, brand management, market segmentation and customer targets."

Whereas the local sales offices are in charge of the implementation of those action plans, the regional office coordinate the local efforts. The country manager stated:

"As a local representative, we are responsible for the implententation of the action plans. Our regional office coordinates the efforts of its sales offices. EMMA is the intermediary between us and the headquarter's. Furthermore, it allocates resources at local level."

A formal and well-documented plan is the result of the strategic planning process. The data used for formulating this plan include historical data reflecting past performance along with forecasts for the current planning horizon of three to five years. The strategic plan ${ }^{10}$ includes strategic imperatives and action plans. The strategic plan is presented to the managerial levels of the organization. It is perceived as the guideline for strategic and operational planning activities at the regional and local level of the sales force organization. The marketing manager explained:

"The corporate strategy is imposed on the regional and the local affices by the strategic imperatives of the headquarters. At the EMMA level, the strategic imperatives are translated into long term objectives and strategies for the sales and business wnits. They. therefore. use historical data on our past performance and market information. The operational targets of the Dutch sales office are set in consultation with EMMA. They take care that we contribute to the achievement of the EMMA long term targets."

It was also found that the regional offices are responsible for attaining these growth objectives in terms of revenue and contribution margin. These objectives are translated into local objectives. The extent to which these sitrategic objectives are turned into local objectives depends on the current market situation and past performance. The local management team is, however, not evaluated on the extent to which these: long tern objectives are achieved because there are too many uncontrollable factors that have an impact on long term performance. Examples are R\&D and product management; these factors are controlled by headquarters and are no part of the decision making authority of local management. 
As for the feasibility of these strategic objectives, it appeared that, at local level whese objectives are percerved as feasible and realistic. This does not imply that these objectives are also atrained. During the process of target setting, the involved parties perceive the targets are feasible and realistic. The marketing manager stated:

"...none will accept untralistic targets. Each targer should be attainable within the predetermined period by working hard and whelligently. If this is not so, then the target is not motivating. Yet this is also the case if the objective is not ambitious enough."

\section{SALES MANAGEMENT CONTROL}

\subsection{Planning, organizing and directing}

\section{Involved parties}

At company $C$, the regional and the country process leaders are involved primarily in sales management planning. These managers define the short term performance measurements, analyze these measurements, and escalate them.

Regarding the local planning activities, it appeared that various parties are involved: segment manager, market management coorclinator, business entity manager, and skills management. These managers are part of the local business units, i.e. product departments or Industry Solution Units (ISUs). Their roles are described in the CRM planning map. They are responsible for translating the outcomes of the strategy process, financial and business planning into operational goals and action plans at the local level of the sales force organization.

\section{Planning procedure}

Overall, the sales planning activities at the regional and local level are described in a process map. This map indicates the process inputs, the planning activities and the outcomes, the map is also used to assign the responsibility. Whereas the process leader is responsible for the planning process, the process manager is responsible for the implementation of the operational business plan.

At the local level, the sales planining activities are described by the CRM planning map. This map is imposed on the local management teams by the headquarters; but there is no supervision on the planning procedures. Process leaders have much freedom in conducting planning activities; yet the regional process leader supervises the planning activities of country leaders by using the international management information system. In this context, the supervision of the regional process leader includes checking whether planned results are attained. The process managers are responsible directly for the implementation of the business plans by employing 'manage by process'. It was also found that the company has a formalized planning format, called "country balanced scorecard'. This management tool is used to link operational elements with the strategic direction of the company by identifying four performance dimensions, nanely: process, customer, personnel and financial. Such a form provides a paper trail to link the operational / local objectives with the long term strategic issues.

\section{Planning process and its outcomes}

Operational planning takes place twice a year. This planning process is a formal and highly structured procedure; it follows phased procedures, with the final process being contingent upon the strategic imperatives of the headquarters. The world wide and regional operational targets ane formulated.

Input to these planning activities include historical data on past performance, i.e. sales figures, and market information including forecasts per quarter of a year. At the regional office, the regional objectives are split into local business objectives. This part of the planning is topdown. The Belgian country manager explained:

"The strategic imperatives are the guidelines for operational planning. The worldwide and regional shor" term objectives are derived from the se gudelines. The regional objectives are the bottom line for the local targets. We, i.e. the local sales offices, have to contribute to the goal attainwent at the EMMA level. The EMMA imposes operational targets on its sales offices. [...]. EMMA is responsible for attaining the se strategic objectives in their region. Our European office uses historical data on past performance of the individual sales offices and local market infornation to formulate the operational financial targets per sales office. EMMA discusses the targets with the country managers, however, the targets are still imposed by EMMA." 
The regional leaders decompose the organizational goals related to four penformance areas and related measurements to produce aligned, analogous goals and measurements for each country unit. The four performance areas and related measures include the process view, the customer wew, the personnel view, and the financial view. These dimensions and the related performance matrics are descrilyed in the "country balanced scorecard".

- As for process performance, there are operational targets related to the speed of execution and efficiency in front of the customer. Four operational targets are identified: opportunity coverage by quarter, opportunity responsiveness in 48 hours, gross profitability and win rate. Each target is specified into a percentage that is based on past performance and outcomes of DSIM cycles. For instance, the opportunity target coverage by quarter should be at least 200 percent. The regional and the country process leaders also formulate a process scorecard. This scorecard is used to indicate the extent to which key process should be implemented.

- With respect to the customer focus, the company has set the target to be best of class in customer satisfaction". Two indicators are designed to measure this performance dimension; these measures are overall customer satisfaction and business process satisfaction.

- The third performance dimension 'Employee view' covers productivicy and morale of the field force. These targets refer to productivity levels, morale, improvement wersus baseline, overall trend up and worldwide comparison. With regard to deployment, the company has set the following target: "the best persons in key" jobs". This business target covers the following topics: certification for client execution and segment managers, and critical skill gap closure. The ISU's should be certified by 1997, and all business units by 1998.

- The 'Financial view' covers the financial dimension and the related performance measures. Key targets are revenue, sales quota, and contribution margin. Regarding 'revenue', targets are expressed in terms of US dollars. Contribution margin for products is defimed as 'revenue minus costs of product sold mimus costs of the local infrastructure including direct and indirect costs"; contribution margin for services is calculated as 'revenue minus costs related to service personnell minus costs of the local infrastructure including direct and indirect costs".

Operational targets for the local offices are stated by the regional process leader in consultation with the country process leaders. In this meeting, the regional and the country process leaders discuss the operational goals for the sales offices; there is some negotiation with each individual to ensure the objectives set for each person are realistic, reasonably within his or her control, and attainable. Since 1996 the local offices participate ${ }^{11}$ more in operational planning to set more attainable targets. The CCOE explained:

"In the past, we used a planning system in which operational targets are imposed on local offices by the regional affice. This system was based on the assumption that we. i,e. the local management. trid to set revenue targets as low as possible and that the EMEA anticipates on this behavior by setring local rargets as high as possible. It was a game by which one party fried to convince the orher party. As a result of such discussions, the EMEA agreed a gap between the local and the regional targets. When the local management could prove that local circumstances made it difficult to attain the EMEA targets, then the local targets were used. The EMEA, however, mever adjusts its targets for the sales office. Experience faught us, and the EMEA, that the local offices could not close the gap between local and regional targets. Maybe nor for 100 percent, but ofien for 80 or 90 percent. Since 1994 the local offices hove had serious problems to close the gap. The market is much more difficult and the transformation from a product into a service organization has had an impact on the profitability. This makes it for much more difficult us ${ }^{2}$ to close the gap. Only heavy investmens in infrastructure make it possible to attain the imposed vargets. More people may result in higher revenue, however, the costs are also rising. Headquanters has realized this and adopted its planning system. Higher participation in operational target setting has to result in more attainable targets. The system based on imposing targets and assuming that the local offices manage fo close the gap is not useful in today"s marketplace. Targets should be aitainable, and local management can evaluate feasibility by using local market information."

The operational targets are primarily of a quantitative nature, and split into targets per quarter. Various types of operational targets are distinguished within the "country balanced scorecard". The business targets includes leadership targets, milestones and diagnostics related to the financial, process, employee and customer focus (internal documents 1997). 
- Leadership targets are the targets which reflect directly the stakeholder view of the business. They are either financial or process measurements. The funancial targets are related to revenue, gross profit, expenses, net profit, inventory, capital expenditures, receivables, and cash. The targets related to process nneasurements are related to satisfaction of customers, employees and business partners, opportumity management, on thmedelivery and solution design and delivery.

- Milestones are the small number of critical exts whose timely performance is pivotal to achieving regional leadership targets. There is a set of categories for the milestones for each business type and all the businesses are required to track and report their milestones within this franework.

- Diagnostics are the indicators and predictors of business and process health across the geography covering areas such ats key price trends, backlog level, resource levels, key cycle-times, and the overall status of the procerseses.

According to internall documents (1997), the leadership targets, milestone frameworks and diagnostic measurements will be standardized for EMEA at a geographic level and for each category of business, i.e. product departments versus ISUs, that operate here. Each business type will apply the same measurement structure to all its sales units but the structure will differ between the product unit versus industry solution unit. The point of accountability for plan execution is the business unit or infrastructure. The superiors have complete authority over the deployment and the execution decision for their leadership targets to support this accountability. The alignment of the unit will be to their worldwide community such as banking and general business. Once the business targets are announced, the country process leaders decompose the organizational goals and measurements to produce aligned, analogous goals and measurements for each business unit, and the business unit leaders do likewise for the individuals and work teams in their unit. The local planning activities then start. These activities are described by the CRM planning map. The department 'marketing staff and support' coordinates and supervises the planning activities of the business units.

- The local planning activities start with the collection and analysis of external and internal market data including forecasts. External information includes the analysis of data concerning the economical/political/regulatory environment, the TT-industry and market analyzes. The marketplace is assessed in terms of market and demographic variables, and competition and market opportunities. Thus external and internal information is related to one local process: relationship management, offering information, customer satisfaction management, business partners, solution design and delivery, and opportunity management. The marker department analyze and translate this information into a rapport 'market description'.

- Once this rapport is written, the segment manager defines a segmentation schema. Therefore, the manager unses the "market description", market experts and the outcomes of the strategy process. The segnentation schema consists of national/international standards related to skills management, i.e. the number and types of personnel required for the operations, market information, and a detailed segment analysis. This schema is sent to the market management coordinator. These managers evaluate the scheme with the national/internal standards regarding skill management.

- Once the schema is ewaluated, the business entity managers select performance criteria and weights. The criteriat are related to customer satisfaction, skill management, segment analysis, and market characteristics. These criteria and related weights are established and deployed in the segmentation schema. Besides, the planner "Skills management" assesses the segmentation schema to analyze the skill needs and gaps. The segmentation schema and the analysis of the skill needs are compared with the views of market experts and with the outcomes of business plaming such as competitive, skills, historical opportunity data, solution. national/international standards, segment analysis, financial, and customer satisfaction. Once the segment data is collected, a segment and a portolio analysis are conducted. Whereas the segment analysis is conducted by the market/data analyst, the segment manager is in charge of the portfolio analysis. For the portfolio andysis, the segment manager used the outcomes of the segment analysis, the results of the business planning and the opinions of market experts. Once the portfolio analysis is conducted, the business entity managers select the appropriate segments and assign objectives to the segment managers. In the next step. the segment strategies and plans are developed. These strategies and plans are based on the segment analysis. and intemal information, i.e., customer satisfaction, opportunity, competitive, segment analysis and financial issues. Overall, the segment strategies and plans cover the following topics: terms and conditions, solution inventory, price, skills, segment analysis, channels, business partners, and customer satisfaction. Based on the segment strategies and plans, a segment financial plan is developed. The segment strategies and plans. 
and the segment financial plan are documented in the segment business plan. This plan has to be approved by the country process leader.

- Having approved this plan and communicated to the managerial levels, segment based cormmitment plans are developed by the market management coordination. The commitment plans include the following issues: a financial plan (a budget), price ranges, customer satisfaction strategy, solution strategy, coverage strategy, required skills, and marketing communicanions. These plans include operational goals conceming the following processes: customer relationship, business partners, offering information, solution design and delivery, and opporiunity management. Regarding customer relationship mamagement, these operational goals are related to the following issues: assess business relationships (i.e. by segnent plans and customer profiles), develop business relationship plans, create an opportunity message plan, create deliverables and response capacity, create a customer value communication plan (CVCP), and execute the CVCP's.

The outcomes of the planning activities are sent to the financial clepartment for calloulating the "expense targets' per local product department and ISU. The 'expense targets' are stated in operating budgets; they indicate the planned revenue on a quarterly and a yearly base, and the related costs for generating the predefined revenue targets. The expense targets include operating costs, such as personnel and advertising costs. It implies that there is a gross profit projection for each sales department of the local sales office. The marketing manager explained:

"Once the sales projections for the next year are set, the product departments and ISUs send these data to the marketing department. At this department, an aggregation of the sales projections of each product units. and of each ISU takes place. We aggregate these sales projections because we want to have fargets per sales department. I examine the se rargets by comparing these figures with the expected market growit. Overall, I set revenue targets by taking the inarket growth plas 4 percent. Our business policy is that we want to growth at least 4 percent faster than the market. Once the sales projects are aggregated, I send these projections to our financial deparmen. This department calculates the related expense fargets per sales department. Input to these expense targets are the upgraded sales projections and pasif performance. The se targets have to be accepted by the responsible business manager. Once they accept these targets, they commit the mselves to goal attaiment."

Once the business unit managers accept the targets for their unit, they are responsible for goal attainment; these targets include operational objectives related revenue and contribution margin (of profit). These managers have decision responsibility for the variables within the revenue and contribution margin calculation of the business unit. The marketing manager stated:

"The expenses per sales department are specified in detailed. Each business anit has it own expense target. We have determined the revenue farget per business unit, and so we know the operating expenses. The financial departiment allocates the costs to the business units. These costs are related to personnel. marketing, administration, etc. Thus, we make a 'profit projecrion 'for each business whit. With 'profit' I wean contribution margin. The business unit manager is responsible for attaining this profit target. Once the business unit managers accept the operational targets for their wnits, they are responsible for the attainment. Busimess units are seen as profit centers, and the managers are evaluated in terms of the realized revenue and profits."

The business plan of the sales department consists of targets related to contribution margin, revenue, expenses, market share and customer satisfaction. The targets related to revenue are split into revenue per product and revenue per service. Furthermore, there is also a specific revenue target called "skew". Skew implies that the tevenue related to specific customers has to be spread in a year. The marketing manager stated:

"Each prodwct whir and ISU receives a business plan. This plan indicates the targets related to contribuiton margin, revenue, market share, employee focus and customer satisfaction. The contributhon margin, revenue and expense targets are expressed in woney, the targets related to market share and customer satisfaction are expressed in a specific percentage. We defined contribution margin as revenue minus the cost price of the good sold and winus the operating costs and expenses of our sales office. In the case of senvices, the costs of the good sold is replaced by labor costs. Besides, the revenue target is split wp into reverue targets per products and services of a business anit on a quarterly and a yearly base. Skew, this is new, is a target related to the revenue related to specific key account customers. Our experience has learned us that the achieved results vary from quarter to quarter. Sales reps were often less active in the first quarter; but they had to work hard during the following quarters to ensure the atrainment of their quota"s. We have dectded to force our sales force fo distribute revenue related to specific key accounts evenly over the four quarters. 
This also helps to inprove sales projections per quarter. By this, we can give better imput to the production schenes of our manufacturing units. The aggregation of the indwidual business plans results in the business plan of our sales office "

The business plan of the sales office is the aggregation of the various business unit plans ${ }^{13}$. The sales offices are seen as profit centers. This implies that the country managers are evaluated in terms of the realized profits, and that they had decision responsibility for the variables within revenue and contribution. margin callculation. The marketing manager stated:

"The sum of the individual business unit plans is the busthess plan of the sales office. The targets of our sales. office are expressed in terms of profit, revenue, expense, market share, and customer satisfaction. The operational targets are formulared for each quarter. The acceptance of the targets proposed by the EMEA implies that our general manager is responsible for gaal attainment. You should know that the sales offices are proffit cemers, and the general manager is responsible for attaining the planned profit. With profit I mean: contributian wargiw. Our country manager has revenue and $P \& L$, i.e profit \& loss ar contribution margin, responsibility."

Nowadays the business unit managers have revenue and contribution margin responsibility. Although the operational targets per business unit are aggregated, there is no overall responsibility assigned for the country manager with respect to goal attainment at the sales office level. The marketing manager explained:

"The function of 'general manager' is changed dramatically due to the implementation of BPM. Decision making authority concerning operational activities is nowadays decentralized at the level of business unit managers. These business unit managers at the level of product units and $15 U$ are responsible for attaining operational targets in their business area. They receive resources for target achievememt. Empowerment ar the level of business uniss is nowadays the key word. The operational targets per product units and ISU are aggregated to ensure that the individual business whit contributes to the attainment of the country targets; this aggregation is done for evaluation purposes. The aggregation helps us to check whether the country targets can be achieved by the business wits, and to evaluate the outcomes of the resource allocation."

It was found that target setting is not only focused on financial performance; the performance areas "process", "customer" and "employee" are equally important as the financial results. The company uses a detailed scorecard to highlight mission, goals and targets for these three dimensions (see Figure C.11). Figure C. 12 includes detail information of a 'sub' scorecard for the mission 'efficiency and speed'. The other dimensions are also described by 'sub' scorecards.

PROCESS:

i. mission: speed of execution and efficiency in front of the customer

ii. goalstargets: related to opportunity coverage by quarter, opportunity responsiveness in 48 hours, gross profitability, and win rates

CUSTOMER SATISFACTION:

iii. mission: best of class in customer satisfaction

iv. goals/targets: related to owerall customer satisfaction, i.e. Wordwide strvey, and to business process satisfaction

EMPLOYEE:

v. mission: high productivity and motal of field force, and best persons in key jobs

vi. goals/targets: related to productivity, moralle, improvement versus baseline, overall trend up, worldwide comparison, certification for client executives and segment managers, critical skill gap closure, all certified by year 1998, and in all ISU's by 1997

Figure C.II A detail scorecard

Source: Internal documents 1997 


\begin{tabular}{|c|c|c|c|c|c|}
\hline GOAL & $\operatorname{CSF} \mathrm{F}^{14}$ & $\begin{array}{l}\text { LEAD } \\
\text { IGOAL KEEPER }\end{array}$ & PROCLSS & MEASUUREMENT & $\begin{array}{l}\text { TWr' } \\
\text { MULSTONES }\end{array}$ \\
\hline \multirow[t]{6}{*}{$\begin{array}{l}\text { 1. appontumb } \\
\text { cowerage }\end{array}$} & opportunity witality & $(T N)$ & 0.46 & 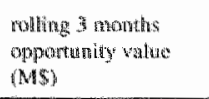 & 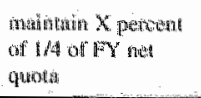 \\
\hline & $\begin{array}{l}\text { opportunites in } \\
\text { omsys" }\end{array}$ & (TN.) & $O M$ & $\begin{array}{l}\text { number lis: } \\
\text { opportanithes }\end{array}$ & mekting \\
\hline & \multirow[t]{2}{*}{$\mathrm{DM}{ }^{2 \pi}$ carrapaigning } & \multirow[t]{2}{*}{ (SH) } & \multirow[t]{2}{*}{ direch marketing } & $\begin{array}{l}\text { "oppontuntides } \\
\text { gefrented }\end{array}$ & racking \\
\hline & & & & qevenue gersented & tracking \\
\hline & relations laip plans & (R.B.) & direct maurketing & compleste & 100 percenn $\mathrm{A} / \mathrm{B} / \mathrm{C}$ \\
\hline & BP leatders & (TN.) & opporturity thgnt & os share os inflow & $\mathrm{THO}$ \\
\hline \multirow[t]{5}{*}{$\begin{array}{l}\text { 1.6 oppontenicy } \\
\text { nempon:averesi }\end{array}$} & \multirow[t]{2}{*}{ OMCs upperational } & \multirow[t]{2}{*}{ CCOE } & \multirow[t]{2}{*}{ appomaty mgme } & $\begin{array}{l}\text { OMC lender } \\
\text { appointed }\end{array}$ & 100 perom by fob 3 \\
\hline & & & & OMC operational & $\begin{array}{l}100 \text { parem by ath } \\
3\end{array}$ \\
\hline & OO rokes assigned & $(\mathrm{T} N)$ & O.M/S.D,D & w country lists & 100 percesu \\
\hline & Oo tramed & $(T, N)$ & $O M$ & Milestone pisall & 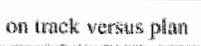 \\
\hline & 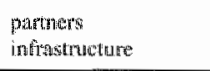 & A.K & B.P.M & 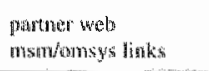 & $\begin{array}{l}\text { on drack werisis plant? } \\
\text { on tuck versts plath }\end{array}$ \\
\hline L.te gross profutability & $\begin{array}{l}\text { Use of price } \\
\text { delegation } \\
\text { selection activity } \\
\text { quality assurzunce }\end{array}$ & (D.CR) & S.D.D. & 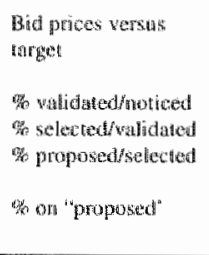 & $\begin{array}{l}\text { TBD l? } \\
\text { tracking } \\
\text { tracking tos be } \\
\text { established }\end{array}$ \\
\hline $\begin{array}{l}\text { 1.d. wint wate (versus } \\
\text { proposed }\end{array}$ & . & $(\mathrm{TN})$ & OM.S.D.D. & \% on "propowed" & $\gamma 0$ pescent \\
\hline
\end{tabular}

Figure C.12 Sub scorecard of "Efficiency and Speed"

Soure: Internal documents 1997

It appears that these operational objectives are perceiwed as feasible and realistic. Our respondents indicated that strategic as well as operational objectives have to feasible and realistic, otherwise they tend to be de-motivating for employees. These objectives have, however, to be ambitious enough that they stimulate to achieve 'excellent' performance.

\subsection{Performance measurement}

At company $C$, the standard set of measures includes the following indicators related to the four performance areas: financial, customer, employee, and process. These measures are stated a "country Balanced Scorecard".

The financial view is measured by performance indicators related to revenue, costs, net profit, inventory, capital expenditures, receivables, and cash. At the local sales offices, it appears that the concept of "net profit" refers to contribution margin. Regarding to products, the net profit or the contribution margin is defined as the generated revenue minus the costs of the good sold minus the costs related to the local organization such as administration expenses etc.

In the case of services, the net profit is calculated as follows: the generated revenue minus the costs related to personnel minus the costs related to the local organization. Information concerning sales transactions are registered on daily base. There are strict guidelines for calculating the revenue of a business unit c.q. 
sales office. Regarding the revenue calculation, the following criteria are employed (internal docunent 1993):

- local sales transaction: the automated system registers sales transactions when the invoice is sent to the customers

- local lease transaction: the fee related to the specific month

- local services: the period specified by the contract or the moment of service delivery

- export" the moment of shipping

- international services: the moment of service delivery

Financial performance is measured on monthly base. The automated system of each local sales office is integrated in a worldwide financial system. It was necessary to standardize the input of the systern strictly to implement such a worldwide system. Nowadays, the head office can study the financial information at each lewel of the organization and do this on a daily base. It appears that in the past the headquarters and its regional offices had problems with analyzing the financial information because there were hughe differences between the local definitions of revenue and operating costs. The aggregation of financial information was almost impossible and very time consuming.

(The marketing managet explained) "A few years ago, it was impossible to compare the perfomance reports of the local sales offices. Each office used an own review system. Owr CEO was not able to compare the revenues and profits of the different sales offices because there were huge differences in the revenue and contribution margin calculation. Furthermore, the regional affice was responsible for aggregating the performance reponts. This was a very difficult task because of the local differences. Besides, it was very vime consuming. Ow $C E O$ decided to invest hecwily in an autamated system with strich guidelines. This new system offers him the opporrunity to follow the local sales activities in detail. Besides, the performance of local sales offices can now be compared."

The customer wiew is measured by the performance indicators "business process satisfaction" and "customer satisfaction". As for business process satisfaction, the key measure is the percentage completed 'partner enhance programs". The company uses a broad set of customer satisfaction measures (see Figure C.13).

- complain managerment
- call center responsiveness
- worldwide survey representative rate
- issue resolution
- open critics

Figure C.13 Customer satisfaction measures

Source: internal documents 1997 percentage complaints solved or action plan in 7 days, percentage satisfaction with complaint resolution

percentage on eligible, national satisfaction index

percentage abandon rate

percentage on managed accounts

number of issue raised, number of issue closed, number to

worldwide call center

number not closed in 60 days

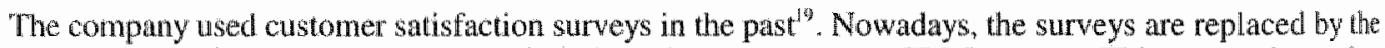
information gathered in the Customer Relationship Management (CRM) system. This system is used 10 formalize each contact with the customer such as mailing, information requests, prospecting, sales transactions, and after sales, and the overall customer satisfaction is measured. At the end of each process in CRM, customer satisfaction data is collected. This information is collected by the "feedback collector' The feedback collector conducts a random sample survey. The quality of the customer relationship is measured on a continuous base as a result of the use of BPM.

With respect to the personnel view, various performance metrics are used. The first group of measures is related to the mission 'Field force productivity and morale'. Productivity improvement is measured by measures related to critical success factors: proposals per country, pricing per country, single moble plattorm, notes infrastructures, and opportunity management coverage. These key measures are country and region coverage figures. Regarding morale, the measures are classified into two groups. The firs! group measures are related to 'lead by example" and to the new incentive plan. "Lead by example" is measured by 'judgment'. The extent to which the new incentive plan is measured by the percentage of countries that have implemented this plan. The second group of measures is related to "win rate'. The key metric is 'percentage on proposed'. 
As for the mission 'best persons in key jobs', it appears that there are two groups of metrics. The first group is related to the certification for client executives and segment managers; the key metrics are the number of employees that has followed courses at WNEAD, and the number of certificates, specific coverage measures are used to measure the gap between the current and the desired situation. These measures are related to management skills, skill assessment, skill development plan, employee satisfaction, and customer satisfaction, and as a result of BPM., the employee view is measured on a continuous base.

The measures related to process view consist of two types of performance measures: indicators related to process effectiveness, and indicators related to process improvement. Overall the "process.' measures can be classified into three groups: input measures, output measures and "key quality control points". According to the BPR manager, an effective measurement system should include all these measures in order to support 'proactive' management decisions. The input or 'leading' indicators are necessary for improving the (cost) effectiveness of a process. An example of such an indicator is the quality of a supplier. Output or 'lagging' indicators are necessary for measuring the process outcomes. The key qualiky control points, such as decision points, measure the progress of implementing TQM within the company's sales force organization. These measures are designed by the worldwide process leader.

Figure C.14 highlights - as a summary- a set of measures used for the CRM process. This table includes primarily non-financial measures, besides these measures, there are also (other) financial measures such as revenue and profit per process. It appears that the performance characteristics, the measures, and the process activities are defined for each process.

\begin{tabular}{|c|c|c|}
\hline Performance characteristics & Measures & What to measure \\
\hline $\begin{array}{l}\text { Customer-driven: } \\
\text { Accuracy }\end{array}$ & $\begin{array}{l}\text { Number of enrors, enrors as a } \\
\text { percentage of output, errors as } \\
\text { percentage of opportunities for error }\end{array}$ & $\begin{array}{l}\text { Sales: incorrect order shipped } \\
\text { Operations: defective units, number of } \\
\text { wartanty claims }\end{array}$ \\
\hline - Timeliness & Process cycle time, wait/delay time & $\begin{array}{l}\text { Proposal turnaround time, order } \\
\text { processing time, issue resolation, } \\
\text { Inquary response time }\end{array}$ \\
\hline - Responsiveness/accessibility & Depends on what is measured & $\begin{array}{l}\text { Phone response, system downtime, } \\
\text { Special recquests met }\end{array}$ \\
\hline - Employee characteristics & $\begin{array}{l}\text { Percentage of employees rated as } \\
\text { have each characteristic }\end{array}$ & Courtesy competence \\
\hline $\begin{array}{l}\text { Internal: } \\
\text { Cost }\end{array}$ & $\begin{array}{l}\text { Percentage of sales, percentage of } \\
\text { operating cost }\end{array}$ & Rework, customer complaint cost \\
\hline - Effect on employees & Depends on what is measured & Overtime, weekends worked, morale \\
\hline
\end{tabular}

Figure C.14 Examples of performance measures

Source: Internal document 1993

Regarding fiscal year (FY) 1996, the key process measures of Customer Relationship Management (CRM) are linked to the mission. "Efficiency and Speed" and the related key success factors. This mission was selected because the company wants to improve its cost structure and customer satisfaction. The following measures are used (see Figure C.13).

The measures rellated to opportunity coverage and responsiveness are used to measure how many prospects and leads are there, and how many prospects and leads are turned into orders. This performance data is then used to evaluate the effectiveness of sales efforts. It appears that sallespersons were not eager enough to follow up prospects and leads; it was believed that the company"s products are so superior that the customer is willing to invest time and efforts to acquire a product.

Nowadays senior management is convinced that the company"s salesforce should be more active with regard to generating sales because the competition is much stronger than ever. Whereas technology was the only key success factor, nowadays technology appears to be only one of the key success factors 
(KSFs). Other KSFs are e. customer orientation and flexibility. These factors are not only related to the ourput of the CRM process but also to the throughput. One performance area related to CRM is opportunity management (OM). OM is one stage of the CRM process in which prospects and leads are transformated into sales orders; senior management stated that "efficiency' and 'speed" are the key success factors in today"s opportunity management. Figure C. 15 is used to demonstrate the employed measures" these measures are related to coverage, responsiveness, gross profitability and win rate.

- opPortunity CONERAGE:

rolling 3 months opportunity value ( $M \$$ ), the number of live opportunities, the number of opportunities generated, revenue generated, the percentage of relationship plans completed, the percentage inflow of business process leads

- OPPORTUNITY RESPONSTVENESS:

OMC leader appointed, OMC operational, \% on country lists, milestone plan, partner web, msm/omsys links

- GROSS PROFITABILILITY:

bid prices versus target, percentage validated/noticed, percentage selected/validated, percentage proposed/selected, percentage on "proposed"

- WTN RATE (versus proposed): percentage an "proposed"

Figute C.15 Kesy measures for CRM

Source: Internal documents 1997

Performance related to "Efficiency and Speed" of processes is measured on a daily base. CRM process is supported by a worldwide management information system, and the various process managers are involved directly in the measurement activities. These process managers measure the 'deployment', the process effectiveness and process improvements on a monthly base.

\subsection{Performance evaluation}

\section{Performance review-meeting cycle}

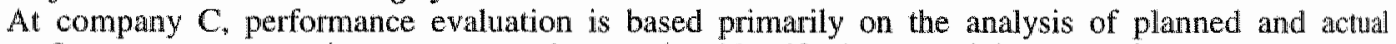
performance to assess the progress-to-plans, and to identify the potential causes of variances between planned and actual results. The performance review is driven by the annual planning cycle that produces the operating and financial plan. Use of the scorecard is common across EMEA and administered at a country level. A set of activities drives this review process and takes place in a disciplined fashion using predetermined formats and agendas on a weekly, biweekly, monthly, bimonthly, quarterly and annually basce (internal document 1997).

- The weekly reviews include the examination and analysis of the order rates and manufacturing loads 10 detemine the likelihood of meeting forecast volumes, and the review of the summary of "call home" activities for trends in market pricing and win/loss ratios. The purpose of these reviews is to indicate the progress.10\% plans, and to identify potential problems.

- The biwe ekty meetings take the form of conference calls with the regional centers reviewing the opportunity lists from the opportunity management system with the participation of the product business units, and the ISU's. The key issues discussed in these meetings are: general updates ${ }^{21}$, country status versus milestones, targets and CSF status, and out of line situations. These biweekly meetings are used to indicate the progress-10. plans, and to identify potential problems, and to ensure timely corrective actions.

- The monthly reviews involve the formal forecast reviews with the product general managers including key strategic business health indicators. These meetings take place at the regional level. The target/CSF results are collected at the EMEA. The data is analyzed to select out of line situations. There is also an EMEA Marketing Board review and approval of the rolling 12 month marketing calendar. 
- The bimonthly meetings take place at the regional office, and the participants are the CCOEs and the members of the EMEA group. The key issues of these meetings are the general update, country status versus milestones, targets and CSF status, and out of line situations.

- The quarterly reviews; quarterly promotion and sales incentives are reviewed and the EMEA marketing board prowides an update for all stakeholders. Regarding financial performance, respondents indicated that once a quarter the financial performance is discussed in a managenent meeting, called the "unit-review meeting". Realized targets are compared with planned results. If the planned targets are not achieved, there are financial consequences for the regional and local offices in terms of contribution margin. As far as the regional of fice does not revise the local targets related to revenue and contribution margin, the positive or the negative impact of unexpected developments are taken into account. The marketing manager explained: "EMEA evaluates our perfomance on a quarrerly base. In a unitreview meering, the local and regional nanagement discuss the local sales performance. During these meetungs, we evaluate the basiness envirowment in terns of competitors, mankets eic. and we evaluate the progress-to-plans. How well are we doing? We analyze the gaps between planned and realized results on a quarterly base. When we ewaluate the gaps between planned and actual results, anexpected and uncontrollable factors are not iaken into account. Neither those with positive impact nor those with a negative impact on performance. If the headquarters decides to adapt the EMEA targets, then the local targets will be adapted; this is the only exceptiow. Orhenwise, another sales office has to compensate ... has to sell more to compensate the impact of the iarget adjustment in our coumtry; ir is not manageable. We are too large."

- The annual audit completes all the business reviews; the review is used to study actual results and to identify issues for the next planning cycle.

\section{Goals-scorecard results}

The company has developed a specific report format, called the 'goals-scorecard results' "Figure C. 16 illustrates the current format, note the simplicity of the format for capturing and recording important information concerning the process, the customer and the employee view. Such a report form provides a paper trail to link the realized targets with the strategic issues in terms of goals and critical sticcess factors. The 'goal-scorecard results' is used to show the actual results and progress-to-plans, and these scorecards are prepared by local management on a monthly base.

\begin{tabular}{|c|c|c|c|c|c|c|c|c|c|c|}
\hline Missiona & Goal & Tirget: & $\begin{array}{l}\text { Goali } \\
\text { kepeper }\end{array}$ & $\begin{array}{l}\text { Last } \\
\text { monith }\end{array}$ & $\begin{array}{l}\text { This } \\
\text { month }\end{array}$ & $\begin{array}{l}\mathrm{R} \\
\text { Fccast }^{22} \text { or } \\
\text { actual }\end{array}$ & $\begin{array}{l}\text { HQ Feast } \\
\text { or actural }\end{array}$ & $\begin{array}{l}\text { Inle } \\
\text { Foast or } \\
\text { actual }\end{array}$ & $\begin{array}{l}\text { WWQ } \\
\text { Foast ar } \\
\text { actual }\end{array}$ & $\begin{array}{l}\text { R.A.G."2 } \\
\text { Shatues }\end{array}$ \\
\hline $\begin{array}{l}\text { Effichency } \\
\text { and spred }\end{array}$ & & & & & & & & & & \\
\hline 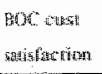 & & & & & & & & & & \\
\hline 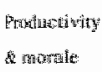 & & & & & & & & & & \\
\hline 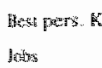 & & & & & & & & & & \\
\hline
\end{tabular}

Fignte C 16

Goals -Scorecard Resulis

Source: Internal documents 1997

\section{Process audits: PDMI and PVI indexes}

A long with the performance reviews related to the "Country Scorecard", the functioning of business processes are also audited by the process leaders twice a year; the process effectiveness and improvements are examined using the Process Deployment Management Index (PDMO), and the Process Vitality Index (PVI). PDMI is an index that is used to indicate the extent to which a process is implemented and how "healthy" or 'vital' the process is. A PDMI of 100 points indicates that a process is fully implemented. This index consists of various issues for which points can be attained such as training programs and courses. The PVI is used to indicate how well or how vital a process is, a PVI of 100 points indicates that a process is operating optimall. Figure C.17 highlights the measures dealt with by PDMI and PVI. 


\begin{tabular}{|c|c|c|}
\hline $\begin{array}{l}\text { Control items } \\
\text { Get started } \\
\text { - Define process } \\
\text { Detemine customer requirements } \\
\text { Describe process }\end{array}$ & $\begin{array}{l}\text { PVI } \\
9\end{array}$ & $\begin{array}{l}\text { PDMI } \\
\text { worldwide process rellease }\end{array}$ \\
\hline $\begin{array}{l}\text { Get organized } \\
\text { Assign ow/nership } \\
\text { - Educate enployees } \\
\text { Ensure deploymemt }\end{array}$ & 9 & $\begin{array}{l}10 \\
40 \\
30\end{array}$ \\
\hline $\begin{array}{l}\text { Analyze process } \\
\text { - Install neasurement system } \\
\text { Define improvementts } \\
\text { - Release process changes }\end{array}$ & 15 & \\
\hline $\begin{array}{l}\text { Improve process } \\
\text { - Establish improvement process } \\
\text { Improve continuously }\end{array}$ & $\begin{array}{l}18 \\
(9) \\
(9)\end{array}$ & 20 \\
\hline $\begin{array}{l}\text { Check business control criteria } \\
\text { Business control self assessment } \\
\text { Meet B/C criteria for "LOW } \\
\text { RISK" }\end{array}$ & 15 & \\
\hline $\begin{array}{l}\text { Benchmark process } \\
\text { Execute bench marking } \\
\text { - Realize benchmark results /prove } \\
\text { competitiveness }\end{array}$ & $\begin{array}{l}22 \\
\text { (11) } \\
\text { (11) }\end{array}$ & $\begin{array}{l}\text { Achieved after execution through } \\
\text { world-wide process owner }\end{array}$ \\
\hline $\begin{array}{l}\text { Process is 'Best-of-Breed' } \\
\text { Process is superior to } \\
\text { competitors' processes } \\
\text { Operational cost of quality are } \\
\text { calculated } \\
\text { TOTAL }\end{array}$ & 100 & 100 \\
\hline
\end{tabular}

Figure C.17 PDNI and P W1

Source: Anternal Document 1995

Company $C$ has also developed a management tool for iterative process improvement. This tool is a close loop system consisting of four repetitive steps: the Define-Solve-Implement-Maintain (DSTM) cycle. The DSIM cycle describes how changes should be made. It includes not only the obvious steps of planning a change; but also those of checking to see that the changes produce the desired or expected improvement and of acting to adjust, correct or further improve a process based on the implementation and maintenance.

Figure C.18 shows the repetitive steps and the related questions and tools. It appears that the DSM cycle provides a powerful tool for managing annual priorities. Process leaders can repeatedly plan, execute, study, and adjust their processes to achieve their desired targets using the DSIM cycle. The cycle helps to ensure proactive adjustment, corrective action, and control. Process leaders use the DSIM cycle twice a year (BPR manager):

- to modify their processes in a dynamic environment, and to improve the reliability of the planning and execution system

- to align key business processes with the operational objectives

- to adhere to the operational plan using measurement and standardization to hold the gains 


\begin{tabular}{|c|c|}
\hline DEFINE & 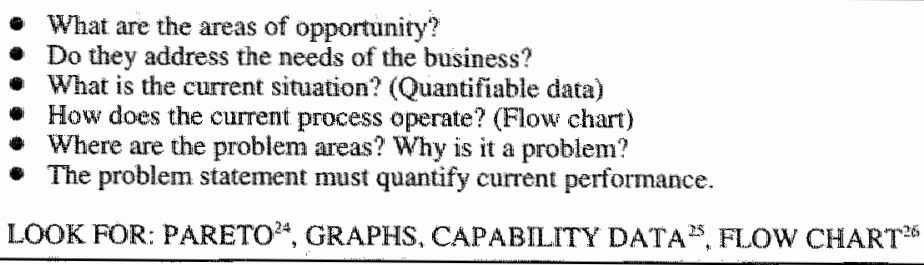 \\
\hline SOLVE & $\begin{array}{l}\text { What could be the cause(s) of the problem? (Fish-bone) } \\
\text { Which solution(\$) will you address? Why and how? } \\
\text { Is it important to your customer? CHECK! } \\
\text { What are the results of your pilot/test? (Quantify) } \\
\text { LOOK FOR: FISH BONE27 }\end{array}$ \\
\hline MMLEMENT" & $\begin{array}{l}\text { How good are your solutions? (Quantify) } \\
\text { Have you improved your customer satisfaction? ASK! } \\
\text { Could your solution be replicated elsewhere? } \\
\text { LOOK FOR: PARETO, GRAPHS, CAPABILITY DATA, SPC }\end{array}$ \\
\hline MAINTAIN & $\begin{array}{l}\text { What control mechanisms are in place? (SPC) } \\
\text { What surveys are in place? When and who? } \\
\text { LOOK FOR: SPC. CAPABILITY DAT, SCHEDULE }\end{array}$ \\
\hline
\end{tabular}

Figur C.18 Checklist for the process leaders

Source: internal document (1993)

\subsection{Feedback and rewarding}

\section{Feedback}

It appears that corrective action is initiated by BPM and 'manage by process". The worldwide process leaders are responsible for the process design. The regional process leader is involved primarily in resource allocation and target setting. If the analysis of planned and realized results indicates that the targets cannot be attained, then this process leader will initiate corrective actions. At the local level, the country process leader is in charge of initiating corrective actions. Overall, the worldwide and regional process manager are not responsible for revisions to plans and operational targets. Their role is restricted to information gathering. The country process manager is responsible for monitoring and cortecting operational actions. These revisions include primarily 'instructions'.

Corrective feedback on long term performance and strategic direction is provided on a quarterly base. The managing director meets the country managers and gives a presentation about the company"s policy and strategic developments. Planning meetings at various managerial levels are used to follow progression in the attainment of long term objectives, corrective action is discussed and formulated by the involved parties. Our respondents stated that revisions to plans and actual outcomes are not programmed formally. These revisions are the result of interactions between supervisors and their subordinates. Overall, senior management at the corporate level can initiate revisions to plans. According to the Dutch marketing manager, it appeared that those revisions to objectives are rarely made.

\section{Rewarding}

The implementation of BPM have had implications for the sales compensation schemes ${ }^{29}$. As a result of the process descriptions, the various functions are described in detail and rated, and based on this rating, i.e. "ob reference system', the financial compensations are determined.

With regard to salespersons, it appeared that there were allso some changes. As announced in August 1996, the EMEA sales incentive plan for 1997 showed significant changes from the 1996 plan. It provides for more flexibility to front line management teams while maintaining the linkage with business results. Its purpose is twofold: setting individual objectives in stupport of the business unit targets focusing on strategic or key opportunities, and evaluating performance and generating a real differentiation in payments and earnings between modest contributors and high performers. Internationalization of the 
business, shorter business cycles, reinforced role of the business partners and subsidiaries, measurement systems difficultieg in tracking the complex go-to-market model and a need to support the re-engineered processes (CRM) has lead the company to realign the sales incentive plan with the new strategies, the desined behavior and the way of doing business. The design of this sales compensation system is based on the common worldwide framework to better support the global objectives with a balanced focus on financial results on one hand, and cross unit teamwork and individual performance recognition on the other. Eligibility should be restricted to business unit members with a direct influence on business performance so that the commission budget is not diluted and is really directed to increase the compensation of the best performers. Although this is finally a country decision, headquarters is reconmending: a high leverage plan (70 base sallary and 30 variable) and a low leverage plan (85 base salary and 15 variable) for salespersons.

The commission budget funding is managed by the country business unit (CBU)/sales manager and is split into three parts: a 80 per cent of the incentive pay is af the disposal of the CBU manager, a 10 per cent is held for the regional general manager campaigns and a 10 percent for the 'top contributors bonus' program. The campaigns are announced by the regional general manager for local implementation by the CBU/sales manager. Half the campaigns will be for corporate focus as decided by the regional executive team. The "Top Contributor Bonus" is kept aside to reward the top business unit performers (applicable to Client / Territory representatives and sales specialists) at the end of the year. If good business performance allows for an extra commissions budget, the major part of the additional money is directed to the best performers.

The total available commission money varies depending on team performance to foster team behavior. One dimension of the variability in commission is the country/region or regional business unit revenue, or gross profit for services units. The other dimension is the total country sum of units revenue in order to promote teamwork across business units. Both dimensions also include the business partner revenue. This is done to compensate sales persons for the discount the distributors receive when they sell a product. Today's compensation plan ${ }^{30}$ offers increased compensation for sales through business partners. When evaluating performance against a PCO the manager takes into consideration, in addition to the level of attainment of the objective, other criteria such as prices (opportunity owner price delegation) and effective utilization of business partners. This can result in over or under payment of a given Personal Contribution Objectives (PCO). Payments are done quarterly (preferably) or yearly.

The country manager and the other members of the management team's rewards are split into two parts: a 60 per cent fixed and a 40 per cent variable. The variable part consists of bonuses derived from the "olympic score. The "olympic score" awards 40 per cent of incentive pay from the corporate results", 50 percent from the regional results ${ }^{32}$ and 10 per cent from customer satisfaction. From the interviews held in both the Belgian and the Dutch sales office, it appeared that although the country managers are familiar with the evaluation devices with the "Olympic Score; they do not receive any information per perfomance measure, they only receive the final score, as a percentage. The best performers can also earn an additional bonus from the "Top Contributors Bonus" program. This bonus consists of stock options at a fixed price that have to be exchanged for shares within three years.

\section{Task control}

From the interview with the Dutch BPR manager, it was found that the implementation of BPM has had a great impact on task control practices.

- Standardization of work processes is achieved by function and job descriptions, and by BPM. As stated earlier, the headquarters impose 68 quite detailed function descriptions on the local sales offices. Regarding these function descriptions, the local managennent teams have formulated appropriate task descriptions consisting of responsibilities and related tasks, and the local business processes are also described in an ISO 9000 handbook. Attaining an ISO 9000 certificate is an initiative of the Belgian and Dutch sales office that is designed to describe the main business processes in detail. The Belgian sales office also applies for the Malcolm Baldrige Quality Award. Therefore, the main business processes and related subprocesses are described in detailed procedures. The use of these procedures are audited by the sales office and by an external firm. Regarding to standardization of work processes (e.g. the sales process and the operationall planning process), it appeared that the key processes are described in detail. The process maps indicate the nature of inputs, the key activities, and the outcomes of process. Furthermore, these maps assign responsibility to process leaders and process managers. BPM has had a great impact on function descriptions. The process leaders indicate and change 'roles' by describing and analyzing situations. For instance, CRM indicates that at least the following roles have to be fulfilled: opportunity 
owner, opportunity justifier, quallity helper, opportunity business manager, proposal tean leader, proposal/development, solution architecture team, quality assurance, deliwery team, project team leader, and feedback collector. Local support processes, e.g. aftersale services, are also formalized, and this formalization is accomplished by an ISO 9000 certification. CRM is supported by an automated system. For instance, each step in opportunity management is documented in a sales information system. The salespersons have to indicate their progress in sales transactions.

- Standardization of outputs is achieved using management by objectiyes. From the interviews it appeared that objectives are assigned to individual employees. The company aims to motivate its employees to produce the desired results by holding them accountable for these results.

- Standardization of skills is accomplished using internal and external training prograns. These programs are organized locally or internationally. BPM has also had a great impact on the standardizition of skills. One key process is skill management. This business process refers to 'managing the functions and skills of employees". Each function has a label, and is described in detail (i.e. the related tasks, responsibilities, and required skills). A worldwide database contains information about the qualifications of the current employees. This database is a powerful tool for analyzing the current skill needs of the company, and training programs can be initiated based on this analysis.

Another important task control devices is the assessment of individual performance. The country/region business unit managers receive quarterly and / or yearly targets together with business directions from their regional executive. These managers transform their targets into individual Personal Contribution Objectives ( $\mathrm{PCO}$ ) for their sales professionals. Besides quantitative objectives such as salles quota, costs and expenses, number of new customers, there are also qualitative objectives. Examples include targets related to competence, skills, specific projects that will generate some cash flows within the next vears, etc. Assessing individual performance is done during an annual formal meeting called a "personal performance encounceling evaluation", between superiors and their subordinates. The outcomes of this meeting has an impact on the career perspectives of the subordinate and financial consequences. The individual performance of salespersons is also evaluated on a monthly base; the outcomes of the performance evaluation at the business unit or ISU level are therefore used. The PCO content of sales professionals is quantifiable but not necessarily; individual PCOs are linked to a measurement system. One third, at least, of the incentive pay should support cross business units opportunities including those fulfilled by business partners. The rest of the $\mathrm{PCO}$ is linked to the country/region business unit targets achievement. No more than three $\mathrm{PCO}$, plus two campaigns are assigned to an individual at any given time to ensure focus and simplicity.

\section{Notes Case Study III}

1. The organizational chart of EMMA will changed in FY 1997; the country organizations will be assigned to one of five groups: North, Nordic. West, Central, and South. The Belgian sales outlet will be assigned to West; a group consisting of France, Luxembourg and Middle East/Africa. The Dutch sales office will be assigned to North; a group consisting of South Africal, UK/lreland.

2. A process owner is responsible for (a part of) a business process. These responsibilities are described in procedures and instructions, job descriptions etc. The concept of process owner will be discussed further in section 3 of this case study description.

3. One may suggest that there is only a slight difference between 'process leader' and 'process manager'. This perception can be explained by the fact that the company integrated the concept of process managenent in its 'bureatucratic' structure consisting of many authority levels and thighly centralized decision making.

4. Examples of these guidelines are disclosure requirements for financial statements, required earnings, required return, number and qualicy of personnel, experience, etc

5. A process leader is primarily responsible for process inmprovement efforts. Four types of process leaders are distinguished, namely: worldwide, regionall, country and business unit. Decision making authority diminishes from the worldwide level to the business unit level. The specific responsibles are demonstrated in Figure C.8.

6. The format and use of these tools will be discussed in the section about sales management control.

7. We refers in this context to "the local management. 
8. The concept "deptrintert" refers in this contaxt to "business umil".

9. The concept "batuetreld" refers in this context to 'challenge".

10.Wote that, wntil 1993, the main priority of the company was tic turn its losses into profits. Since 1994 it has been proftable. Now that this goal of profrability has been achieved, the other strategic imperatives have to be atlained. "Thege imperatiwes focus primarity on growth.

11.In comparison with the previous planning system, the operationst targets are not imposed by the regional wfice but negociated. According to the Dutch CCOE, the old planning system was based on the assumption that the local management team set revente targets as low as possible whereas regional management sets operanonal targets as high ass possible. This assumption led to gaps between local and regional targets. Up to 1994 the lock offices had succeded in 'closing the gap'. Since 1994 the locall offices have often had problems to "closing the gap" between the local and regional offices. The regional targets may be too ambitious. The only way to aitain these targets was to invest heavily in the infrastructure, however, this may cause a deterioration in the cost effectiveness.

12.i.e. the local nuaragement

13. With the ofd planning system, the country managers were responsible for attaining the operational targets of their siales office:

14. i. critical suciess factor

15.i.e. targets

16. Opportunity Management

17. i.e. the number of sales opportunities registrated in the company's customer database.

\section{8.j.e. direat marketing activities}

19. Two customen salisfuction surweys were conducted before BPM was implenented. Boulh the regional and the local oflice organizies stuch surveys. The customer satisfaction survey of the regional office was addressed to several local customers, and included items concerning the quality of the company's products and services; this research was conducted on a quarterly base. The survey of the local office included items for comparing the performance of business units with those of the competitors; this survey was organized once a year. Overall, the surveys were not anonymous, and the research results could be obrained by the customers: customers could use the outcomes for contacting the local offices to solve identified problems.

20. 'Call home' activities are visits to customerg whereas the initiative is coming from the satesperson and not from the customer

21. For instance, general update with respect to new products of R\&D developments.

22. i.e. hirst quater forecast or actual pertormance

23.R.A. G. Sthts is used to indicato the extent to which operational targets are attained.

24. Pareto refers to Pareto chats: data pints drawn as propontionally sized bars and ranked by relative size, with or without a line indicating cumulative total with the addition of each item. The purpose of these chats is twofold: to break down broad causes into smaller categonies, and to identify the vatal few and the trivial maty for efficient problemwolving.

25. Capability data is used to measure the capacity of the process to neach a certain level of quality. A process capability chart is used to illustrate the variation in dispersion of quality over time, relative to a specified or target value.

26. Fowcharts are pictorial representations of a process. Flowcharts can be useful in identifying where errors are likely to be found in the system by breaking the process down into its constituent steps. 
27. Fishbone diagrams, also called 'cause-effect diagrams' or AKA Ishikawa diagram, refers to a simple tool for doing 'root cause' analysis, the search for and elimination of the one key cause of quality problems. Ir can be used to illustrate the relationships between causes, and between the causes and the net effect.

28.SPC includes a broad set of tools, and analytical techriques to monitor and undertand processes and the variation in processes and outcome. Examples are ' $\mathrm{x}$ bar $\mathrm{R}$ chart" and " $\mu, \mathrm{np}, \mathrm{c}$, and $\mathrm{p}$ charts". The purpose of these control charts are four fold: to determine whether process characteristics consistently approach extreme control limits, to determine whether a process is in or out of control, to identify upwards or downwards trends in process characteristics, and to separate variations due to assignable causes from those due to chances.

29. In the old system, rewarding was based primarily on a comparison with functions within the company. Nowadays, the company benchmarks its rewarding structure against other companies.

30. The old pay plan discouraged sales through business partners; these distributors were viewed the sales representatives as their competitors. When a sales representative sold a product through a distributor with the distributor receiving a discount, the salesperson was paid a commission based on the list prices minus the discount; when the sales reps sold direct to the customer, they were paid commissions based on the full list selling price.

31. i.e. 80 per cent of the corporate net income and 20 per cent of the corporate cash flow.

32.i.e. 80 percent of the regional net income and 20 per cent of the regional cash flow. 


\section{Case study IV}

\section{Company D}

An IT firm with a process oriented work culure

\section{BACKGROUND OF THE COMPANY}

\section{Introduction}

Company D, founded in the late thirties, started its first business activities in the market for electronic test and measurement systems in which it became the leading manufacturer in a short time. In the early sixties, the company extended its electronics technology to the fields of medicine and analytical chemistry. It introduced its first computer in the late sixties, built to gather and analyze data produced by the company's electronic instruments. Company $D$ belongs to the three largest computer manufacturers of the World.

\section{Products}

Company $D$ 's products are sold in more than 120 countries around the world. They can be classified as:

- computer products, service and support: computer hardware, software, peripherals, callculators, and service and support to these products

- $\quad$ electronic test and measurement systems, service and support: test and measurement equipment that helps the designing, manufacturing, operating and repairing of electronic equipment, and service and support to these products

- medical equipment: equipment and information systems for patient diagnosis, monitoring and therapy, and service and support to these products

- analytical products: equipment for the analysis of chemical components, information systems, and service and support to these products

- electronic components: like among other things advanced semiconductors, LEDs, and fiber optic transmitters and receivers.

The company employs a product division structure; five worldwide product divisions responsible for $R \& D$ and product management.

\section{Worldwide sales force organization}

Compwny's international activities are classified by the major geographical areas in which it operates: Americas, Europe/Middle-East/Africa, i.e. EMEA, and Asia/Pacific (see Figure D.1). Each region"s headquarters functions as an intermediary between the headquarters and the local sales and support offices. All sales and support offices are wholly owned by headquarters, and they are responsible for implementing the company's marketing and sales strategy. The regional product departments are responsible for coordinating the business efforts regarding specific product groups. 


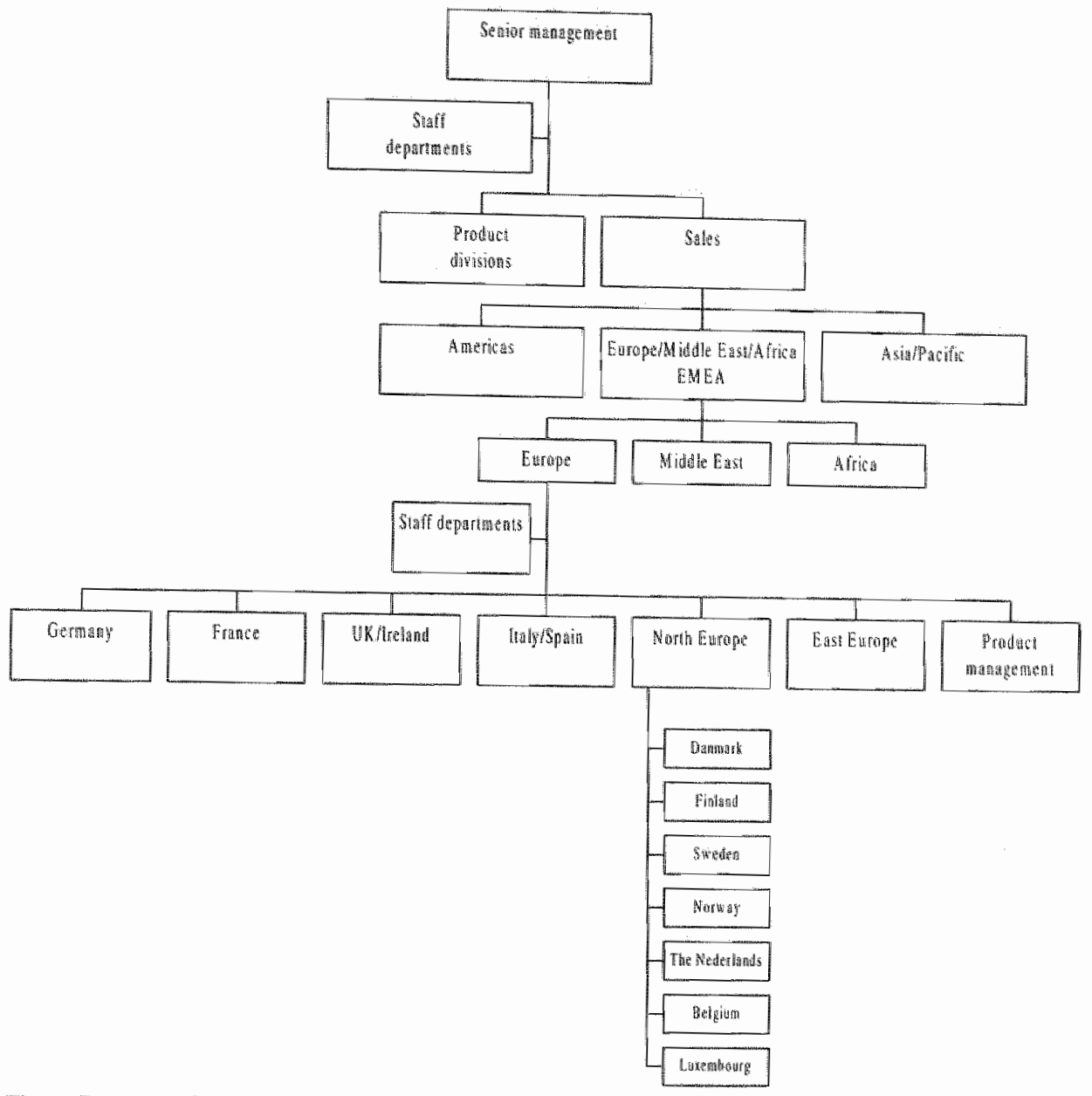

Figure D.1 Organizational chart of the company

Source: adapted from internal documents 1996

\section{The Belgian and Duth sales office}

The Dutch and the Belgian sales office are part of the sub region North Europe. This sub region consists of Norway, Sweden, Finland, Danmark, The Netherlands, Belgium, and Luxembourg. The manager of this subregion is also the country manager of the Dutch local sales office. Each country organization is responsible for the activities in its sales area. With respect to financiall reports, it appears that each country organization reports to the manager of region North Europe; this manager consolidates the financial information and he reports to the regional office, i.e. EMEA.

Each local sales office is managed by a management team; this management team consists of the leaders of the business units mentioned in the organizational chart (see Figure D.2). The following sales organizations can be distinguished: Computer Systems Organization, Computer Products Organization, Customer Support Organization, Components Group, Test and Measurement Organization, Medical Products Group, Analytical Products Group, and Sales Finance and Remarketing. These organizations are supported by the following staff organizations: Finance and Administration, Personnel, and Quality. All salles and staff organizations will now be elucidated briefly. 


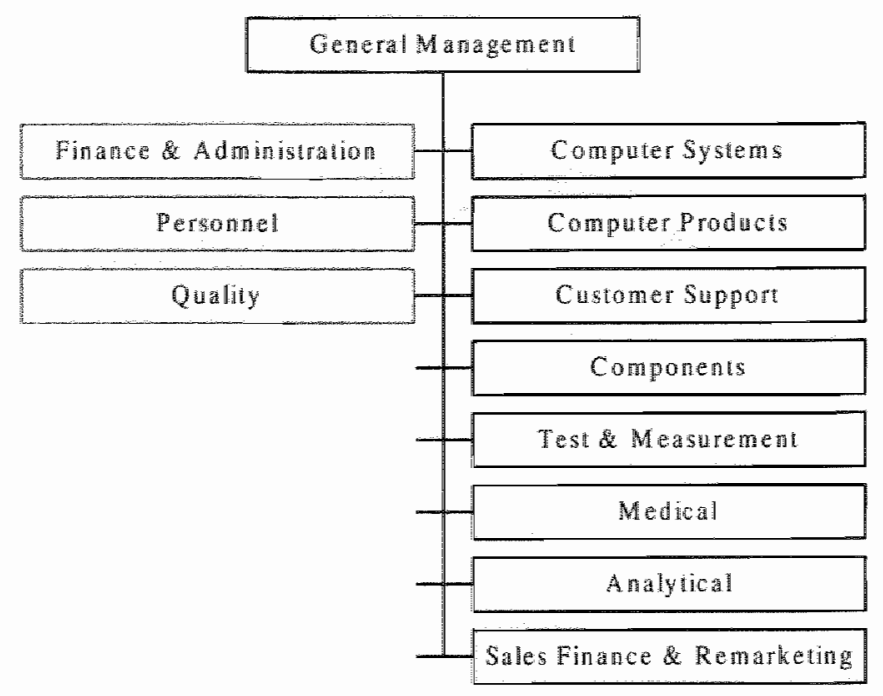

Tugute D.2 Organizational chart of a local salus office

Source: adapted from intemal documents 1995

Computer Systems Organization helps companies use information technology to reshape their business and technical processes. It also helps organizations to move from traditional computing systems, such as mainframes, to more flexible and cost-effective solutions based on open, client/server computing. Company $\mathrm{D}$ is considered to be the worldwide market leader in this segment. Computer Products Organization produces and markets computer, communication and calculation products. Among the most successful products of this business unit are laser and inktjet printers. Customer Support Organization develops and markets important new services to meet the changing needs of customers; moving from traditional, proprietary technology to a standards-based computing environment means redefining the role of service and support. Where yesterday's customers required mostly maintenance and repair, today"s customers want a much broader range of services. Components Group produces and markets more tharu 9,000 products that help people to communicate quickly, reliably and cost effectively. Test and Measurement Organization produces and markets state-of-the-art test and measurement systems and customet specific solutions based on them. Medical Products Group devellops and markets solutions for health care providers. Analytical Products Group produces and markets instrumentation for scientists; it. competes in pharmaceutical, petrochemical, environmental and biomsciences markets. The activities of the business unit Sales Finance of Remarketing are twofold. Sales Finance is the company's internal lease organization for clients, and Remarketing markets repaired "renovated or even completely recycled products of the company.

Various staff departments support the activities of the business units. Finance \& Administration organizes and controls the financial administration and the financial information system; it also provides juridical support. Persomel tecruits and trains employees. As company D identifies quality as being important for its products and its services, it has also a decentralized quality control besides the centralized quality control at the production sites. The Quality organization reports directly to the General Manager.

\section{QUALITY MATURTTY SYSTEM}

\section{An integrated quality management system}

From the early 1980 s onwards, the company has developed a management system consisting of four comerstones: customer focus, planning, process management and an improvement cycle. This system is built around a specific set of traditional and TQM principles, tools and techniques. It consists of traditional practices, such as "Management by Wandering Around", "Management by Objectives", and an "Open Door Policy' supported by a quality system called 'Quality Maturity System' (QMS). 
QMS was first implemented at the corporate level of the organization and the product divisions in the mid 1980 s. The quality system has been implemented in the worldwide sales force organization since the early 1990s. Sales control practices are embedded in the qualiry system, and local people are trained to employ the methodology at their sales office. The Belgian sales manager stated that the extent to which QMS is employed at the local level of the EMEA region varies from sales office to sales office. It was observed that the headquarters encourages poor performing sales offices to employ the QMS methodology because it beliefs that QMS leads to business excellence. It was also found that company D audits the five business function' once a year, and that the senior level managers implement the audit.

QMS consists of five dimensions: strategic dinection, a particular way of business planning, process management, process improvement, leadership and participation, and a handbook has been written for each dimension. These handbooks highlight the key issues of the quality dimensions, and elaborate on specific management tools.

\section{Strategic Direction}

The strategic direction is designed to give all areas of the organization a central focus for developing an integrated business plan of how the organization can go from where it is, to where it wants to go, i.e. an integrative strategic plan. The handbook 'Strategic Direction' indicates how managers must develop strategic goals and strategies to attain these goals. Important steps for articulating the integrating plan are:

the determination of the strategic focus or mission

- the development of indicators of progress toward the mission

- the driving elements of the indicators

- the determination of the current baseline position

- the identification of current trends affecting the organization

- the determination and prioritizing customer needs

- target setting

The integrated business plan includes a set of long term targets and means for achieving goals with regard to cost, delivery and corporate citizenship. The items that are relevant to "cost' include production, price strategies and general finances like revenue and product share. The items for "delivery" include new product development cycle and distribution. Unlike traditional planning, this process is not done solely by the "corporate planners"; it is done by each layer of the hierarchy, from the senior management to the local management teams.

\section{Business planning}

The handbook 'Business Planning' describes how organizational units hawe to develop long term and one-Year business plans for achieving objectives in conjunction with the management's choice of specific targets and means/resources for cost, delivery, and moratle. A specific planning tool the 'Ten-Step Business Planning Process' has been developed by headquaters. Setting operational targets, assigning responsibilities, developing measures of accomplishment and time lines are important planning steps.

It was found that the 'Ten-Step Business Planning Process' is used to develop the short term action plans at each level to obtain consistency with the overall strategy. This is accomplished by linking these plans to the measures derived from the policies and the objectives of the higher management. This is a highly participatory, vertical, top down and bottom up process that is used as a coordinating activity in the organization. This business planning system is based on the principles of Hoshin Kanri ${ }^{2}$. Its key principle is identifying the annual plans and goals, i.e.Hostins, which must be met each year to achieve the long range plan; these plans are deployed throughout the organization, reviewed at regular intervals, and corrective action is taken where shortalls are identified. It is a system of forms and rules that encourage employees to capture and concretize strategic goals, and flashes of insight about the future and develop the means to bring them into reality. Hoshin's primary benefit is to focus activity on the key things necessary for success.

\section{Process management}

A third dimension of QMS is "process management". Since the late eighties the company"s management system has been based on the principle that changes can be made most effectively by identifying and modifying processes, not by focusing narrowly on inputs or outputs. Process management includes all activities which operate, analyze, change, improve, or change processes; process management or process improvement are also processes themselves. 
As a result of process managenent, the company's operations are structured around the critical business processes including local marketing and sales processes. A description of how activity is carried out in an organization, usually to produce products or services. A process is not limited to repetitive, assembly-line type activities, but may include holding meetings, communicating with others, solving problems, managing subordinates, doing analyzes, preparing reports, and other similar activities. All work is part of some process, whether or not described as such. The nature of the business processes are described in process maps, called "relationship process maps". Such a map is used to indicate the "process" responsibilities, the links with other critical processes, and the critical business processes of customers. The process characteristics are described in terms of input and output requirements. Process owners are assigned and authorities are highlighted at each level of the organization,

The concept of "process owner' specifies who or what is responsible for a process. In consultation with a superior, the process owner determines the points of measurement and develops appropriate measures of accomplishments; these measures are related to output and process effectiveness. A process owner is allso in charge of supervising a process, and each year an audit described in the QMS handbooks is conducted by an external consultant. The assigned authorities make clear how the process is specified, and they form the basis for actions and decision making. It appears that the 'authorities' of process owners can be found in documented procedures and instructions, in job descriptions and in the code of practice of the company.

\section{Process improvement}

It was tound that Hoshin Kanri is a component of the company" TQM system that allows an organization to plan and execute incremental improvements to existing processes or methods, i.e. Kaizen, and if needed to initiate breakthrough improvements in core business systerns and processes (hoshin) to improve performance. At the heart of the company's hoshin management is the Plan-Do-Check-Act (PDCA) cycle, i.e. an iterative improvement process.

PDCA is a closed loop system consisting of four repetitive steps. The situation is analyzed and the improvement is planned (Plan). The improvement is tried ( Do); then data is gathered to see how the new approach works (Check), and then the improvement is either implemented or a decision is made to try something else (Act). This process of contimuous improvement makes it possible to reduce variations and lower defects to nearly zero. The processes that produce good results are standardized and documented. The documented processes are followed. If the process is changed the documentation is changed. Figure D. 3 demonstrates the use of the PDCA cycle in the company"s hoshin management.

PDCA is used to stimulate process owners to improve the output and the effectiveness of their processes; process ownership implies that the responsible employees are held accountable for managing and improving the performance of a specific process. Company $\mathrm{D}$ uses deployment matrices to document the process owner"s conmitment to support the incremental improvement or breakthrough objectives: "Business fundamentals" is used for attaining incremental improvements, and Hoshin" is used for achieving breakthrough improvements. The headquarters has summarized a number of tools to be used for improvement efforts in a handbook 'Process improvement". 
CHECK

Long term business plan or ten-step plan review

$\mathrm{ACT}$
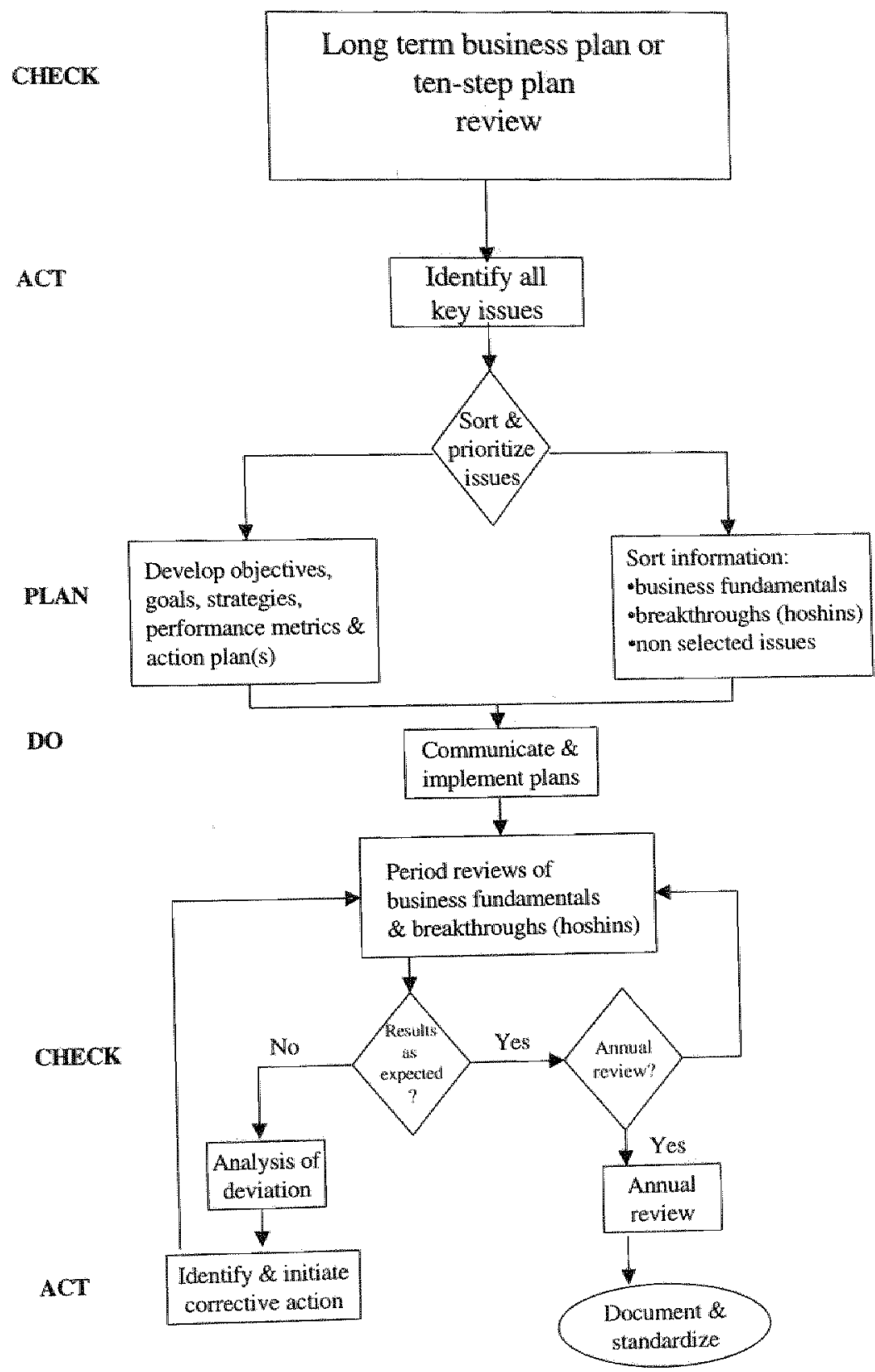

Figure D.3

The use of PDCA cycle in the conpany"s hoshin managenent source: adapted from internal documenis

The fifth dimension of the company"s quality system refers to 'Leadership and Participation'. It is based upon shared values, expectations, and purposes; communicated and reinforced via interactions among ected in the decisions the leaders make; and evident in the actions of the firm. 
It includes the formal and informal bases and mechanisms for leadership development used to select leaders and managers, to develop their leadership skills, and to provide guidance and examples regarding behaviors and practices. The management book 'Leadership and Participation' is used to demonstrate how leadership is exercised throughout the organization, i.e. the way that key decisions are made, communicated, and carried out at all levels.

If was found that the company's planning system operates on the principle that individuals should make their commitments; top management identifies the vital performance issues, and these strategic priorities are deployed. Employees design their own plans, neview their own progress, and communicate with other employees to ensure alignment and coordination. Leadership should, therefore, include setting clear targets, motivating subordinates to work toward the targets, and providing systems and resources to attain the targets. 'Leaders' should also build an innovative culture that is responsive to customers and flexible enough to take advantage of opportunities. It implies that subordinates should be encouraged to question every practice, submit suggestions, and to improve the critical business processes. Tools for improving leadership and participation are described in the handbook "Leadership and Participation".

\section{THE SALES FORCE ORGANIZATION}

\subsection{Formalization}

The company employs many mechamisms to formalize behavior at the various levels of the organization. These mechanisms include structuring the sales operations, function and job descriptions, the management handbooks developed and imposed by the headquarters, the ISO 9000 handbooks ${ }^{3}$, and the training programs.

\section{Structuring Local sales operations}

It appears that the headquarters imposes an organization chart on each level of the sales force organization: from the regionall offices to the local sales offices. As stated earlier, the local sales offices are wholly owned subsidiaries responsible for the implementation of the company's strategy. "The task environment of these sales offices is specified by the headquarters. The distribution tacit that the company uses in distribution is 'through dealers' and 'direct selling"; yet the major part of revenue is generated by distribution through partners, dealers and distributors.

With respect to the commodity products such as printers and $\mathrm{PC}$ products, the company put its business through their party outlets like dealers and distributors. The more complex product, such as products based on system integration, are sold by its own sales force or by party outlets such as business partners. Regarding the selection of business partners, it was found that the headquarters has a list of 'qualified' business partners and it also maintains a standard checklist for selecting dealers and distributors.

\section{Function and job descriptions}

Overall, function titles are imposed by the headquarters; yet the contents of the function and job descriptions are determined by the local management teams. These descriptions also include authorities necessary to clarify the basis for the actions and decisions with critical processes. Headquarters produces function titles and descriptions including the responsibilities and tasks for specific sales positions, such as general manager and business unit managers.

\section{Management handbooks}

Headquarters has developed five handbooks in which management tools are highlighted; these tools are related to strategic planning, business planning, process management, process improvement, and leadership and participation. The organizational units are audited annually with regard to the use of QMS.

\section{ISO handbooks}

Company D also uses ISO 9000 handbooks. Our respondents stated that customers are asking companies to have their quality systems registered under ISO 9000 . It appears that this registration offers the customets an internationally recognized measure of the company's commitment to quality and adherence to an effective quality system. 
ISO 9000 registration has had numerous positive impacts on the business operations: it provides a common vocabulary and set of standards where the internal procedures overlap with customer processes and procedures. It also appears that ISO 9000 is a key element in the approach to customer satisfaction and Total Quality Management (TQM) at the sales offices. "Our customers can be confident in the company"s ability to continually and consistently deliver products and services of superior qualify and value" (Internal document 1997).

\section{Training programs}

Finally, it was found that training programs and other forms of education are organized at each level of the organization. These programs are related primarily to technical and management skills. There are also programs to highlight QMS methodology.

\subsection{Centralization}

It was found that decision making authority is highly decentralized, however, the size of the international operations makes it impossible to decentralize completely. Overall, the headquarters is responsible for strategy formation. The regional and local sales offices implement the corporate strategy in the sales area. In face of the intensive competition and changing consumers' needs in the current business environment the company commits great efforts to its marketing functions. The decision making authonity concerning the company's marketing mix is quite centralized, and some of the key issues are described below.

With respect to the product decisions, it appears that decision making authority is delegated to worldwide product divisions. These divisions are responsible for product development and management: they can also decide what distribution model is used, i.e. indirect versus direct selling. Company D adopts a diversification strategy with its product lines. Company D has more than 18,000 products that have broad applications in various fields; it also uses a pro active approach in product development. Moreover. the company puts emphasis on providing high quality customer service to add value to the products of the company purchased by customers. It also stresses good interpersonal relationship with customers, good computer services like setting up computer networks for its customers and providing warranties for its products. In addition, the company also pays considerable attention to brand management. The company commits to achieve high quality for every product line standards, and it aims to produce innovative and high quality products to maintain its brand reputation.

With regard to price decisions, it appears that for highly standardized products the decision making authority is centralized primarily at the product division level; the product divisions then impose 'global' prices on the local sales offices. The markets of these products are characterized by a high transparency; price differences cause grey import. As for services and the more customer based products, the product divisions determines price ranges per product line and impose these ranges on their local offices. In face of the intense competition in the IT industry, the company prices its products aggressively. Lls basic strategy is to price competitively with top-level players in the market. In the past it followed other competitors in the market to adjust the price, now it slashes prices to steal market share. In other words. the company sets a minimum acceptable profit level and then seeks to maximize sales in the bellef that increased sales are more important than immediate high profits in the long term competitive picture. The specific goal is to maintain and increase market share. It was observed that the pricing objective of the company is long term rather than one of just maximizing immediate profit.

Regarding the promotion efforts of the company, there is an emphasis on promoting in unified image of the company"s products, which are of high quality, are innovative and can meet the diversified needs of customers. It also promotes its image as ft contributor in economic, social, educational and phillanthropic areas. The promotion efforts include mainly advertising and public relations efforts. Overall, the media that company $D$ commonly employs for advertising are exhibitions, television, newspapers, magazines and direct mailing. The global advertising campaigns are used at the local level. If specific campaigns cannot be used in a local market, then the local office can develop an adapted advertising campaign.

The main tacit that the company uses for distribution is "through dealers". "The company aims for at high wolume of sales at the low end and service and quality at the high end. It is trying to do its business through party outlets such as partners, dealers, and distributors. The main objective is to reduce the cost of a dedicated sales force. Two thirds of the company's products are sold in this way. It appears that the local sales offices are in charge of developing and managing a local distribution network. 


\subsection{Integration}

Company $\mathrm{D}$ commits considerable effort to the integrating mechanisms used to achieve its values and corporate goals in terms of profit, customers, field of interest, growth, people, quality and citizenship. These mechanisms are embodied in both the formal and informal organization. It was observed that these devices are employed to encourage liaison contacts among the employees. The major integrating mechanisms are "Management by wandering around" "Management by objective", "Open door policy", a high degree of decentralization, a divisional structure and TQM. These mechanisms are employed as follows.

- "Management by wandering around" is an informal company practice that involves keeping up-to-date with individuals and activities through informal or structured communication. Trust and respect for individuals are apparent when 'Management by wandering around' is used to recognize the concens and ideas of employees. This may be carried out by managers consistently reserving time to walk through their department and being available for impromptu discussions, indiwiduals networking across the organization. holding coffee talks, communication lunches and hallway conversations. "Management by wandering around ${ }^{3}$ is a management principle that is employed worldwide. It was observed that this principle stimulates formal and informal direct contact between superiors and their subordinates at the different levels of the organization.

- Individuals at each level contribute to company goals by developing objectives that are integrated with their managers and those of other parts of the company. Flexibility and innowation in recognizing alternative approaches to meeting objectives provide an effective means of meeting customers" needs. "Managennent by objective" is reflected in written plans that guide and create accountability throughout the organization: coordinated and complementary efforts; cross-organizational integration; and shared plans and objectives. The open door policy may be used to share feelings and frustrations in a constructive manner, to gain clearer understanding of atternatives, and to discuss career options, business conduct and communication breakdowns.

- The company employs the planning method 'Hoshin Kanri' which is based on focus, alignment and freqtent performance review. It is a useful tool for encouraging managers to pay close attention to coordination and integration at all organizational levels. The deployment method was implemented at the headquarters in the late 1983 and it has been employed worldwide since the early 1990s.

- Company D has also been largely decentralized since the early 1990 s; this is the result of a worldwide reorganization. In the United States, a string of poor financial results drove the company's stock price down to an all-time low in 1990. The company founders reorganized the company away from centralization and towards decentralization. Instead of setting up councils to support consensus decision making and the forming of the hierarchical structure, the company decided to reduce its headcount and to decentralize power to its workforce who are familiar with an area and able to be responsible for decision making.

- The company also has a divisional stncture; it operates as a set of global, cross-functional teams. Each cross-functional tean owns its business and can react quickly to the market. Managers are both autononbus and accountable: they know exactly what their casts are, can reinvest the capital their divisions make and are free to attack markets in their own way; but there is a strong emphasis on technology sharing and correlation across divisions.

- The company puts considerable emphasis on the quality of its products and services. It uses a qualiry system which is designed to satisfy custonners and produce better products thus increasing profits; this system is implemented worldwide. According to the Belgian sales manager, "... it ensures that we work more closely as a European team to meer key customer needs; and it provides a common vocabulary".

Line management has allso an integrative role at the sales force organization. For instance, the regional management is in charge of integrating and coordinating the planning and the field operations of its sales offices. With respect to planning, the regional office ensures that the local sales offices contribute to the attainment of the regional goals. It implies that there are negotiations with local management teams to set appropriate and realistic targets, and to allocate the required resources for goal attainment. Furthermore, they review the performance of the local sales offices to assess progress-to-plans and to ensure that corrective actions are undertaken. 
The manager of region 'North Europe' has the same integrating and coordinating tasks for his sub region; he reports to EMEA. The country managers are responsible for integrating and coordinating activities melated to the business units; these managers ensure that local planning activities take place, stimulate the business units managers to contribute to the attainment of the country targets, and allocate the required resolirces for target achievement.

It was found that integration is accomplished by quality deployment and process management. Horizontal integration is achieved by quality deployment in the narrow sense, i.e. a process focus and deployment of quality activities toward employees representing the warious functional departments. Vertical deployment is accomplished by structuring the linkages of key processes in the provision of services and products. Processes and their links are described in process maps. Furthemore, specific tools have been developed to ensure vertical integration regarding planning and improvement efforts. These tools include the deployment matrices "Business fundamentals" and "Hoshin", and the improvement cycle "PDCA". Deployment matrices are used to ensure total organizational alignment (TOA). At company D, TOA starts with all employees throughout the organization sharing a clear understanding of and commitment to the company's mission, i.e. the primary reason for existing, and the vision, i.e. long term future state and objectives. The PDCA cycle is used to modify strategic and operational plans, to improve the quallity of planning and implementation, and to align key business processes with operational targets.

\subsection{Participation}

It appears that goal setting is perceived as to be highly participatory; it is used to align people, activities and resources behind the company's policy and targets. Company D uses participative management to ensure consistency of processes, actions, information, and decisions among company units in support of key company wide goals. It emphasizes common understanding of purposes and goals and use of complementary measures and information to enable planning, tracking, analysis, and improvement at the company level, the key business process level, and the work unit level. Participative management is based on three principles:

- Senior management uses consensus and team review to deploy strategic priorities

Employees and their managers use facts and analysis to select vital strategies that they will use to close the critical strategic gaps.

- Employees verify systematically that their plans add up to close the strategic gaps

With respect to target setting, a superior negotiates with each individual to ensure the objectives set for each personal are realistic, reasonably within his or her control, and attainable. It is the task of the superiors to see that their subordinates understand clearly what exactly is expected of them ${ }_{*}$ how they are expected to go about achieving these personal objectives, and how their success will be measured. It has the advantage that there are no gaps between what individuals are prepared to do and what the Unil or organization as a whole must achieve, to push additional goals and expectations down to individuals to filll the gaps.

Furthermore, company D links rewards with achievement of personal targets; this implies that the company has expressed its willingness to reward in a positive manner. Decision making is based on reaching a consensus between the stiperior and the subordinate. It has the adwantage of being more democratic, and instilling in each employee some responsibility for their own learning and career development. The sales manager explained:

"Our management system operates on the principle that employees should make their own commitments to the company. Our senior managenent [...] identifies the vilal strategic gaps, ie. performance issues that require improvements; these issues can require incremental or dramatic improvements. They do not. however, tell us how we have to close these gaps. Teans design their plans and review the ir awn prograss. These teams also communicate with other teams to ensure alignment and coordination; our organization is perceived to be a network. Communication lines are vertical and horizontal, and especially informat. Employees are seen as partners, and they know what targets are realistic in their was coble of affecting responsibility for target achievement and improvement is put in the hare linked with the achievement of performance by employee participarion. Furthemore, our rewards personal targets." 


\section{STRATEGIC PLANNING}

\section{Involved parties}

'Strategic direction' involves the entire company but this broad level of participation is hierarchically stratified. It was found that all managerial levels of the organization participate but their responsibilities vary as do their relative commitments to the strategic plan and daily management tasks. The corporate 'strategic direction' representatives of the headquarters, the regional offices, and the worldwide product divisions are involved mainly in strategic planning for the company; the role of the local sales offices is limited to information gathering, giving feedback and strategy implementation. The marketing manager explained:

"... Whereas our senior management at the headquarters is charged with setting the mission and defining the objectives of the whole arganization, the line management negotiate with the senior management to establish goals that will signify the achievement of these goals. In other words, senior management is in charge of the mission and the objectives of the worldwide organization; but they do no tell us how we have to attain these goals. The regional line management negociate with them to establish goals that will signify the atainment of these goals. The regional tine management is charged with the formulation of she mission statement and the definition of the objectives of their sales region. The local managenent reams negotiate with the regional line management to signify the achievement of the se goals."

\section{Planning procedure}

"Strategic direction" or strategic planning is a top down process, and it is programmed formally. Target setting is accomplished by interchange between the various managerial levels of the company. This interchange is called 'catch ball' by the company. It was found that 'catch ball' is a disciplined maltilevel planning methodology for "tossing an idea around". The term describes a planning process where objectives and the means and measures to attain them are tossed back and forth between the layers in the management hierarchy until a consensus is reached. The planning procedure is part of the company's quality management system. The fundamentals include the planning process, information gathering, the process owners, the authorities, control, the links between sub processes, and the planning formats. Company D has formalized this process by setting official deadlines and checkpoints throughout the planning period. The marketing manager stated:

"Strategic direction is a scheduled rowtine process with planned review and adjustment periods. It is a thorough analysis of the customers, the suppliers, our strengths and weaknesses, and enwironmenial variables and their relationships. This analysis helps us to identify the root cause or causes of barriers to achieving the mission. We review the strategic plans anually, at which time management removes completed goals from the agenda and identify mew initiatives for the coming period. The company's planning methad ensures that line management can deploy the appropriate level of focus and resources to the assigned intitarives. The planning process is a participative process based on iterative planning sessions to field questions, clarify priorities, buld consensws and ensure that the strategies, objecrives and measures are well understood. This process is described in defail. The handbook "Strategic direction' includes the planning gudetines. It includes official deadlines and checkpoints through the planning period."

The handbook "Strategic direction" describes a planning system for translating the organization's mission and objectives into actionable and measurable strategies throughout the company. Some of the key elements are given below:

- Strategic planning is described as a managerial process consisting of a sequence of steps, i.e., sub processes, to transform market and company information into the "strategic direction' of the company. The critical processes are "strategic focus", "strategic audit", "infrastructure" including the business processes and 'business environment'. Each process is broken down into activities to describe the characteristics of critical processes. The important processes are: determination of current baseline position, validation of corporate mission, identification of current trends affecting the company, determination of customer needs, establishment of priorities, setting objectives for a period of five years, setting first years goals and objectives, time lines, audit processes and vehicles for first year goals.

- Inputs and outputs of the planning processes are described in the handbook "Strategic direction". It includes the relevant topics and offers key questions for gathering the required information, and describes tools and techniques that must be used for the audit, and the planning outcomes. The handbook "Strategric direction" also indicates who is responsible for these planning activities, the condition(s) under which the strategic planning process should take place and a time line for the planning activities. The links with operational 
planning are described in detail. It was found that the supervision on the planning procedure is done by the hiexarchy; an audit of planning activities is conducted yearly by an external consultancy firm.

The corporate mission, objectives and related strategy are transformed into local long term objectives and marketing tactics. This planning process, called Business planning, is also programmed formally. Its fundamentalls are described in the compary"s handbook "Business planning". 'Business planning' is broken down into ten steps. The 'ten-step' plan review includes a thorough analysis of: the statement of purpose. five-year objectives, customers and marketing channels, competition in the market segments, necessary product/services, the developmentpurchase plan, financial indicators, potential problems, and recommendation. This leads to step 10, develop the plan for the next fiscal year. The integrative business plans for a period of five years and the related short-term action plans at each levell have to be consistent with the overall strategy of the company.

\section{Planning process and its outcomes}

It was found that strategic planning or "strategic direction" begins by viewing the planning system as a whole. This planning process is used to establish the external boundaries of the company with respect to the environment it operates in. While not every organizational unit is required to develop a strategic plan, every unit is governed by a strategic plan. Subordinate strategic plans are subsets of higher anthority strategic plans. At the sales force organization, the lowest organizational level requiring a strategic plan is the local sales office. Below this point, only anmual business planning is employed. The sales manager explained:

"At our company, there are two levels of planning: strategic and annual planning. Strategic plamming looks outward to establish the context in which our company or the local sales office will operate with respect to the corporate mission. It is a frame of reference in which the corporate, the regional and the lacal managers define the purpose of their current business. The strasegic plans of the lower levels have to be approved by the higher authority. This is, for our sales office, the regional affice. Nor every organizational whit needs to develop a strategic plan. The local business units for instance, have a sirctegic plan for the ir operations, but every these organizational wnits are governed by the strategic plan of the sales office. The strategic plans of the local offices are a subset of corporate and regional strategic plans. The local office is the lowest level at the regional sales force organization that requires a long term plan. Regarding the business wnits and the lower managerial levels, only annul business planning is used."

At corporate level, the senior management is responsible for strategy formation. The outcome of strategy formation is called 'strategic direction'; it implies that the process owner has to formulate a strategic focus, to conduct a strategic audit, and to audit the infrastructure and the business environment. There are specific questions to be asked which relate to the following issues:

- What are the critical success factors?

- What is the company's mission?

- What are the company" objectives, in which the market segments is the company interested?

- What is the competitive behavior in these segments?

- What strategy will be used to differentiate the company from its competitors?

The answers on these questions are used to identify the core competencies of the company, to develop/validate the mission, to identify the major customer groupings and general customer requirements, and to establish performance targets. The outcome of the planning activities is a strategic plan including a mission statement. In other words, it articulates the organization's current "reason for being", and it includes a description of environmental conditions, of the resource constraints and of the core piocesses. The marketing manager stated:

"... The autcome of the strategic planning activities is a strategic plan This plan includes ont mission statement, and our objectives. Our mission statement addresses many business variables: what busthess are we in? What is our purpose? Who are our castomers? What are the core competencies of our buxiness? What are our primary product/services? What is our geographic domain? the plan also speciffes the environmental conditions, resonarce constraints and detail definitions of core business processes."

The company"s strategic direction is described in terms of the corporate mission, the objectives and the strategy. Related to this mission statement, the company has formulated various corporate objectives for a period of five years. These objectives can be classified into financial/accounting and nonfinancial targets. The company"s objectives are summarized below (see Figure D.4) 


\begin{abstract}
Financial/accounting objectives
i. cost and expenditure stucture: cost of sales, operating expenses, general and administrative expenses, and invertory levels

ii. balanced growth in revenues, earnings per share, and return on assets.
\end{abstract}

\title{
Nonfinancial objectives
}

iii. Corporate citizenship: "To honor our obligations to society by being an economic, intellectual and social asset to each nation, and to each community in which we operate by providing high-skill jobs, tax revenues, exports, other economic benefits derived from business activities, and benefits acrewing from activities in the environmental, educational, and philanthropic areas"

iv. "Rapidly to develop, manufacture and market technologically innovative products that meet consumers" needs."

Figure D.4 Overview of the corporate goals

Source: Internal document 1996

To attain these financial and nonfinancial goals, company $D$ has formulated a corporate strategy in which offering innovative and high quality products that meet customers" needs is the departure point. It appears that the concept of "value for money" is central, the company wants to offer innovative and high quality products with a highly competitive price. Nevertheless, the company is striving toward a cost and expenditure structure that will allow the company to lead the industry. From the interviews with managers of other computer firms, it appeared that the company is perceived as one of the most cost efficient companies. Although it has chosen for a diversified strategy, the company has succeeded in maintaining a cllear cosit and expenditure structure. According to our respondents, it is one of the computer firms that has succeeded in maintaining the cost structure of a small company despite expanding.

Headquarters formulates the strategic direction for its worldwide operations, and the worldwide product divisions translate the headquarters' strategic direction into long-term objectives and strategies for their business operations. The corporate objectives and strategy are translated into regional long term objectives and tactics for a period of three years. These objectives and tactics are stated in a three-year business plan that outlines:

- what the company and its organizational units are all about, i.e. the mission

- whom they will serve, i.e. the customers and the stakeholders

- what needs they will fulfill, i.e. the products and services

- how well they should perform, i.e. the objectives

The ten-step process for developing a three-year plan is also employed at the sales force organization. The country manager stated:

"... these plawning activities take place at the regional office and the local settements. Each year, the strategic plawing activities start with a strategic analysis. We use a detailed analytical approach. called the ten-step process for developing our three-year plan. This approach includes a lor of financial and cussomer analysis. We are very data driven, we use data to get started on a long term plan. You could call it 'management decisions by data'. The ten-step strategic analysis, conducted by our local management team and supervised by the regional office. inchudes activities related to a business enviromment audit. market segmentation, and a market positioning. The statement of purpose ... our business mission is defined based on the ourcomes of the strategic analysis and the corporate guidelines. This mission statement highlights the strategic direction of a specific organizational entity such as the regional office. my sales office, and the business units. Once the business mission is determined, the various customers and marketing channels are described. Based on this description, the market segments and the related customers" needs are identified. The competition in each market segment is also described. Based on the outcomes of the previously described planning activities, the long-term abjectives for a period of five years are ser. These objectives are quamtifiable. Our key objectives are related to revente, cost and expenditure structure, operating budgets and market share. These objectives are related to the local sales office, to the local business units, and to separate product lines. Examples of non-financial objectives include targets related to quality, such as customer satisfaction. commitment to achieving total quality, and process improvement." 
According to our respondents, the dominance of quantitative objectives can be explained by the background of the founders of the company. The marketing manager said:

"The founders of our company, $1 . . .1$, were both specialists "n measuremen equipment and financial engineers, their credo "to measure is to know" is still used in the entire organization."

Once the long term objectives for the sales organization are determined, each managerial level specifies the required marketing tactics for a local market. The country manager explained:

"... these marketing tactics include the decisions related the appropriate producf-narke combinations for the selected segments, the marketing chanmels, and market communication. Once the local markering tactics are formulated, a financial statement is made. Various financial analyzes are made to evaluate the feasibility of the long-tem objectives and related marketing tactics, to identify potential problems and to give suggestions. The output of previously described planning activities are used for formulating the annwal business plans of the local sales offices."

\section{SALES MANAGEMENT CONTROL}

\subsection{Planning, organizing and directing}

\section{Involved parties}

Regarding sales management planning at the local sales office level, it was found that the following parties are involved in the planning activities: the regional office, the general managers, and the local business unit managers who are directly involved in these operational planning activities.

\section{Planning procedure}

Operational planning refers to the company"s daily management component of the planning process which focuses on tactical issues, continuous improvement and short-term frames. This managerial process is a top down process and it is programmed formally. Its fundamentals are described in the company"s quality system. As strategic planning, its fundamentals" are described in the handbook "Business planning". It appeared that various levels of business planning processes can be distinguished: the corporate level, the level of worldwide product divisions, the regional offices, and the local offices. The participants, their inputs and outputs, and their linking processes are described in a handbook about business planning. The outcomes of the annual business planning are described in two deployment matrices: "Business fundamentals' and the 'Hoshin' for each unit or level. These two documents are used to communicate the objectives, the priorities, and the logic behind the planning.

'Business fundamentals' is a one-year plan for achieving objectives developed in conjunction with the management"s choice of specific targets and means. These are applicable wo every function within the company. Figure D.5 outlines the basic format of a 'business fundamentals' plan. It is used to document the manager's commitment to support the business objectives. These daily management tables include information that aims to assist in

- identifying performance measures for customer satisfaction

identifying the key business processes that deliver customer requirements

establishing process targets and control values

developing employees to improve and control the key processes

studying the actual results and standardize

documenting financial performance: 


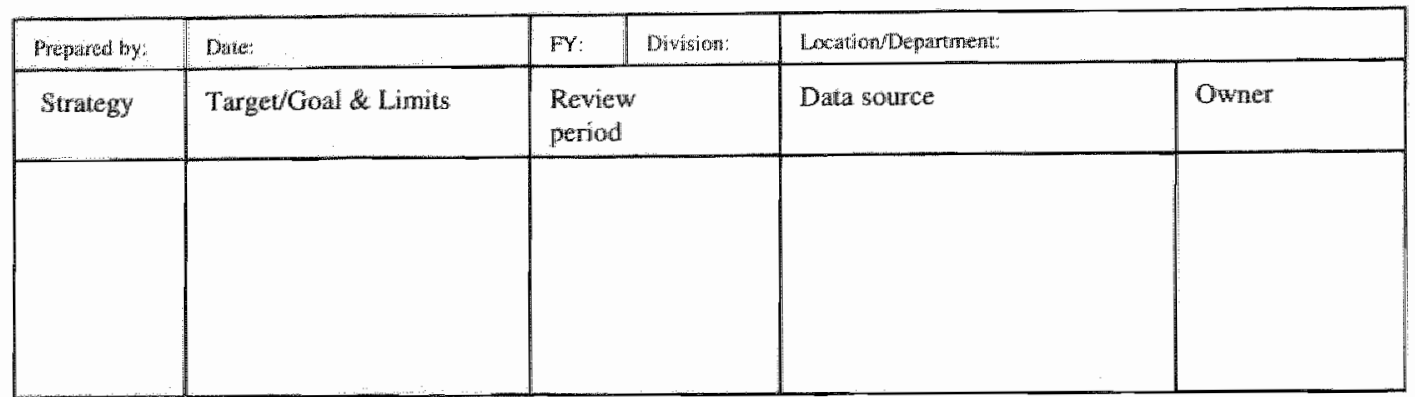

Figune D.5 The standardized table of a "Business findamentals"

Source: derived from internal documents

The column 'Strategy' is used to mark key performance areas for concentrated effort; these are issues critical to the health of today's business. Examples of such issues are cost effectiveness, customer satisfaction and commitment to employees. The column "Target/Goal \& Limits' includes one or more target statements per strategy. A target statement can be established by using an objective, such as a cost reduction of 20 percent, and a limit. The standard format for 'Business fundamentals' includes information concerning the review period, the data source and the owner. The hierarchy of the "Business fundamentals' is described in "Linkage tables". Such tables are used to show the linkages between the 'Business fundamentals' at the different organizational levels.

Company D uses a deployment matrix, called "Hoshin', to document a manager's commitment to the breakthrough objectives. It is a one-year plan for achieving one or more 'breakthrough'-objectives in conjunction with the management's choice of specific targets and means. According to our respondents, these "breakthrough" -objectives focus on:

- improwing the output and effectiveness of existing processes, e.g. customer satisfaction surveys among customers and business partners may lead to process improvements

- initiating new processes

The standard planning format of a "Hoshin" is outlined in Figure D.6. This table includes the identity of the business unit the author and owner of the plan, a column to list each annual objective and its goal, a column to reference the number of each strategy to achieve the objective, a column to record the strategies and the owner of the strategy, and a column to list the performance measures for each strategy.

\begin{tabular}{|l|l|l|l|l|}
\hline Prepared by: & Datc: & Fiscal year & Division & Location/departanent: \\
\hline Simation: & No. & Strategy (owner) & Performance measure \\
\hline Objective & & & \\
\hline Target/goal & & & \\
\hline & & & & \\
\hline
\end{tabular}

Figure D.6

The standardized table of a Hoshin

Source: derived from internal docunnents 
It was found that employees receive two or three "Hoshin" objectives that require significant changes in process or structure. Examples of such objectives are define plans for 10 per cent increase in customer satisfaction from (dare) to (date)'. Such an objective points to the specific performance gap that must be closed. 'Strategy" refers to the actions that lead managers to the objectives; these strategies are formulated to close the performance gap on a managers's understanding of the situation. Performance measures are the metrics used to quantify the degree to which a manager is meeting the stated objectives. Targetgoal refers to numeric values associated with the performance indicators. The marketing manager stated:

"Business fundamentals and Hoshins. As I stated earlier, there are standardized plamwing formats for the se documents with a standardized vocabulary. The use of standardized vocabulary is a powerful manugement tool. The same vocabulary is used by managers and their subordinates at each level of the orgunization. Its purpose it to increase the quality and speed with which we can communicate and negotiate our local plans. Regarding Hoshin, there are four basic concepts. First, we have 'objective'. The colurm 'objective" usually includes two or three objectives that require significam changes in process or structure. These objectives are used to demonstrate the specific performance gaps that must be closed. The colwan 'strategy' is used to identify the actions that lead us to the objectives. I and the other managers develop these strategies to close the performance gap based on our understanding of the situation. We are in charge of goal attaimment: this implies that we have to develop appropriate actions to achieve the prederermined objectives. The extent to which we meet our stated objectives is measured by specific metrics. These metrics are developed by the process owners. The performance measures are used to quantify the degree to which we are meeting the stated objectives. There is also a column called "target/goal', which is used to state the mumeric values or goals associated with the metrics."

The contents of the 'Business fundamentals' and 'Hoshin' of a department or a branch are summarized in an action plan. An action or implementation plan is used to demonstrate how strategies will be implemented. It includes information concerning the following questions. What steps and actions are needed first? What activities can be done simultaneously? What are the contingency plans? From the interviews it appeared that the action plan also includes a written document. The standard planning format of an action plan is outlined in Figure D.7

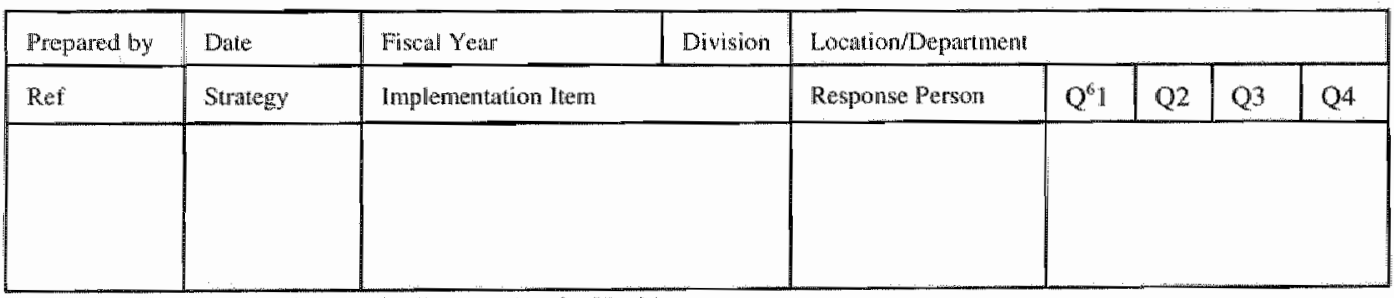

Figure D.7

The standardized fable of a Hoshin

Source: derived from internal documents

The standardized format used to document action plans generally include certain pieces of information concerning:
- the identity of the business unit
- the author and owner of the action plan
- the indicators and goals.
- a column to list each objective/strategy
- a column to list the implementation items, i.e. the activities, tasks, actions and means to achicve the objective/strategy
- a column to list the responsible employee per implementation item
- a column to establish a time line or deadline for each activity, reporting formats, and progress reviews

\section{Planning process and its outcomes}
The purpose of the company"s operational planning system is to develop goal consensus throughout the whole organization. The annual policy is deployed throughout the organization using participative planning; the negotiation process is based on a fact-based, inter-level negotiation system, called "catclin ball'. Once the senior management defines the key objectives, they are cascaded to the next layer of the management. 
The senior managers communicate vertically the vital business objectives and their indicators to all employes who can make a quantitative contribution. The individuals who are closest to the business define the most appropriate action plans. In selecting action plans, direct reports are careful to take into account their subordinates" input as well as that of their peers. The next step includes the megotiation of the means and measures. Using iterative planning sessions, the employees develop and coordinate their strategies and indicators with peers and managers; they participate in a back-and-forth discussion until they agree on the essence of the action plan, the targets, and how the plan will play out in their business unit.

The company ensures the vertical integration of plans by linking its activities downward in an endsmeans fashion. The desired outcome of each layer of the hierarchy becomes the target for the means at the next lower level of the hierarchy. In other words, the objectives are received from above and the strategies are designed from below and sideways to achieve these objectives. "Business fundamentals" and "Hoshin". the two standardized annual deployment matrices used, help the employees to link the local objectives to the assumptions and long term strategic issues. This information not only helps in communicating the operational objectives to others in the organization but it also serves as a record of the key assumptions to be reviewed in the next operational planning cycle. These deployment matrices are used to develop action plans. The marketing manager explained:

"... the planning system is used to develop short term action plans. 'Business fundamentals', at each level to be consistent with the overall strategy by linking these plans to the measures derived from the objectives established by the higher managers. An annual policy is detemined to support the strategic direction. The 'Business fundantentals' and 'Hoshiss' of the superiors are velated directly to those of their subordinates. The operational planning process is highly participatory. vertical, top down processes are used as a coordinating activity in the organization. It is a "catch ball' process in which it is necessary to reach the consensus for targett and means berween varying levels of the organization. The handbook "Leadership and Participation 'prowides us with tools and techniques to stimulate subordinates to participate in decisionmaking. Participation encourages employees to resolve potential implementation pitfalls through dialogue and consensus. I can assure you that targets are not imposed by the supervisors, but decision-making is based primarily on dialogue and wonsensus. If it is not possible to attain a consensus, than the superior decides alone but this is rarely the case."

Action plans refer to principal company-level drivers, derived from strategic and operational planning. These plans are set to accomplish those things the company must do well for its strategy to succeed. Action plan development appears to be the critical stage in planning when general strategies and goals are made specific so that effective company wide understanding and deployment are possible. The deployment of action plans requires analysis of overall resource needs and creation of aligned measures for all work units. This is done by using the deployment matrices.

Since targets and means will be determined individtally, it appears necessary and important to identify the relationships between targets. Additionally, it is necessary and important to identify the relationships between the targets and means of each level and targets between the different levels of the organization. Depending on the particular organizational unit, the means may differ from other units that share the same targets. Customarily, there are a few means for each target. It is consequential to determine both the targets and means for the Business fundamental and the Hoshin. The hierarchical management levels, such as top management and middle management, must determine the 'Business fundamentals" and "Hoshin" according to the above rules.

The managers at each level of the hierarchy consolidate local plans to verify that these plans are sufficient to achieve their superior"s stated contribution. The executives go back with the consolidated plans to their superiors. In these meetings, the executives talk about how they are going to deploy their objective/strategy and what additional ones should be added to contribute to this objective/strategy. The final plans are communicated upward to ensure organization capability. The marketing manager stated:

"Our planning process takes place as follows. Each year our senior managenent communicate their key objecthes and the related indicarons to their subondinates who can make a quantitative contribution to the achievement of these objectives. The subordinates develop and negotiate their plans to support their superior's stated contribution. In other words, the superiors communicate measurable objectives, and the subordinates have to close the gaps. This takes place through iterative planning sessions. Whereas the coumpry manager organizes planming sessions with the business unit managers, the business unit managers organize sessions with their people. During these sessions, it is important that everyone understands and accepts the business objectives. This often implies going back for explanation and clarification. Once the 
participanis of the discussion agree on the essence of the plan, the langers, and its implementation, the execurives consolidate the plans of their subordinates and go back with their own direct report, this is the consolidated plan. The managers from the botom of our sales office upward make a consolidated matrix covering the groups for which they are responsible. They ralk with their superiors about how they are going to deploy the objective/strategy and what new ones should be added to contribute to this. Later, the final plans are commuicated upward to ensure organizational capability"

It was found that the objectives are primarily of a quantitative nature. The main objectives are related to revenue, costs, and market share; the related targets/goals are expressed in quantitative terms. With respect to the country managers, it was found that these line managers have primarily 'profit \& loss' responsibility for their local sales office. Their key performance areas are "order volume", "profit", and 'costs'. 'Profit' is used for business units that are highly centralized. The printing business, for instance, is highly centralized. The worldwide operations are based on selling through dealers; the market is very transparent. It appears that the 'printing' business is a very global business in which price differences can cause immediately 'grey import'. The printing division employs strict price guidelines on the local sales. It implies that the local management has no impact on the selling price nor on the selling costs including the infrastructure. In these cases, the country managers have cost responsibility instead of profit responsibility. There is profit responsibility for e.g. the business unit 'services' including maintenance. services and $\mathrm{TT}$-consultancy.

Regarding business unit rnanagers, there is a similar system. The performance areas are also rellated to 'order volume', 'profit' and 'cost". "Profit" is used in the case of business units in which there is some freedom to set selling prices; 'cost' is used in business units in which the selling price is imposed by the product division. Within the business units, the performance areas are related to performance relative to effectiveness and efficiency measures and indicators. Three types of performance are addressed:

- operational, including product and service quality

- customer-related

- financial and marketplace

Regarding product and service quality, the performance areas refer to operational performance relative to measures and indicators of product and service requirements derived from customer preference information. Examples include reliability, on-time delivery, defect levels, and service response time. Customer-related performance refers to performance relative to measures and indicators of customers" perceptions, reactions, and behaviors. Examples include customer retention, complaints, customer survey results. Financial and marketplace performance refers to performance using measures of cost and revenue, including asset utilization, order volume, and market share.

It was found that the desired measurable outcome of each level in the hierarchy becomes the target for the means at the next lower level; objectives are received from above and strategies (means) are designed from below and sideways to attain these objectives. Examples of qualitative objectives include "attaining an ISO 9000 certification" or 'improving employee participation in managerial decisionmaking". The operational business plan contains a summary of each objective along with the narne of the objective"s owner, an implementation strategy and the specific improvement focus i.e. competitive pronites related to costs, quality and cycle time. The local line management is empowered to formulate their 'Business fundamentals' and 'Hoshins" to meet the country manager's targets. It was found that the business targets are generally perceiwed as ambitious but realistic and feasible. The marketing manager explained:

"[...] each participant of the local planning activities is expected to contribute to the attainment of one or more targets, and then pass it to we next individual. Consensus in farget sething is acheved with minimal conflict and maximal participation. It also helps to set targets which are feasible."

\title{
5.2 Performance measurement
}

\author{
Measures \\ It was found that the measures stated in the target seting of the "Business fundamentalls" and "Hoshins" \\ of the country managers and their line managers are used as performance measures. These performance \\ measures are of a quantitative and primarily a financial nature. According to the country manager,
}


"... performance measuremen occurs bottom-up and the outcomes of each arganizational level are aggregated These aggregations require quantifiable data. Regarding the quantitative measures, it appears that these measures are related directly to revenue, unit sold, costs and expenditures. 'Qualiry' is measured by customer satisfaction surveys. Regarding customer complainds, the nature and the number of complaints are registered."

\section{Measuring organizational performance}

Measurement is performed by each level of management. Thus, from bottom to top, all members related to the 'Business fundamentalls' and "Hoshin' must observe the performance measure for each level. From the interviews with our respondents it appeared that financial and sales performance is measured on a daily base. A measurement, called "quota achievement", is done by an automated information system; this performance measurement is focused on orders, i.e. number of orders and revenue. The outcomes of this performance measurement are reported on a monthly and a quarterly base. The local sales affice also makes a final performance report at the end of a fiscal year.

Qualitatiwe performance, such as customer satisfaction and the QMS audit, is measured at least once a year. For instance, customer satisfaction surveys are conducted once a year. These surveys are used to measure the qualitative aspects of sales (i.e., the quality of customer relationships, satisfaction related to products and (support) services, and product and service quality). It appears that these surveys are conducted among business partners, distributors and end-users. Further qualitative measures include "customer complaint" and "education level of employees'. Regarding the QMS-audit, it was found that the sales offices are andited once a year.

\subsection{Performance evaluation}

\section{Performance review tables}

The outcomes of the performance measurement are used for the review tables. These tables help an objective's owner to evaluate progress-to-plans, and to evaluate progress-to-benchmarks. These evaluations are based on a gap analysis, a root cause analysis, and an annual review. The Belgian sales manager explained the use of these review tables:

"As an objective's owner, I use a progress report, called 'review table". This review table charts the achievements of the owner's action programs on a weekly and a monthly base. These reports are extremely detailed and document current achievement versus planned levels of achevemen by data, and any discrepancies between planned and actual progress. The review tables are generally reported once a month. $U_{p}$ to now, the se management reports have been generated manually, in the mear future these reports will be generated automatically. There are also review tables generated on a quarterly and a yearly base; these review tables are less detailed but they are also used to demonstrate the progress-to-plans."

The review table has a standardized format that is used to report progress on a weekly, monthly, quarterly and a yearly basis. It includes information concerning the objective/strategy, progress indicators and actual performance, a summary of the analysis of deviations, and the implications for the future. The progress indicators report the current performance. The standard planning format of a review table is outlined in Figure D.8.

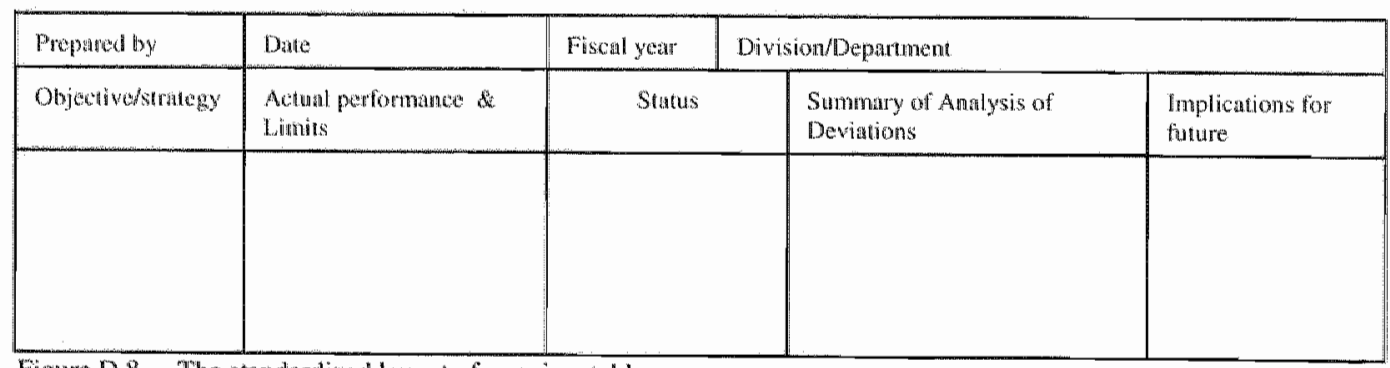

Figure D.8 The standardized layout of a review table Source: derived from internal documents 
If was found that the company uses a flag system to track progress throughout the year. A flag is used to demonstrate to the appropriate manager that sonething or someone needs attention. Three flag colors are used to show progress against schedule: "green" for "on target", "yellow" lor "bohind plan", and "red" for "far below expectations".

With regard to the red flag, the appropriate parties can focus quickly on the problem and initiate comective action to keep things on track. Meanwhile, the higher layers of the hieranchy receive regular and Trequent performance reports. At any point in time, the superiors know precisely what is working and how quickly their subordinates make progress. Each deviation from plan is perceived as critical and it receives the focused attention of the appropriate parties. The Belgian marketing manager stated:

"For our quarterly and annually reviews, we use a flag system based on three colors. Let me explain this. To illustrate the discrepancies, our company uses three colors: green, yellow, and red. These colors are used to visualize and compare the current state against the desired or optimal state. "Green" indicates that the progress is as planned, whereas "yellow" indicates that there is a delay but it is not critical. The color 'red' indicates that there is a warning delay. If the color of an objective rewains 'red'. then the discrepancy between planned and actual progress is 'crinical'. It appears that the 'linkage table' is a useful tool to track the objective's owner that has caused the delay. Each layer of the hierarchy. from local team leader to CEO, receives regular and frequent reports on progress-to-plans. They know precisely whar is working and how quickly their employees are making progress. Any deviation from plan is perceived as critical. Such deviations therefore recerve focused attention."

As for breakthrough improvement, the standardized Hoshins are used. Company D also uses here a flag system to indicate progress-to-plans based on three colors: "green' for "on target", "yellow' for "behind plan', and "red" for 'far below expectations".

\section{Performance review-meeting cycle}

The company has formalized its review process; these performance reviews are related to continuous improvement, i.e. daily management, and to breakthrough improvement. Overall, reviews start at the team level and roll up to the corporate level. Whereas expectations are communicated downwards during the deployment phase of operational planning, performance reviews flown from the bottom of the organization upward to the senior management of the headiquarters.

On a level-by-level basis, managers meet with their direct superior and report upward any significant deviations from plan. As for daily management, this process is a bottom-up review consisting of four pieces:

weekly reviews
monthly reviews
- consolidated quarterly reports
an annual review

The weekly reviews are used to identify problems to progress and evaluate the need for and assist with early corrective action. These reviews take place within a department or a branch. The monthly reviews are used to encourage adherence to the plan and timely corrective action. These reviews take place during the local management meetings.

The quarterly reviews are used by the company to consolidate the individual review tables vertically and horizontally to assess their collective impact on the strategy and group objectives. The consolidated quarterly reports of the country managers, for instance, are used to assess the collective impact of a local sales office on the strategy and the regional objectives. At this point, the key obstacles to progress are explained. These reports are discussed with the regional office. The consolidated quarterly reports of the business unit managers assess the collective impact of the business unit on the strategy and regional objectives. These reports are discussed at the local level during management meetings and at the regional level during meetings with the representatives of the worldwide product divisions. Finally, the annual audit is used to evaluate the effect of the actions plan results on the strategy measures. It implies that the reliability of the operational planning and the deploynent system is improved. New developments in the market environment that might have an impact on existing targets are incorporated into the plan, and issues for the next planning cycle are identified. 
With respect to breakthrough improvement, the performance review generally takes place on a quarterly base. These reviews are used to consolidate the individual Hostin tables vertically and horizontally to atsisess their collective impact on the strategy and group objectives.

Regarding the QMS audit, it appears that the local sales units conduct a self-assessment concerning the implementation of QMS in the local business practices. This self-assessment includes an evaluation of the organizational performance with the five dimensions:

- Strategic direction
- Pusiness planning
- Process management
- Lecess improvement
-

Each dimension is evaluated in terms of a score between 1 to 10 . The audit report is sent to the headquarters. The headquarters assigns an external auditor for assessing the local QMS practices again. The local QMS practices are evaluated based on the local and the auditor's reports. It was found that the organizational performance in terms of QMS is also an important evaluation device for assessing sales perfformance.

\subsection{Feedback and rewarding}

\section{Feedback}

The company under investigation documents and standardizes its feedback system using process maps and time lines. The managers review their group results with the next higher level of management. Feedback can also be received via e-mail, wia the automated management system, via informal meetings or via management reports.

From our interviews it was found that evaluative feedback on organizational and individual performance is provided on a regular base. The actwal results are the starting point in the monthly reviews. The regional office examines the performance reports of its sales office. The emphasis is on the root cause analysis of deviations from plan to identify the necessary adjustments to the plan. The country managers receive feedback on their performance based on this analysis. The facts are used and analyzed to determine corrective actions. If the country manager decides to change the initial focus of the plan, then this executive has to revaluate priorities, to assign an owner to the new focus area, to reallocate resources, and define the details. The final step is to communicate the change in direction so that others can modify their action plans as necessary, i.e. corrective actions. The layers of the management that are affected directly by the revisions to plans negotiate these changes to ensure alignment within and across functions. The marketing manager explained:

"Once a month, our achieved results are discussed with the regronal office. The se monthly reviews are used to identify 'problems' to progress, and to encourage timely correcrive action. The review tables indicates the progress-lo-plans against the time schedule; numerical indicators are displayed to show progress-to. plans. The deviations from plan are analyzed in detail to determine the causes and ro identify the necessary corrective action. The executive can decide to change his or her action plan based on the outcomes of we root cawse analysis. If a plan is changed, then the executive has to reevaluate his or her priorities. Besides, he or she has to assign an owner for the new focus area. It may also amply that the resources have to be reallocated tinally, he or she has to define the details. Sach changes often have an impact at higher and lower layers of the hierarchy. The layers of the hierarchy that are directly affected by the revisions negociate these changes to ensure alignment within and across functions. If for instance, a country phanager has to pursue anew opportunity in the large system segment then this executive has to negotiate with his or her superior at the regional level and with the appropriate business unit manager."

Each quarter there are 'follow-up' meeting in which the progress of 'quota achievement" is discussed; the focus is on deviations from plan. It is a formal roll up, right up to the senior management of the headquarters. Each layer of the hierarchy rolls up its piece of the plan. The managers report only on their whole plans; details are only reported on exceptions. These review reports include primarily information concerning key objectives and the related indicators by the time it gets to the senior management. Each layer of the hierarchy reviews their performance with the next layer. This continues until results and unsolved issues are reviewed by the senior management. The marketing manager stated: 


\begin{abstract}
"Each quarter, we have a formal performance revew. We conduct quarterly reviews to consolidate the progress reports. There is a formal calendar for it. This review process is a formal roll wp, right up to our sentor management team in [...]. Each manager has to repont on his or her plan: details are only reported or exceptions. Each manager reviews his or her group results with the superior. This contimues until the actual results and unsolved problems are reviewed by our senior managentent in $\left[\ldots I^{\text {th }}\right.$
\end{abstract}

From our respondents, it appeared that the target achievements of business unit managers are discussed formally on a monthly and a quarterly base. These discussions take place at the warious managerial levels of the organization. Our respondents stated that if a target is achieved, the target walue is accordingly adjusted. The objective's owner has to initiate corrective action(s). Existing target values might be low or activities for the means might be highly effective due to unexpected and uncontrollable circumstances. In both cases, it is significant to realize why and how the targets were achieved. The case may be that the Garget values do not require adjustment.

Regarding long term performance, it was found that operational planning and control systems are used to evaluate to which extent long term objectives are attained. The outcomes of strategic planning cover a planning period of five years: the targets for the first year are described in detail. The planned outcomes for the first year in the strategic plan are compared with the actual results of that year to assess long term organizational performance. The differences between planned and actual results are analyzed and extrapolated; then the progress in strategy implementation is evaluated. The outcomes of the analysis of deviation are used to identify and initiate corrective action.

\title{
Rewarding
}

The employees, except for the salespeople and business unit managers, generally receive a fixed salary. All employees are awarded stock options and profit sharing to motivate and reward long term performance. It was found that there is a profit sharing, called 'Cash Profit Sharing'; this bonus is at percentage of the corporate profit. There are also bonuses for excellent "quality" performance of an individual, a team or a business unit. It allso appears that the company does not use a system of careen development for individual employees. Employees are free to improve their knowledge and management skills; but they are responsible for making their way in the company.

With respect to business unit managers and their salespersons, it was found that there is a worldwide performance based reward system and recognition programs. People working in sales are offered individual incentives and commissions that constituted a large part of their total income. "There are corporate guidelines consisting of ten worldwide reward schemes, these schemes are related to specific sales positions. The extent to which rewards are variable depends on sales experience and individual choices. For instance, new employees or salespersons that are exploiting a new market receive a fixed salary. Second, experienced sales persons generally have performance based rewards. The key performance indicator is quota achievement. The variable part of the reward consist of a financial incentive. If the salespersons achieve their individual sales targets, then 100 percent of the financial incentive is paid; yet once the sales quota is acheved, the financial incentive is limited. This system is used to reduce the impact of excessive sales that are the result of unexpected and uncontrollable factors. For instance, if a salesperson achieves 110 per cent of the original sales quota then he or she receives a financial incentive of 105 per cent, i.e. 100 per cent of the target achievement and 50 per cent of the additional sales. It was also found that various reward systems are used: i.e. 70 per cent is fixed, and 25 per cent based on quota achievement, 80 percent is fixed and 20 per cent is based on quota achievement, and 85 per cent fixed and 15 per cent based on quota achievement. Finally there is a system of team-based rewards. The variable part of the reward is based on team performance. Another form of incentives are based on sales contests; excellent sales persons and sales teams are rewarded. Contest prizes include cash, travel, and merchandise.

With respect to recognition programs, it appears that the company employs a wide variety of incentive plans. Some are small-time: employee of the month type of things, or short-term blitzes for the benefit of specific products. The elite makers-of-profit get treated like conquering heroes. Furthermore, there is the High Achievers Club, the top 20 per cent of the sales force. This incentive is a trip for the winner and their significant other; but the real draw of the High Achievers Club is bragging rights. It appears that there is a certain status that sales people feel in achieving the High Achievers Club; members get name tags and a little star beside it for the number of times that they have attended. The highest level of recognition is 'The President's Club'. The criteria are a little different, in that it has to do with 
teamwork, customer satisfaction, and sales performance. Members of this club are all made up of High Achicvers; but they must be recommended by their senior management to go to that. The incentive is a very exclusive dinner with the president of the company. The High Achievers and the President's Club is perceived as a constant positive re-enforcement, encouraging sales people face-to-face when they are doing well, gets them motivated a long way.

It was found that the country managers have a straight salary. These salaries are comparable with the ones of top managers in the industry. Company D uses a standard scale of salary for its country managers; the individual stiaight-salary plans are evaluated once a year. The evaluation devices are total order volume, customer satisfaction, employee satisfaction, the outcome of the frnancial audit, and the outcome of the QMS audit; there are also some subjective criteria, e.g. general attitude, cooperation in project teams, reliability. A group of EMEA representatives use these devices to evaluate the overall performance of the country managers; the outcome is a ranking between 1, i.e. poor performers, to 5 , excellent performers. If a country manager has an excessive order volume which is not the result of personal effort but of uncontroliable and unexpected factors then subjective criteria become much more important as evaluation devices; thus, the impact of excessive sales as a result of factors outside the control of the country manager is reduced. The outcome of this evaluation is used to determine whether to raise the salary of country manager.

\section{TASK CONTROL}

It appears that the company employs various task control devices. These control devices are related to standardization of work processes, standardization of outputs, standardization of skills, and assessing the individual performance of employees.

Regarding work processes, it was found that the vital business processes are highly standardized using QMS. According to the Belgian respondents, at least 80 percent of the business processes are described in maps. The main characteristics are described for each critical process. The processes are also broken down into sub processes and process owners are assigned for each (sub)process. The process owners are not only responsible for the execution of their process; they also carry out the actions which form their process. From the interviews it also appeared that the concept 'process owner' specifies who is responsible for the (sub)process. Furthermore, 'authorities' are described. The 'authorities' make clear how the process is specified and provide the basis for decision-making authority. Our respondents stated that the "authorities" are found in documented procedures and instruction, as well in job descriptions and codes of practices. The condition(s) under which the process, the time of process activation and the links with other (sub)processes are described in the process maps; the follow-up of the processes is accomplished by the process owners.

Standardization of outputs is accomplished primarily using Hoshin Kanri and Management by objectives": whereas Hoshin Kanri places more emphasis on process than on outcome, "Management by Objectives" focuses on outcome. It appears that the current IT-market with short product-life cycles is forcing the company to invest heavily in the skills and knowledge of its employees. The company, therefore, orgmizes internal and external training programs related to product management and QMS skills and knowledge. Assessment of individual performance is one of the main task control devices. At the company, each employee has a position plan with standards or targets. Some of these targets are related to a set of business fundamentals that a particular person owns, other targets relate to the annual "Hoshin" commitments. The performance of individuals is assessed by the individual and his or her superior; this assessment takes place during a formal meeting. Such meetings are generally organized at least once a year. Salespeople have various formal meetings with their superior; during such a face-to-face conversation, the effect of uncontrollable and unexpected circumstances that have had an impact on individual performance are taken into account. If the market demand, for instance, drops dramatically then the supervisor will decide to lower the sales quota. Our respondents also stated that sales quota will not be increased if market demand increases strongly. Company $D$ employs this business practice to motivate the sallespersons.

\section{Notes Case Study IV}

1..Process management, total participation of employees, planning process, process management and the improvenent cycle. 
2. "Hoshin" means compass, or pointing the direction" "kanr" mears management or control. It is a process or technique for large scale planning which helps focus nearly all of an organzation on the key activities which contribute to a specific goal. Hoshin Kanri, also called "Policy deployment" or "Management by Planining", was developed in Japan to communicate company policy to everyone in the fim. In 1965, Toyota toveloped systematized policies, policy management and deployment, cross-functional management, process targets, means, and measures. Bridgestone The followed with an outline of the Hoshia $K$ anni mathod. Hoshn Kanr bectane accepted worldwide as a policy deploynent method in 1976.

3. The QMS and the ISO 9000 handbooks are two diffentent types of mandagement handbooks

4. Taken from internal documents and annual reponts, the corporate mission is " "to create information products what accelerate the advancement of krowledge and improve the effectiveness of people and organization."

5. 1.e. the process, the inpat and outputs, the process owners and their athorities, the controls, and the links berween processes.

6.01 refers to the furst quanter of a year.

7.i.e. related to contimus improventent 


\section{References}

Agarwal, A. and S.N. Ramaswami (1993) "Marketing controls and Employee Responses: The Moderating Role of Task Characteristics", Joumal of Academy of Marketing Science 21 (fall): 293-306

Albaum, G. and R.A.Peterson (1984) "Empinical research in international marketing", Jouval of Intemational Business Studies, $161-173$

Aldrich, H.E. (1979) Organizations and Environments, Englewood Cliffs NJ: Prentice-Hall

Amey, L. (1979) Budget Planning and Contral Systerns. London: Pitman

Arderson, R.E. (1973) "Customer dissatisfaction: the effect of disconfirmed expectancy on perceived product performance", Journal of Marketing Research, 10, 38-44

Anderson, E. and R.L. Olivier (1987) "Perspectives in Behavior-Based versus Outcome-Based Salesforce Control Systemss", Jounud of Marketing 51 (October), 76-88

Anderson, W.T. and Hoyer, W. D. (1991), "Marketing in the Age of Intelligence: The Case for Control" European Jounal of Marketing, 25(8), 32-54.

Ansari, S. (1989) "A behavional interpretation of decentralization", in Behavioral Accounting edited by $G$. Sicgel and H. Ramanauskas-Marconi, 232-268, Cincinnati: South-Western Publishing

Anthony, R.N. (1965) Planning and Control Systems, Boston: Harvard University School Press

Anthony, R.N. (1988) The mandgenent control function, Boston: Harvard University School Press

Anthony, R.N. and J. Dearden (1980), Management Control Systems, Homewood: Richard D. Irwin Inc.

Anthony, R. N... I. Dearden, and V. Govindarajan (1992) Management Control Systems, Homewood, IL: Irwin

Anthony, R.N. and D. W. Young (1984) Management Control in Nomprofit Organizations, Homewood: Richard D. Irwin

Appleton, J. (1995) "Analyzing qualitative interview data: addressing issues of validity and reliability" Jounal of Advanced Nursing 22(January), 993-997

Archer, S. and D.T. Otley (1991) "Strategy, Structure, Planning and Control Systems and Performance Evaluation-Rumenco Ltd ${ }^{*}$, Management Accounting Research, 263-303

Argyris, C. (1953), "Human Problems with Budgets", Harvard Business Review 31(January/Februari): 97110

Argytis, C. (1969) Integrating the Individual and the Orgamization, New York: Willey

Arrow, K. (1964) "Control in Large Organizations", Management Science, 10(April), 397-408

Asseal, H. (1985) Marketing Management, New York: Kent Publishing

Baden-Fuller, C. and J.M. Stopford (1994) Rejuvenating the mature business, Boston M.A.: Harvard Business School Preșs

Baliga, B.R. and A.M. Jaeger (1984) "Multinational corporations: control systems and delegation issues, Joumal of International Business Studies (Fall), 2540

Banker, R.D., G. Potter and R.G. Schroeder (1993) "Reporting Manufacturing Performance Measures 10 Workers: An Enpirical Study", Jownal of Management Accounting Research, 33-55

Banker, R.D. Seok-Young, L., G. Potter and D. Srinivasan (1996) "Contextual analysis of performance impacts of outcome-based incentive compensation", Academy of Management Jaumal, 39(4), $920-948$

Banks, R.L. and S.C., Wheelwright (1979), "Operations versus strategy - trading tomorrow for today", Han ard Business Raview, May-June, I12-120

Buss. F.M. (1963) "Marketing Research Expendittres: A Decision Model," Joumal of Business $36: 1$ (Jantiany) $77-90$

Buteson. J.E.G. (1989) Managing Services Marketing: Text and Reading, Chicago: The Dryden Press

Batumler, J.V. (1971) "Defined Criteria of Performance in Organizational Control", Administrafive Science Quarterly, 11 (December), $340-349$

Bavon, A. (1995) "Innovations in performance measurement systems: a comparative perspective", Interno tional Journal for Public Administration, $18(283), \mathrm{pp} .491-519$

Buhrman. D.N. and W.D. Perrault jr. (1984) "A Role Stress Model of the Performance and Satisfation of Industrial Salespeople", Journal of Marketing, 48(Fall), 9-21

Berliner. J.S. (1957) Factory and manager in the USSR, Canbridge (Mass): Harvard Business Studies

Berry, LL (1995) "Relationship Marketing of Services - Growing Interest, Energing Perspectives", Jommal of the Academy of Marketing Science, 23(4), 236-245.

Berty, L.L., V. Zeitham and A. Parasuraman (1991) "The Service Marketing Audit", Joumal of Academy of Marketing Science, 19,3541 .

Berry. A.J. J. Broadbent and D. Otley (1995) Managenent Control: Theories, Issues and Practices, Houndrnills. Macmillan Press LTD

Best, R.J. (1997) Market-Based Management, Englewood Cliff: Prentice Hall

Bhaskar, K.N. and R.J.W. Housden (1985) Accounting Information Systems and Data Processing, Oxford: Heinemann

Biemans, W. G. (1990) "De voor- en nadelen van case research", Tijdschrift voor Marketing, 6, 61-72

Birnberg, J.G. Turopolec, L. and S.M. Young (1983) "The Organizational Context of Accounting", Accoum ing. Organizations and Society $8,111-129$

Bimberg, J.G., and Snodgrass, C (1988) "Culture and Control: a field study", Accounting, Organizations and Sociery, $13(5), 447-464$

Blackburi, R. and B. Rosen (1993) "Total quality and human resources management: Lessons leamed from Baldrige Award-winning companies," Academy of Management Executive $7(3), 35-51$ 

Blalock. H.(1991) "Are there really any constructive alternatives to causal modeling?" Sociological Method
ology $21,325-335$

Blau, P. and W.R. Scont (1962) Famal Orgamizations, San Francisco CA Chandler

Blau, P. and R.A. Schoemhert (1971) The Structure of Organzations. New York: Basic Books

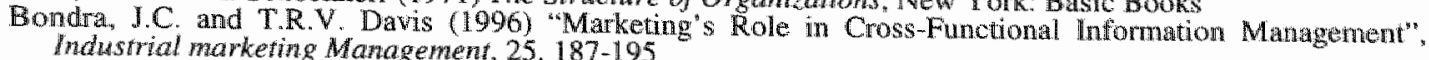
Bonoma, T.V. (1985) "Case research in marketing: opportunities, problems and a process", Journal of
Marketing Research 22, 199-208

Bonoma, T.V. and Clarke, B.H.(1988): Marketing Performance Assessment, Mass: Harward Business School Press

Bom, G. (1994) Process Management to Quality Impronement, West Sussex: John Wiley \& Sons Ltd.

Borghgraef, S, and Verbeke, W. (1995) "The effects of Sales Force Control on Job Performance and Organi zational effectiveness, "Rotterdam: Rotterdam Institute for Business Economic Studies, 1.22

Boulding. William, Ajay Kalra, Richard Staelin, and Valarie A. Zeitham (1993), "A Dymamic Process Model of Service Quality, Journal of Marketing Research, 30 (February), 7-27.

Bowen. D. and E.E.Lawler (1992) "The Empowerment of Service Workers: What. Why. How and When". Sloan Management Review 33, 31-39 Bragg, A. (1988) "Are Good Salespeople Born or Made?", Sales Marketing Management, September, 74-

Brink, P.J. (1989) "Issues of reliability and validity" in Qualihative Nursing Reseonch: A Contemporary Dialogue, ed Morse J.M

Brownell, P. (1981) "Participation in budgeting, lacus of control and organizational effectiveness". Joumal of Accounting Research, $56,844-860$

Brownell, $P_{;}$(1985) "Budgetary systems and the control of Functionally Differentiated Organizational Activities", Journal of Accounting Research, Autumn, 502-512

Brownell. P. (1995) Research methods im Management Accounting. Ausiralia: Cooper Lybrand and Accoumting Association of Australia and New Zealand

Burns, T. and G.M. Stalker (1961) The Management of Inmovation. London: Tavistock Institute

Burns, N. and S.K. Grove (1987) The Practice of Nursing Reseanch: Conduct, Critigute and Utilizanion. Philadelphia: W.B. Saunder

Buzzell, R.D. and M.J. Gale (1985) The PIMS Principles: Linking Strategy to Perfornance, New York: Free Press

Camillus, J.C. (1986) Strategic planning and management control, Massachusetts/Toronto: Lexington Books

Camp, R.C. (1989), Benchmarketing - The Search for Industry Best Practices that Lead to Superior Perfor mance, Milwaukee WI: ASQS Quality Press

Campbell. D.T. and J. Stanley (1966) Experimental and quasi-experinental designs for research, Chicago Rand MCNally

Carthy, M.L. (1988) "Negative information at the point of sale: cost and benefits to new car deals", Joumal of Consumer Satisfaction, Dissatisfaction and Complaining Behavior $1,80-85$

Cespedes,F.V, (199i) Organizing and Implementing the Marketing Effort: Text and Cases, Reading: Addison-Wesley Publishing Company,

Challagala, G.N. and T. A. Shervine (1996) "Effects on Salesperson Performance and Satisfaction," Journal of Marketing 60(January). 89-105

Chenhall, R.H. and D. Morris (1986) "The impact of structure, environment and interdependence on the perceived usefulness of management accounting systems" . Accounting Review, January, 16 -35

Chicwood, R.E. (1989) Futuresell: A Selling Guide for the 2 Ist Century Salesperson, Max Sacks International, in Ingram, T.N. and R.W. LaForge (1992) Sales Management: Analysis and Decision Making, 2nd edition, Forth Worth: The Dryden Press (A Harcourt Brace College Publisher)

Church, A.H. (1914) The Science and Practice of Mandgement, New York: Engineering Magazine Co.). Originally serialized in six parts as "Practical Principles of Rational Management," Engineering Mogazine

44/45(January through July 1913)
Churchill jr, G.A., N.M. Ford and O.C. Walker jr (1993) Sales Force Managemesu, $4^{\text {th }}$ edition, Chicago: Irwin

Churchill, G.A., Ford, N.M. and O.C. Walker jr. (1985) "The Determinarts of Salesperformance: A MetaAnalysis", Joumal of Marketing Research, $103-118$

Coad, A. (1995) "Strategic control", in Berry, A.J. Broadbent, M. and D. Otley (eds) Management control: Theories. Issues and Practices. Houdmills: MacMillan Press LTD

Cocanougher, B. and J.M. Iwancewich (1978) "BARS" Performance Rating for Sales Force Personnel" Joumal of Marketing 42(July), 87-95

Colombo, G.W. (1994) Sales Force Awtomation, New York: McGraw-Hill

Cooper, D.J., D. Hayes and F. Wolf (1981) "Accounting in Organized Anarchies: Understanding and Design ing Accounting Systems in Ambiguous Situations", Accowning Organizations and Society, 175-191

Cortada, J. W. (1993) TQM for Sales and Marketing Managenent, New York: McGraw-Hill Inc.

Cravens. D.W., T.N. lngram, R. W. Laforge, and C.E. Young (1993) "Behavior-based and Outcome-Based Salesforce Control Systems", Journal of Marketing 57 (October), 47-59

Cray, D. (1984) "Control and coordination in multinational corporations," Journal of International Business Sindies (Fall), 85.98 
Cron, W.L. and M. Lewy (1987) "Sales Management Performance Evaluation: A Residual Income Perspec tive" Joumal of Sales Management and Personal Selling. August, 14-16

Cyert, R.M. and J.G. March (1965) A Behaviowral Theory of the Frm, Englewood Cliff: Prentice

Daft, R.L. and KKE. Weick (1984) "Toward a model of organizations as unterpretation systems", Acadewy of Management Review $9,284-295$

Daft, R. and N. Macintosh (1984) "The nature and use of formal control systems for managenent control and strategy implerinentation". Joumal of Mamagement 10(1), 43-66

Dalton, G.W. (1971) "Motivation and Control in Organizations", in Motivation an Control in Organizations; G. W. Dalion and P. P. Lawrence eds., Homewood, IL: Richard D. Irwin, 1-35

Daniel, S.J. and W.D. Reitsperger (1991) "Linking Quality Strategy with Management Control Systerns: Empinical Evidence from Japanese Industry", Accounting, Organizations and Society, 601-618

Darmon, R.Y. (1997) "Seleating Appropitate Sales Quota Plan Structures and Quota Setting Procedures", Joumal of Personal Selling and Sales Management, Winter, $1-16$

D'A veni, R. (1994) Hypercompetition. Managing the dynamics of strategic manewering, New York: The Free Press

Davis. R.C. (1940) Industrial Organization and Management, 2nd ed., New York: Harper

Dawson, P. (1994) Organizational change: a processual approach, London: Paul Chapmatn

Dawkins, Peter and Frederick F. Reichheld (1990) "Customer Retention as a Competitive Weapon", Direc tors and Boards, 14 (Summer), $41-47$

Day, G.S. (1990) Market Driven Strategy: Processes for Creating Value, New York: The Free Press

Dent, J.F. (1990) "Strategy, Organization and control: some Possibilities for Accounting Research" Account ing. Organizations and Society, 3-24

Dent, J.F. (1991) "Accounting and Organizational Culture: A Field Study of the Emergence of a New

Organisationall reality", Accounting, Organizations and Society, 705-732

Dent, $J$ and $M$. Ezzamel (1987) "Organisational control and management accounting," Performance Mea surement and Evaluation (1995), eds. Holloway, J., J. Lewis and G. Mallory, London : Sage Publications

Dhawale, D.G. (1996) "Performance. Measures for Cell Manufacturing and Focused Factory Systems," Cost Managemenr, Spring, 59-69

Dubinsky, A.J. and T.E. Barry (1982) "A Survey of Sales Management Practices" Industrial Marketing" Management 11, 133-141

Dubinsky, A.J. and R.W. Hansen (1981) "The Salesforce Management Audit", Califomia Managment Review, Winter, 86-95

Duncan, R.G. (1971) Multiple Decision-Making Structures in Adapting to Environmental Uncertainty: The impact on Organizational Effectiveness. Working Paper Rapport no 5471 1. Northwestem University Graduate School of Management

Eccles, R. G. (1991) The Performance measurement manifesto", Harvard Business Review January/February, $131-137$

Eccles, R.G. and P.J. Puburn (1992) "Creating a comprehensive system to measure performance", Manage ment Accounting, October in Hope, T. and J. Hope (1996) Transforning the Bottom Line: Managirg Performance with the Real Numbers, London: Nicholas Brealey Publishing, 111

Edvardson. B., B. Thomasson, and J. Ovretweit (1994) Quality of Services, Making It Really Work, London: MeGraw-Hill

Edwards. M.R. W. Theodore Cummings, and IIL. Schalacter (1984) "The Peris-Peoria Solution: Innovations in Appraising Regional and International Sales Personnel". Joumal of Personal Selling and Sales Management 5(May), 26-38

Eillon, S. (1979) Management Control, Second Edition, Oxford: Pergamon Press

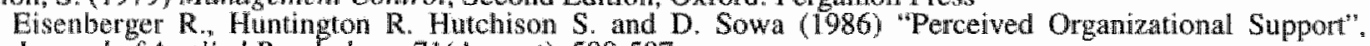
Jownal of Applied Psychology, 71 (August). 500-507

Eisenthard, K.M. (1985) "Control: Organizational and economic approaches". Management Science, 31,134 149

Eisenhardt, K.M. (1989) "Building theories for case study research", Academy of Management Review 144 , $532-550$

Emch. A.F. (1954) "In todays business more than ever control means action on the part of every key execu tive", Harvard Business Review, No. 54405 (July-August)

Enmanuel, C., D. Otley and K. Menchant (1990) Accounting for Management Control. London: Chapman and Hall

Etmanczyk, J.S. (1995) Strategic Planning, Total Quality and Performance Measurement: A Quality Direc

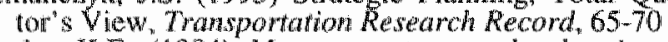

Euske, K.E (1984) Management control: planning, control, measurement and evaluation, Reading MA: Addison- Wesley

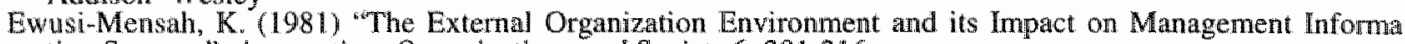
tion Systems", Accounting, Organizations and Sociery 6:301-316

Feldman, M.S. and J.G. March (1981) "Information in organizations as Signal and Symbol", Admintstrative Science Quarterly, June, $171-186$

Fielld, A.P. and J.M. Morse (1985) Nursing Research.: The Application of QualitativeApproaches, London: Croom Helm 

Firestone, W. A (1993) "Alternative arguments for generalizing from data as applied to qualitative research".
Educational Researcher $22(4), 16-23$.

Fisher, J. (1992) “Use of nonfinancial performance measures", Joumal of Cost Management, spring, $45-49$

Flamholtz, E (1979) "Behavioral Aspects of Accounting/Control Systems", in Kerr" $\mathrm{S}$. (ed.), Organtzational Behavior, Columbus $\mathrm{OH}$ : Grid Publishing

Flamboliz, E. (1983) "Accounting, Budgeting, and Control Systems in their Organizational Context: Theoreti cal and Empirical Perspectives, Accouming, Organizations and Society, $8,153-169$

Fllmimolk, E., T.K. Das and A. Tsuil (1985) "Towards and Integrative Framework of Organizational Control," Accounting, Organizations and Society, 10, 35-50

Flint, D.J., Woodruff, R.D. and S.F. Gardial (1997) "Customer Value Change in Industrial Marketing Relarionships: A Call for New Strategies and Research"', Industrial Marketing Management, 26, 163-175

Ford, N.M., Waiker jr. O.C. and G.A. Churchill jr. (1976) "The Psychological Consequences of Role conflict and Ambiguity in the Industrial Salesforce" in Markering: 1776-1976 and Beyond, ed. K.L. Bernhardt, Chicago: American Marketing Association

Ford N., O.C. Walker jr and G.A. Churchill jr "Selecting Successful Salespeople: A Meta-Analysis of Biographical and Psychological Selection Criteria," in Annual Rewew of Marketing (1987), ed. MJ. Houston, Chicago: American Marketing Association, 90-131

Ford, N.M. Walker jr. O.C. and G.A. Churchill jr. (1988) "Selecting Successful Salespeople: A MetaAnalysis of Biographical and Psychological Selection Criteria", In Review of Marketing, ed. M.J. Hotiston, Chicago: American Marketing Association, 90-131

Fornel", C. (1992) "A National Customer Satisfaction Barometer: The Swedish Experience", Journal of Marketing, 56 (January), 6-21

Fornell. $C_{n}$ and Birger. Wernerfelt (1987), Defensive Marketing Strategy by Customer Complaint Manage ment: A Theoretical Analysis," Journal of Markesing Research, 24 (November), 337-346

Fry, L.W., Futrell, C.M., Parasuraman, A and M. Chmielewski (1986) "An Amalysis of Alternate Causal Models of Salesperson Role Perceptions and Work Related Aititudes", Jourwal of Marketing Research 23(May), 153-163

Futrell, C. (1994.) Sales Management, 4th edition, Fort Worth: The Dryden Press

Futrell, C.M. and A. Parasuraman (1984) "The Relationship of Satistaction and Performance to Salesforce "Turnover", Journal of Marketing. 48(Fall), 33-40

Gadd, K.W. and J.S. Oakland (1995) "Re-engineering a total quality organization", Business Procexs Reengineering \& Management Jourmal, 1 no. 2,7,27

Gale, B.T. (1994) Managing Customer Value: Creating Quality and Service Thar Customer Cam Se, New York: The Free Press

Gersick, C. (1988) "Time and transition in work teams toward a new model of group develiopment", Academy of Managenent Journal, $31,9-41$

George, A.L. (1979) "Case studies and theory development: the method of structured, focused comparison". in P.G. Lauren (ed.) Diplomacy: new approaches in history, theory and policy. New York: Free Press, $43-68^{\circ}$

Ghosh, A. (1994) Reiail Management, $2^{\text {thi }}$ edition, Forth Worth: The Dryden Press

Ghosh, S. (1998) "Making Business Sense Of The Internet: To assess the Risks and Opportunities, You Need To Know What's Possible", Harvard Business Review, march $\propto$ April, 126-135

Gilbert, X and P. Strebel (1991) "Developing competitive advantages", in H. Mintzberg and J.B. Quins (eds), The Strategic Process. Concepts, contex and cases, $2^{\text {nat }}$ edition, Englewood Cliffs NJ: Prentice Hall

Glanser, B. And A. Straus (1967) The Discovery of Grounded Theory: Strategies of qualitative research. London: Wiedenfield and Nicholsen

Govindarajan, $V$. (1984) "Appropriateness of accounting data in performance cvaluation: An empirical examination of environmental uncertainty as an intervening variable". Accowning, Organizahons and Soctiety $9,125-135$

Govindarajan, V. and A.K. Gupta (1985) "Linking control systems to business unit strategy: impact on pertor mance" Accounting, Organizations and Society 10:51 66

Gordon, $\mathbb{L}$.A. and D. Miller (1976) "A contingency framework for the design of accounting information systems", Accounting, Organizations and Society 1:59-70

Gordon, L.A. and V.K. Narayanan (1984), "A contingency framework for the design of accounting informa tion systems", Accounting. Organizations and Socieb 9.33-47

Granick, D. (1954) Management of the Industrial firm in the USSR. New York: Studies of the Russion Instiute Columbia University.

Gresov, C. (1989) "Exploring Fit and Misfit with Multiple Contingencies", Administrative Science Quarterly $34: 431-451$

Grizzle. G.(1981) "A Manager's Guide to the Meaning and Uses of Performance Measurement". Anevican Review of Public Administration 15, 16-28

Grönroos, C. (1990) Senvice management and marketing: Managing the moments of truth in service compet tion, Lexington: Lexington Book

Grunert, K.G., S.C. Grunert and S.E. Beatty (1989) "Cross-cultural research on consumer values", Markerimg and Research Today, 30

Guba, E.G. and Y.S. Lincoln (1981) Effective Evaluation, San Francisco:Jossey-Bass

Gul, F.A. and Y.M. Chia (1994), "The Efects of Management Accounting Systems, perceived cnvirommental uncertainty and decentralization on managerial performance: a Test of Three-way interaction", Accoun- 
tancy, Organization and Society 19(4/5): $431-453$

Gummesson, E. (1991) Qualitative methods in inancgement research, Newbury Park: Sage

Hads, R.W, and T.R. Wortroba (1983) Marketing Management. Plano/Texas: Business Publications Inc.

Hall, R.H. (1962) "Intraorganizational Structure Variation: Application of the Bureaucratic Model", Adminis rative Science Quarterly 7(December): 295-308

Halliburton, $C$, and $\mathrm{R}$. Hunerberg (1993) Eupopean murketing: reading and cases, Wokimham: AddisonWestey

Hame1, G. and C.K. Prahalad (1994) Competing for the future. Breakthrough strategies for sieizing control of your industry and creating the markets of tomorrow, Boston MA: Harvard Business School Press

Hammer, M. and J. Champy (1993) Reengimeering the Corporation: A Manifesto for Business Revolution, New York: McGraw-Hill

Hayes, D. (1977) "The contingency theory of management accounting", The Accoumting Review 52: 22-39

Hayes, R.H. and W.J. Abernathy (1980) "Managing our way to economic decline" Harvard Business Review, July-August, $66-77$

Hayes, RH and D.A. Garvin (1982) "Managing as if tomorrow mattered", Harvard Business Review, MayJune, $70-79$

Heckert, J.B. and R.B. Miner (1953) Distribution Costs, New York: Ronald Press

Hedberg, B. L. T. (1981) "How Organizations Learn and Unlearn" in P. Nystrom, W. Starbuck (eds.), Handbook of Organizational Design, No. 1 (October), Oxford: Oxford University Press, $3-27$.

Henry, P. (1975) "Manage Your Sales Force as a System", in Perspectives on Strategic Marketing Manage ment, eds. R. A. Kerin and R.A. Peterson (1980), Boston: Allyn and Bacon Inc, 378-391

Hersen, M. And D.H. Barlow (1976) Singlewase experinnental designs; Strategies for studying behavior, New York: Pergamon

Hesket, J.L., Jones, T.O. Loveman, G.W., Sasser jr, W.E. and L.A. Schlesinger (1994) "Putting the ServiceProfit Chain to Work, Harvard Business Review, March-April, 164-174

Hersey, M.L. (1937) "The elements of a System of Marketing Control", Joumal of Marketing 2(October): $201-208$

Herzberg, F. (1968) Work and the Nature of Man, London: Staples Press.

Hirst, M.K. (1981) "Accounting information and the evaluation of subordinate performance". The Accosmt ing Review 56: $771-784$

Hirst, M.K. (1983) "Reliance on Accounting Performance Measures, Task uncertainty and Dysfunctional Behavior: Some Extentions", Journal of Accownting Research 21(Autumn): 596-605

Hofstede, G. H. (1967) The Game of Budget Control, London: Tavistock

Holden, E. L.S. Fisch and H.L. Smith (1941) Top managememt-organization and control: a research study of the manager policies and practices of thirty-one leading industrial corporations, Stanford: Stanford University Press

Honeycutt jr.. E.D. (1996) "Introduction to the Special Issue of Selling and Sales Management", Industrial Marketing Managenent, 25, 323-325

Hope, $\mathrm{T}$, and J. Hope (1996) Transforming the Bottom Line: Managing Perfornance with the Real Numbers, London: Nicholas Brealey Publishing

Hopwood, A. (1972), "An empitical study of the role of accounting data in performance evaluation". Empimi cal Research in Accowning Supplement to Joumal of Accounting Research 10 (supplement), $156-182$

Hopwood, A. (1973), An Accounting System and Managerial Behavior, Hampshire, Uk: Saxon House

Hopwood, A.G. (1974) Accounting and Hwman Behavior, London: Haymarket Publishing

Hopwood, A.(1976) Accounting and Haman Behavior, Englewood Ciiffs, NJ:Prentice Hall

Horngrea, C.T. Foster, C.T. and S.M. Datar (1994) Cost Accounting: a Managerial Emphasis, 8th edition, London: Prentice-Hall

Hrebinitk, L.G. and W.F. Joyce (1984) Implementing Strategy. New York: Macmillan

Huber G.P. (1991) "Organizational Learning: The Contributing Process and the Literatures", Organizarion Science, $2,88-115$

Hui, H.C. and H.C. Triandis (1985) "Measurement in cross-cultural psychology", Journal of Cross-Cultural Psychology 16, 131-152

Hughes C.D. and C. H. Singler (1983) Strategic Sales Management. Reading: Addison-Wesley Publishing Company

Hulbert, J. M. and N.E. Toy (1977) "A Strategic Framework for Marketing Control," Journal of Marketing 41:2(April), $12-20$

Hutt, M.D. and T.W. Speh (1992) Business Marketing Manogement, Forth Worth: The Dryden Press

ljiri, Y. (1975) Theory of Accounthng Measurement, Snudies in Accounting Reseanch, no. 10, American Accounting Association

Vlgen, D. Fisher, C. and Taylor (1979) "Consequences of Individual Feedback on Behavior in Organiza tions". Joumal of Applied Psychology, 349-371

Imoiselii, O. (1985) Task Complexity. Budget Style of Evaluating Performance and Managerial Stress: An Empirical Imesrigation, Unpublished Dissertation. Graduate School of Business, University of Pittsburgh

Ingram, T.N. and R.W. LaForge (1992) Sales Management: Anaiysis and Decision Making, 2nd edition, Forth Worth: The Dryden Press (A Harcourt Brace College Publisher)

Inkson. J. D. Hickson and D. Pugh (1968) "Administrative Reduction of Variance in Organization and Behavior." Paper presented at the British Psychological Society Annual Conference, April 1968 

Jackson jr, D.W. L.L. Ostrom, and K. E. Evans (1982) "Measured Used to Evaluate Industrial Marketing
Activities". Industrial Marketing Mamagement 11 (October), 269-274

Jahoda, G. (1984) "Do whe need a concept of culture?", Joumal of Cross-Cwltural Psyohology 15, 139-151

Jain. S.C. (1989) "Standardization of international marketing strategy: some research hypotheses", Jourral of
Markering 53,70-79 $J$ aworski, B. I. (1986) The Impact of control systems-in-use and lask-related knowledge on select psychologi
cal and behavioral responses, Dissertation, University of Pittsburgh

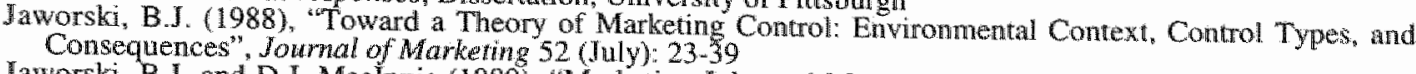

Jaworski, B.J. and D.J. Maclnmis (1989), "Marketing Jobs and Mantgement controls: Toward a Framework", Journal of Marketing Research 26 (November): 406-419

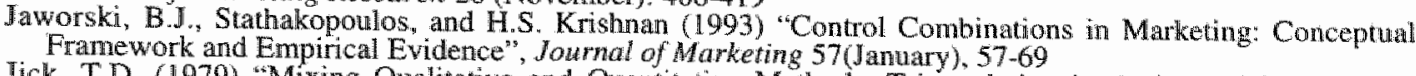
Jick, T.D. (1979) "Mixing Qualitative and Quantitative Methods: Triangulation in Action", Admintrstrative
Science Quarterly, 24(December), 602-611 Johmson, H.T and R. Kaplan (1987a) Relevance Last: The Rise and Fall of Managemen Accouming, Boston:
Harvard Business. School Press Johnson, E.M. D.L. Kurtz, and E. Scheuing (1986) Sales Managentent; Concepts, Practices, and Cases, New
York: McGrawhill

Johnston, M.W. Parasuraman A. , Futrell, C.M. and W.C. Black (1990) "A Longitudinal Assessment of the Impact of Selected Organizational Influences on Salespeople's Organizational Commitment During Early

Jones, C.S. (1985) "An empirical study of the role of management accounting systems following takeover or merger", Accouning, Organizations and Sociery 10,303-328.

Kahm, R.L., Wolf, D.M., Quinn, R.P., Snoek, J.P. and R.A. Rosenthal (1964) Organizational Stress: Siudies in Role Conflict and Ambiguity. New York: John Wiley \& Sons lnc.

Kamensky, J. (1993) "Program Performance Measures: Designing a System to Manage for Resuits". Public Productivity and Management Review 16, pp.395-402

Kaplan, R. (1983) "Measuring manufacturing performance: a new challenge for managerial accounting research", The Accounting Review 58(4), pp.686-705

Kaplan, R.S. (1984) "Must CIM be Justified on Faith Alone?", Harvard Business Review March/April, $44(3), 211-229$

Kaplan, R.S. (1985) "The evolution of management accounting", The Accourting Review. LIX (3), 390418

Kaplan, R. and A. Atkinson (1989) Advanced Management Accomnting, wnd ed. Englewood Cliffs NJ: Prentice Hall.

Kaplan, R.S. and D.P. Norton (1992), The balanced scorecard - measures that drive performance", Harvard Business Review, 71-79

Kasper, J.D.P. W. De Vries jr. and P.J.C. van Helsdingen (1998) Services Marketing Management, forthoon. ing

Keenan jr., W. (1994) "Death of the Sales Manager", Sales \& Marketing Management, "46(October), 66-74

King, B. (1989) Better Designs in Half the Time, Methuen, Mass.: Goal/oPC

Kings, W. R. and D.I Cleland (1974) "Environmental Information Systems for Strategic Marketing Planning", Joumal of Marketing, 38, $35-40$

Kloot, L. (1997) "Onganizational learning and management control systems: responding to environmental change", Management Accounting Research, 8(1), 47-74

Knight, D. and H. Wimot (1993) "Its a Very Foreign Discipline: The genesis of Expenses Control in a Mutual Life Insurance company", British Joumal of Management, I-18

Kohli, A.K. and B.J Jaworski (1990) "Market orientation: The construct, research propositions, and manage rial implications" Joumul of Marketing, $54,1-18$

Koontz H. (1959) "Management Control: A Suggested Formulation of Principles", California Managememt Review, $47-55$

Kotler, P.(1994) Marketing management; analysis, planning, implementation and conmol, $7^{\text {th }}$ edition, London: Prentice Hall

Kotler, P. W. Gregor, and W. Rodgers (1977) "The Marketing Audit Comes of Age", Sloan Management Review 18:2(Winter) $25-43$

Kwandwalla, P.N. (1972) "The effects of different types of competition on the use of management control",

Joumal of Accounting Research 10:275-285
K. wandawalla, P.N. (1973) "Effect of Competition on the Structure of Top Management Control". Acadewy of Managenent Journal, 10 (June), 285-295

Langfield-Smith, K. (1997) "Management control systems and strategy: a critical rewiew" , Accownting.

Organizations and Society, 22(2), 207-232
Lawler, E.E. (1976) "Control Systems in Organizations", in Dunnette, M.D. (1976) (ed.), Handbook of Industrial and Organizational Psychology, Chicago: Rand McNally College Publishing Comp.

Lawler, E.E. and I.G. Rhode (1976) Infomation and Control in Organizations, Santa Monica: Goodyear Publishing Company

Lebas. M.J. (1995). Performance measurement and performance management, Invemational yournat of Producrion Economics 41, 23-35 
Lee, A.S. (1989) "A scientific methodology for MIS case studies", MIS Quarterly, 33-50

Leeflang, P.S.H. en Beukenkamp, P.A. (1987) Probleemgebied marketing: een management benadering, Leiden-Antwerpen: Stenfert Kroese B $V$,

Leifer, R. and G.P. Huber (1978) "Relations among Perceived Environmental Uncertainty, Organization Structure, and Boundary Spanning Behavior", Administrative Science Quarterly: 235-247

Levit, B. and J.G. March (1988) "Organizational Learning", Anmual Review of Sociology, 14, 319-340

Longman, D.R. and M Schiff (1955) Practical Distribution Cost Analysis, Homewood Mil.: Rjchard D. Irwin

Lorange, P. (ed) (1982) Implemenhatiom of Strane gic Planning, Englewood Cliffs NJ: Prentice Hall

Lowe, E.A. and R.W. Shaw (1968) "An aralysis of managerial biasing; evidence from a company's budgeting process", Joumal of Mandgement Situdies, $5,304-315$

Lowe, T. and J.L.J. Machin (1983) New Perspectives in Management Control, New York: St. Martin's Press

Lusch, R.F. and B.J. Jaworski (1991) "Management Controls, Roles Stress, and Retail Store Manager Perfor mance", Jowmal of Retailing, 67 (Winter), $397-419$

Machin, J.L.J. in Lowe, T. and J.L.J. Machin (1983) (ed.) New Perspectives in Management Control. New York: St. Martin's Press

Maciariello, J A. (1984) Management Control Systems, Englewood Cliffs: Prentice Hall

Marshall, C. and G. B. Rossman (1989) Dessigning Qualitative Research, London: Sage

Mantinko, M. (1995) The nature and function of attribution theory with the organizational sciences. In Atribution Theory: An Organizutional Perspective, edited by M. Martinka. Delray Beach. FL. St. Lucie Press

Maske!l, B. (1989) "Performance measures of world class manufacturing", Management Accounting, May, $32-33$

McCarthy, J.A. (1989) "Current theory and research on cross-cultural factors in consumer behavior" , Advances in Consumer Research 16, 127-129

Macintosh. N.B. and R. L. Daft (1987) "Management control systems and departmental interdependencies: an empirical study", Accounting, Organizations and Society, $12(1), 49-61$

Matihyssens, P., Martens, R and K. Vandenbempt (1998) Concurrentie, Strategie en Marktdynamiek: Op weg naar concurrentielle voordelen in industrielle markten, Antwerpen: Kluwer Bedrijfsinformatie

Mathyssens, $\mathbb{P}$. and W. Feas (1997) "Coordinating Purchasing: Strategic and Organizational Issues", in H.G. Gemünden, T. Ritter and A. Walter (eds.) Relationships and Nenworks in Intemational markets, Oxford: E]sevier Science Ltd, 323-342

Mathyssens, P. and P. Verhulst (1996) "Management van de interface Marketing - Verkoo p: een uitdaging voor de industrible ondernemer" Bhedriffskunde, $68(3), 83-96$

McKinnon, S.M. and W.J. Bruns (1992) The Irformation Mosaic, Boston: Harvard Business School Press

MeNair, C., R. Lynch, and $K$. Cross (1990) Do financial and nonfinancial performance measures have to agree? Management Accounting 72 (November), $28-36$

Merchant, K.A. (1981) "The design of the corporate budgeting system: influences on managerial behaviour and performance", The Accounting Review LVI(4), 813-829

Merchant, K.A. (1982) "The control function of management", Sloan Management Review 23, 43-55

Merchant, K.A. (1984) "Influences on Departmental Budgeting: An Empirical Examination of a Contingency Madel", Accounting, Organizations and Society $9,291-307$

Merchant, K.A. (1985a) Control in Business Organization, Ballinger: Pitman

Merchant, K. A. (1985b) "Budgeting and the propensity to create budget slack", Accounting, Organizations and Society, $10(2), 201-210$

Merchant, K.A. and Simons, R.(1986), "Research and Control in Complex organizations: an overview", Jowrwal of Accounting Literature, $5,183-203$.

Merchant, K.A. (1990) "The Effects of Financial Controls on Data Manipulation and Management Myopia", Accounting. Organizations and Society, 15,297-313

Merchant, K.A. (1997) Modem Management control: Text and Cases, Englewood Cliff: Prentice Hall

Mia, L. and R.H. Chenhall (1994) "The usefulness of management accounting systems", Accounting, Organizations ard Society, $19(1), 1-14$

Michaels, R.E. Cron, W.L., Dubinsky, A.J. and E.A. Joachimsthaler (1988) "Influence of Formalization on the Organizational Commitment and Work Alienation of Salespeople and Industrial Buyer". Joumal of Marketing research, XXV(November), $376-383$

Milles, M. B, and A.M. Huberman (1994) Qualitative Data Analysis, London: SAGE Publications

Milligan, B.L. (1969) "Contributing Maring in Decision-Making," Management Accounting, 51 (October) 3338

Mintzberg, H. (1979) "An emerging strategy of "direct" research", Administrative Science Quarterly, 24, 582589

Mintaberg. H. (1979) The Structuring of Organizations. A Synthesis of the Research, Englewood-Clifts (NJ): Prentice-Hall.

Moore. C.L. (1969) "An Extension of Break-Even Analysis"" Management Accounting, 50(May), 55-58

Moorman, R.H. and G.L. Blakely (1993) "Individualism-collectivism as an individual difference predictor of organizational citizenship behavior." Paper presented at the annual meeting of the Academy of Management, Atlanta, GA

Morris, M.H. and S.R. Atten (1990) "Salesforce Performance Appraisal: Contemporary Issues and Prac tices," in Progress in Marketing Thought, eds. Capella, L.M., H.W. Nash, J.M. Starling and R.D. Taylor, Mississippi: Sonthern Marketing Association, $413-418$ 
Morris, M.H. D.L. Davis, J.W. Allen, R.A. Avila, and J. Chapman (1991) "Assessing the Relationships between Performance Measures, Managerial Practices, and Satisfaction when Evaluating the Salesforce," Joumal of Personal Selling and Sales Management Summer, 25-36

Mossman, F.H., Fischer, P.M. and W.J.E Crissy (1974) "Wew' Approaches to Analyzing Marketing Profitabil ity", Journal of Marketing, 38(April), 43-48

Muczyk, J.P. and M. Gable (1987), "Managing Sales Performance through a Comprehensive Performance Appraisal system," Joumal of Personal Selling and Sales Management 7, 41-52

Nanni, A.J., J.R. Dixon and T.E. Vollman (1992) "Integrating Performance measurement: Management Accounting to Support the New Manufacturing Realities" "Journal of Managentent Accounting Research, 1. 19

Narus, J.A. and J. C. Anderson (1996) "Rethinking Distribution: By sharing resources and capabillities, companies can meet their customers' most extraordinary needs", Harvard Business Review" July-August, $112-120$

National Industrial conference Board (1965) Sales Analysis Studies in Business Policy no. 13, New York: National Industrial conference Board (1965)

Neely, A., M. Gregory and K. Platts (1995), "Performance measurement system design, at literature review and research agenda", International Journal of Operations 15(4), 80-1.16

Nelson. Eugene, Roland T. Rust, Anthony Zahorik, Robin L. Rose, Paul Batalden, and Beth A Siemanski (1992), "Do Patient Perceptions of Quality Relate to Hospital Financial Performance?" Journal of Healh Care Marketing, 13 (December), 1-13

Oakland. J.S. (1993) Total Quality Management: The Route to Improving Performance, 2nd ed., Oxford: Butterworth-Heunemann IL.

Olivier, R.L. and E. Anderson (1994) "An Empirical Test of the Consequences of Behavior and OntcomeBased Salles Control Systems", Jounal of Marketing 58(October), 53-67

Ouchi (1977) "The Relationship between Organizational Structure and Organizational control", Administra tive Science Quarterly, 22(1), 95-113

Otley, D. T. (1978) "Budget use and managerial performance" Journal of Accounting Research 16, 122-149

Otley, D.T. (1980) "The Contingency Theory of Management Accounting: Achievement and Prognosis", Accounting. Organizations and Society, 4, 413-428

Otley, D. (1987) Accounting control and organizational behaviour, Oxford: Heinemann Publishing.

Ottey, D.T. and A.J. Berry (1980) Control, Organization and Accounting. Accounting, Organizations and Sociery, 5(2), 231-244

Parry, R., F. Sharp, W. Wallace, and J. J. Vreeland (1994) The role of service efforts and accomplishments reporting in total quality management: Implication for accountants, Accounting Horizons 8(June):25-43

Parkhe, A. (1993) "Messy Research. Methodological Predispositions, and Theory Development in Interna tional Joint Venture", The Academy of Management Review, 18(2), 227-268

Piper, J. (1978) Determinants of financial control systems for multiple retallers - sone case siudy evidence,

Umpublished paper, University of Loughborough
Poel van de, J.H.R (1986) Judgment and Control: Individual and Organization Aspects of Performance

Evaluation, Groningen: Wolters-Noordhoff B.V.
Polit, D.F. and B.P.Hungler (1991) Nursing Research Principles and Methods, fourth edition, Pliladelphian:

J.B.Lippincott
Porter, M. (1980) Competinive Strategy: Techniques for Analyzing Industries and Conperinors, New York: Free Press

Powers. B.A. and T.R.Knapp (1990) A Dictionary of Nursing Theory and Research, London: Sage

Rangan, V.K. (1994) "Reorienting Channels of Distribution"" in Business Marketing Strategy: Cases, Con cepts and Applications, edited by Rangan, V.K., B.P. Shapiro and R.T. Moriarty jr. cepts and Applications, edited by Rangan,
Rawaswami, S.N.(1996) "Marketing. Controls and Dysfunctional Employee Behaviors. A Test of Traditional
and Contingency Theory Postulates", Jownal of Markering 60 (April), 105 -120

Rayburn. L.G. "Accounting Tools in the Analysis and Control of Marketing Performance", Andustrial Marketing Management 6, 175-182

Reeves, "I.K. and J. Woodward (1970) "The Study of Managerial Control", in Industrial Organizations: Behowior and Control, J. Woodward ed., London: Oxford University Press

Reichheld, F.F. and W. E.Sasser (1990), "Zero Defections: Quality Comes to Service", Harward Busines: Review, September-October, 105-111

Roberts, J. (1990) "Strategy and Accounting in a U.K. Conglomerate", Accounting, Organizations and Society, $107-125$

Roberts, K. (1997) MO PIMS Europe, presentation at Customer Value Network meeting hosted by Lever on June 1997 , Kingston, UK June 1997, Kingston, UK
Robbins, S.P. (1990) Organization Theory: Structure, Design and Applications, $3^{\text {rd }}$ edition, Englewood
Cliff: Prentice-Hail

Roy, D. (1985) "Quota Restriction and Goldbricking in a Machine Shop". American Journal of Sociology, $427-44$ 
Ruekert, R.W., Walker, O.C. and KJ) Roering (1985) "The Organization of Marketing Activities: A Contin gency Theory of Struchure and Performance", Joumal of Marketing 49(Winter): 13-25

Rust, R.T. A.J. Zahorik and T.L. Keiningham (1995) Retum on Quality (ROQ): Making Service Quality Financially Accountable, Jownal of Marketing, 59(April), 58-70

Ruyter de, K (1993) Dissatigfaction Management: A study into the use of consumer dissatisfaction as a source of management information by arganizations, Thesis Enschede

Salter, M. (1973) "Tailor Incentive Compensation to Strategy", Harvard Business Review 51:94-102

Samson, D.A. K.M. Langfield-Smith and P.M. McBride (1991) "The Alignment of Management Accounting with Manufacturing Priorities: A Strategic Perspective", The Australian Accounting Review", 29-40

Sanchez, R. (1995) "Strategic flexibility in product competition", Strategic Managenent Joumal, 16(summer), special edition, 135i-159

Schiff, A.D. and L. R. Hoffman (1995), "An Exploration of the Use of Financial and Nonfinancial Measures of Performance by Executives in a Service Organization" $134-153$

Schneider, B. (1980) "The service organization: climate is crucial", Organizational Dynamics, Autumn, 5265

Schonberger, R.J (1992) Creating a Chain of Customers, London: Guild Publishing

Senge, P. (1990) The Fifth Disciplime, Sidney: Random House

Sevin, C. H. (1965) Marketing Productivity Analysis, New York: McGraw-Hill

Shapiro, B.P. (1977), "Can marketing and manufacturing coexist?", Harvard Business Review, SeptemberOctober, $104-114$

Shapiro, S.J. and V.H.Kurpalini (1984) Marketing Effectiveness: Insights from Accounting and Finance, Boston: Allyn and Bacon Inc.

Sharma, A. (1997) "Customer Satisfaction-Based Incentive Systems: Some Managerial and Salesperson Consideration", Journal of Personal Selling and Sales Management, Spring, 61 -70

Simon, A. A. Sohal, and A. Brown (1996) "Generative and case study research in quality management, Part I: theoretical considerations", Intemational Joumal of Quality \& Reliability Management 13(1), 32-42

Simon, S.R (1969) Managing Marketing Profitability, New York: American Marketing Association

Simons, R. (1.987) "Accounting control Systems and Business Strategy: An Empirical Analysis", Accounting, Organizations and Society, 357-374.

Simons, R. (1990) "The role of Management Control Systerns in Creating Competitive Advantage: New Perspectives". Accounting, Organizations and Society, $127-143$

Simons, R. (1995) Lewels of Control: How Managers Use Mnovative Control Systems to Drive Strategic Renewal. Boston: Harward Business School Press

Sinclair, D. and M. Zairi (1995) "Pertormance measurement as an obstacle to TQM", The TQM Magazine, $7(2), 42-44$

Skinner, W. (1974) "The Focused Factory", Harvard Business Review, May-June, 113 121

Skinner, W. (1986) "The productivity paradox", Harvard Busimess Review, July-August, 55-59

Slack, N. (1991) The Manufacturing Advantage: Achieving Conpetitive Manufacfuring Operations, London: Mercury

Slater, S. and I. Narver (1994) "Does compentitive enwironment moderate the market orientation-performance rellationship?", Journal of Marketing, 35, 292-327

Sumih, K. G. (1088); Entrepreneurial Organizations of the Future, in: Hage, J. (ed.): Funures of Organizations. Imovation to Adapt Strategy and Human Resounces to Rapid Technological Change, Lexington (Mass.) Heath

Soln, K. "Management control in the financial services sector" in Management Control: Theories, Isswes and Practices (1595), edited by Berry A.J. Broadbent. J. and Otley. D., Antony Rowe Lid, Chippenham

Stanton, W.I., R.H. Buskirk, and R.L. Spiro (1990) Management of a Sales Force, 8th editiom. Homewood/Boston:Richard D. Irwin

Stacey, R D. (1996) Strategic Management \& Organisational Dynamics, 2nd edition, London: Pitman

Still, R.R., E.W. Cundiff, and N.A.P Govoni (1988) Sales Management: Decistons "Strategies, and Cases, Fifth Edition, Engle wood Cliffs, N.J.: Prentice-Hall International

Stoner, J.A.F. and C. Wankel (1986), Management, Englewood Cliff: New Jersey

Straus, A. (1.987) Qualitaitwe Analysis for Social Sicientist, Cambridge: Uniwersity Press

Swieringa, R.J. and R.H. Moncur (1972) "The Relationship Between Managers" Budget Oriented Behavior and Selected Attitude, Position, Size and Performance Measures", Empirical Research in Accounting: Selected Sindies, supplement to Joumal of Accounting Research, 10, 194-209

"Tannenbaum, A. (1968) Control tu Organisations. New York: MoGraw-Hill Book Company

"Teas, R.K. (1983) "Supervisory Behavior, Role Stress, and the Job Satisfaction of Industrial Salespeople", Joumal of Marketing Research 20(February), $84-91$

Trebuss, A.S. (1984) "Improving Corporate Effectiveness: managing the Marketing/Finance Interface" in Marketing Effectiveness: Insights from Accounting and Finance, edited by S.J. Shapiro and V.H. Kirpalani. Boston: Allyn and Bacon Inc

Tyagi. P.K. (1985) "The effects of Stressful Organizational Conditions on Salesperson Work Motivation", foumal of the Academy of Marketing Science, B3(Winter/Spring), 290-309

Vijver van de, F.J.R. and Y.H. Poortinga (1982) "Cross-cultural generalization and universality". Journal of Cross-Cultural Psychology, 13, 387-408 
Waker jr., O.C.W Churchill, G.A. and N.M. Ford (1975), "Organizational Deterwinants of the Role Conflict and Ambiguity Experienced by Industrial Salesmen" Jourval of Marketing 39 (Tarwary ). 32.39

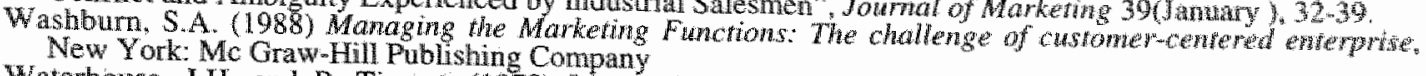

Waterhouse, J.H. and P. Tiessen (1978) "A contingency framework for management accounting systems
research". Accounting Organizations and Society 3.65-76 research Accounting Organizations and Society 3:65-76

Profit, New York Chichester. Systems Engineering: Managing Breakthrowgh Changes For Prodartwity and Webb, E. D.T. Cambell. R.D. Schwartz and in the social sciences, Chicago: Rand McNall

Weber, M. (1947) Theory of Social and Economic

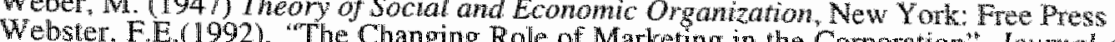
17

Weele van. A. en F. Rozemeijer (1996) "Revolutie in Inkoop", HollandBbelgium Managemen Review, 19, $19-27$

Weick, K.E. (1987) "Theorizing about organizational communication", in F.W. Jablin. L.L. Pentum, K.M. Roberts, and L.W. Ponter (eds) Handbook of Organizational Communication $97-122$ Nabury Pard CA. Sage

Weiner, N. (1948) Cybemetics, Cambridge Mass.: MTT Press

Weilbaker, D.C. (1990) "The Identification of Selling Abillites Neded for Missionary Type Sales" Joumw of Personal Selling and Sales Managemem, Summer, 45-58

Wilensky, H. (1967) Organizational Intelligence, New York: Basic Books

Williamson, O.E. (1970) Corporate Control and Business Behavior, Englewood Clifs NJ: Prentice Hall

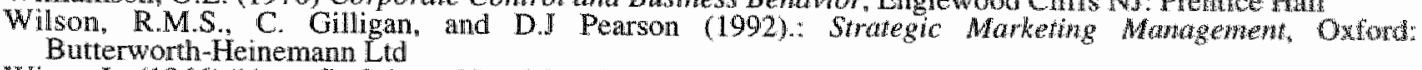

Winer, L. (1966) "A profit-Oriented Decision System", Joumal of Marketing 30(Jamuary), 3844

Woodruff, R.B. and S.F. Gardial (1996) Know Your Customer. New Approaches in Cusioner Value and Satisfacion, Cambridge MA: Blackwell Publishers

Woodward, J. (1958) Management and Technology, HMSO

Wotruba, T.R. (1996), "The Transformation of Industrial Selling: Causes and Conseguences". Industriat Marketing Management, 25, 327-338

Yin, R.K. (1989) Case Study Research: Design and Methods, Beverly Hills: Sage

Yin, R.K. (1993) Applications of Case Study Research, London: Sage

Zahorik, Anthony J and Roland T. Rust (1992) "Modeling the Impact of Service Quality on Profitabilivy: A. Review," in Advances in Service Marketing and Management, T. Swartz, ed., Greenwich, CT: MA Press. $247-276$.

Zairi, M. (1994) Measuring Performance for Business Results, London: Chapman \& Hall

Zeithami, Y.A. and M.J. Bitner (1996) Services Marketing, New York: The McGraw-Hin Conmany lac.

Zeithaml, V.A., A. Parasuraman and L. Berry (1993) Delivering quality senvice: Balancing castomer percep thons and expectations, New York: Free Press

Zinkhan, G.M. and A. Perreira (1994), "An overview of marketing strategy and planning", International Joumal of Research in Marketing, 11(3), 185-218 


\section{Nederlandse samenvatting}

Hoe stuurt een onderneming haar verkooporganisatie aan? Deze vraag staat centraal in dit proefschrift. Aansturen of beheersen is hierbij veel meer dan het controleren of de vooropgestelde verkoopdoelstellingen zijn bereikt. Het is het motiveren en inspireren wan verkooppersoneel om weel meer te bereiken dan het realiseren van de organisatiedoelstellingen. Het is ook detecteren en corrigeren van verkoopinspanningen die niet het gewenste resultaat opleweren. Op dit moment lijken onderzoekers zich vooral op planning en implementatievraagstukken te concentreren. Vragstukken over het gebruik en de effectiviteit van beheersingsinstrumentem blijven meestal onbeantwoord. Het accent in dit proefschrift ligt daarom ook op het beschrijwen van "best practices" van een aantal bedrijven om zo meer inzicht te verwerven in dit relatief onbekend onderzoeksgebied van marketing. en sales management. Om een goede balans tussen de theorieworming en de unanagement praktijk te verkrijgen is er voor een wolgende opbouw van hoofdstukken gekozen.

In hoofdstuk 1 wordt het onderzoeksgebied van dit proefschrift besproken. Hierbij wordt er aandacht besteed aan de nieuwe invulling van de verkoopfunctie. Het gemereren van verkooptransacties blijft de kern van deze bedrijfsfunctie. Evenwel worden steeds meer relatiegerichte activiteiten steeds belangrijker. Deze activiteiten richten zich meer op het genereren van transacties in de toekomst. De oorzaken en de gevolgen van deze transformatie van de verkoopfunctie worden in dit hoofdstuk verder toegelicht. Daarmaast wordt er in hei kort het onderzoek naar marketing- en verkoopbeheersing besproken. Op basis van deze literatuurstudie wordt de focus en de doelstellingen wan deze studie verder toegelicht. Tenslotte worden de onderzoeksvragen en de opzet van de studie verder toegelicht.

Hoofdstuk 2 ontwikkelt thet theoretisch raamwerk wan deze studie. De start is een literatuuronderzoek naar de begrippen 'beheersingsproces' en 'beheersingsysteem" om een theoretisch raamwerk te bepalen. Uitgangspunt van dit raamwerk zijn de bevindingen van R.N. Anthony. Stap voor stap wordt dit raamwerk opgebouwd en verder aangevuld met de bevindingen van $E$. Flamholtz en andere onderzoekers. Daarnaast wordt er aandacht besteed aan het ontwerpen van beheersingsystemen en de gevolgen van systeemontwerpen. Tenslotte wordt er aandacht besteed aan de ontwikkelingen in het onderzoeksgebied van sales control vanuit het vakgebied 'management control'.

In hoofdstuk 3 wordt het theoretisch raamwerk dat in hoofdstuk 2 is afgeleid en toegepast op de verkoopfunctie. leder onderdeel van het raamwerk wordt aangevuld met de bevindingen vanuit de sales management literatuur.

Hoofdstuk 4 behandelt de onderzoeksmethode van deze studie. De gekozen onderzoeksmethode is inductief van aard. De theorievorming vindt plaats aan hand van de bevindingen van case studies. In het vooronderzoek zijn een zestigtal bedrijven benaderd. Het doel van dit onderzoek was tweeledig:

- het ontwikkelen van ecn vragenlijst die alle onderdelen van het theoretisch raamwerk afdekt;

- het verwerven van inzicht in management praktijken.

Op basis van deze bevindingen werd een methodiek woor het case study onderzoek ontwikkeld. Deze methodiek bestond erin dat eerst een aantal bedrijven uit êtn bedrijfstak werden benaderd. Aan hand wan de bevindingen werden er een anantal bedrijven geselecteerd met het doel om werschillen in management praktijken verder te onderzoeken. In onze studie bleek al snel dat er verschillen waren fussen functionele en procesgerichte bedrijven. Op basis van de eerste bevindingen werd beslist om de onderzoeksinspanningen op twee functionele en twee procesgerichte ondernemingen te richten.

In hoofdstuk 5 worden de resultaten van het onderzoek besproken. Hierbij zijn bevindingen gegroepeerd rond de verschillende onderdelen van het theoretisch raamwerk. Tevens worden de overeenkomsten en verschillen verder toegelicht.

Hoofdstuk 7 bevat een samenvatting van de belangrijkste bevindingen en implicaties van dit onderzoek. Tol slot wordt er ook aandacht besteed aan nieuwe onderzoeksgebieden. 


\section{Curriculum Vitae}

Mireille Suchanek was born on $28^{\text {th }}$ Jnne 1966 in Leut (Belgium). From 1985 to 1989 she studied economics at the Catholic University of Leuven. After accomplishing her Master degree, she worked for Algeneen Burgerlijk Pensioenfonds (The Netherlands); first as project manager in an IT project, later as portfolio analyst real estate investments. From march 1992 to January 1998, she worked as assistant professor International Marketing at the University Maastricht. In this period, she was responsible for (international) marketing research courses. From February 1998 onwards, the author works as management consultant for KPMG Management Consulting (The Netherlands). 